Zweiter Beratungsgegenstand:

\title{
Verträge und Absprachen zwischen der Verwaltung und Privaten
}

1. Bericht von Prof. Dr. Joachim Burmeister, Saarbrücken

\section{Inhalt}

Einleitung: Die Diagnose dogmatischer Defizite der Lehre von den Handlungsformen der Verwaltung . . . . . . . . .

I. Die verfassungsrechtlichen Legalitätskriterien des Verwaltungshandelns .......................

II. Erfordernis einer dogmatischen Umformung der Handlungslehre? . . . . . . . . . . . . . . . . . . . 194

1. Das Phänomen des informellen Staatshandelns im Blickwinkel sozial- und verwaltungswissenschaftlicher Problemanalyse .................. 196

2. Ausbruch aus den Rechtsformen - Konsequenz gesetzlichen Übermaßes oder der Steuerungsschwäche des Gesetzes? . . . . . . . . . . . . . . . . . . 200

3. Was unterscheidet schlichtes und informelles Verwaltungshandeln? .................... 203

III. Die zentrale Rechtsfrage: Lassen sich die sogenannten kooperativen Handlungsformen den normativen Handlungsbindungen der Verwaltung unterstellen? . . . . . . . 204

1. Teil: Die vertraglichen Handlungsformen der Verwaltung . . 206

I. Die Unterscheidung von Handlungsformen der Verwaltung und Rechtsformen des Verwaltungshandelns . . . . 206

1. Der Charakter der Handlungsformen als verwaltungspraktische $Z$ weckschöpfungen ............ 206

2. Gebrauchsauswahlermessen zwischen den Rechtsformen . . . . . . . . . . . . . . . . 207

3. Unzulässigkeit der Begründung rechtlicher Befugnisse durch die Rechtsformen . . . . . . . . . . . . . . 210 
a) Auflösung der gegenständlichen Begrenzung der Verwaltungstätigkeit als Grundproblem privatvertraglichen Verwaltungshandelns . . . . . . . . 210

b) Auflösung der inhaltlichen Handlungsbindungen der Verwaltung als Grundproblem des subordinationsrechtlichen Vertrages . . . . . . . . . . . . 212

II. Der privatrechtliche Vertrag als Rechtsform des Verwaltungshandelns - Symptom verfassungskontroverser verwaltungsrechtsdogmatischer Theorie- und Systembildung .......................... 213

1. Die Privatrechtsfähigkeit des Staates als Konstruktionsbasis des verwaltungsrechtsdogmatischen $\mathrm{Ge}-$ bäudes ......................... 214

2. Die Grundthese von der Selbstbestimmungsgewalt des Staates über Form und Qualität seines Handelns . 215

a) Die Kontroverse zwischen P. Laband und O. Mayer . . . . . . . . . . . . . . 215

b) Staatliche Kompetenz zur Entstaatlichung? ..... 216

3. Unaustauschbarkeit der Identität des Staates als Adressat der grundgesetzlichen Verfassungsbindungen .......................... 217

a) Die normdirigierende Kraft der Verfassung gegenüber der als Einheit verstandenen Staatsgewalt . . . . 217

b) Organtheoretische Zurechnung aller Formen der Kompetenzausübung auf die juristische Person „Staat" ...................... 218

4. Qualifizierung des durch Gebrauch der privatvertraglichen Rechtsform begründeten Rechtsverhältnisses als ermächtigungsgebundener öffentlich-rechtlicher

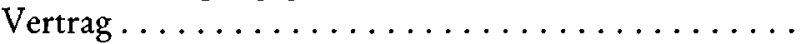

III. Der subordinationsrechtliche Vertrag als Rechtsform des Verwaltungshandelns - Korrekturbedürftigkeit einer dogmatischen Fehlkonstruktion . . . . . . . . . . 222

1. Unmöglichkeit der Qualifizierung der anstelle des Erlasses eines Verwaltungsaktes oktroyierten Vereinbarung als Vertrag .................. 222

2. Freiheit der Rechtsausübung als Wesenselement des Vertrages ...................... 228

3. Koordinationsrechtlicher Vertrag zwischen Verwaltung und Privaten als Instrument zur Übertragung von Verwaltungsaufgaben auf Private . . . . . . . . 229 
2. Teil: Die regelungsersetzenden Absprachen $\ldots \ldots \ldots \ldots 230$

I. Die Verknüpfung der Rechtsformen des Verwaltungshandelns mit den Regelungshandlungen als Fundament des verwaltungsrechtsdogmatischen Systems . . . . . . 230

1. Individueller Rechtsschutz als ausschließliches Interesse an dogmatischer Durchformung des Verwaltungshandelns .................. 231

2. Alleinige Unterstellung der administrativen Regelungen unter den Rechtsformvorbehalt . ......... 232

3. Rechtsformmanipulation als Grundproblem des informellen Verwaltungshandelns ......... 233

II. Qualifizierung der regelungsersetzenden Absprachen als Verfügung des Verwaltungsträgers über die Bindung an den normativen Handlungsauftrag . . . . . . . . . 234

1. Das informelle von schlichtem Verwaltungshandeln unterscheidende Kennzeichen als Ersatzhandlung für die Vornahme einer rechtsformgebundenen Regelung. 235

2. Der Kompensationsgedanke als alleinige rechtskonstruktive Möglichkeit der Legalisierung von Absprachen ....................... 236

a) Grundsätzliche Möglichkeit der „Kompensation“ des Regelungsverzichts durch Erfüllung der eingegangenen Handlungs- oder Unterlassungsversprechen des Privaten . . . . . . . . . . . . . 237

b) Vielfalt ungelöster Fragen zu den Voraussetzungen der Kompensationsfähigkeit von Vollzugsdefiziten durch privaten Handlungsbeitrag . . . . . . . . 238

3. Abspracheverbot im Bereich gesetzlich oder grundrechtlich geschützter Teilhabe von Dritten am Verfahren administrativer Entscheidungsbildung . . ..... 241

4. Die dogmatischen Probleme der Anerkennung von Kompensationsansprüchen bei Nichteinhaltung von Absprachen ..................... 242 


\section{Einleitung: Die Diagnose dogmatischer Defizite der Lehre von den Handlungsformen der Verwaltung}

\section{Die verfassungsrechtlichen Legalitätskriterien des Verwaltungshandelns}

Der demokratische Rechtsstaat umgrenzt, bestimmt und formt das Verwaltungshandeln. Gegenständlich umgrenzt wird die Tätigkeit der Verwaltung durch ihren Bezug auf den Gemeinwohltatbestand und ihre Zwecklimitierung auf das Ziel der Gemeinwohlverwirklichung'; inhaltlich bestimmt wird sie durch die Bindung an Gesetz und Recht sowie das Übermaßverbot in seinen Ausprägungen der Erforderlichkeit und Verhältnismäßigkeit ${ }^{2}$; geformt wird sie durch den rechtsstaatlich und demokratisch begründeten Gesetzesvorbehalt sowie durch die Grundrechte, insbesondere die Rechtsschutzgarantie des Art. 19 Abs. 4 GG sowie weitere verfahrensrelevante Grundrechtspositionen ${ }^{3}$. Diese gegenständlichen, inhaltlichen und formellen Hand-

1 Grundlegend dazu H.P. Bull, Die Staatsaufgaben nach dem Grundgesetz, 2. Aufl. 1977, S. 47 ff.; ferner H. Peters, Öffentliche und staatliche Aufgaben, in: Festschrift für Nipperdey, Bd. II, 1965, S. 877 ff.; P. Häberle, Öffentliches Interesse als juristisches Problem, 1970, S. 32 ff.; ders., „Gemeinwohljudikatur" und Bundesverfassungsgericht, AöR Bd. 95 (1970), S. 86 ff., 260 ff.; ders., Die Gemeinwohlproblematik in rechtswissenschaftlicher Sicht, in: Rechtstheorie Bd.14 (1983), S. 257 ff.; G. Püttner, Verwaltungslehre, 2. Aufl. 1989, S. 33 ff.; H.H. v.Arnim, Staatslehre der Bundesrepublik Deutschland, 1984, S. $103 \mathrm{ff}$.; D. Czybulka, Die Legitimation der öffentlichen Verwaltung, 1989, S. 42 ff.; G.F. Schuppert, Die Erfüllung öffentlicher Aufgaben durch verselbständigte Verwaltungseinheiten, 1981, S. 191 ff.; ders., Die öffentliche Aufgabe als Schlüsselbegriff der Verwaltungswissenschaft, VerwArch. Bd. 71 (1980), S. 309 ff.; zuletzt J. Isensee, Gemeinwohl und Staatsaufgaben im Verfassungsstaat, in: Isensee/Kirchhof (Hrsg.), Handbuch des Staatsrechts der Bundesrepublik Deutschland, Bd. III, 1988, $\$ 57$, S. 3 ff. - Aus der Rechtsprechung vgl. BVerfGE 50, 50 (51); 59, 216 (229); 12, 205 (206); 38, 281 (299).

2 Grundlegend dazu P. Lerche, Übermaß und Verfassungsrecht, 1961; ferner E. Grabitz, Der Grundsatz der Verhältnismäßigkeit in der Rechtsprechung des Bundesverfassungsgerichts, AöR Bd. 98 (1973), S. 568 ff.; H.Schneider, Zur Verhältnismäßigkeitskontrolle insbesondere bei Gesetzen, in: Bundesverfassungsgericht und Grundgesetz, Bd. II, 1976, S.390 ff.; U. Ch. Jakobs, Der Grundsatz der Verhältnismäßigkeit, 1985, insbesondere S. 127 ff.; zuletzt $P$. Lerche, Grundrechtsschranken, in: Isensee/Kirchhof (Hrsg.), Handbuch des Staatsrechts, Bd. V, 1992, $\$ 122$, S. 775 ff., 783 f. - Aus der Rechtsprechung vgl. BVerfGE 23, 127 (133); 79, $311(341) ; 81,310$ (338).

${ }^{3}$ Grundlegend R. Alexy, Theorie der Grundrechte, 1985, insbesondere S. 75 ff.; H. Goerlich, Grundrechte als Verfahrensgarantien, 1981, S. 19 ff.; ders., Schutz- 
lungsbindungen stellen Legalitätskriterien des Verwaltungshandelns dar, auf die sich das Geltungsregime des rechtsstaatlichen Verwaltungsrechts stützt und die sich in der Maßstabsfunktion des Verwaltungsrechts niederschlagen.

Mit Blick auf das Vortragsthema ist dabei klarzustellen, daß sich diese Legalitätskriterien nicht auf die sogenannten normativen Handlungsformen der Verwaltung, d.h. die auf Erlaß von Normen Verordnungen, Satzungen, Verwaltungsvorschriften - gerichtete Tätigkeit der Verwaltung beziehen, die anderen Maßstäben unterliegt. Die rechtsetzende Tätigkeit der Verwaltung ist nicht Gegenstand des Vortrags, weshalb die auf Vorbereitung oder Verhinderung rechtssatzförmiger Regelungen gerichteten Absprachen, die normvorbereitenden oder normverbindernden Absprachen zwischen Verwaltung und Privaten außer Betracht bleiben.

\section{Erfordernis einer dogmatischen Umformung der Handlungslehre?}

Es ist die Aufgabe einer Handlungslehre der Verwaltung, alle Erscheinungen administrativen Handelns in der überreichen Formengestalt der Verwaltungsrealität zu erfassen und der Maßstabsfunktion des Verwaltungsrechts mit dem Ziel eines sachangemessenen Ausgleichs zwischen behördlichem Handlungsauftrag und bürgerlichem Rechtsschutz zu unterstellen ${ }^{4}$. In der Einschätzung, daß die derzeitige

pflicht - Grundrechte - Verfahrensschutz, NJW 1981, S. $2616 \mathrm{ff}$.; H. Bethge, Grundrechtsverwirklichung und Grundrechtssicherung durch Organisation und Verfahren, NJW 1982, S.1 ff.; F. Ossenbübl, Grundrechtsschutz im und durch Verfassungsrecht, in: Festschrift für K. Eichenberger, 1982, S. 183 ff.; H.W. Laubinger, Grundrechtsschutz durch Gestaltung des Verwaltungsverfahrens, Verw Arch. Bd. 73 (1982), S.60 ff.; J.P. Müller, Grundrechtliche Anforderungen an Entscheidungsstrukturen, in: Festschrift für Eichenberger, 1982, S. $169 \mathrm{ff} ., 173$; F. Hufen, Fehler im Verwaltungsverfahren, 1986, S. 136 ff.; J. Burmeister, Grundgesetzliche Verfahrensstrukturierungsgebote komplexer Verwaltungsentscheidungen, in: Jahrbuch des Umwelt- und Technikrechts, Bd.5, 1988, S.121ff.; E.Schmidt-Aßmann, Verwaltungsverfahren, in: Isensee/Kirchhof (Hrsg.), Handbuch des Staatsrechts, Bd. III, 1988, $\$ 70$, S. $623 \mathrm{ff}$., Rdn. 17; zuletzt E. Denninger, Staatliche Hilfe zur Grundrechtsausübung durch Verfahren, Organisation und Finanzierung, in: Isensee/Kirchhof (Hrsg.), Handbuch des Staatsrechts, Bd.V, 1992, $\$ 113$, S. 291 ff., Rdn. 29 ff. - Aus der Rechtsprechung vgl. BVerfGE 24, 367 (401); 35, 79 (115f.); 51, 324 (343 ff.); 53, 30 (65f.); 65, 1 (46).

4 Allgemein zur Funktion der Handlungsformenlehre vgl. insbesondere E.Schmidt-Aßmann, Die Lehre von den Rechtsformen des Verwaltungshandelns, 
Handlungsformenlehre der Verwaltung dieser Aufgabe nicht zu entsprechen vermag, scheint sich die Verwaltungsrechtslehre weithin einig zu sein ${ }^{5}$. Diesen Befund rechtlich präzise, d.h. in konkreten dogmatischen Defiziten der Formenlehre festzumachen, bereitet indessen erhebliche Schwierigkeiten.

Beispielhaft für diese Einschätzung ist das opus magnum von Rainer Pitschas über "Verwaltungsverantwortung und Verwaltungsverfahren" 6 , in dessen Einleitung sich die Feststellung findet, daß „in der Rechts- und Verwaltungswissenschaft heute kaum noch Zweifel daran bestehen, daß unser (Allgemeines) Verwaltungsrecht der umfassenden Modernisierung, insbesondere einer dogmatischen Umformung der gegenwärtigen Handlungsformen öffentlicher Verwaltung bedarf", und wo die Konzeption der notwendig erachteten Modernisierung des Verwaltungsrechts wie folgt umrissen wird: „Die Abbildung der Interaktion zwischen Verwaltung und Bürger im Verwaltungsrechtsverhältnis, der ,Dia$\log ^{6}$ und die Suche nach ,Konsens' erweisen sich als die tragenden Elemente eines im Ergebnis gewandelten Begegnungsmusters zwi-

DVBl. 1989, S. 533 ff.; P. Krause, Rechtsformen des Verwaltungshandelns, 1974, S. 14 ff.; F. Ossenbübl, Die Handlungsformen der Verwaltung, JuS 1979, S. 681 ff.; W. Pauly, Grundlagen einer Handlungsformenlehre im Verwaltungsrecht, in: Wandel der Handlungsformen im öffentlichen Recht, 1991, S. 25 ff.; U. Di Fabio, System der Handlungsformen und Fehlerfolgenlehre, in: Wandel der Handlungsformen im öffentlichen Recht, 1991, S. $47 \mathrm{ff}$.

$5 \mathrm{Vgl}$. insbesondere W. Hoffmann-Riem, Reform des allgemeinen Verwaltungsrechts als Aufgabe - Ansätze am Beispiel des Umweltschutzes, AöR Bd. 115 (1990), S. $400 \mathrm{ff}$., $403 \mathrm{ff}$; ders., Selbstbindungen der Verwaltung, VVDStRL H. 40 (1982), S. $187 \mathrm{ff}$., $220 \mathrm{ff}$;; zur Reformdiskussion vgl. ferner insbesondere E.SchmidtAßmann, Das allgemeine Verwaltungsrecht als Ordnungsidee und System, 1982; ders., Der Verfahrensgedanke in der Dogmatik des öffentlichen Rechts, in: Lerche/ Schmitt Glaeser/Schmidt-Aßmann (Hrsg.), Verfahren als staats- und verwaltungsrechtliche Kategorie, 1984, S. 3 ff.; ders., Verwaltungsverfahren, in: Isensee/Kirchhof (Hrsg.), Handbuch des Staatsrechts, Bd.III, 1988, S.623ff., 628; H. Hill, Das fehlerhafte Verfahren und seine Folgen im Verwaltungsrecht, 1986, S. 7 f.; F. Kopp, Zehn Jahre Verwaltungsverfahrensgesetz, Die Verwaltung Bd. 20 (1987), S. 1 ff., 5 ff.; W. Schmidt, Einführung in die Probleme des Verwaltungsrechts, 1982, S. 17 f., 72 ff.; H. U. Erichsen, Das Verwaltungshandeln, in: Erichsen/Martens (Hrsg.), Allgemeines Verwaltungsrecht, 9. Aufl. 1992, $\$ 10$, S.179ff.; W. Brohm, Die Dogmatik des Verwaltungsrechts vor den Gegenwartsaufgaben der Verwaltung, VVDStRL H. 30 (1972), S. $246 \mathrm{ff}$

6 R. Pitschas, Verwaltungsverantwortung und Verwaltungsverfahren. Strukturprobleme, Funktionsbedingungen und Entwicklungsperspektiven eines konsensualen Verwaltungsrechts, 1990. 
schen Verwaltung und Bürger; das darauf zugeschnittene Verwaltungsrecht ist ,konsensuales" Verwaltungsrecht".

Die Schwierigkeiten, die Diagnose dogmatischer Insuffizienz der Handlungsformenlehre in konkreten Symptomen festzumachen, ist wohl in erster Linie auf den Umstand zurückzuführen, daß sich die Verwaltungswissenschaft bei der ihr obliegenden Analyse bestehender Strukturen der Verwaltung des Vokabulars aus der Begriffswelt der empirischen Sozialwissenschaften und der Wirtschaftswissenschaften bedient, um Verkrustungen aufzuweisen, die gegenüber den juristischen Mitteln und Methoden der Problemerfassung immun zu sein scheinen. Begriffe wie Verwaltungsmanagement, Verwaltungsmarketing, Verwaltungsoutput, Verwaltungswettbewerb, die Umbenennung von Zuständigkeitsbereichen in Geschäftsbereiche von Verwaltungsträgern sind dafür beispielhaft, auch das "soft law" und die „weichen Handlungsmittel“ gehören dazu, ebenso wie die Auflösung der dogmatischen Substanz des Begriffs „Rechtsverhältnis“ durch attributive Verbindung mit Vokabeln wie diskursiv, interaktionistisch, dialogisch, kommunikativ, reflexiv, situativ und dergleichen mehr. Ohne Zweifel ist diese sozialwissenschaftlich imprägnierte Begrifflichkeit von großer Veranschaulichungskraft über Ursachen und Wirkungszusammenhänge vorgefundener Strukturen, ihre Verwendung als Rechtsbegriffe bereitet jedoch beträchtliche Verlegenheit und stiftet nicht selten Verwirrung.

\section{Das Phänomen des informellen Staatshandelns im Blickwinkel sozial- und verwaltungswissenschaftlicher Problemanalyse}

Dies verweist auf ein grundsätzliches Problem des reflexionsbedürftigen Verhältnisses zwischen Verwaltungswissenschaft und Verwaltungsrechtswissenschaft ${ }^{7}$, auf das hier nicht vertieft eingegangen, sondern nur andeutungsweise hingewiesen werden kann: Wenn Sozial- und Verwaltungswissenschaften die Grenzen ihrer genuinen Aufgabe überschreiten, vorgefundene Erscheinungen der Rechtsrealität daraufhin zu analysieren, warum sie so sind, wie sie sind, und sich anschicken zu bewerten, wie sie sein sollten, so ist zumindest Vorsicht geboten $^{8}$. So ist es beunruhigend, wenn der Einbruch informaler

\footnotetext{
7 Grundsätzlich dazu W. Naucke, Über die juristische Relevanz der Sozialwissenschaften, 1972.

${ }^{8}$ Zum Erfordernis „kritischer Distanz“ gegenüber dem Argumentieren mit den Ergebnissen der empirischen Sozialwissenschaften vgl. insbesondere W. Bydlinski, Fundamentale Rechtsgrundsätze. Zur rechtsethischen Verfassung der Sozietät,
} 
Praktiken in ein Kernstück verfahrensförmlich gesicherter und dogmatisch gründlich durchgebildeter Rechtsstaatlichkeit, nämlich in den Strafprozeß, durch eine verbreitete Absprachepraxis zwischen Staatsanwalt und Verteidiger außerhalb der mündlichen Verhandlung bewertet wird als "Ausdruck eines geänderten, von Konfrontation auf Kooperation umgestellten Verhältnisses zwischen Staatsanwaltschaft und Verteidigung“"

Das gilt aber auch für die im verwaltungswissenschaftlichen Lager verbreitete Haltung, das Streben der Verwaltung, sich den Bindungen des - wie es heißt - unflexiblen, verworrenen, systemlosen, situations- und lebensfremden Rechts zu entziehen, allenfalls mit milder Skepsis zu betrachten. Das flutende Schrifttum ${ }^{10}$, das sich ganz über-

1988, S. $1 \mathrm{ff} ., 19 \mathrm{f}$; ders., Juristische Methodenlehre und Rechtsbegriff, 1982, S. 84 ff.; ders., Die normativen Prämissen der Rechtsgewinnung, in: Rechtstheorie Bd. 16 (1985), S. 1 ff., 7; Th. Geiger, Vorstudien zu einer Soziologie des Rechts, 2. Aufl. 1970, S.61 ff., $242 \mathrm{ff}$; J. Burmeister, Praktische Jurisprudenz und rechtsethischer Konsens in der Gesellschaft, in: Gedächtnisschrift für W. K. Geck, 1989, S. $97 \mathrm{ff} ., 108 \mathrm{f}$.

${ }^{9}$ In diesem Sinne insbesondere W. Schmidt-Hieber, Verständigung im Strafverfahren, 1986; U. Gallondi, Vertrauen im Strafprozeß, MDR 1987, S. $801 \mathrm{ff}$.; C. Rückel, Verteidigertaktik bei Verständigungen und Vereinbarungen im Strafverfahren, NStZ 1987, S. 297 ff.; H.J. Bode, Verständigung im Strafprozeß, DRiZ 1988, S. $281 \mathrm{ff}$; H.Dabs, Absprachen im Strafprozeß - Chancen und Risiko, NStZ 1988, S. 153 ff.; H.J. Krüger, Verantwortung und Selbstbewußtsein bei der Verständigung im Strafverfahren, DRiZ 1989, S. 150. - Kritisch demgegenüber K.F. Schumann, Handel mit Gerechtigkeit, 1977; Schünemann, Absprachen im Strafverfahren? Grundlagen, Gegenstände, Grenzen, Gutachten B zum 58. Deutschen Juristentag, 1990; W. Hassemer, Pacta sunt servanda - auch im Strafprozeß?, JuS 1989, S. 890 ff.; J.Baumann, Von der Grauzone zur rechtsstaatlichen Regelung, NStZ 1987, S. $157 \mathrm{ff}$.; Th. Weigend, Abgesprochene Gerechtigkeit, JZ 1990, S. 774 ff. mit weiteren Nachweisen.

10 Aus der Fülle des Schrifttums vgl. insbesondere H. Bauer, Informelles Verwaltungshandeln im öffentlichen Wirtschaftsrecht, VerwArch. Bd.78 (1987), S. $241 \mathrm{ff}$;; W. Beyer, Der öffentlich-rechtliche Vertrag, informales Handeln der Behörden und Selbstverpflichtungen Privater als Instrumente des Umweltschutzes, Diss. Köln 1984, S. $113 \mathrm{ff}$.; U. Beyerlin, Schutzpflicht der Verwaltung gegenüber dem Bürger außerhalb des formellen Verwaltungsverfahrens, NJW 1987, S. $2713 \mathrm{ff}$.; E. Bobne, Der informale Rechtsstaat, 1981, S. $42 \mathrm{ff}$.; ders., Informelles Verwaltungs- und Regierungshandeln als Instrument des Umweltschutzes, VerwArch. Bd. 75 (1984), S. 343 ff.; W. Brobm, Verwaltungshandlungen mit Hilfe von Konfliktmittlern?, DVBI. 1990, S. $321 \mathrm{ff}$.; ders., Beschleunigung des Verwaltungsverfahrens - Straffung oder konsensuales Verwaltungshandeln?, NVwZ 1991, S. 1025 ff.; H.P. Bull, Allgemeines Verwaltungsrecht, 2. Aufl. 1985, Rdn. 295 ff.; M. Bulling, Kooperatives Verwaltungshandeln (Vorverhandlungen, Arrangements, 
wiegend mit dem weiten Spektrum einseitigen oder kooperativen informellen Verwaltungshandelns befaßt, vermittelt den Eindruck, als

Agreements und Verträge) in der Verwaltungspraxis, DÖV 1989, S. 277 ff.; K. Bussfeld, Informales Verwaltungshandeln - Chancen und Risiken, in: H. Hill (Hrsg.), Verwaltungshandeln durch Verträge und Absprachen, 1990, S. 39 ff.; G. Dauber, Möglichkeiten und Grenzen kooperativen Verwaltungshandelns, in: Wandel der Handlungsformen im öffentlichen Recht, 1991, S.67ff.; C.E. Eberle, Arrangements im Verwaltungsverfahren, Die Verwaltung Bd. 17 (1984), S. 439 ff.; H.U. Erichsen, (Anm. 5), \$35, S. 419 ff.; Ch. Gramm, Aufklärung durch staatliche Publikationsinformationen, Der Staat 1991, S. $51 \mathrm{ff} . ;$ R. Gröschner, Öffentlichkeitsaufklärung als Behördenauftrag, DVBl.1990, S.619ff.; M.Heintzen, Staatliche Warnungen als Grundrechtsproblem, VerwArch. Bd. 81 (1990), S. 532 ff.; H. G. Henneke, Informelles Verwaltungshandeln im Wirtschaftsverwaltungs- und Umweltrecht, Natur und Recht 1991, S. 267 ff.; H. Hill, Rechtsstaatliche Bestimmtheit oder situationsgerechte Flexibilität des Verwaltungshandelns, DÖV 1989, S. 885 ff.; W. Hoffmann-Riem, Konfliktmittler in Verwaltungsverhandlungen, 1989, S. 20 ff.; ders., Selbstbindungen, (Anm.5), S. 187 ff.; J.H. Kaiser, Industrielle Absprachen im öffentlichen Interesse, NJW 1971, S. 585 ff.; P. Kirchbof, Mittel des Verwaltungshandelns, in: Isensee/Kirchhof (Hrsg.), Handbuch des Staatsrechts, Bd.III, 1988, \$59, S. $121 \mathrm{ff}$., Rdn. $157 \mathrm{ff}$; M. Kloepfer, $\mathrm{Zu}$ den neuen umweltrechtlichen Handlungsformen des Staates, JZ 1991, S. 737 ff.; ders., Umweltrecht, 1989, \$4 II, Rdn. $150 \mathrm{ff}$; K. König, Rechtliche und tatsächliche Formen des Verwaltungshandelns, Verwaltungsrundschau 1990, S. $401 \mathrm{ff}$; W. Krebs, Konsensuales Verwaltungshandeln im Städtebaurecht, DÖV 1989, S. $969 \mathrm{ff}$;; Ph.Kunig, Verträge und Absprachen zwischen der Verwaltung und Privaten, DVBl. 1992, S. $1193 \mathrm{ff}$.; Pb.Kunig/S. Rublack, Aushandeln statt Entscheiden?, Jura 1990, S. 1 ff.; H. Lecheler, Verträge und Absprachen zwischen der Verwaltung und Privaten, BayVBl. 1992, S. 545 ff.; G. Lübbe-Wolff, Das Kooperationsprinzip im Umweltrecht - Rechtsgrundsatz oder Deckmantel des Vollzugsdefizits?, Natur und Recht 1989, S. 295 ff.; H. Maurer, Allgemeines Verwaltungsrecht, 8. Aufl. 1992, \$15 III, S. 369 ff.; J. H. Müggenborg, Formen des Kooperationsprinzips im Umweltrecht in der Bundesrepublik Deutschland, NVwZ, 1990, S. $909 \mathrm{ff}$.; M. Oldiges, Staatlich inspirierte Selbstbeschränkungsabkommen der Privatwirtschaft, WiR 1973, S. 1 ff.; F. Ossenbühl, Umweltpflege durch behördliche Warnungen und Empfehlungen, 1986; ders., Informelles Verwaltungshandeln im Gesundheits- und Umweltrecht, Jahrbuch des Umwelt- und Technikrechts, Bd.3, 1987, S.27ff.; W. Pauly, Der Regelungsvorbehalt, DVBl.1991, S. 521 ff.; R. Philipp, Staatliche Verbraucherinformation im Umwelt- und Gesundheitsrecht, 1989; H. Sodan, Gesundheitsbehördliche Informationstätigkeit und Grundrechtsschutz, DÖV 1987, S.858ff.; R.Schmidt, Öffentliches Wirtschaftsrecht, 1990, $\$ 10$ II, S. $494 \mathrm{ff}$.; E.SchmidtAßmann, Die Lehre von den Rechtsformen des Verwaltungshandelns, DVBl. 1989, S. $533 \mathrm{ff}$; F. Schoch, Staatliche Informationspolitik und Berufsfreiheit, DVBl. 1991, S.667ff.; M.Schulte, Informales Verwaltungshandeln als Mittel staatlicher Umwelt- und Gesundheitspflege, DVBl. 1988, S. $512 \mathrm{ff}$;; Th. Würtenberger, Akzeptanz durch Verwaltungsverfahren, NJW 1991, S. 257 ff.; Fr. v. Zezschwitz, Wirtschaftsrechtliche Lenkungstechniken, JA 1978, S. $497 \mathrm{ff}$. 
stelle das Phänomen des Ausbruchs aus den Rechtsformen die logische und im Prinzip begrüßenswerte Reaktion auf die durch ein undurchdringliches rechtliches Regelungsdickicht eingetretene Lähmung von Verwaltungsinitiative dar. Die Situation der Verwaltung wird so geschildert, als werde die Durchsetzung von Staatsaufgaben durch die Bindung an das Gesetz nicht initiiert und gesteuert, sondern durch ein normatives Übermaß sowie vor allem durch eine den administrativen Innenbereich durchdringende Grundrechtshypertrophie gelähmt ${ }^{11}$ - eine Einschätzung, die mit logischer Konsequenz in die Feststellung einmündet, daß „von einer Verwaltung, die sich mit Blick auf die Grundrechte des Bürgers so verhält wie das Kaninchen vor der Schlange, nichts zu erwarten ist" ${ }^{\text {12. }}$.

An dieser Situationsbeschreibung ist sicherlich viel Richtiges; Vorsicht ist jedoch geboten, wenn aus der Analyse der komplexen Wirkungsmechanismen sogenannter normersetzender oder normvertretender informeller Absprachen zwischen Staat und Wirtschaft in Form von Selbstbeschränkungs- oder Branchenabkommen Therapievorschläge zur Lösung der Deregulationsproblematik hergeleitet werden, die in die Formulierung eines dem Subsidiaritätsgedanken verwandten Rechtsprinzips einmünden, das eine gesetzgeberische Regelungssperre errichten soll, bis „die Möglichkeiten ausgeschöpft sind, durch freiwillige Maßnahmen unterhalb der Schwelle rechtlich verbindlicher Regelungen zu einer Situationsverbesserung zu gelangen"13.

${ }^{11}$ Zur Klage über die "Gesetzesflut" vgl. insbesondere W. Leisner, Rechtsstaat - ein Widerspruch in sich?, JZ 1977, S. $537 \mathrm{ff}$; H.D. Weiß, Verrechtlichung als Selbstgefährdung des Rechts, DÖV 1978, S.601; H.J. Vogel, Zur Diskussion um die Normenflut, JZ 1979, S. 321 ff.; Th. Mayer-Maly, Gesetzesflut und Gesetzesqualität heute, in: Festschrift zum 125jährigen Bestehen der juristischen Gesellschaft Berlin, 1984, S. $423 \mathrm{ff}$.; zuletzt dazu F. Ossenbübl, Gesetz und Recht - Die Rechtsquellen im demokratischen Rechtsstaat, in: Isensee/Kirchhof (Hrsg.), Handbuch des Staatsrechts, Bd. III, 1988, $\$ 61$, S. $281 \mathrm{ff}$., Rdn. $55 \mathrm{ff}$.

12 So J. Becker, Informales Verwaltungshandeln zur Steuerung wirtschaftlicher Prozesse im Zeichen der Deregulierung, DÖV 1985, S. 1003 ff., 1010; ähnlich M. Oldiges, (Anm. 10), S.24, der darauf hinweist, daß die Zulassung gesetzesfreier Kooperation zwischen Staat und Wirtschaft „eine gewisse Grundrechtsschmälerung" bewirkt.

${ }_{13}$ So J. Becker, (Anm. 12), S. 1007 f.; ferner H. Freiberr v. Lersner, Verwaltungsrechtliche Instrumente des Umweltschutzes, 1983, S. 10; vgl. E. Bobne, Privatisierung des Staates, Absprachen zwischen Industrie und Regierung in der Umweltpolitik, in: Jahrbuch für Rechtssoziologie und Rechtstheorie, 1982, S. 267 ff., 271; 


\section{Ausbruch aus den Rechtsformen - Konsequenz gesetzlichen Übermaßes oder der Steuerungsschwäche des Gesetzes?}

Von untergeordneter Bedeutung ist dabei, daß die Problemdimensionen der Grundsatzfrage nicht ausgelotet sind, ob sich der Staat über bereichsspezifische Einzelfälle hinaus auf einen vom do-ut-des-Prinzip beherrschten Tauschhandel zwischen Gemeinwohlbelangen und Individualinteressen einlassen darf. Zu Skepsis besteht deshalb Anlaß, weil bei der Formulierung eines solchen Rechtsprinzips die Wirkungszusammenhänge zwischen Gesetzesflut und informellem Verwaltungshandeln verkannt werden: Es ist nicht die durch ein undurchdringliches Regelungsgestrüpp verursachte Lähmung der Verwaltungsinitiative, die die Administration dazu treibt, aus den Rechtsformen auszubrechen, sondern es verhält sich so, daß die Lage der Verwaltung trotz des unstillbaren Normenhungers des Gesetzgebers durch eine bis dahin nicht gekannte Stenerungsschwäche des Gesetzes gekennzeichnet ist.

Das Auftreten des informellen Verwaltungshandelns läßt sich ziemlich genau an den tiefgreifenden Veränderungen der verfassungsrechtlichen Stellung der Exekutive festmachen, die mit der Fortentwicklung des Staates der Daseinsvorsorge, Wirtschaftsintervention und Planung ${ }^{14}$ zum Staat der Daseinssicherung, der Wirtschaftsförderung und der Zivilisationsentsorgung eingetreten sind. Dieser Entwicklungsumbruch, der doch immer am sinnfälligsten gekennzeichnet ist als staatlicher Übergang von der sozialen zur technischen Realisation ${ }^{15}$, hat nicht nur zu einer Veränderung der Gegenstände staatlicher Problembewältigung geführt, sondern Kräfte- und Funktionsverschiebungen im rechtsstaatlichen Gewaltengefüge in einem bis dahin nicht gekannten Ausmaß bewirkt. Die Symptome und vielschichtigen

ders., (Anm. 10), VerwArch. Bd. 75 (1984), S. 343 ff., 361. - Zur Vorsicht, „auf eine plakative Diagnose mit einer plakativen Therapie zu antworten“, mahnt demgegenüber J.Isensee, Mehr Recht durch weniger Gesetze, ZRP 1985, S. 139.

${ }_{14}$ So die klassische Kennzeichnung durch P. Lerche, Übermaß (Anm. 2), S. 259.

15 So E. Forsthoff, Von der sozialen zur technischen Realisation, Der Staat Bd. 9 (1970), S. 145 ff.; ders., Der Staat der Industriegesellschaft, 1971, S. $30 \mathrm{ff}$., 42 ff.; vgl. ferner G.F. Jünger, Die Perfektion der Technik, 5. Aufl. 1968; H. Freyer, Über das Dominantwerden technischer Kategorien in der Lebenswelt der industriellen Gesellschaft, in: Gedanken zur Industriegesellschaft, 1970, S.131 ff.; ders., Die Technik als Lebensmacht, Denkform und Wissenschaft, ebenda, S. 145 ff.; K. Hïbner, Von der Intentionalität technischer Entwicklung, in: Sprache im technischen Zeitalter, H.25 (1968), S.27 ff.; H.Jonas, Das Prinzip Verantwortung, 1979, S. $26 \mathrm{ff}$. 
Auswirkungen dieses Wandels der Staatsaufgaben sind eingehend beschrieben worden ${ }^{16}$. Sie bestehen vor allem in der Einbuße der politischen Steuerungs- und Regelungspotenzen des Gesetzgebers, zunehmender Selbststeuerung und Entscheidungsverantwortung der Verwaltung aufgrund steuerungsschwacher, mit unbestimmten Rechtsbegriffen, administrativen Beurteilungsermächtigungen und Verweisungen auf außerrechtliche technische Standards durchsetzter normativer Handlungsanweisungen ${ }^{17}$, daraus resultierender Veränderung des Verhältnisses zwischen Verwaltung und Verwaltungsgerichtsbarkeit durch Verlagerung von Elementen des verwaltungsgerichtlichen Kontroll- und Rechtsschutzauftrages in das Verwaltungsverfahren ${ }^{18}$. Es liegt auf der Hand, daß die gegenüber der technischen

16 Verwiesen sei aus der Fülle der Literatur auf $R$. Scholz, Verwaltungsverantwortung und Verwaltungsgerichtsbarkeit, VVDStRL H. 34 (1975), S. 145 ff. (148); W. Brohm, Die staatliche Verwaltung als eigenständige Gewalt und die Grenzen der Verwaltungsgerichtsbarkeit, DVBl. 1986, S.321 ff.; G.Püttner/F.Kopp/ O. Kaufmann, Handlungsspielräume der Verwaltung und Kontrolldichte gerichtlichen Rechtsschutzes, in: Götz/Klein/Starck (Hrsg.), Die öffentliche Verwaltung zwischen Gesetzgebung und richterlicher Kontrolle, 1985, S. $131 \mathrm{ff}$., $146 \mathrm{ff}$.; $F$. Weyreuther, Verwaltungsverantwortung und gerichtliche Kontrolle, UPR 1986, S. $121 \mathrm{ff}$; H.J. Papier, Zur verwaltungsgerichtlichen Kontrolldichte, DÖV 1986, S.621 ff.; J. Schwab, Möglichkeiten der Kontrollrestriktion im Umweltrecht, DVBl.1986, S. 170 ff.; G.Schmidt-Eichstaedt, Der Konkretisierungsauftrag der Verwaltung beim Vollzug öffentlich-rechtlicher Normen, DVBl.1985, S. $654 \mathrm{ff}$. (insbesondere S. $658 \mathrm{ff}$.); H.W. Rengeling, Anlagenbegriff, Schadensvorsorge und Verfahrensstufung im Atomrecht, DVBl. 1986, S. $265 \mathrm{ff}$. (269 ff.); K. Grupp, Der Rechtsschutz in Verwaltungssachen, in: Burmeister (Hrsg.), Die verfassungsrechtliche Stellung der Verwaltung in Frankreich und in der Bundesrepublik Deutschland, 1991, S. 97 ff., 109 ff. mit umfassender Literaturübersicht in Fn. 69; jeweils mit weiteren Nachweisen zum älteren Schrifttum.

$17 \mathrm{Vgl}$. dazu insbesondere E.Schmidt-Aßmann, Der Rechtsstaat, in: Isensee/ Kirchhof (Hrsg.), Handbuch des Staatsrechts, Bd.I, 1987, \$24, S. 987 ff., Rdn. 61; W. Blümel, Grundrechtsschutz durch Verfahrensgestaltung, in: ders. (Hrsg.), Frühzeitige Bürgerbeteiligung bei Planungen, 1982, S.23ff.; H.W. Laubinger, Grundrechtsschutz durch Gestaltung des Verwaltungsverfahrens, VerwArch. Bd.73 (1982), S.60 ff., $83 \mathrm{ff}$;; K. Stern, Das Staatsrecht der Bundesrepublik Deutschland, Bd.III/1, 1988, S. $953 \mathrm{ff}$; $R$. Wahl, Verwaltungsverfahren zwischen Verwaltungseffizienz und Rechtsschutzauftrag, VVDStRL H.41 (1983), S. 151 ff., 182; Ch.Degenhart, Das Verwaltungsverfahren zwischen Verwaltungseffizienz und Rechtsschutzauftrag, DVBl.1982, S.872 ff., 878; W. Hoffmann-Riem/ S. Rubbert, Atomrechtlicher Erörterungstermin und Öffentlichkeit, 1984, S.23 f.; J. Burmeister, (Anm. 3), S. 149 ff.; K. Grupp, (Anm. 16), S. $121 \mathrm{ff}$.

${ }_{18}$ Zur Tendenz der technischen Entwicklung, sich der Steuerung durch das Recht zu entziehen, vgl. außer den Nachweisen in Anm. 15 insbesondere D. Murs- 
Entwicklung besonders einschneidende Einbuße der politischen Steuerungspotenzen des Gesetzgebers zu einer tiefgreifenden Veränderung der Strukturen administrativer Regelungsaufgaben führt und die Tendenzen fördert, sich den Verfahrens- und Formbindungen steuerungsschwacher normativer Handlungsanweisungen zugunsten eines instrumentellen Zweckpragmatismus bei der Aufgabenwahrnehmung zu entledigen.

In dieser Aufhellung der zwischen der Steuerungsschwäche des Gesetzes und dem Auftreten informellen Verwaltungshandelns bestehenden Wirkungszusammenhänge deutet sich bereits an, daß sich die Forderung nach stärkerer rechtsstaatlicher Disziplinierung des informellen Verwaltungshandelns ${ }^{19}$ nur in begrenztem Maße durch eine dogmatische Umbildung der Handlungsformenlehre bewerkstelligen läßt und dementsprechend auch eine solche nur in begrenztem Maße erforderlich macht; es handelt sich dabei vielmehr in erster Linie um ein Problem der Wiederherstellung der dem Rechtsstaat angemessenen Steuerungskraft des Gesetzes, durch die zugleich die verfassungsrechtlich vorausgesetzte politische Entscheidungsverantwortung der Legislative wiederhergestellt wird ${ }^{20}$.

wiek, Die staatliche Verantwortung für die Risiken der Technik, 1985, insbesondere S.252ff.; ders., Die Bewältigung der wissenschaftlichen und technischen Entwicklungen durch das Verwaltungsrecht, VVDStRL H. 48 (1990), S. $207 \mathrm{ff}$., 227 f.; W. Hoppe, Staatsaufgabe Umweltschutz, VVDStRL H. 38 (1980), S. 211 ff., $254 \mathrm{ff}$.; Ch. Degenhart, Die Bewältigung der wissenschaftlichen und technischen Entwicklungen durch das Verwaltungsrecht, NJW 1989, S. $2435 \mathrm{ff}, 2436 ; K . M$. Groth, Die gentechnische Herausforderung, KJ 1988, S. 247 ff., 253 ff.; J. Burmeister, Medienmarkt und Menschenwürde - Der Rundfunk unter der Herrschaft der technischen Entwicklung, in: Schriftenreihe des Instituts für Europäisches Medienrecht, Bd. 2, 1992, S. $38 \mathrm{ff} ., 40 \mathrm{ff}, ;$ P. T. Stoll, Technologischer Wandel und staatliche Kontrolle, in: Wandel der Handlungsformen im öffentlichen Recht, 1991, S. $143 \mathrm{ff}$.

$19 \mathrm{Vgl}$. dazu insbesondere E.Schmidt-Aßmann, Das allgemeine Verwaltungsrecht als Ordnungsidee und System, 1982, S. $14 \mathrm{ff} ., 21 \mathrm{ff}$.

${ }_{20} \mathrm{Zu}$ diesen Wirkungszusammenhängen vgl. außer den Nachweisen in Anm. 17 auch E. Munzert, Die öffentliche Verwaltung im Spannungsfeld technischer, gesellschaftlicher und rechtlicher Veränderungen, Verwaltungs-Rundschau 1990, S. 353 ff.; H. Hill, Staatliches Handeln bei veränderten Bedingungen, in: Ellwein/ Hess (Hrsg.), Staatswissenschaften: Vergessene Disziplin oder neue Herausforderung?, 1990, S. 55 ff.; E. H. Ritter, Das Recht als Steuerungsmedium im kooperativen Staat, Staatswissenschaften und Staatspraxis, 1990, S. 50 ff.; R. Steinberg, Komplexe Verwaltungsverfahren zwischen Verwaltungseffizienz und Rechtsschutzauftrag, DÖV 1982, S. 20; J.J. Hesse, Verhandlungslösungen und kooperativer Staat, in: Hoffmann-Riem/Schmidt-Aßmann (Hrsg.), Konfliktbewältigung durch Verhandlungen, Bd.1, 1990, S. 97 ff., 99; G.Dauber, (Anm. 10), S.68ff.; M.Kutscha, 


\section{Was unterscheidet schlichtes und informelles Verwaltungshandeln?}

Die Schwierigkeiten, den defizitären dogmatischen Zustand der Handlungsformenlehre präzise in bestimmten Symptomen festzumachen, resultieren aber auch aus Ungenauigkeiten und Unsicherheiten bei der Verwendung der Rechtsbegriffe, die gewissermaßen die Bausteine der verwaltungsrechtlichen Handlungslehre bilden ${ }^{21}$ - Unsicherheiten der Begriffsverwendung, die sich in Aussagen niederschlagen, die schlicht „sinnlos" sind; darauf ist noch zurückzukommen. So drängt sich angesichts einer viele Jahrzehnte zurückreichenden Verwaltungspraxis, zu deren Alltäglichkeit Verlautbarungen, Hinweise, Empfehlungen, Warnungen, bewußte Duldungen und auch vielfältige Absprachen unsicherer Verbindlichkeit mit Privaten gehörten, geradezu die Frage auf, wodurch sich denn diese traditionellen, unter den Blanketten des Realakts und der schlichten Verwaltungshandlung zusammengefaßten Handlungsformen der Verwaltung von den Erscheinungen informellen Verwaltungshandelns unterscheiden ${ }^{22}$. Diese Frage drängt sich vor allem auf, weil mit Wegfall der rechtsschutzeröffnenden Funktion des Verwaltungsaktes ${ }^{23}$ die Vielfalt von schlichten Verwaltungshandlungen unter dem Gesichtspunkt faktischer oder mittelbarer Rechtsbeeinträchtigung der verwaltungsgerichtlichen Kontrolle unterliegen ${ }^{24}$.

Abschied vom Prinzip demokratischer Legalität?, in: Wandel der Handlungsformen im öffentlichen Recht, 1991, S.13 ff., $16 \mathrm{ff}$.

${ }^{21} \mathrm{Vgl}$. H. Hill, in: Verwaltungshandeln durch Verträge und Absprachen, 1990, S. 166; M. Bulling, (Anm.10), S. 288; A.Benz, Verhandlungen, Verträge und Absprachen in der öffentlichen Verwaltung, Die Verwaltung 1990, S. 83 ff., 84; G. Dauber, (Anm. 10), S.69; W. Pauly, Grundlagen einer Handlungsformenlehre im Verwaltungsrecht, in: Wandel der Handlungsformen im öffentlichen Recht, 1991, S. $25 \mathrm{ff} ., 31 \mathrm{ff}$.; B. Kempen, Die Formenwahlfreiheit der Verwaltung, 1989, S. $92 \mathrm{ff}$.

${ }_{22}$ Vgl. F. Ossenbübl, (Anm. 10), S. 28; ders., (Anm. 4), S. 681 ff., 685; H.P. Bull, Allgemeines Verwaltungsrecht, 2. Aufl. 1986, S. 15; H.J. Wolff/O. Bachof, Verwaltungsrecht I, 9. Aufl. 1974, S. 111 f.; H.U. Erichsen, (Anm.5), $\$ 33,34$, S. $411 \mathrm{ff} . ;$ P.Krause, (Anm.4), S.56f.; H.Maurer, (Anm. 10), $\$ 15$, S.363 ff.; G. Robbers, Schlichtes Verwaltungshandeln - Ansätze zu einer dogmatischen Strukturierung, DÖV 1987, S. 273 ff. mit umfangreichen weiteren Nachweisen.

$23 \mathrm{Vgl}$. BVerwGE 77, 268 (274 f.); ferner E. Schmidt-Aßmann, (Anm. 4), S. 536.

${ }^{24}$ Vgl. außer den Nachweisen in Anm. 22 G. Lübbe-Wolf, Rechtsprobleme der behördlichen Umweltberatung, NJW 1987, S. 2705 ff.; W. Frotscher, Rechtsschutz gegen „Nicht-Verwaltungsakte“, Jura 1980, S.4ff.; M.Schulte, (Anm. 10), S. $516 \mathrm{ff}$;; G.Robbers, Behördliche Auskünte und Warnungen gegenüber der Öffentlichkeit, AfP 1990, S. 84 ff.; F. Schoch, (Anm. 10), S.667 ff.; R.Zuck, Die 
In der Literatur findet sich keine klare Abgrenzung zwischen schlichtem und informellem Verwaltungshandeln ${ }^{25}$. Die Verschränkungen beider Kategorien sind jüngst wie folgt beschrieben worden: „In Relation zu den Rechtsformen des Verwaltungshandelns sind sowohl informelles wie schlichtes Verwaltungshandeln informell; gesteigerte Formlosigkeit zeigt das informelle Verwaltungshandeln deswegen, weil die Beteiligten feste Verfahrensformen und rechtsverbindliche Ergebnisse zu meiden suchen. Demgegenüber findet sich schlichtes Handeln durchaus auch in geordneten Verfahren und erfolgt im Willen, vorzeigbare und angreifbare Ergebnisse zu schaffen ${ }^{\star 26}$. Verwirrt ist man dann jedoch, wenn dieser klarsichtigen Beschreibung der Schwierigkeiten einer präzisen Abgrenzung zwischen schlichtem und informellem Verwaltungshandeln die Feststellung folgt, daß ,eine solche Abgrenzung wohl auch nur von geringem dogmatischen Wert wäre“ 27 .

So bleibt die Antwort auf die sich aufdrängende Frage offen, weshalb das Fehlen normativer Strukturen des schlichten Verwaltungshandelns offenbar nicht als dogmatisches Defizit, die Formlosigkeit informellen Verwaltungshandelns hingegen als ein Defizit von solchem Gewicht angesehen wird, daß seine sachangemessene rechtsstaatliche Disziplinierung eine weitgehende dogmatische Umformung der verwaltungsrechtlichen Handlungslehre erforderlich mache.

\section{Die zentrale Rechtsfrage: Lassen sich die sogenannten kooperativen Handlungsformen den normativen Handlungs- bindungen der Verwaltung unterstellen?}

Eine präzise Vorstellung, auf welche konkreten Symptome sich die Diagnose dogmatischer Defizite der Lehre von den administrativen Handlungsformen stützt, läßt sich nur gewinnen, wenn auf der Grundlage bedeutungsgenauer Rechtsbegrifflichkeit deren dogmati-

Eingriffswarnung, MDR 1988, S. 1020 ff.; W. Berg, Die behördlichen Warnungen - eine neue Handlungsform des Verwaltungsrechts?, ZLR 1990, S. $565 \mathrm{ff}$. - Aus der Rechtsprechung vgl. insbesondere BVerwGE 82, 76 (81 f.); 87, 37 (41 ff.); BaWü VGH, NVwZ 1989, S.279ff.; OVG Münster, GewArch. 1988, S.11; OVG Münster, NJW 1986, S. 2783; LG Stuttgart, NJW 1989, S.3269; LG Göttingen, NVwZ 1992, S. $98 \mathrm{ff}$.

${ }^{25}$ Das konstatiert auch F. Ossenbübl, (Anm. 10), S. 28.

${ }^{26}$ So W.Pauly, (Anm. 10), S. 521, Fn. 5.

27 A. a. O., Fn. 5. 
sche Konstruktion daraufhin überprüft wird, ob sie die Handlungsvielfalt der heutigen Verwaltungsrealität den hinsichtlich der gegenständlichen Umgrenzung, der inhaltlichen Bestimmung und der Formung des Verwaltungshandelns bestehenden normativen Bindungen zu unterstellen und damit die Durchsetzung der Maßstabsfunktion des Verwaltungsrechts gegenüber der heutigen Verwaltung $\mathrm{zu}$ gewährleisten vermag. Im Lichte dieser Frage gewinnen die Sachprobleme, die für die Schwerpunktbildung meines Vortrags ausschlaggebend sind und dessen Duktus vorzeichnen, konkrete Konturen:

Verträge und Absprachen zwischen Verwaltung und Privaten verbindet als Prototypen sogenannten kooperativen Verwaltungshandelns nicht nur eine instrumentelle Sachnähe, vielmehr werfen die kooperativen Handlungsformen allesamt Probleme hinsichtlich ihrer Unterstellung unter die durch die verfassungsrechtlichen Legalitätskriterien errichteten normativen Handlungsbindungen auf. Die Zuerkennung der Befugnis zu privatvertraglichem Handeln ${ }^{28}$ ermöglicht der Verwaltung ersichtlich, die durch die gegenständliche Begrenzung der Verwaltung auf öffentliche Aufgaben bestehenden Handlungsschranken zu überwinden. Demgegenüber vermittelt die Befugnis, im Über- und Unterordnungsverhältnis zwischen Verwaltung und Bürger die Realisation von Verwaltungszwecken auf die Basis öfentlich-rechtlicher Verträge zu stellen, die Möglichkeit, sich den in Gesetzmäßigkeit und Verhältnismäßigkeit festgeschriebenen inbaltlichen Handlungsmaßstäben zu entziehen. Diesen Aspekten sind die nachfolgenden Ausführungen des 1.Teils gewidmet. Die Probleme der informellen Absprachen liegen schließlich darin, daß sich die Verwaltung der Handlungsbindungen entledigt, die in der grundrechts- und rechtsschutzgebotenen Formung des Verwaltungshandelns angelegt sind. Dieser Problematik gelten die Ausführungen des 2. Teils.

Herr Kollege Krebs und ich haben uns bei unseren Bemühungen um eine thematische Abschichtung darauf verständigt, daß er sich

28 Sie ist in der Verwaltungsrechtslehre nahezu unbestritten, wie sich aus der kaum überschaubaren Literatur zur Abgrenzung des öffentlich-rechtlichen und privatrechtlichen Vertrages sowie zur Erfüllung von Verwaltungsaufgaben in den Formen des Privatrechts ergibt; vgl. dazu statt vieler $I$. $v$. Münch, Verwaltung und Verwaltungsrecht, in: Erichsen/Martens (Hrsg.), Allgemeines Verwaltungsrecht, 9. Aufl. 1992, S. 39 ff.; D. Ehlers, Verwaltung in Privatrechtsform, 1984, S. $74 \mathrm{ff}$., 442 ff.; P. Badura, Wirtschaftsverwaltungsrecht, in: v. Münch/Schmidt-Aßmann (Hrsg.), Besonderes Verwaltungsrecht, 9. Aufl. 1992, S. 179 ff., 221; H.U. Erichsen, (Anm. 5), §31, S. 404 f. jeweils mit umfangreichen weiteren Nachweisen. 
schwerpunktmäßig mit dem Verwaltungsvertrag befaßt, während ich mich insoweit auf die Erörterung der Grundfrage beschränken werde, ob sich der subordinationsrechtliche Vertrag den verfassungsrechtlichen Handlungsbindungen der Exekutive unterstellen läßt.

\section{Teil: Die vertraglichen Handlungsformen der Verwaltung}

\section{Die Unterscheidung von Handlungsformen der Verwaltung und Rechtsformen des Verwaltungshandelns}

Den Ausgangspunkt für die Beantwortung der Frage, ob sich die vertraglichen Handlungsformen den in den Legalitätskriterien aufgefangenen Handlungsbindungen unterstellen lassen oder diese sprengen, bildet die sachliche Unterscheidung der Begriffe „Handlungsform der Verwaltung“ und „Rechtsform des Verwaltungshandelns“29.

\section{Der Charakter der Handlungsformen als verwaltungspraktische Zweckschöpfungen}

Die Handlungsformen der Verwaltung sind nicht durch das Recht bereitgestellte, d.h. normative Konstrukte, derer sich die Verwaltung bei der Aufgabenerfüllung bedient, unter Umständen auch zu bedienen hat. Jeder Handlung und so auch den Handlungen der Verwaltung ist eine Form wesenseigentümlich, die sie hat und in der sie real in Erscheinung tritt, und dies gilt auch für die Gegenstücke zu positiven Handlungen - für die als Unterlassungen und Duldungen in Erscheinung tretenden Verhaltensweisen der Verwaltung ${ }^{30}$. Es ist daher widersinnig, eine real in Erscheinung tretende Handlung der

${ }^{29} \mathrm{Zu}$ dieser Unterscheidung klarsichtig W.Pauly, (Anm.21), S. $31 \mathrm{f} . ;$ ders., (Anm. 10), S. 521 ff.; G. Robbers, (Anm. 22), S. 274; E. Schmidt-Aßmann, (Anm. 19), S. 27, Fn. 41; R. Wabl, Rechtsfragen der Landesplanung und Landesentwicklung, Bd.1, 1978, S.21, Fn. 1; Ch. Gusy, Die Bindung privatrechtlichen Verwaltungshandelns an das öffentliche Recht, DÖV 1984, S. $872 \mathrm{ff}$.

30 Zur Duldung als verwaltungsrechtliche Kategorie vgl. insbesondere A. Randelzhofer/D. Wilke, Die Duldung als Form flexiblen Verwaltungshandelns, 1981, S. 34; A. Randelzhofer, Stichwort „Duldung“, in: Kimminich/v. Lersner/Storm, Handbuch des Umweltrechts, Bd. I, 1986, Sp. 360 ff; vgl. auch J. Becker, Öffentliche Unternehmen als Gegenstand des Wirtschaftsrechts, DÖV 1984, S.317f.; W. Hoffmann-Riem, Selbstbindungen, (Anm. 5), S. 205 f.; H.J. Papier, Altlasten und polizeirechtliche Störerhaftung, 1985, S. 40 f.; skeptisch zu dieser Kategorie K. Platz, Die Duldung im Verwaltungsrecht, BayVBl. 1983, S.622 ff.; G. Hermes/ J. Wieland, Die staatliche Duldung rechtswidrigen Verhaltens, 1988. 
Verwaltung als formlos zu bezeichnen oder gar - wie dies nicht selten geschieht - von einer Austauschbarkeit von Handlungsformen zu sprechen. Verwaltungshandlung und Handlungsform der Verwaltung sind der Sache nach Synonyme.

Die Formen des Verwaltungshandelns sind vielmehr praktische Zweckschöpfungen, zunächst nichts anderes und nichts mehr als geeignete und nach den Gesetzen der Eignung gestaltete Instrumente zur effektiven Erfüllung von Verwaltungszwecken ${ }^{31}$. Aufgrund ihres instrumentellen Charakters unterliegen sie einem ständigen Anpassungsdruck an die sich wandelnden Bedingungen administrativer Aufgabenerfüllung. Die formbildende und formändernde Kraft des praktischen Bedïrfnisses, die pragmatische Orientierung am Gesichtspunkt aufgabenspezifischer Zwecktauglichkeit, ist für die Herausbildung einer Typologie von Handlungsformen von ungleich größerer Wirkungsintensität als die Formungskraft normativer Grund- und Leitprinzipien. Aufgabenvielfalt und Aufgabenwandel verlangen von der Verwaltung instrumentelle Erfindungsgabe; an der Berührungsfläche von Verwaltung und Bürger vollzieht sich fortwährend ein pragmatisch gewendeter Prozeß der Erprobung und Praktizierung neuer Handlungsformen ${ }^{32}$.

Eine auf Formstrenge und -bindung des Verwaltungshandelns angelegte Handlungslehre vermag daher niemals die Verwaltungsrealität exakt widerzuspiegeln; sie ist - wie Eberhard Schmidt-Aßmann $n^{33}$ feststellt - „nie eine fertige, sondern eine stets zu reformierende Lehre". Mehr noch: eine Handlungslehre der Verwaltung, die ihre Aufgabe darin sähe, alle der staatlichen Exekutive zurechenbaren Handlungen in ein Korsett rechtlich zur Verfügung gestellter Formen einzubinden, verkennte den instrumentellen Charakter der Realisationsform von Aufgaben; sie litte zudem an notorischer Insuffizienz und bewirkte nichts anderes als eine Verminderung der Verwaltungseffizienz.

\section{Gebrauchsauswablermessen zwischen den Rechtsformen}

Die Rechtsform des Verwaltungshandelns ist demgegenüber bildlich gesprochen - das von der Rechtsordnung für eine bestimmte

31 Vgl. dazu die Literaturübersicht bei B. Kempen, (Anm. 21), S. $91 \mathrm{ff}$.

${ }^{32}$ So zutreffend W.Pauly, (Anm. 21), S. 38 f.; ferner C.E. Eberle, (Anm. 10), S. $439 \mathrm{ff} . ;$ H.Bauer, (Anm. 10), S.241 ff.; G.Robbers, (Anm.22), S.272ff.; E.Schmidt-Aßmann, (Anm. 4), S. 540 f.

33 (Anm. 4), S. 541. 
Handlung zur Verfügung gestellte „Kleid“, das gegen ein anderes austauschbar ist, sofern das Recht für die Vornahme der konkreten Handlung ein weiteres Kleid zur Verfügung stell ${ }^{34}$; in diesem Falle besteht ein Auswahlermessen des Handlungsträgers zwischen verschiedenen Rechtsformen ${ }^{35}$. Daraus ergibt sich wiederum, daß der vielgebrauchte Satz, es bestehe eine Wahlfreiheit zwischen Handlungs- und Rechtsformen der Verwaltung ${ }^{36}$, ohne Sinn ist; der Gebrauch einer Rechtsform setzt vielmehr die Existenz einer Handlung voraus, ohne die sie - bildlich gesprochen - als ungenutztes Kleid im Schrank hängt.

Gegen die Möglichkeit, ein solches Gebrauchsermessen zwischen verschiedenen Rechtsformen vorzusehen, sind rechtsgrundsätzliche Bedenken nicht anzumelden, insbesondere läßt sich aus den benannten verfassungsrechtlichen Legalitätskriterien nicht ein Gesetzesvorbehalt für die Ausübung des Auswahlermessens herleiten ${ }^{37}$. So sieht es auch die geltende Handlungsformenlehre vor: Rechtsformen des Ver-

${ }^{34}$ Die Rechtsformen des Verwaltungshandelns sind begrifflich wiederum zu unterscheiden von den normativen Handlungsformen, unter denen die rechtsetzende, auf Erlaß von Normen (Verordnungen, Satzungen, Verwaltungsvorschriften) gerichtete Tätigkeit zu verstehen ist. Die normativen Handlungsformen bleiben hier außer Betracht (s. Einleitung, sub I). Entgegen der herrschenden Begriffsverwendung begreift H.Meyer, in: Meyer/Borgs-Maciejewski (Hrsg.), Verwaltungsverfahrensgesetz, 2. Aufl. 1982, $₫ 35$, Rdn. 5 und $\$ 54, R d n .4$, sowohl den Verwaltungsakt wie den öffentlich-rechtlichen Vertrag als Rechtsquelle, d.h. als normative Handlungsform (ihm folgend: G. Robbers, (Anm. 10), S. 274; W. Pauly, (Anm. 10), S. 521; ders., (Anm. 21), S. 33; ferner U. Di Fabio, Vertrag statt Gesetz?, DVBl. 1990, S. $338 \mathrm{ff}$.), so daß nach dieser Auffassung die begriffliche Unterscheidung von Rechtsformen des Verwaltungshandelns und normativen Handlungsformen entfällt; in der Begriffsverwendung wie hier E.Schmidt-Aßmann, (Anm. 10), S. 535 f.; Ph. Kunig, (Anm. 10), S. 1195.

35 Nicht eine Wahl- „Freiheit“, sondern ein an Sachgesichtspunkten ausgerichtetes Ermessen; so zutreffend auch Ph.Kunig, (Anm. 10), S. 1196 f., der von „Verfahrensermessen" spricht; so auch H. Maurer, Der Verwaltungsvertrag - Probleme und Möglichkeiten, DVBl. 1989, S. 798 ff. (805); H.U. Erichsen, (Anm. 5), $\$ 27$ II, S. $370 ;$ P.M. Efstratiou, Die Bestandskraft des öffentlich-rechtlichen Vertrages, 1988, S.177f.; A.Scherzberg, Grundfragen des verwaltungsrechtlichen Vertrags, JuS 1992, S. 205 ff. (209); U.Di Fabio, (Anm. 34), S. 345.

${ }^{36}$ Diese "unsinnige“ Formulierung ist Folge der mangelnden begrifflichen Unterscheidung der Handlungsformen der Verwaltung und der Rechtsformen des Verwaltungshandelns; idealtypisch H.U. Erichsen, (Anm. 5), $\$ 31, \mathrm{~S} .404 \mathrm{ff}$.

${ }_{37}$ Diese Feststellung ist nicht zu verwechseln mit der Frage der Geltung des Vorbehalts und Vorranges des Gesetzes als Grenzen der Inhaltsgestaltung des Vertrages; näher dazu unter sub $3 \mathrm{~b}$. 
waltungshandelns sind der Verwaltungsakt, der öffentlich-rechtliche Vertrag und - nach insoweit einhelliger Auffassung ${ }^{38}$ - auch die privatrechtlichen Instrumente der Rechtsgestaltung, insbesondere die Haupttypen des Kauf-, Dienst- und Werkvertrages. Zwischen diesen Rechtsformen besteht rechtsvorbehaltloses Gebrauchsauswahlermessen, wie sich aus der dem öffentlich-rechtlichen Vertrag in $\$ 54$ Abs. 1 S. $2 \mathrm{VwVfG}$ grundsätzlich zugeschriebenen Ersatzfunktion gegenüber dem Verwaltungsakt ergibt. Aber auch zwischen Handeln durch Verwaltungsakt oder durch privatrechtlichen Vertrag besteht administratives Auswahlermessen, wie das Beispiel des Enteignungsabwendungsvertrages ${ }^{39}$ zeigt: Die Behörde kann bei Vorliegen der Enteignungsvoraussetzungen anstelle des Erlasses eines Enteignungsaktes das Grundstück durch Kaufvertrag erwerben; nach verbreiteter Auffassung ${ }^{40}$ ist sie dazu unter dem Gesichtspunkt der Verhältnismäßigkeit sogar verpflichtet, was aber nicht überzeugt. Ein aus dem Verhältnismäßigkeitsgrundsatz abgeleiteter, genereller subjektiver Anspruch auf vorrangigen Gebrauch vertraglicher Rechtsformen vor Rückgriff auf die Rechtsform des Verwaltungsaktes ist schon deshalb abzulehnen $^{41}$, weil dadurch ein normatives Subsidiaritätsverhältnis zwischen Verwaltungsakt und Vertrag festgeschrieben würde, welches das Auswahlermessen gerade ausschlösse. Im übrigen ist die Annahme unzutreffend, die Rechtswirkungen einer durch Vertrag bewirkten Rechts-

38 Vgl. die Nachweise in Anm. 28.

39 Zur privatrechtlichen Qualifikation des „Enteignungsvertrages“ vgl. BGHZ 50, 284 (287); 84, 1 (3); demgegenüber zur Qualifikation des Enteignungsabwendungsvertrags als öffentlich-rechtlicher Vertrag vgl. J. Burmeister /D. Bodenheim, Die Rechtsstellung der Gemeinden in der Landesverteidigung, 1982, S. $32 \mathrm{ff}$.; so auch E.Schmidt-Aßmann/W. Krebs, Rechtsfragen städtebaulicher Verträge Vertragstypen und Vertragsrechtslehre, 1988, S. $10 \mathrm{f}$., hinsichtlich der während eines laufenden Enteignungsverfahrens geschlossenen Verträge mit der Begründung, daß der Vertragsschluß in jener "Verwaltungsrechtssituation“ erfolgt, die $\$ 54$ S. 2 VwVfG als Charakteristikum des Subordinationsvertrages ansieht; näher dazu unten in Anm. 72.

${ }^{40}$ So insbesondere $H$. Goerlich, „Formenmißbrauch" und Kompetenzverständnis, 1987, S. 102; von einem „Vorrang der Vertragsform" spricht auch W. Krebs, (Anm. 10), S. 969 ff. (974), freilich nur in bezug auf den Sachbereich des Städtebaurechts; einen speziellen „Vertragsformvorrang" im Enteignungsrecht bejaht auch $H$. Reckers, Gesetzwidrige und gesetzesabweichende Regelungen in Verwaltungsverträgen zwischen Bürger und Staat, Diss. Tübingen 1986, S. $82 \mathrm{f}$; ähnlich J. Kottke, System der subordinationsrechtlichen Verwaltung, Diss. Hamburg 1966, S. 42.

${ }^{41}$ So auch Ph.Kunig, (Anm.10), S.1197; ferner Ph.Kunig/S.Rublack, (Anm. 10), S. 11; A. Scherzberg (Anm. 35), S. 209. 
gestaltung seien weniger belastend als die Regelungswirkungen der durch Verwaltungsakt vorgenommenen Aufgabenerfüllung; sie sind vielmehr identisch.

\section{Unzulässigkeit der Begründung rechtlicher Befugnisse durch die Rechtsformen}

Die der Verwaltung zur Verfügung stehenden Rechtsformen müssen jedoch ihrerseits rechtlich so konstruiert sein, daß ihr Gebrauch nicht zu einer Aufhebung, Durchbrechung oder Auflösung der verfassungsrechtlichen Legalitätskriterien führt. Dies ist insbesondere dann nicht gewährleistet, wenn den Rechtsformen als reinen Instrumenten zur Verwirklichung von Verwaltungszwecken eine befugnisbegründende Funktion zukommt. Die Befugnis eines Verwaltungsträgers zur Vornahme einer konkreten Regelungshandlung setzt die Existenz einer kompetenzbegründenden Aufgabenzuweisungsnorm voraus, die einen Handlungsauftrag einschließ $\mathrm{t}^{42}$. Auch wenn der Aufgabenzuweisungsnorm - wie etwa im Polizei- und Ordnungsrecht - gesetzliche Eingriffsermächtigungen an die Seite gestellt sind, sind die Kompetenzen des Verwaltungsträgers allein und abschließend in der Aufgabenzuweisungsnorm enthalten mit der Konsequenz, daß die zur Verfügung stehenden Rechtsformen der Aufgabenwahrnehmung dem Verwaltungsträger weder andere oder weitergehende rechtliche Befugnisse vermitteln dürfen noch ihr Gebrauch zu einer Geltungsrelativierung der verfassungsrechtlichen Legalitätskriterien führen darf.

Mit der Erkenntnis, daß der Rechtsform einer Verwaltungshandlung aufgrund ihres rein instrumentellen Charakters keine befugnisbegründende Funktion zukommt, ist die Frage der dogmatischen Konsistenz der vertraglichen Rechtsformen des Verwaltungshandelns auf den Punkt gebracht:

a) Auflösung der gegenständlichen Begrenzung der Verwaltungstätigkeit als Grundproblem privatvertraglichen Verwaltungshandelns

Die Grundaussage, daß sich die Verwaltung anstelle des Erlasses eines Verwaltungsaktes der privatvertraglichen Rechtsformen bedie-

${ }^{42}$ Als Ausfluß des rechtsstaatlichen und demokratischen Gesetzesvorbehalts, zuletzt dazu F. Ossenbübl, Vorrang und Vorbehalt des Gesetzes, in: Isensee/Kirchhof (Hrsg.), Handbuch des Staatsrechts, Bd. III, 1988, \$62, S. 315 ff., Rdn. 40. 
nen darf ${ }^{43}$, um eine konkrete Verwaltungsaufgabe zu verwirklichen, ist dogmatisch unhaltbar, wenn oder soweit mit dem Gebrauch der Rechtsform rechtliche Befugnisse begründet werden, die nicht in der Aufgabenzuweisungsnorm aufgefangen sind. Um es am Sachbeispiel zu verdeutlichen: Wenn die Befugnis eines Verwaltungsträgers, sich Grundstücke anstelle durch Enteignung durch Kaufvertrag zu verschaffen, rechtlich zu einem Austausch der zugrundeliegenden Aufgabenzuweisungsnorm und zur Begründung einer Befugnis - gar eines subjektiven Rechts ${ }^{44}$ - des Verwaltungsträgers führt, außerhalb der gesetzlich festgelegten Enteignungsvoraussetzungen freihändig wie ein Privater am Grundstücksverkehr teilzunehmen ${ }^{45}$, dann ist es dog-

${ }^{43}$ Basierend auf dem noch immer anerkannten "Dogma“ der Wahlfreiheit zwischen der Rechts- und Organisationsform des privaten und des öffentlichen Rechts; vgl. die Literatur- und Rechtsprechungsübersicht bei B.Kempen, (Anm. 21), S. 111, Fn. 106; zuletzt in diesem Sinne W. Rüfner, Daseinsvorsorge und soziale Sicherheit, in: Isensee/Kirchhof (Hrsg.), Handbuch des Staatsrechts, Bd. III, 1988, $\$ 80$, Rdn. 55 ff., S. $1057 \mathrm{ff}$, der feststellt, daß „dieses Wahlrecht entgegenstehenden Tendenzen in der Literatur zum Trotz - als Teil des geltenden Rechts anzuerkennen ist". - Kritisch oder ablehnend demgegenüber $C h$. $v$. Pestalozza, Formenmißbrauch des Staates, 1973, S. 167 ff.; D. Ehlers, (Anm. 28), S. 66 ff.; W. Bosse, Der subordinationsrechtliche Verwaltungsvertrag als Handlungsform öffentlicher Verwaltung, 1974, S.24ff.; F. Ossenbiübl, Öffentliches Recht und Privatrecht in der Leistungsverwaltung, DVBl. 1974, S.541 ff.; F.J. Kunert, Staatliche Bedarfsdeckung und Öffentliches Recht, 1977, S. $45 \mathrm{ff}$.; K.A. Schachtschneider, Staatsunternehmen und Privatrecht, 1986, S. $5 \mathrm{ff}$; Fr. v. Zezschwitz, Rechtsstaatliche und prozessuale Probleme des Verwaltungsprivatrechts, NJW 1983, S. $588 \mathrm{ff}$; B. Kempen, (Anm. 21), S. $112 \mathrm{ff}$.

${ }_{44}$ Zur „deformierenden" Wirkung der verfehlten Bezeichnung staatlicher Befugnisse (Kompetenzen) als subjektive Rechte staatlicher Funktionsträger eingehend J. Burmeister, Innenrecht der Verwaltung zur Gewährleistung der Kooperation von Verwaltungsträgern und der Koordination von Verwaltungszwecken, in: Drittes deutsch-polnisches Verwaltungssymposium, 1983, S. 45 ff. (47 f.); ders., Die Privatrechtsfähigkeit des Staates - Symptom verfassungskontroverser Theoriebildung im öffentlichen Recht, in: Prütting (Hrsg.), Recht und Gesetz im Dialog III, 1986, S.11ff. (17); ferner E.W. Böckenförde, Organ, Organisation, Juristische Person. Kritische Überlegungen zu Grundbegriffen und Konstruktionsbasis des staatlichen Organisationsrechts, in: Festschrift für H.J. Wolff, 1973, S.269ff. (302).

${ }^{45}$ Idealtypisch für diese befugniserweiternde Konsequenz des Rückschlusses von der Befugnis zum Gebrauch der privatvertraglichen Rechtsform auf die Begründung privatrechtlicher Handlungsbefugnisse E. Gassner, Der freihändige Grunderwerb der öffentlichen Hand, 1983, S. 143 f., $217 \mathrm{ff}$., der von "genuinfreihändigem" Grundstückserwerbsrecht der Gemeinde spricht, das in keinem greifbaren Zusammenhang mit konkreten städtebaulichen Maßnahmen steht, und 
matisch nicht haltbar, der Verwaltung den Gebrauch der privatrechtlichen Rechtsform statt des Verwaltungsaktes zuzubilligen. Die darin liegende Erweiterung der rechtlichen Befugnisse stellt in der Sache eine Aufhebung der verfassungsrechtlich im Gemeinwohlbezug aufgefangenen gegenständlichen Begrenzung der Verwaltungstätigkeit dar: es liegt dann Handeln außerhalb des Wirkungskreises des Verwaltungsträgers vor.

\section{b) Auflösung der inhaltlichen Handlungsbindungen der Verwaltung als Grundproblem des subordinationsrechtlichen Vertrages}

Demgegenüber ist die Konstruktion des öffentlich-rechtlichen Vertrages als alternatives Handlungsinstrument zum Verwaltungsakt deshalb problematisch, weil dem aus dem Zivilrecht stammenden Rechtsinstitut des Vertrages möglicherweise begriffsprägende oder typusbestimmende Elemente wesenseigentümlich sind, die bei Gebrauch des Rechtsinstituts als Handlungsinstrument der Verwaltung notwendigerweise zu einer Auflösung der Bindung an Gesetzmäßigkeit und Verhältnismäßigkeit führen. Die Problematik der dogmatischen Konsistenz des subordinationsrechtlichen Vertrages liegt darin, daß das Rechtsinstitut des Vertrages einer anderen Rechtsordnung - der gesellschaftlich-privaten Rechtssphäre - entstammt, die durch das Merkmal der Willensautonomie der Rechtssubjekte, der Freiheit und Beliebigkeit der Rechtsausübung, gekennzeichnet ist und in seinen gesamten Funktionsmechanismen auf diese der Privatrechtsordnung vorausliegenden Bedingungen angewiesen ist $^{46}$. Wird der Vertrag als Handlungsinstrument aus dieser Rechtswelt herausgelöst, so treten unausweichlich Anwendungsprobleme auf. Auch dies sei wiederum am Beispiel verdeutlicht: wenn es so ist, daß der Vertrag als Rechtsinstitut etwa die Geltung des Satzes „volenti non fit iniuria“ voraussetzt und infolgedessen die allgemeinen Regeln des Vertragsrechts im Hinblick auf die Geltung dieses Satzes dogmatisch ausgeformt sind, so kann das Rechtsinstitut nicht ohne Deformationswirkungen in ein

bei dessen Ausübung die Gemeinde nicht als Hoheitsträger, sondern als Mitbewerber am Markt auftritt; so auch E.Schmidt-Aßmann/W.Krebs, (Anm. 39), S. 3 f.; näher dazu unten in Anm. 72.

46 Am klarsichtigsten zu diesen - den Gegenstandsbereichen des Privatrechts und des öffentlichen Rechts vorausliegenden - Bedingungen, die "die Existenz und Unentbehrlichkeit des Dualismus auch normativ erklären", F. Bydlinski, Rechtsgrundsätze, (Anm. 8), S. 305 ff. 
rechtliches Umfeld verlagert werden, in dem dieser Satz nicht gilt ${ }^{47}$. Die Konsequenzen der Verlagerung in ein solches Umfeld sind logisch: Mit der Indienstnahme des Rechtsinstituts „Vertrag“ als Handlungsinstrument der Verwaltung werden automatisch und zwangsläufig die den allgemeinen Vertragsregeln inhärenten Momente der Willensautonomie und der Handlungsfreiheit auf staatliche Kompetenzausübung übertragen, die gerade durch die Nichtexistenz von Autonomie und Freiheit gekennzeichnet ist, wodurch die Bindung der Verwaltungshandlung an Gesetzmäßigkeit und Verhältnismäßigkeit aufgelöst wird.

Darin deutet sich abermals an, daß es sich bei den Anwendungsproblemen der vertraglichen Handlungsformen nicht um korrekturfähige dogmatische Defizite der Handlungslehre, sondern um Symptome handelt, die letztlich in der Andersartigkeit von autonomiegeprägter subjektiver Rechtsausübung und pflichtgebundener staatlicher Kompetenzausübung wurzeln und sich in der Unaustauschbarkeit der jeweiligen Handlungsinstrumente niederschlagen ${ }^{48}$.

II. Der privatrechtliche Vertrag als Rechtsform des Verwaltungshandelns - Symptom verfassungskontroverser verwaltungsrechtsdogmatischer Theorie- und Systembildung

Der in der Verwaltungsrechtslehre einhellig anerkannte Satz, daß der Verwaltung grundsätzlich die Befugnis zusteht, sich zur Verwirklichung einer bestimmten Aufgabe anstelle der öffentlich-rechtlichen Rechtsformen des je nach Aufgabenstellung in Betracht kommenden

47 Zur Nichtgeltung dieses Satzes im öffentlichen Recht vgl. insbesondere M.Sachs, „Volenti non fit iniuria“. - Zur Bedeutung des Willens des Betroffenen im Verwaltungsrecht, VerwArch. Bd. 76 (1985), S. 398 ff.; ferner P. Kirchbof, Mittel staatlichen Handelns, in: Isensee/Kirchhof (Hrsg.), Handbuch des Staatsrechts, Bd. III, \$59, Rdn. 128, S. 175; vgl. im übrigen die Nachweise in Anm. 82.

48 Zutreffend daher die Ausführungen von A.Scherzberg (Anm. 35), S. 206, daß die allgemein vorausgesetzte Befugnis der freien Wahl der Handlungsform keine Qualifikationsfreiheit der Parteien als privatrechtlichen oder öffentlich-rechtlichen Vertrag begründet; anders H. Maurer, (Anm. 10), $₫ 14$, S. 322, Rdn. 9, der umgekehrt folgert, daß es für die Bestimmung der Rechtsnatur des Vertrags "doch gleichsam im Vorfeld - auf den Willen der Behörde ankommt, weil der Verwaltung ein (begrenztes) Wahlrecht zwischen öffentlich-rechtlichen und privatrechtlichen Handlungsformen zusteht". 
privatrechtlichen Vertrages zu bedienen ${ }^{49}$, wäre völlig unbedenklich, wenn er nichts anderes beinhaltete als die Aussage, daß der Verwaltung bei der Aufgabenerledigung ein Gebrauchsauswahlermessen zwischen zwei verschiedenen Rechtsformen zusteht. In der Tat stellt das Rechtsinstitut des Vertrages, wie es in den Vorschriften des Bürgerlichen Rechts ausgeformt ist, ein für die sachgerechte Erfüllung der Aufgaben heutiger Verwaltung schlechterdings unerläßliches Handlungsinstrument dar.

\section{Die Privatrechtsfähigkeit des Staates als Konstruktionsbasis des verwaltungsrechtsdogmatischen Gebäudes}

Die Verwaltungsrechtsdogmatik begreift diesen Satz jedoch nicht nur als Hinweis auf das Auswahlermessen zwischen zwei zur Verfügung stehenden Rechtsformen, sondern schließt in ihn die weitere Aussage ein, daß mit dem Gebrauch der privatrechtlichen Rechtsform ein Austausch der Rechtsmaßstäbe verbunden ist, die für das konkret begründete Rechtsverhältnis gelten ${ }^{50}$. Die Dogmatik verknüpft mit der Befugnis zum Gebrauch der privatrechtlichen Rechtsform die Herauslösung des begründeten Rechtsverhältnisses aus dem Geltungsregime des Öffentlichen Rechts und dessen Einbeziehung in das Geltungsregime der Privatrechtsordnung dergestalt, daß der Verwaltungsträger an dem Vertragsverhältnis als Privatrechtssubjekt teilhat, auf dieses die Regelungen des bürgerlich-rechtlichen Vertragsrechts zur Anwendung kommen und sich aus ihnen die im gegenseitigen Verhältnis bestehenden Rechte und Pflichten der Vertragsparteien ergeben ${ }^{51}$. Durch die Verknüpfung der Rechtsform des Privatrechts mit der rechtlichen Qualifikation des Rechtsverhältnisses als solches zwischen zwei Privatrechtssubjekten werden die für die staatliche Aufgabenerledigung geltenden materiellen Rechtsmaßstäbe ausgetauscht: An die Stelle der den Handlungsauftrag begründenden Aufgabenzuweisungsnorm treten als befugnisbegründende Normen die Regeln des bürgerlichen Vertragsrechts, die den Charakter subjektiver Berechtigungsnormen tragen ${ }^{52}$.

49 Vgl. außer den Nachweisen in Anm. 43 explizit A. Bleckmann, Subventionsrecht, 1978, S. 85 ff. mit weiteren Nachweisen; ders., Verfassungsrechtliche Probleme des Verwaltungsvertrages, NVwZ 1990, S.601 ff. (605); a. A. insbesondere W. Bosse, (Anm. 43), S. $22 \mathrm{f}$.

50 Zutreffend die Feststellung von E. Schmidt-Aßmann, (Anm. 10), S. 535, Fn. 14, daß es bei deren Formauswahlermessen zwischen öffentlichem und privatem Recht nicht primär um die Wahl der Form, sondern des Rechtsregimes geht.

${ }^{51}$ Näher dazu J. Burmeister, Privatrechtsfähigkeit, (Anm. 44), S. 7.

s2 Klarsichtig dazu E.W. Böckenförde, (Anm.44), S. 302. 


\section{Die Grundthese von der Selbstbestimmungsgewalt des Staates über Form und Qualität seines Handelns}

Der Rückschluß von der privatrechtlichen Rechtsform der Verwaltungshandlung auf die privatrechtliche Qualität des begründeten Rechtsverhältnisses ist zwar nicht das einzige, wohl aber das folgenschwerste Symptom verfassungskontroverser verwaltungsrechtsdogmatischer Theorie- und Systembildung und im übrigen der eindringlichste Beweis für die Richtigkeit des geflügelten Wortes, daß „Verfassungsrecht vergeht, Verwaltungsrecht hingegen besteht“.

\section{a) Die Kontroverse zwischen P. Laband und O. Mayer}

Es verbietet sich an dieser Stelle, die staatstheoretischen und staatsrechtlichen Wurzeln dieses Symptoms verfassungskontroverser Systembildung der Verwaltungsrechtsdogmatik aufzuweisen; in gebotener Kürze kann dazu nur soviel gesagt werden: In dem Rückschluß von der privatrechtlichen Form der vom Verwaltungsträger vorgenommenen Handlung auf die privatrechtliche Qualität des dadurch begründeten Rechtsverhältnisses lebt das Staatsverständnis aus vordemokratischer Zeit fort, wie es Paul Laband in seiner Kontroverse mit Otto Mayer vor über 100 Jahren anläßlich der Beprechung von dessen "Theorie des französischen Verwaltungsrechts“ gezeichnet und gegen dessen Auffassung von der Nichtverfügbarkeit der staatlichen Identität ins Feld geführt hat ${ }^{53}$. Mayer bestritt nicht die Befugnis des Staates, sich anderer Formen als der des Befehls und Zwangs zu bedienen. Er bestritt jedoch, daß der Formenaustausch quasi automatisch die Qualifikation eines solcherart begründeten Rechtsverhältnisses impliziere. Wörtlich: „Der Staat hat hier nicht etwa ein Ernennungsrecht auszuüben. Nichts kann einen daher hindern, nach den geltenden Rechtsbestimmungen zu untersuchen, ob ein Rechtsverhältnis unter Verwendung privatrechtlicher Normen nicht doch öfentlich-rechtlicher Natur ist" ${ }^{* 54}$. Diese Aussage bekräftigte Mayer in seiner Erwiderung auf Laband dahin, daß das im französischen Verwaltungsrecht anerkannte Institut des Verwaltungsvertrages sich unter Zugrundelegung der Grund-und Wesensvorstellungen der deutschen Zivilistik nicht als ein Vertrag bezeichnen lasse, weil er - daran

53 P. Laband, Besprechung von: O. Mayer, Theorie des französischen Verwaltungsrechts, AöR Bd. 2 (1887), S. 149 ff.; dazu die Erwiderung von O. Mayer, Zur Lehre vom öffentlich-rechtlichen Vertrage, AöR Bd. 3 (1888), S. 3 ff.

${ }^{54}$ So O. Mayer, Theorie des französischen Verwaltungsrechts, 1886, Einl. S. 21. 
gemessen - „kein wabrer Vertrag ist ${ }^{455}$. Dem hielt Laband ${ }^{56}$ folgendes entgegen: „Die einzelnen staatlichen Handlungen sind nur dann Äußerungen der Macht, des imperium, wenn sie einen Befehl, wenn sie einen Zwang enthalten; der Staat kann sich aber auch anderer Formen bedienen. Wenn man behauptet, der Staat könne deshalb mit Privaten keine Verträge schließen (im zivilrechtlichen Verständnis), weil er ihnen nicht gleichstehe, sondern über sie herrsche, so ist dieser Grund nicht stichhaltig. Gerade im Gegenteil! Weil der Staat Herrscher ist, kann er sich nach eigenem Belieben aller Rechtsformen bedienen, die ihm nützlich scheinen, und wenn er sich auf das Niveau des Privatrechts stellt und mit dem Einzelnen nach den Regeln desselben Rechtsverhältnisse begründet, so ist dies eben eine Betätigung seiner Freiheit, seiner ,hoheitlichen Macht', diejenige Rechtsform zu wählen, die ihm beliebt. Der souveräne Staat handelt im Gegensatz zu den Untertanen stets rechtlich frei, nur durch sich selbst bestimmt, durch keinen höheren Befehl gebunden, keiner Herrschermacht unterworfen, sondern mit ihr selbst ausgestattet ${ }^{57 *}$.

\section{b) Staatliche Kompetenz zur Entstaatlichung?}

Labands Vorstellung von der inneren Souveränität des Staates impliziert also die freie Selbstbestimmung nicht nur in der instrumentellen Wahl der Rechtsformen, sondern auch in der damit dekretierten Qualifikation des Handelns als Staat oder als Nicht-Staat, also die Souveränität der Entstaatlichung. Gegenstand dieser Staatsauffassung ist der nur durch sich selbst bestimmte bindungslose Staat; sie ist konstitutiv für die prätendierte Qualifikationshoheit: Der Staat, der keinen Willen mehr über sich hat, besitzt diese Souveränität zur Selbstbestimmung über sein Handeln als Staat oder Nicht-Staat ${ }^{58}$.

Die Frage, die sich hiernach aufdrängt, ist die, wie es um die Hoheit des Staates bestellt ist, den Rechtskreis, nach dem sein Handeln zu beurteilen ist, selbst zu bestimmen, wenn dieser - wie der Staat des Grundgesetzes - ein Verfassungsstaat ist, nicht bindungsfrei und

55 (Anm. 53), S. 42; später ders., Verwaltungsrecht Bd. 1, 1. Aufl. 1895, S. 113 ff.

56 (Anm. 53), S. 156.

$57 \mathrm{Zu}$ dieser Kontroverse eingehend J. Burmeister, Der Begriff der „vollziehenden Gewalt" unter dem Grundgesetz und seine Auswirkungen auf die verwaltungsrechtliche Dogmatik, in: Wadle (Hrsg.), Recht und Gesetz im Dialog I, 1982, S. $105 \mathrm{ff}$;; darauf rekurrierend H. Maurer, (Anm. 10), S. 799; vgl. ferner G. Püttner, Wider dem öffentlich-rechtlichen Vertrag zwischen Staat und Bürger, DVBl. 1982, S. 122 f.; zuletzt B. Kempen, (Anm. 21), S. 18 ff.

${ }_{58} \mathrm{Vgl}$. J.Burmeister, (Anm. 57), S. $119 \mathrm{f}$. 
souverän wie der Labandsche Staat der Monarchie, sondern eingebunden in verfassungsrechtliche Maßstabsnormen, die gerade ihn als Staat bzw. ihn in seiner Erscheinungsform als "vollziehende Gewalt" zum Adressaten haben. Es stellt sich damit zugespitzt das Problem, ob überhaupt die Entscheidung über die Frage, ob staatliches Handeln privatrechtlich, d.h. gleichrangig, oder öffentlich-rechtlich, d.h. hoheitlich, in Erscheinung tritt, unter dem Grundgesetz noch disponibel ist. Oder grundlegender formuliert: Gibt es staatliches Verwaltungshandeln außerhalb der vollziehenden Gewalt? Gibt es normative Handlungsdirektiven mit dem Staat als Zuordnungssubjekt, die nicht dem öffentlichen Sonderrecht zugehören?

\section{Unaustauschbarkeit der Identität des Staates als Adressat der grundgesetzlichen Verfassungsbindungen}

Die Frage zu stellen heißt, sie eindeutig zu verneinen: $\mathrm{Ob}$ und welches Recht für die Beurteilung staatlicher Willensäußerungen heranzuziehen ist, ob es je nach der vom Staat kraft Selbstbestimmung getroffenen Formenwahl einmal Privat-, das andere Mal Öffentliches Recht ist, oder ob es stets das Öffentliche Recht als staatliches Sonderrecht ist, kann in einem Verfassungsstaat nicht bloß aus einem ontischen Wesen des Staates, geschweige denn aus logisch-formalen Zuordnungsregeln nach Art des Kollisionsrechts erfolgen ${ }^{59}$, sondern muß aus dem gerade diesen Staat bindenden und für ihn unmittelbar verbindlichen Verfassungsgesetz ermittelt werden.

\section{a) Die normdirigierende Kraft der Verfassung gegenüber}

der als Einheit verstandenen Staatsgewalt

Das Grundgesetz enthält in Art. 1 Abs. 3, 20 Abs. 2 und 3 eine abschließende Zuordnungsregel für Willensäußerungen, Handlungen, Wirkungen staatlicher Emanationen. Einziges Zurechnungssubjekt ist die juristische Person Staat in ihren drei Erscheinungsformen. Eine Ausklammerung eines Teils staatlicher Äußerungen aus dem Bereich

59 So insbesondere Ch. v. Pestalozza, (Anm. 43), S. 172; ders., Kollisionsrechtliche Aspekte der Unterscheidung vom öffentlichen Recht und Privatrecht, DÖV 1974, S. 188 ff.; kritisch zur „kollisionsrechtlichen“ Bestimmung des Geltungsbereichs von staatlichem Sonderrecht $M$.Zuleeg, Die Anwendungsbereiche des öffentlichen Rechts und des Privatrechts, VerwArch. Bd. 73 (1992), S. 384 ff. (390); D. Eblers, (Anm.28), S.70, Fn.32; eingehend ferner B.Kempen, (Anm.21), S. $112 \mathrm{ff}$. 
der vollziehenden Gewalt verstieße gegen den Universalitätsanspruch des Grundgesetzes. Erscheinungen von Staatlichkeit unter dem Grundgesetz sind funktional und organisatorisch Äußerungen entweder der rechtsetzenden oder der vollziehenden oder der rechtsprechenden Gewalt; sie können nichts anderes sein, denn die Staatsgewalt erschöpft sich in der Summe der dreigeteilten Funktionen. Daneben oder außerhalb dessen gibt es nichts, was Ausfluß von Staatsgewalt sein könnte oder dem Staat zurechenbar wäre ${ }^{60}$. Eine Erscheinung von Staatlichkeit als Privatrechtssubjekt oder eine Rechtshandlung, die dem Staat als Privatrechtssubjekt, als „Fiskus“, zurechenbar wäre, ist nach geltendem Verfassungsrecht ausgeschlossen ${ }^{61}$. Darin kommt der Gedanke der Einheit der Staatsgewalt zum Tragen, in dem sich die Vorstellung der identischen Wurzel aller unterscheidbaren Teilstaatsgewalten im Volk ausdrückt, dem die explizit statuierte legitimatorische Rückbindung aller Staatgewalt an den Volkswillen als Forderung in Art. 20 Abs. 2 GG korrespondiert ${ }^{62}$.

Die hieraus abgeleitete Rechtsgebundenheit ist der Tätigkeit der vollziehenden Gewalt verfassungsunmittelbar vorgegeben und prägt das Öffentliche Recht als ihr Sonderrecht. Der Unterschied zwischen offentlichem und privatem Recht gelangt also nicht in verschiedenen rechtlichen Handlungsformen, sondern in unterscbiedlichen rechtlichen Handlungsmaßstäben zum Ausdruck. Austauschbar sind die Rechtsformen, indisponibel dagegen die Rechtsmaßstäbe, denen die Verwaltung bei ihrem Handeln unterliegt.

\section{b) Organtheoretische Zurechnung aller Formen} der Kompetenzausübung auf die juristische Person "Staat“

Die Unaustauschbarkeit der rechtlichen Handlungsmaßstäbe kennzeichnet die staatliche Zuständigkeit, die kompetenzbegründende Norm als causa von Willensäußerungen und Handlungen der Verwal-

$60 \mathrm{Vgl}$. J.Burmeister, (Anm. 57), S. $123 \mathrm{ff} . ;$ ders., Privatrechtsfähigkeit, (Anm. 44), S. 4; so auch B. Kempen, (Anm. 21), S.37f.

61 Zur Obsoleszenz des Fiskusbegriffs noch immer grundlegend W. Mallmann, Schranken nichthoheitlicher Verwaltung, VVDStRL H. 19 (1961), S. 165 ff.; ferner aus dem umfangreichen Schrifttum J. Burmeister, Der Begriff des Fiskus in der heutigen Verwaltungsrechtsdogmatik, DÖV 1975, S.695ff.; H.Bethge, Die Grundrechtsberechtigung juristischer Personen nach Art. 19 Abs.3 GG, 1985, S. 100 f.; Ch. v. Pestalozza, (Anm. 43), S. 161 ff.; M. Zuleeg, (Anm. 59), S.401; K.A. Schachtschneider, (Anm. 43), S. 189 ff., 218 ff. u. 260 ff. mit umfangreichen weiteren Nachweisen.

${ }^{62} \mathrm{Vgl}$. insbesondere K. A. Schachtschneider, (Anm. 43), S. $272 \mathrm{ff}$. 
tung und unterscheidet diese von den Privatrechtssubjekten zustehenden Berechtigungsnormen fundamental: Die Zuständigkeit, die Befugnis, die Verwaltungsträger ausüben, ist ihnen nicht um ihrer selbst willen eingeräumt, ist nicht subjektives Recht im Sinne des Privatrechts, nicht Ausdruck ihrer „persönlichen“ Freiheit und Selbstbestimmung, sondern eingeräumt nur zur Hervorbringung des Staatswillens ${ }^{63}$. Es gibt in aller Welt keine Befugnis des Staates, die sich sachlich zutreffend als Ausfluß von Freiheit, als ein dem staatlichen Funktionsträger um seiner selbst willen zuerkanntes subjektives Recht kennzeichnen ließe ${ }^{64}$; nicht einmal der ausnahmsweise staatlichen Funktionsträgern zuerkannte Grundrechtsschutz vermittelt diesen Befugnisse, die ihnen um ihrer selbst willen zuerkannt wären ${ }^{65}$. Die Kompetenz ist durch das Pflichtmoment vom subjektiven Recht unterschieden ${ }^{66}$. Über sie kann daher der Kompetenzinhaber auch nicht ohne weiteres verfügen. Sein Handeln im Rahmen der Kompetenz verliert daher nie die legitimatorische Verbindung zur juristischen Person Staat als Bezugs- und Zurechnungspunkt ${ }^{67}$.

Mehr noch: Der Staat und seine verselbständigten organisatorischen Untergliederungen sind rechtskonstruktiv als nur innerhalb der ihnen jeweils zugewiesenen Kompetenzen existent gedacht. Juristische Personen des Öffentlichen Rechts sind nur innerhalb des ihnen zugewiesenen Wirkungskreises rechtlich vorhanden, und sie besitzen daher Rechtsfähigkeit nur in bezug auf die ihnen übertragenen Kompetenzen. Wie der Bundesgerichtshof ${ }^{68}$ in Übereinstimmung mit der

${ }^{63} \mathrm{Vgl}$. statt vieler K.Stern, Das Steuerrecht der Bundesrepublik Deutschland, Bd. 1, 2. Aufl. 1984, $₫ 18$ I, S. 595 ff.; ferner P. Kirchbof, (Anm. 47), $₫ 59$, Rdn. 21, S. $129 \mathrm{f}$.

$64 \mathrm{Vgl}$. dazu auch J. Isensee, (Anm. 1), \$57, Rdn. $28 \mathrm{ff} .$, S. $15 \mathrm{ff}$.

$65 \mathrm{Zu}$ Struktur und Gehalt grundrechtsgeschützter staatlicher Aufgabenwahrnehmung (Rundfunk) als „dienende" Freiheitsgewährleistung jüngst J. Burmeister, (Anm. 18), S. $51 \mathrm{ff}$.

${ }_{66}^{6} \mathrm{Vgl}$. dazu auch J.Isensee, (Anm. 1), $\$ 57, \mathrm{Rdn} .140 \mathrm{ff} .$, S. 65 ff.; P. Kirchbof, (Anm. 63), \$59, Rdn. 19 ff., S. 129 f.

${ }^{67}$ Vgl. K.H. Hesse, Grundzüge des Verfassungsrechts der Bundesrepublik Deutschland, 18. Aufl. 1991, $\$ 11$, Rdn. 348: „Die Verfassung kennt nur konstituierte Staatlichkeit. Der von ihr konstituierte Staat hat nirgends wie ein Privater das Recht zur Beliebigkeit. Es geht der Verfassung in den Grundrechten nicht nur um die Formen, sondern auch um die sachliche Gestaltung des staatlichen Wirkens. Deshalb verbietet sich die Annahme eines Reservats staatlichen Wirkens, das, weil es sich in Formen des Privatrechts vollzicht, dem Geltungsanspruch der Verfassung nicht untersteht."

${ }^{68}$ BGHZ 20, 119 ff. (126 ff.); 52, 283 (286); vgl. ferner BVerwGE 34, 69 (74 ff.); $59,231(237) ; 64,115$ (117ff.). 
staatsrechtlichen ultra-vires-Lehre ${ }^{69}$ festgestellt hat, entbehren Rechtshandlungen, die juristische Personen des Öffentlichen Rechts durch ihre Organe außerhalb des durch Gesetz oder Satzung bestimmten körperschaftlichen Wirkungskreises vornehmen, schlechthin der Rechtswirksamkeit. Die Unfähigkeit wirksamen rechtlichen Handelns außerhalb des Wirkungskreises der juristischen Person des Öffentlichen Rechts resultiert nicht etwa daraus, daß die Vertretungsmacht des handelnden Organs auf die ihr übertragenen Kompetenzen beschränkt ist, sondern daraus, daß die juristische Person des Öffentlichen Rechts nur innerhalb des ihr zugewiesenen Wirkungskreises rechtlich vorhanden ist ${ }^{70}$; außerhalb desselben existiert überhaupt kein Rechtsgebilde, das Zurechnungsendpunkt eines Rechtsverhältnisses mit Privaten sein könnte. Darauf gründet sich schließlich die wesentliche Erkenntnis, daß die einer juristischen Person des Öffentlichen Rechts zustehende Rechtsfähigkeit niemals eine Vollrechtsfähigkeit im Sinne des Bürgerlichen Rechts, sondern begriffsnotwendig nur eine kompetenzbezogene Teilrechtsfähigkeit sein kann ${ }^{71}$.

Dies ist im wesentlichen der verfassungsrechtliche Befund, den die Verwaltungsrechtsdogmatik mit dem Rückschluß vom Gebrauch der privatrechtlichen Rechtsform auf die privatrechtliche Qualität des dadurch begründeten Rechtsverhältnisses mißachtet.

\section{Qualifizierung des durch Gebrauch der privatvertraglichen Rechtsform begründeten Rechtsverhältnisses als ermächtigungsgebundener öffentlich-rechtlicher Vertrag}

Es erübrigt sich, über das Ausmaß der daraus resultierenden Diskrepanz zwischen Verfassungsrecht und Verfassungswirklichkeit viele

${ }^{69}$ Vgl. H.J. Wolff/O.Bachof, Verwaltungsrecht I, 9. Aufl. 1974, S. $208 \mathrm{f}$.; M. Eggert, Die deutsche ultra-vires-Lehre, 1977, S. $56 \mathrm{ff}$.; E. Klotz, Beschränkter Wirkungskreis der juristischen Personen des öffentlichen Rechts, DÖV 1984, S. $181 \mathrm{ff}$; E.W. Fuß, Die Überschreitung des Wirkungskreises juristischer Personen des öffentlichen Rechts, DÖV 1956, S. 566 ff.; K. Schmidt, Ultra-vires-Doktrin: tot oder lebendig, AcP Bd. 184 (1984), S. $529 \mathrm{ff}$.; M. Oldiges, Die Verbandskompetenz, DÖV 1989, S. $873 \mathrm{ff}$.

${ }_{70}$ Vgl. E. Klotz, (Anm. 69), S.284; M. Oldiges, (Anm. 69), S. 882 f. mit weiteren Nachweisen.

${ }_{71}$ So schon J. Burmeister, Privatrechtsfähigkeit, (Anm. 44), S. 9; ebenso B. Kempen, (Anm.21), S.74; vgl. auch H.U. Erichsen, (Anm. 5), $\$ 10$ III, S. $200 \mathrm{ff}$; F. Fabricius, Die Relativität der Rechtsfähigkeit, 1963, insbesondere S. $53 \mathrm{ff}$., $67 \mathrm{ff}$., 103 ff.; O. Bachof, Teilrechtsfähige Verbände des öffentlichen Rechts, AöR Bd. 83 (1958), S. 208 ff. (263f.). 
Worte zu verlieren: die mit Privatrechtsfähigkeit ausgestatteten und auf der Grundlage subjektiver Berechtigungsnormen privatvertraglich agierenden Einrichtungen oder Unternehmungen von Bund, Ländern und Gemeinden sind so vielfältig, daß sie sich ohnehin einer nur annähernden Erfassung entziehen. Es bleiben nur kurz die sich aus dem dargelegten verfassungsrechtlichen Befund ergebenden verwaltungsrechtsdogmatischen Konsequenzen anzudeuten, wozu sich der gebrauchte Beispielsfall des gemeindlichen Grundstückskaufs bestens eignet.

Die Verneinung der Privatrechtsfähigkeit stellt nicht einen rechtlichen Hinderungsgrund für die Gemeinde dar, ein Grundstück durch Kaufvertrag zu erwerben. Die Befugnis dazu vermitteln der Gemeinde aber nicht die Vorschriften der $\$ \$ 433 \mathrm{ff}$. BGB, sondern allein die gesetzlichen Bestimmungen, die die Gemeinde ermächtigen, sich in Wahrnehmung einer Angelegenheit der Selbstverwaltung oder einer Auftragsangelegenheit ein Grundstück zu verschaffen ${ }^{72}$. Die Befugnis der Gemeinde, sich des Mittels des privatrechtlichen Kaufvertrags zur Erfüllung einer ihr übertragenen Selbstverwaltungsaufgabe oder Auftragsangelegenheit zu bedienen, erschließt der Gemeinde nicht etwa Handlungsbefugnisse als Privatrechtssubjekt, die außerhalb des ihr nach Art. 28 Abs. 2 GG zuerkannten Status und Kompetenzbereichs als Einrichtung mittelbarer Staatsverwaltung oder des ihr zur auftragsgemäßen Erledigung übertragenen Aufgabenbereichs lägen. Partei des Kaufvertrages ist die Gemeinde in ihrer Stellung als Einrichtung der mittelbaren oder unmittelbaren Staatsverwaltung, und bei dem Vertrag handelt es sich um einen solchen, der auf der Grundlage staatlichen Sonderrechts geschlossen wird und infolgedessen öffentlich-

72 Die Befugnis muß kompetenzrechtlich fundiert sein. Bei Wahrnehmung von Auftragsangelegenbeiten finden sich die befugnisbegründenden Normen abschliessend in den spezialgesetzlichen Enteignungsermächtigungen, so z. B. in $\$ \$ 1,10,28$ Landbeschaffungsgesetz (für Zwecke der Verteidigung); die in \$2 LBG enthaltene Vorschrift, daß „die für Verteidigungszwecke benötigten Grundstücke nach Möglichkeit freihändig erworben werden sollen", vermittelt der Gemeinde kein über den Enteignungstatbestand hinausreichendes „Recht“ zum Grundstückserwerb. Bei Wahrnehmung von Selbstverwaltungsangelegenbeiten finden sich die weitreichendsten befugnisbegründenden Normen in den Regeln über das Bestehen eines gemeindlichen Vorkaufsrechts. Jenseits dieses gesetzlich begründeten Eintrittsrechts in den Grundstücksverkehr existiert nicht eine in keinem greifbaren Zusammenhang mit konkreten städtebaulichen Maßnahmen stehende Befugnis der Gemeinde, als Mitbewerber am Markt Grundstücke zu erwerben, wie - in Übereinstimmung mit der herrschenden Meinung - beispielsweise E.SchmidtAßmann/W.Krebs, (Anm. 39), S. 3 f. meinen. 
rechtlicher Natur ist. Ein Kaufvertrag, zu dessen Abschluß die Gemeinde nicht durch den ihr als Selbstverwaltungs- oder Auftragsangelegenheit übertragenen Wirkungskreis ermächtigt ist, entbehrt jeder Rechtswirksamkeit und ist daher nichtig ${ }^{73}$.

Auf diese - aber auch nur auf diese - Weise ist die Einbindung der Verwaltung in die durch den Gemeinwohltatbestand errichteten gegenständlichen Handlungsgrenzen der Verwaltung gewährleistet. Darin liegt die eigentliche Bedeutung und zugleich der verfassungsrechtliche Rückhalt der Unterscheidung von privatem und öffentlichem Recht als Abschichtung zweier Gegenstandsbereiche rechtlicher Betätigungsbefugnis und der darauf bezogenen Unterscheidung der Rechtsformen des privatrechtlichen und des öffentlich-rechtlichen Vertrages: Handeln der Verwaltung ist nicht in privatvertraglicher Rechtsform unzulässig, wohl aber im Gegenstandsbereich des Privatrechts, d. h. außerhalb des einem Verwaltungsträger durch Gesetz zur Wahrnehmung übertragenen öffentlichen Aufgabenbereichs; insoweit handelt der Verwaltungsträger ultra vires, jenseits seines rechtlichen Handlungsvermögens.

\section{Der subordinationsrechtliche Vertrag} als Rechtsform des Verwaltungshandelns Korrekturbedürftigkeit einer dogmatischen Feblkonstruktion

Für den hiernach aufgabenspezifisch, insbesondere im Bereich der Bedarfsdeckung, auch in privatvertraglichen Rechtsformen möglichen Gebrauch der Rechtsform des öffentlich-rechtlichen Vertrages stellt sich somit die Zentralfrage, ob er sich in seiner dogmatischen Ausformung als Ersatzinstrument für den Verwaltungsakt den verfassungsrechtlichen Handlungsbindungen unterstellen läßt und, sofern dies zu verneinen ist, ob und gegebenenfalls in welchem Bereich der Verwaltungstätigkeit er als Handlungsinstrument zum Einsatz gelangen kann.

1. Unmöglichkeit der Qualifizierung der anstelle des Erlasses eines Verwaltungsaktes oktroyierten Vereinbarung als Vertrag

Der öffentlich-rechtliche Vertrag verdankt seine Anerkennung dem über viele Jahre geführten Kampf gegen obrigkeitsstaatliche Relikte im

${ }_{73}$ Vgl. die Nachweise in Anm. 68-70. 
Verwaltungsrecht ${ }^{74}$. Dieser Kampf gründete sich auf die Diagnose, daß das Verwaltungsrecht nicht den vom Grundgesetz vollzogenen Wandel vom liberalen Rechtsstaat zum sozialen Leistungsstaat nachvollzogen habe und es der Verwaltungsrechtsdogmatik nicht gelungen sei, ein den veränderten Aufgaben der staatlichen Daseinsvorsorge entsprechendes Handlungsinstrumentarium der Verwaltung zu entwickeln ${ }^{75}$. Verhaftung in obrigkeitsstaatlichen Handlungs- und Entscheidungsstrukturen, so lautete weithin die Beschreibung des defizitären Zustands des Verwaltungsrechts, für den die Zentralfigur, der Verwaltungsakt, als Instrument der einseitigen Durchsetzung des Staatswillens gegenüber dem Bürger als Untertan Symptom und zugleich Symbol war. Dieser Kampf ist zumindest teilweise mit erstaunlich unjuristischen, nicht selten ideologiegefärbten Mitteln geführt worden, so etwa, wenn rechtliche Aussagen ganz unprätentiösen Inhalts dadurch verfälscht wurden, daß ganz einfach die Begriffe "hoheitlich" oder „hoheitsrechtlich" durch den Begriff „obrigkeitsstaatlich" ersetzt wurden. Rückblickend läßt sich jedenfalls die Feststellung treffen, daß sich die Diagnose der Verhaftung in obrigkeitsstaatlichen Handlungs- und Entscheidungsstrukturen nicht auf konkrete rechtliche Defizite der Handlungslehre - etwa in bezug auf die Gewährleistung umfassenden und effektiven Rechtsschutzes ${ }^{76}-$

${ }^{74} \mathrm{Zu}$ diesem „Kampf“ vgl. J.Burmeister, Plädoyer für ein rechtsstaatliches Instrumentarium staatlicher Leistungsverwaltung und Wirtschaftsbetätigung, WIR 1972, S. $311 \mathrm{ff}$.

${ }^{75}$ Zur frühzeitigen Diagnose obrigkeitsstaatlicher Prägung des Handlungsinstrumentariums der Verwaltung vgl. insbesondere P. Badura, Verwaltungsrecht im liberalen und sozialen Rechtsstaat, 1966; ders., Das Verwaltungsrecht des liberalen Rechtsstaats, 1967; ders., Die Daseinsvorsorge als Verwaltungszweck der Leistungsverwaltung und der soziale Rechtsstaat, DÖV 1966, S. 624 ff.; ders., Anfang und Grenzen der Verwaltung im sozialen Rechtsstaat, DÖV 1968, S. $446 \mathrm{ff}$.; H. Krüger, Allgemeine Staatslehre, 2. Aufl. 1966, S. 239 ff.; O. Bachof, Über einige Entwicklungstendenzen im gegenwärtigen deutschen Verwaltungsrecht, in: Staatsbürger und Staatsgewalt, Bd. 1, 1963, S. 3 ff.; ders., Die Dogmatik des Verwaltungsrechts vor den Gegenwartsaufgaben der Verwaltung, VVDStRL H.30 (1972), S. $194 \mathrm{ff} .(206 \mathrm{f}$.); W. Brobm, Die Dogmatik des Verwaltungsrechts vor den Gegenwartsaufgaben der Verwaltung, VVDStRL H. 30 (1972), S. $245 \mathrm{ff}$. (253ff.); H. H. Rupp, Grundfragen der heutigen Verwaltungsrechtslehre, 1965, S. $1 \mathrm{ff} . ;$ ders., Die Dogmatik des Verwaltungsrechts vor den Gegenwartsaufgaben der Verwaltung, DVBl. 1971, S.669ff.; V. Götz, Das Recht der Wirtschaftssubventionen, 1966, S. 56 ff.; K. Hesse, Der Rechtsstaat im Verfassungssystem des Grundgesetzes, in: Festgabe für R. Gmend, 1962, S. 79 ff. u. a. m.; zuletzt dazu $H$. Hill, Das hoheitliche Moment im Verwaltungsrecht der Gegenwart, DVBl. 1989, S. $321 \mathrm{ff}$.

${ }^{76}$ Der Aspekt von Rechtsschutzdefiziten ist spätestens mit Wegfall der rechtsschutzeröffnenden Funktion des Verwaltungsaktes entfallen. 
stützte, sondern auf recht vage Vorstellungen über einen dem Staat des Grundgesetzes angemesseneren Verwaltungsstil, für dessen Kennzeichnung sich die Begriffe der Kooperation bzw. der kooperationsrechtlichen Handlungsformen, des Dialogs und auch des Konsenses anboten ${ }^{77}$.

Nichts beweist indessen den mangelnden Erklärungswert der gewandelten Bedingungen des modernen Sozialstaats für die Anerkennung des öffentlich-rechtlichen Vertrages ${ }^{78}$ als Handlungsinstrument eindeutiger als die Tatsache, daß er für die Erfüllung der spezifischen sozialstaatlichen Aufgaben so gut wie überhaupt keine praktische Relevanz erlangt hat, und dies erklärt sich aus einem einfachen Grunde: Die vom Sozialstaatsbekenntnis geforderte Aufwertung der Stellung des Bürgers aus der Position des rechtlosen Almosenempfängers zum Inhaber gesetzlich festgeschriebener subjektiver Leistungsansprüche verbietet geradezu den Gebrauch der

77 Zur Bedeutung des Kooperationsprinzips als Erscheinung und Instrument der Abkehr von der hoheitlich aufgefaßten Staat-Bürger-Beziehung vgl. insbesondere Ch.Schrader, Das Kooperationsprinzip - ein Rechtsprinzip?, DÖV 1990, S. $326 \mathrm{ff}$. (331 ff.); O. Passavant, Mittlerunterstützte Kooperation in komplexen Verwaltungsprojekten, DÖV 1987, S. 516 ff.; M. Bulling, (Anm. 10), S. 277 f.; B. Holznagel, Der Einsatz von Konfliktmittlern, Schiedsrichtern und Verfahrenswaltern im amerikanischen Umweltrecht, Die Verwaltung 1989, S. 421 ff.; E. H. Ritter, Der kooperative Staat, AöR Bd. 104 (1979), S. 389 ff. (393ff.); H.Bauer, (Anm. 10), S. $250 \mathrm{ff}$;; B. Haussmann-Grassel, Bürgerbeteiligung an gebundenen Verwaltungsentscheidungen, 1985, S. 70 ff.; W. Krebs, Konsensuales Verwaltungshandeln im Städtebaurecht, DÖV 1989, S. 969 ff; W. Hoffmann-Riem, (Anm. 10), S. 31 ff.; W. Brohm, Verwaltungsverhandlungen, (Anm. 10), S. $321 \mathrm{ff}$; sowie am weitreichendsten in den Folgerungen R.Pitschas, (Anm.6). - Zutreffend stellt demgegenüber H.Lecheler, (Anm. 10), S. 547 fest: „Eine im Einzelfall normativ angeordnete oder normativ zugelassene Gleichordnung von Staat und Bürger taugt nicht zum generellen Strukturprinzip eines neuen Verwaltungsrechts, wie es die Formeln vom kooperativen Staat oder vom, Funktionswandel' staatlicher Machtausübung weg vom Verwaltungsakt hin zum Vertrag nahelegen sollen".

${ }^{78}$ Aus dem frühzeitigen Schrifttum sind insbesondere hervorzuheben K. Stern, Zur Grundlegung einer Lehre des öffentlich-rechtlichen Vertrages, VerwArch. Bd. 49 (1958), S. 106 ff. (der jedoch eine gesetzliche Ermächtigung für den Abschluß von Verwaltungsverträgen forderte); ferner J. Salzwedel, Die Grenzen der Zulässigkeit des öffentlich-rechtlichen Vertrages, 1958; M.Imboden, Der verwaltungsrechtliche Vertrag, 1958; H.Peters, Die Verwaltung, 1949, S. $154 \mathrm{ff} . ;$ entschieden gegen die Anerkennung M. Bullinger, Vertrag und Verwaltungsakt, 1962; ders., Zur Notwendigkeit funktionalen Umdenkens im öffentlichen und privaten Vertragsrecht im leistungsintensiven Gemeinwesen, in: Gedächtnisschrift für $\mathrm{H}$. Peters, 1967, S.667 ff. - Zur historischen Entwicklung der Lehre vom öffentlichrechtlichen Vertrag unter dem Grundgesetz zuletzt eingehend H.Maurer, (Anm. 35), S. $799 \mathrm{ff}$. 
Rechtsform des öffentlich-rechtlichen Vertrages bei der Aufgabenerfüllung, weil es insoweit für die Verwaltung nichts zu verhandeln und nichts zu paktieren gibt, sondern schlicht den gesetzlichen Leistungsanspruch des Bürgers zu erfüllen gilt. Sozialstaatlichkeit, die diesen Namen verdient, dokumentiert sich in der Unbedingtheit der staatlichen Leistungserbringung ${ }^{79}$. Deshalb verfehlen alle Erklärungsversuche, die die Anerkennungsbedürftigkeit des subordinationsrechtlichen Vertrages aus der gewandelten empirischen Realität des modernen Sozialstaats abzuleiten trachten, das Problem gründlich. Die Verbindung des sozialstaatlichen Aufgabenwandels mit dem Kooperationsgedanken vermag unter allen Argumenten, die sich für den öffentlich-rechtlichen Vertrag als dem Staat des Grundgesetzes angemesseneren Handlungsinstrument anführen lassen, am wenigsten zu überzeugen.

So ist es kein Zufall, daß die Geltungsbereiche der Rechtskonstruktion des Verbots mit Erlaubnisvorbehalt, das ausschließlich der Durchsetzung von ordnungsrechtlichen Belangen dient, die hauptsächlichen Anwendungsbereiche des subordinationsrechtlichen Vertrages in der Verwaltungspraxis darstellen ${ }^{80}$. Die Sach- und Rechtslage des Verbots mit Erlaubnisvorbehalt, für die das Erfordernis der Baugenehmigung idealtypisch ist, ist durch das elementare Interesse des Bürgers an dem Erhalt der Begünstigung gekennzeichnet, und diese Abhängigkeit ermöglicht überhaupt nur der Verwaltung, den Bürger faktisch zu zwingen, sich auf Verhandlungen mit der Verwaltung einzulassen, in der diese naturgemäß Bedingungen für die Ertei-

\footnotetext{
${ }^{74}$ Vgl. insbesondere K.Stern, (Anm. 63), $\$ 21$ III, S. 914 ff.; H.F. Zacher, Das soziale Staatsziel, in: Isensee/Kirchhof (Hrsg.), Handbuch des Staatsrechts, Bd. I, 1987, \$25, Rdn. $106 \mathrm{ff}$. mit umfassender Literaturübersicht in Fn. 440; ferner $J$. Wiedenbrug, Der Einfluß des Sozialstaatsprinzips auf die Zuerkennung subjektiver öffentlicher Rechte. - Zugleich ein Beitrag über Wesen und Motorik des Sozialstaatsprinzips, 1978, insbesondere S. $174 \mathrm{ff}$. - Konsequent daher die Regelung in $\$ 53$ Abs. 2 SGB $X$, wonach über gesetzlich festgelegte Sozialleistungen keine Verträge abgeschlossen werden dürfen.

${ }^{80} \mathrm{Vgl}$. dazu die instruktive Rechtsprechungsauswertung von H.Maurer/ B. Hüther, Die Praxis des Verwaltungsvertrags im Spiegel der Rechtsprechung, 1989, S. $10 \mathrm{ff}$.: von 278 erfaßten subordinationsrechtlichen Verträgen betreffen 155 das Baurecht, „für deren Abschluß die Motivation auf seiten des Bauherrn zur Erlangung einer Baugenehmigung ausschlaggebend ist“" (S.11). - Vgl. auch die Rechtsprechungsanalyse bei G. Püttner, (Anm. 57), S. 123.
} 
lung der Begünstigung durchzusetzen vermag, die außerhalb des Gesetzmäßigkeits- und Verhältnismäßigkeitsprinzips liegen ${ }^{81}$.

Die Bilanzierung der verwaltungsgerichtlichen Judikatur zum subordinationsrechtlichen Vertrag über die Erteilung gesetzesgebundener Begünstigungen ${ }^{82}$ ist in der Tat ernüchternd: Es bedurfte ungezählter Urteile mit der wiederkehrenden Hervorhebung der Selbstverständlichkeit, daß die Befugnis zum Gebrauch der Rechtsform des öffentlich-rechtlichen Vertrages die Verwaltung nicht von der Bindung an Gesetzmäßigkeit und Verhältnismäßigkeit enthebt ${ }^{83}$, um die Neigung der Verwaltung, die Abhängigkeit des Bürgers auszunutzen, in

81 Auf die Situation der Abhängigkeit des Bürgers vom Erhalt einer Begünstigung als „Grundkonstellation" des Abschlusses subordinationsrechtlicher Verträge verweist auch A.Bleckmann, Verfassungsrechtliche Probleme des Verwaltungsvertrages, NVwZ 1990, S.601 ff. (604 ff.); ferner G. Püttner, (Anm. 57), S. 124.

${ }_{82}$ Die dem subordinationsrechtlichen Vertrag wesensmäßig innewohnende Tendenz, das Gesetzmäßigkeits- und Verhältnismäßigkeitsprinzip zu unterlaufen, beruht letztlich auf der verfehlten Geltungsanwendung des Satzes "volenti non fit iniuria“ auf das Staat-Bürger-Verhältnis. Darauf gründet sich die Annahme, das Verwaltungsverfahrensgesetz anerkenne die Kategorie des (nur) rechtswidrigen, aber nicht nichtigen Verwaltungsvertrags; vgl. dazu insbesondere H. Meyer, (Anm. 34), $\$ 54$, Rdn. 77, $\$ 59$, Rdn. $28 \mathrm{ff}$; H.J. Bonk, in: Stelkens/Bonk/Leonhardt, Verwaltungsverfahrensgesetz, 3. Aufl. 1990, $\$ 56$, Rdn. 27; Ch.Schimpf, Der verwaltungsrechtliche Vertrag unter besonderer Berücksichtigung seiner Rechtswidrigkeit, 1982, S. 202 ff.; Ch. Gusy, Öffentlich-rechtliche Verträge zwischen Staat und Bürgern, DVBl. 1983, S. 1222 ff. (1228); E. Schmidt-Aßmann/W. Krebs, (Anm.39), S. 115 f.; D. Göldner, Gesetzmäßigkeit und Vertragsfreiheit im Verwaltungsrecht, JZ 1976, S. 352 ff. (355); D. Ehlers, (Anm. 28), S. 120 ff.; differenzierend H. U. Erichsen, (Anm. 5), $\$ 27, \mathrm{Rdn} .9 \mathrm{ff} .$, S. $374 \mathrm{ff}$. - Speziell zur Anwendbarkeit des Satzes "volenti non fit iniuria“ auf den öffentlich-rechtlichen Vertrag vgl. P. Krause, (Anm.4), S. 22; A. v. Mutius, Zulässigkeit und Grenzen verwaltungsrechtlicher Verträge über kommunale Folgelasten, VerwArch. Bd.65 (1974), S. $201 \mathrm{ff}$. (208); A. Bleckmann, Der Verwaltungsvertrag und die Gesetzmäßigkeit der Verwaltung, AöR Bd. 86 (1961), S. 320 ff. (321); W. Thieme, Der verfassungswidrige Verwaltungsvertrag, NJW 1974, S. 2201 (2203f.); W.R. Schenke, Der rechtswidrige Verwaltungsvertrag nach dem Verwaltungsverfahrensgesetz, JuS 1977, S. $281 \mathrm{ff}$. (285f.); A. Blankennagel, Folgenlose Rechtswidrigkeit öffentlichrechtlicher Verträge?, VerwArch. Bd. 76 (1985), S. 276 ff. (279). - Zurückhaltend demgegenüber BVerwGE 43, 331 (335); Ph. Kunig, (Anm. 10), S. 1198; G. Robbers, Der Grundrechtsverzicht, JuS 1985, S. 925 ff. (930); W. Bosse, (Anm. 43); J. Pietzcker, Die Rechtsfigur des Grundrechtsverzichts, Der Staat Bd. 17 (1978), S. 527 ff.

${ }^{83}$ Auch nach Inkrafttreten des Verwaltungsverfahrensgesetzes zutreffend BVerwGE 49, 359 (361 f.); 42, 331, (334); BSGE 4, 31 (34), 14, 104 (108); ferner BayVGH, DVBl. 1967, S. 314 (315). - Vgl. auch E.Schmidt-Aßmann, in: Maunz/ Dürig/Herzog/Scholz, Grundgesetz-Kommentar, Art. 19 IV, Rdn. 281 ff., der feststellt, daß Art. 19 IV GG die Forderung an den Gesetzgeber zu entnehmen ist, das 
Schranken zu verweisen. Dennoch bleibt die Feststellung zutreffend, daß der rechtsstaatliche Standard im Bereich der subordinationsrechtlichen Verwaltungstätigkeit deutlich hinter dem bei der Aufgabenerledigung durch Verwaltungsakt zurücksteht ${ }^{84}$. Auf die anstelle des Erlasses eines Verwaltungsaktes zustandekommende Vereinbarung trifft exakt die Feststellung O.Mayers zu: „Sie ist kein wabrer Vertrag; die hoheitliche Natur des einen Kontrahenten schließt die im Begriffe eines solchen liegende Rechtsgleichheit aus" ${ }^{\text {"85 }}$. Genauso ist es: Die Behauptung, eine zwischen Verwaltung und Privaten geschlossene Vereinbarung etwa über die Ablösung der Stellplatz- oder Garagenbaupflicht um eine der ältesten und praktisch bedeutsamsten Arten des subordinationsrechtlichen Vertrages heranzuziehen ${ }^{86}$ - stelle wabrbaft einen Vertrag dar, geht an den rechtlichen wie realen Gegebenheiten gleichermaßen vorbei. Wenn sich der einzelne nicht auf das Verhandlungsangebot der Verwaltung einläßt, so erhält er keine Baugenehmigung; der Bürger steht faktisch unter Kontrahierungszwang. Und was für den Ablösevertrag gilt, trifft ebenso auf alle anderen Arten von „subordinationsrechtlichen" Verwaltungsverträgen zu, die verwaltungspraktische Bedeutung erlangt haben und sich typologisch auf den Sachverhalt der Erteilung rechtsgebundener Begünstigungen des einzelnen beziehen. Die unter dem Damoklesschwert des Erlasses eines Verwaltungsaktes zustandegekommene Vereinbarung trägt einen Namen, den sie nicht verdient: sie ist nicht ein Vertrag, sondern stellt die Modifikation einer

System der Fehlerfolgenregelung unter Berücksichtigung des verfassungsrechtlich intendierten Rechtsschutzstandards auszugestalten. - In diesem Sinne auch A. Blankennagel, (Anm. 82), S. 281 f.; P. M. Efstratiou, (Anm. 34), S. 203 ff.; zu den „Vorwirkungen“ des Art.19 IV GG vgl. auch BVerfGE 61, 82 (110).

${ }^{84}$ So auch Ph. Kunig, (Anm. 10), S.1198; A.Bleckmann, (Anm. 81), S.604 ff.; klarsichtig zuletzt A.Scherzberg, (Anm. 35), S.214 mit der Feststellung: „Würden Gesetzesverstöße im Rahmen verwaltungsrechtlicher Verträge schlechthin Rücktritts- oder Leistungsverweigerungsrechte oder einen Anspruch auf Beseitigung der Vertragsfolgen begründen, so wäre die Eignung dieser Handlungsform zur verbindlichen Gestaltung des zwischen den Parteien bestehenden Rechtsverhältnisses schlechthin in Frage gestellt." - Diese Feststellung ist dahin zu „korrigieren": Weil Gesetzesverstöße der Verwaltung ... stets einen Anspruch auf Beseitigung der Vertragsfolgen auslösen müssen, ist die Handlungsform des subordinationsrechtlichen Vertrags zur verbindlichen Gestaltung des zwischen den Parteien bestebenden Rechtsverhältnisses ungeeignet.

${ }_{85} \mathrm{Vgl}$. oben Anm. 55; dezidiert in diesem Sinne auch E. Forsthoff, Lehrbuch des Verwaltungsrechts, 10. Aufl. 1973, S. 278; ferner G. Püttner, (Anm. 57), S. 123 f.

${ }_{86} \mathrm{Vgl}$. dazu die Rechtsprechungsübersicht bei H. Maurer/ B. Hüther, (Anm. 80), S. $23 \mathrm{ff}$. 
einseitigen Regelung dar, deren Charakter am besten in der Bezeichnung als „Verwaltungsakt auf Unterwerfung" ${ }^{47}$ zum Ausdruck kommt.

\section{Freibeit der Rechtsausübung als Wesenselement des Vertrages}

Das Wesen des gegenseitigen Austauschvertrages, um dessen Rezeption als Ersatzinstrument zum Verwaltungsakt es im wesentlichen geht, läßt sich überhaupt nicht zutreffend mit dem Prinzip der Kooperation erklären; fast möchte man sagen: Der gegenseitige Vertrag verkörpert den Gegensatz zur Kooperation zweier Rechtssubjekte. Am sinnfälligsten ist der gegenseitige Vertrag gekennzeichnet als Rechtsform des praktizierten Eigennutzes, und dem haftet nichts Negatives $a^{88}$. Der einzelne verpflichtet sich zu einer Leistung allein wegen seines Interesses am Erhalt der Gegenleistung, und die gesamten Funktionsmechanismen des Vertragsrechts gründen sich auf die Wirksamkeit des eigennützigen Verhaltens, dem nicht die Spur eines kooperativen Elementes eigentümlich ist. Auch dem Konsens kommt im Vertragsrecht nur die Bedeutung der Feststellung der Deckungsgleichbeit zweier Willenserklärungen zu; der Konsens hat dagegen nichts zu tun mit der Herbeiführung eines Interessenausgleichs zwi-

${ }^{87}$ Die Kategorie des Verwaltungsakts auf Unterwerfung stammt von O. Mayer, Deutsches Verwaltungsrecht, Bd. 1, 3. Aufl. 1924, S. 98; das Bundesverwaltungsgericht bezeichnet als einen Verwaltungsakt auf Unterwerfung einen solchen, der „von der Übernahme einer Verpflichtung abhängt, die ihn überhaupt erst wirksam macht"; vgl. BVerwGE 30, 185 (187); ferner OVG Lüneburg, NVwZ 1988, S. 450; HessVGH, DÖV 1986, S.809; zu seiner Funktion - trotz Kritik an seiner Bezeichnung - eingehend F. Kirchbof, Der Verwaltungsakt auf Zustimmung, DVBl. 1985, S. 651 ff. (654 ff.); vgl. auch $P$. Weides, Widerruf von Zuwendungsbescheiden, JuS 1985, S. 364 ff. (368f.); H.U. Erichsen, (Anm.5), \$11 II, S.238; H. Meyer, (Anm. 34), \$36, Rdn. 33; M.Sachs, (Anm.47), S. 412 ff. mit umfangreichen weiteren Nachweisen in Fn. 59.

${ }^{88}$ Klarsichtig dazu F. Bydlinski, (Anm. 8), S. 266 ff., 305 ff.; zur Eigennützigkeit als Wesenselement des grundgesetzlichen Freiheitsverständnisses vgl. statt vieler Ch. Starck, Grundrechtliche und demokratische Freiheitsidee, in: Isensee/Kirchhof (Hrsg.), Handbuch des Staatsrechts, Bd. II, 1987, \$29, Rdn. 16ff.; K. Stern, Das Staatsrecht der Bundesrepublik Deutschland, Bd. III/1, 1988, $\$ 60$ II 2 b, S. $628 \mathrm{ff}$;; K. Hesse, (Anm.67), \$9, Rdn. 288; H.U. Erichsen, Allgemeine Handlungsfreiheit, in: Isensee/Kirchhof (Hrsg.), Handbuch des Staatsrechts, Bd.VI, 1989, $\$ 152$, Rdn. $1 \mathrm{ff}$;; W.Schmitt Glaeser, Die Meinungsfreiheit in der Rechtsprechung der Bundesverfassungsgerichte, AöR Bd.113 (1988), S. 52 ff. (55); P. Häberle, Die Wesensgehaltsgarantie des Art. 19 Abs. 2 GG, 2. Aufl. 1983, S. 145 ff.; vgl. auch J. Isensee, Gemeinwohl und Staatsaufgaben im Verfassungsstaat, in: Isensee/Kirchhof (Hrsg.), Handbuch des Staatsrechts, Bd. III, \$57, Rdn. 28 ff., S. 15 f. 
schen den Vertragsparteien im Sinne eines durch Zusammenwirken angestrebten gemeinsamen Zieles. Daraus erklärt sich, daß der gegenseitige Vertrag Bedingungen voraussetzt, ohne deren Vorhandensein ein zwischen zwei Rechtssubjekten herbeigeführter Konsens sich nicht als Vertrag bezeichnen läßt. Dazu gehört die Entscheidungsfreiheit, eine rechtliche Verpflichtung eingehen zu wollen oder nicht ${ }^{89}$. Diese Freiheit besitzt ein zur Wahrnehmung und Erfüllung der ihm gesetzlich übertragenen Aufgabe verpflichteter Verwaltungsträger nicht. Dazu gehört weiter die Befugnis, über den Vertragsgegenstand verfügen zu können, weil sich grundsätzlich niemand zur Erbringung einer Leistung verpflichten kann, die nicht seiner Verfügungsbefugnis unterliegt. Die einem Verwaltungsträger durch normative Handlungsanweisung übertragene Zuständigkeit, seine Kompetenz, ist dagegen grundsätzlich indisponibel ${ }^{90}$.

\section{Koordinationsrechtlicher Vertrag zwischen Verwaltung und Privaten als Instrument zur Übertragung von Verwaltungsaufgaben auf Private}

Für den öffentlich-rechtlichen Vertrag bleibt daher nur Anwendungsraum im Bereich rechtlicher Gleichordnung zwischen Verwaltung und Privaten, also dort, wo die Verwaltung gerade nicht eine Regelungsaufgabe durch Erlaß eines Verwaltungsaktes durchsetzen könnte. Dies trifft im wesentlichen für den Bereich daseinsvorsorgerischer Wirtschaftsbetätigung sowie für die Bedarfsdeckung der öffentlichen Hand $\mathbf{z u}^{91}$. Darüber hinaus erweist sich der Verwaltungsvertrag als vorrangiges, bereichsweise sogar einzig zulässiges Handlungsinstrument zur Übertragung von Verwaltungsaufgaben auf Private,

$89 \mathrm{Vgl}$. statt vieler $D$. Schmidt, Die Unterscheidung von privatem und öffentlichem Recht, 1985, S. 49 ff., 166 ff.; L. Raiser, Die Zukunft des Privatrechts, 1971, S. $19 \mathrm{ff}$; F.Böm, Privatrechtsgesellschaft und Marktwirtschaft, Ordo 1966, S. 76 f.; F. Bydlinski, (Anm. 8), S. $31 \mathrm{ff}$.

90 Außer den Nachweisen in Anm. 44 E.W. Böckenförde, Die verfassungstheoretische Unterscheidung von Staat und Gesellschaft als Bedingung der individuellen Freiheit, 1973, S. 32 f.; zuletzt J. Isensee, (Anm. 88), \$57, Rdn. $60 \mathrm{ff}$., S. $29 \mathrm{f}$.

91 Im Gegensatz zur herrschenden Lehre und Rechtsprechung handelt es sich bei der ganz überwiegend in privatrechtlichen Formen abgewickelten daseinsvorsorgerischen Wirtschaftsbetätigung und Bedarfsdeckung rechtsqualitativ um öffentlich-rechtliche Verträge, die der Kontrollzuständigkeit der Verwaltungsgerichte unterstellt werden sollten; zuletzt dazu im Sinne der herrschenden Lehre W. Rüfner, Daseinsvorsorge und soziale Sicherheit, in: Isensee/Kirchhof (Hrsg.), Handbuch des Staatsrechts, Bd. III, 1988, $₫ 80$, Rdn. 55 ff., S. 1057 ff.; ferner P. Badura, (Anm. 28), S. $171 \mathrm{ff}$. 
deren verschiedene Erscheinungen Fritz Ossenbü̈b ${ }^{92}$ in subtiler Weise systematisch ausgebreitet hat. Die als echte Delegation erfolgende Übertragung von Verwaltungsaufgaben auf Private durch einseitigen Hoheitsakt stellt einen Rechtseingriff dar, der seinem Wesen und seinen Wirkungen nach in "nächster Verwandtschaft" zur polizeirechtlichen Inanspruchnahme eines Nichtstörers steht ${ }^{93}$. Soweit das Gesetz einem Verwaltungsträger die Befugnis einräumt, sich der Verpflichtung zur Aufgabenerledigung durch deren Übertragung auf einen Privaten zu entledigen, ist dieser grundsätzlich auf den Konsens des Privaten mit der Aufgabenübernahme angewiesen, so daß sich insoweit die Form des (koordinationsrechtlichen) Verwaltungsvertrages als allein zulässiges Handlungsinstrument erweist ${ }^{94}$.

\section{Teil: Die regelungsersetzenden Absprachen}

I. Die Verknüpfung der Rechtsformen des Verwaltungshandelns mit den Regelungshandlungen als Fundament des verwaltungsrechtsdogmatischen Systems

Die Probleme einer sachangemessenen Einbindung von Absprachen zwischen Verwaltung und Privaten als Erscheinungen informellen Verwaltungshandelns liegen demgegenüber auf der Ebene der grundrechts- und rechtsschutzgebotenen Formung administrativer Aktivitätsentfaltung.

Diese Probleme haben ihre Ursache in der die gesamte verwaltungsrechtsdogmatische Systembildung tragenden Verknüpfung der Rechts-

${ }_{22}$ F. Ossenbübl, Die Erfüllung von Verwaltungsaufgaben durch Private, VVDStRL, H. 29 (1971), S. 137 ff. (147 ff.); ders., Staatshaftungsrecht, 4. Aufl. 1991, S. $15 \mathrm{ff}$; grundlegend ferner U.Steiner, Verwaltung durch Private, 1975, insbesondere S. $106 \mathrm{ff}$.; zuletzt W.Krebs, Verwaltungsorganisation, in: Isensee/Kirchhof (Hrsg.), Handbuch des Staatsrechts, Bd. III, \$69, Rdn. 10, S. 573 f.

${ }_{93}$ Über die Geltung des Gesetzesvorbehalts für die Beleihung und die Aktualisierbarkeit grundrechtlicher Abwehransprüche gegen die Aufbürdung "lästiger" Verwaltungshilfe vgl. F. Ossenbübl, Die Erfüllung (Anm. 92), S. 159 ff., (175 ff.); darüber hinaus besteht ein auf die Rechtsform der Aufgabenübertragung bezogenes Verbot der Zwangsbeleihung; a. A. U. Steiner, (Anm. 92), S. 46 ff., der hervorhebt, daß über den Gesetzesvorbehalt nicht eine bestimmte Rechtsform der Kompetenzübertragung erforderlich sei; sogar gegen Beleihung durch öffentlich-rechtlichen Vertrag R. Michaelis, Der Beliehene, Diss. Münster 1969, S. 141.

${ }^{94}$ So auch G. Püttner, (Anm. 57), S. 125; zur Beleihung durch öffentlich-rechtlichen Vertrag vgl. im übrigen BVerwGE 12, 205 (242); J. Stuible-Treder, Der Beliehene im Verwaltungsrecht, Diss. Tübingen 1986, S.89; G. Kentrotis, Das Recht der öffentlichen Verträge in Deutschland und Griechenland, Diss. Saarbrükken 1991, S. $852 \mathrm{ff}$. 
formen des Verwaltungshandelns mit den administrativen Regelungsbandlungen ${ }^{95}$. Diese Verknüpfung von Rechtsform und Regelung läßt sich nicht eigentlich als ein der Verwaltungsrechtsdogmatik anhaftendes Defizit bezeichnen, wohl aber hat diese Verbindung durch die angedeuteten Kräfte- und Funktionsverschiebungen im verfassungsrechtlichen Gewaltengefüge und die dadurch bewirkte Veränderung der Formen administrativer Aufgabenwahrnehmung ihre Fähigkeit zur Durchsetzung der Maßstabsfunktion des Verwaltungsrechts gegenüber den Handlungsformen der Verwaltung eingebüß $t$, und dies hat einen verblüffend einfachen Erklärungsgrund:

\section{Individueller Rechtsschutz als ausschließliches Interesse an dogmatischer Durchformung des Verwaltungshandelns}

Dem rechtsstaatlichen Verwaltungsrecht geht es gemäß seinem historischen Anliegen und Selbstverständnis um die Bändigung der Staatsmacht mit dem Ziel des individuellen Rechts- und Interessenschutzes. Dieses - und nur dieses - Anliegen begründet ein Interesse und Erfordernis an dogmatischer Durchdringung des Verwaltungshandelns und bedingt die ausschließliche Verknüpfung dogmatischer Systembildung mit der Kategorie der administrativen Regelungen, ja - noch enger - mit final gesteuerten, rechtsfolgenintendierenden Regelungshandlungen ${ }^{96}$, die die Rechtssphäre des einzelnen tangieren. Die Handlungskategorie der Realakte und vor allem die Vielfalt der unter dem Sammelbegriff der schlichten Verwaltungshandlungen zusammengefaßten administrativen Verhaltensäußerungen bleiben als dogmatisch uninteressante oder irrelevante Handlungsformen außer Betracht, weil sie als Tathandlungen nicht die Eigenschaften der prinzipiell eigenständigen, verbindlichen Festlegung einer Rechtsfolge oder der Feststellung eines Rechtszustandes aufweisen. Auch soweit Tathandlungen Bedingungen für den Eintritt einer Rechtsfolge sind, bilden sie keinen Bestandteil der verwaltungsrechtlichen Handlungslehre, weil sie sich ihrem Wesen nach der Unterwerfung unter normative Handlungsbindungen entziehen;

$95 \mathrm{Vgl}$. zu dieser Verknüpfung statt vieler E.Schmidt-Aßmann, (Anm. 19), S. 27 ff.; ders., (Anm. 10), S.534; G.Robbers, (Anm.22), S.274; W.Pauly, (Anm. 10), S. 521; ders., (Anm. 4), S. 35 ff.; H. Meyer, (Anm. 34), $\$ 35$, Rdn. 53; zuletzt P. Kirchbof, (Anm. 47), $\$ 59$, Rdn. 41, S. 139; F. Ossenbïhl, (Anm. 4), S. 682; a. A. insoweit - wegen eines anderen Regelungsbegriffs - P. Krause, (Anm. 4), S. $56 \mathrm{ff}$

96 G. Robbers, (Anm. 22), S. 274; P. Kirchbof, (Anm. 47), \$59, Rdn. 41, S. 139. 
ihnen kommt dogmatische Relevanz nur als tatbestandliche Anknüpfung des verwaltungsrechtlichen Subsystems der staatlichen Wiedergutmachung $\mathrm{zu}^{97}$. Bedeutung hat das tatsächliche Handeln der Verwaltung nur für die Bestimmung des Begriffs der Verwaltung in Abgrenzung zur Gesetzgebung und Rechtsprechung. Es ist, wie namentlich Gerhard Robbers ${ }^{98}$ klarsichtig aufgewiesen hat, der Befund zu konstatieren, daß das schlichte Verwaltungshandeln eine „profillose Auffangkategorie darstellt, deren gängige Einteilung in verschiedene Handlungstypen auf der Ebene empirischer Beschreibung verharrt und anerkanntermaßen dogmatisch folgenlos bleibt“.

\section{Alleinige Unterstellung der administrativen Regelungen unter den Rechtsformvorbehalt}

Gewährleistet wird die Durchsetzung der Maßstabsfunktion des Verwaltungsrechts gegenüber Regelungen der Verwaltung durch deren Unterstellung unter den Rechtsformvorbehalt: Regelungen dürfen nur in den benannten Rechtsformen des Verwaltungshandelns vorgenommen werden". Die Verknüpfung der Handlungsqualifikation als Regelung mit den Rechtsformen ist für Ordnungsidee und System des Verwaltungsrechts prägend. Diese systemprägende Bedeutung der Lehre von den Rechtsformen des Verwaltungshandelns und die spezifischen Konsequenzen der strikten Rechtsformanknüpfung für die Verwaltungsrechtsdogmatik hat Eberhard Schmidt-Aßmann ${ }^{100}$ in unübertrefflicher analytischer und sprachlicher Schärfe dargestellt; erhellend sind vor allem die als "Speicherfunktion" ${ }^{101}$ umschriebene rechtspraktische Bedeutung der Rechtsformen sowie die als „Folgenzentriertheit ${ }^{{ }^{102}}$ der Formenlehre gekennzeichnete Ausrichtung der Dogmatik an den Wirkungen von Verwaltungshandlungen, die sich bemängeln läßt, weil eine allein an den Regelungswirkungen ausgerichtete Dogmatik in der Reaktion verharrt und den prospektiven Gestaltungsauftrag des Rechts verspielt. Wenn - so die zutreffende

$97 \mathrm{Vgl}$. statt vieler $F$. Ossenbübl, Staatshaftungsrecht, (Anm. 92), \$6, S. 26; ders., Zur Staatshaftung bei behördlichen Warnungen vor Lebensmitteln, ZHR Bd. 155 (1991), S. $329 \mathrm{ff}$.

${ }^{8}$ (Anm. 22), S. 272.

99 Vgl. die Nachweise in Anm. 95.

100 (Anm. 19), insbesondere S. 27 ff.; ders., (Anm. 10), S. 534; vgl. dazu auch W. Pauly, (Anm. 4), S. $35 \mathrm{ff}$.

101 (Anm. 10), S. 533.

102 (Anm. 10), S. 537. 
Situationsbeschreibung - „das Verwaltungsrecht Verwaltungshandeln leiten und nicht nur begrenzen soll, dann greift eine allein folgenorientierte Betrachtungsweise zu kurz, weil sie die Folgen als gegeben hinnimmt, statt sie in den Ordnungsauftrag einzubeziehen “ 103 .

Dieses Symptom stellt jedoch die dogmatische Konsistenz der Handlungsformenlehre nicht in Frage: In der Gegenüberstellung von Tathandlungen und Regelungen sind alle der Exekutive zurechenbaren Verhaltensäußerungen erfaßt, und mit der Verknüpfung von Regelungen und Rechtsformen ist auch dem Anliegen des Verwaltungsrechts Rechnung getragen, weil es neben den rechtsfolgenorientierten Akten keine Verwaltungshandlungen gibt, an deren dogmatischer Durchdringung aus der Sicht des individuellen Rechtsschutzes ein Interesse bestehen könnte.

\section{Recbtsformmanipulation als Grundproblem des informellen Verwaltungshandelns}

Brüchig wird jedoch die durch den Rechtsformvorbehalt gewährleistete Durchsetzung der Maßstabsfunktion des Verwaltungsrechtes gegenüber den Äußerungen der Verwaltung, wenn durch Rechtsformmanipulationen sozusagen die Nabelschnur zwischen Regelungshandlungen und den für diese geltenden normativen Bindungen durchschnitten wird. Eine solche Manipulation kann vorliegen, wenn anstelle des rechtlich zulässigen Erlasses von Rechtsfolgeentscheidungen Handlungen ohne Regelungscharakter vorgenommen werden, die sich daher am sinnfälligsten als regelungsersetzende Verwaltungshandlungen ${ }^{104}$ bezeichnen lassen. Damit ist das rechtliche Kernproblem des informellen Verwaltungshandelns bezeichnet.

103 (Anm. 10), S. 537.

${ }^{104}$ Diese Bezeichnung ist nicht zu verwechseln mit der Kategorie der „normersetzenden “ Absprachen, die hier außer Betracht bleiben; zu letzteren vgl. insbesondere J.Scherer, Rechtsprobleme normersetzender „Absprachen“ zwischen Staat und Wirtschaft am Beispiel des Umweltrechts, DÖV 1991, S. 1 ff.; J. Oebbecke, Staatliche Mitwirkungen an gesetzesabweichenden Vereinbarungen, DVBl.1986, S. 793 ff.; E. Becker, (Anm. 12), S. 1003 ff.; R. Mayntz, Vollzugsprobleme der Umweltpolitik, 1978, S. 33 ff., $318 \mathrm{ff}$., $405 \mathrm{ff}$; H.Bauer, (Anm.10), S. $242 \mathrm{mit}$ umfangreichen weiteren Nachweisen; E. Bobne, Privatisierung des Staates, Absprachen zwischen Industrie und Regierung in der Umweltpolitik, JbR Soz. Bd. 8 (1982), S. 266 f.; Fr. v. Zezschwitz, (Anm. 10), S. 497 mit weiteren Nachweisen. 


\section{Qualifizierung der regelungsersetzenden Absprachen als Verfügung des Verwaltungsträgers über die Bindung an den normativen Handlungsauftrag}

Informelles Verwaltungshandeln umfaßt nach allgemein gebräuchlicher Definition „alle rechtlich nicht geregelten Tathandlungen, die der Staat anstelle von rechtlich geregelten Verfahrenshandlungen oder Rechtsfolgeentscheidungen wählt, die jedoch zur Herbeiführung des beabsichtigten Erfolges auch in den von der Rechtsordnung bereitgestellten öffentlich-rechtlichen oder privatrechtlichen Handlungsformen hätten erfolgen können" ${ }^{105}$. Kennzeichnend sind hiernach für alle Erscheinungen zweiseitigen informellen Handelns die Merkmale: rechtliche Nichtregelung der Handlungsform, Unverbindlichkeit der Handlung, Alternativverhalten zu rechtsförmlichem Handeln sowie Handeln auf der Grundlage des Tauschprinzips.

Verwaltungsabsprachen mit Privaten lassen sich typologisch einteilen in regelungsvorbereitende und regelungsverhindernde Absprachen; weitergehende Differenzierungen ${ }^{106}$ sind zumindest für die Beantwortung der Frage, ob und gegebenenfalls wie sie sich sachangemessenen normativen Handlungsbindungen unterstellen lassen, nicht erforderlich, weil damit - soweit ersichtlich - alle in der Realität auftretenden Absprachen erfaßt werden.

Das Zustandekommen von Absprachen zwischen Verwaltung und Privaten ist durch folgende Grundkonstellation gekennzeichnet:

Erstens, es besteht eine Aufgabenzuweisungsnorm, die den Handlungsauftrag eines Verwaltungsträgers einschließt, bei Vorliegen eines bestimmten Sachverhaltes gegenüber einem Privaten eine rechtsformgebundene Regelung (regelmäßig den Erlaß eines Verwaltungsaktes) vorzunehmen, wobei für die Vornahme der Regelung ein förmliches Verwaltungsverfahren im Sinne der $\mathbb{\$} 63 \mathrm{ff}$. VwVfG vorgeschrieben sein kann.

Zweitens, der den Handlungsauftrag begründende Sachverhalt ist gegeben, so daß der Verwaltungsträger zur Vornahme der Regelung gegenüber dem Privaten ermächtigt ist und deren Vornahme rechtmäBig wäre.

105 So grundlegend E. Bohne, Der informale Rechtsstaat, 1981, S. $42 \mathrm{ff} . ;$ ders., Informales Verwaltungshandeln im Gesetzesvollzug, in: Blankenburg/Lenk (Hrsg.), Organisation und Recht, 1980, S. 20 ff.; ders., Informelles Verwaltungsund Regierungshandeln, (Anm. 10), S. $343 \mathrm{ff}$.; zur Entwicklung der Diskussion um diesen Begriff eingehend H. Schultze-Fielitz, Der informale Verfassungsstaat, 1984, S. 12 f.; kritisch zur "Huldigung“ des Informalen J. Isensee, DVBI. 1986, S. $955 \mathrm{ff}$.

106 Vgl. insbesondere G. Robbers, (Anm. 22), S. $274 \mathrm{ff}$. 
Drittens, der Verwaltungsträger signalisiert dem Privaten die Bereitschaft, auf die Vornahme der Regelung - vorübergehend oder ganz - unter der Voraussetzung zu verzichten, daß dieser bestimmte, näher bezeichnete Handlungen vornimmt oder unterläßt.

Viertens, der Private läßt sich darauf ein; der Verwaltungsträger und der Private sprechen den Bedingungszusammenhang zwischen dem behördlichen Regelungsverzicht und der dafür vorzunehmenden oder zu unterlassenden Handlung ab.

\section{Das informelle von schlichtem Verwaltungshandeln unterscheidende Kennzeichen als Ersatzbandlung für die Vornabme einer rechtsformgebundenen Regelung}

Diese Betrachtung zeigt, daß die Wesenseigentümlichkeit informellen Verwaltungshandelns in seiner Natur als ,alternatives Handeln" zu rechtsformgebundener Regelung liegt und es sich dadurch von schlichtem Verwaltungshandeln unterscheidet ${ }^{107}$. Nicht als Typus unter den Tathandlungen noch durch seine Wirkungen hebt sich informelles von schlichtem Handeln ab, sondern durch seine Eigenart als Handlungsersatz gegenüber an sich zulässiger Vornahme einer mit Rechtsverbindlichkeit ausgestatteten Regelung. Auf diese Eigenart gründen sich die beträchtlichen Schwierigkeiten, informelles Verwaltungshandeln rechtlich zutreffend zu qualifizieren.

Festzuhalten ist zunächst nochmals, daß der Entschluß des Verwaltungsträgers, auf den von der Handlungsermächtigung gedeckten Erlaß einer Regelung zu verzichten, nichts zu tun hat mit dem Gebrauch eines Auswahlermessens zwischen förmlichem und schlichtem Handeln; wie dargelegt ${ }^{108}$, kann es ein Ermessen, zwischen

107 In diesem Sinne - ungeachtet erheblicher Definitionsvariationen - insbesondere F. Ossenbübl, Informelles Hoheitshandeln, (Anm.10), S.29ff.; ders., (Anm. 4), S.685; E. Becker, (Anm. 12), S. 1003; A. Eichenmüller, Das Gesetz über das Kreditwesen und die Postbank, DÖV 1986, S. $108 \mathrm{ff}$. (413); M.Kloepfer, Umweltrecht, 1989, \$4 II, Rdn. 150 ff.; R. Stober, Handbuch des Wirtschaftsverwaltungs- und Umweltrechts, 1989, S. 817 ff.; G. Robbers, Behördliche Auskünfte und Warnungen gegenüber der Öffentlichkeit, AfP 1990, S. $84 \mathrm{ff}$. (87); zuletzt H.Schultze-Fielitz, Informales oder illegales Verwaltungshandeln, in: Benz/Seibel (Hrsg.), Zwischen Kooperation und Korruption, 1992, S. $233 \mathrm{ff}$.

${ }_{108}$ Vgl. 1. Teil, sub I 2. - Rechtlich präziser Aussagekraft entbehren demgegenüber Formulierungen wie: „Die Dichotomie legales (illegales) Verwaltungshandeln verdeckt eine stärker problemverdeutlichende Dreiteilung, die zwischen (relativ) eindeutigen rechtswidrigem und (relativ) eindeutig gesetzlich festgelegtem Verwaltungshandeln eine breite Zone des Verwaltungshandelns sieht, das weder gesetzlich 
rechtsformgebundener Regelung und formungebundener Tathandlung wählen zu können, nicht geben. Dies gilt auch, wenn das Gesetz der Verwaltung ein Entschließungsermessen einräumt, denn wenn sie sich überhaupt zu einem Handeln entschließt, so kann sie sich nur der vom Recht vorgegebenen Form der Regelung bedienen. Der Verzicht auf die Setzung einer verbindlichen Rechtsfolge bezieht sich überhaupt nicht auf die dem Verwaltungsträger zur Verfügung stehenden Mittel der Realisation von Verwaltungszwecken, sondern läßt sich nur begreifen als eine Loslösung von dem in der Aufgabenzuweisungsnorm enthaltenen Handlungsauftrag, der die Vornahme einer Regelungshandlung vorschreibt, mithin als ein Vorgang, der auf der Ebene der Normbindung und nicht nur auf der Ebene der Gestaltung des Normvollzugs angesiedelt ist: Indem der Verwaltungsträger seine Bereitschaft erklärt, bei Vornahme oder Unterlassung bestimmter Handlungen des Privaten auf den Erlaß eines Verwaltungsaktes zu verzichten, verfügt er über seine Bindung an das Gesetz und nicht nur - um es nochmals zu verdeutlichen - über den Einsatz von Instrumenten, die zur Vollziehung der ihm übertragenen Aufgabe zu Gebote stehen.

\section{Der Kompensationsgedanke als alleinige rechtskonstruktive Möglichkeit der Legalisierung von Absprachen}

Diese Erkenntnis ist von zentraler Bedeutung für die Beantwortung der Frage, ob sich die Absprachepraxis sachangemessenen Handlungsbindungen unterstellen läßt, denn sie verdeutlicht, daß sich die Antwort darauf außerhalb bisheriger verwaltungsrechtlicher Fragestellung bewegt. Es scheint zunächst völlig zweifelsfrei zu sein, daß einem Verwaltungsträger nicht die Befugnis zukommen kann, über seine Bindung an das Gesetz, über die Wahrnehmung seines Handlungsauftrags zu verfügen. Ein eindeutigerer Fall von illegalem Verwaltungshandeln erscheint kaum denkbar, und darüber vermögen auch nicht,

präzise festgelegt noch illegal ist. In dieser ,Grauzone liegt der Schwerpunkt informalen Verwaltungshandelns; es ist nicht umstandslos mit dem sog. ,schlichten Verwaltungshandeln' gleichzusetzen" (so E. Schultze-Fielitz, [Anm. 107], S. 239f.). - Ähnlich unklar: „Das informale Verwaltungshandeln ist deshalb auch nicht generell als abweichendes Verwaltungshandeln zu qualifizieren, sondern es ist Ausdruck von bestimmten Sachgesetzlichkeiten heutiger Verwaltung und Staatlichkeit, die zu einem Funktionswandel führt, der nicht gleichsam qua Definition pathologisiert werden sollte. Die Informalisierung des Verwaltungshandelns folgt also tatsächlichen Entwicklungen und Zwängen, die sich nicht mit einem schlichten ,Zurück zum Gesetzmäßigkeitsprinzip' und seinen rechtsstaatlichen Formen eliminieren lassen" (so a.a. O., S.243, 244). 
worauf Philip Kunig ${ }^{109}$ ganz zu Recht hingewiesen hat, Redeweisen vom harten und weichen Recht hinwegzutäuschen. Von "soft law" läßt sich allenfalls in bezug auf Normen sprechen, deren Nichteinhaltung nicht unmittelbar Rechtsfolgen auslöst, weil sie sanktionslos ausgestaltet sind. Solche Normen bleiben jedoch Rechtsnormen; ihre Nichtbefolgung stellt einen Rechtsverstoß dar, und es erscheint denkunmöglich, demjenigen, an den sich die Norm richtet, eine Befugnis zu deren Nichtbefolgung einzuräumen. So gesehen scheint aus rechtsdogmatischer Sicht die Konsequenz zwingend vorgegeben zu sein, daß Absprachen als Alternativhandlungen zur rechtlich gebotenen Vornahme von Regelungen illegal und damit unzulässig sind.

a) Grundsätzliche Möglichkeit der "Kompensation" des Regelungsverzichts durch Erfüllung der eingegangenen Handlungs- oder Unterlassungsversprechen des Privaten

Diese rechtliche Betrachtung wird jedoch der Sache nicht gerecht, wie folgende Erwägung zeigt: Die rechtsgrundsätzlichen Bedenken, die gegen die Anerkennung einer Befugnis zur Nichtbefolgung einer Norm bestehen, reduzieren sich gewissermaßen auf Null, wenn der Verwaltungsträger seinen Verzicht auf Erlaß einer Regelung an Bedingungen knüpft, bei deren Erfüllung dem im Handlungsauftrag zur Geltung gebrachten öffentlichen Interesse vollauf Rechnung getragen wird. Der im Verzicht auf Ausführung des normativen Handlungsauftrages liegende Rechtsverstoß wird in dem Maße „kompensiert“, wie das im öffentlichen Interesse liegende, durch Ermächtigung zur hoheitlichen Regelung angestrebte „Ergebnis" durch die Befolgung der vom Privaten versprochenen Handlungen oder Unterlassungen tatsächlich erreicht wird. Wird durch Befolgung der Handlungs- oder Unterlassungsversprechen des Privaten das Ziel erreicht, dessen Verwirklichung dem Verwaltungsträger durch Rechtsgebot auferlegt ist, so gibt es nichts zu reklamieren. Kopfzerbrechen bereitet eine solche gegen das Gesetz verstoßende Art und Weise der Verwirklichung des offentlichen Interesses keinem Verwaltungspraktiker, nur uns Juristen, weil es an einer Rechtskonstruktion fehlt, die diesen Vorgang zu legalisieren und vor allem näher zu präzisieren vermöchte, auf welches Maß an Abstrichen vom rechtlich vorgegebenen Ziel des Handlungsauftrags sich der Verwaltungsträger bei der Absprache mit dem Privaten einlassen darf. Je weiter jedoch die vom Verwaltungsträger zur Bedin-

109 (Anm. 10), S. 1197. 
gung seines Verzichts auf Erlaß einer bestimmten Regelung gemachten Handlungen oder Unterlassungen des Privaten hinter dem Inhalt, Ziel und auch dem Zeitpunkt des gesetzlichen Handlungsauftrags zurückbleiben, je weniger also das mit dem Verzicht auf den Rechtszwang verbundene Vollzugsdefizit durch den Beitrag des Privaten aufgewogen wird, desto mehr werden sich die Kopfschmerzen des Juristen auch dem Verwaltungspraktiker mitteilen: im Ergebnis kann es jedenfalls nicht angehen, daß durch eine ihrem Inhait nach deutlich hinter dem Regelungsauftrag zurückbleibende Absprache langfristig ein Vollzugsdefizit eintritt, zu dessen Beseitigung der Verwaltungsträger nicht obne Verstoß gegen das Verbot des venire contra factum proprium ${ }^{110}$ befugt wäre.

\section{b) Vielfalt ungelöster Fragen zu den Voraussetzungen der Kompensationsfäbigkeit von Vollzugsdefiziten durch privaten Handlungsbeitrag}

Rechtlich präzise ist also die regelungsersetzende Absprache zu kennzeichnen als Inanspruchnahme der Befugnis des Verwaltungsträgers, sich über die Bindung an den normativen Handlungsauftrag hinwegzusetzen in der Erwartung, daß es durch die Erfüllung der vom Privaten versprochenen Handlungen oder Unterlassungen zu einer dem Ziel und Inhalt des Handlungsauftrags entsprechenden Situationsverbesserung kommt ${ }^{111}$. Im Lichte dieser Charakterisierung wird erkenntlich, daß als einzige rechtskonstruktive Möglichkeit zur Legitimierung dieserart Absprachen der Kompensationsgedanke in Betracht kommt.

Rupert Scholz ${ }^{112}$ hat „das Prinzip der wechselseitigen Kompensation als eine allgemeine Funktionsmaxime der sozialen Rechtsstaatlichkeit “ bezeichnet, was eine im gedanklichen Ansatz sicherlich richtige Aussage ist, die in der Erhöhung zum überwölbenden Rechtsprinzip aber wohl doch zu weit geht, weil sie geeignet ist, als Staatsauftrag zu „sozialen“ Rechtsumschichtungen mißdeutet zu werden. Wohl aber trifft zu, daß die Möglichkeit der Rechts-, vor allem aber der Kompetenzkompensation sich auf einen Rechtsgedanken gründet, der sich sinnfällig als Ausgleichsmechanismus bei Vorgängen der $A b$ - und Anwachsung von Inhaberschaften, insbesondere bei rechtlich nicht geregelten Wande-

110 Vgl. zur Problematik eingriffsabwehrender, bestehende Vollzugsdefizite perpetuierender Absprachen R. Mayntz, (Anm. 104), S. $408 \mathrm{ff}$.

111 Vgl. die Nachweise in Anm. 105.

112 R.Scholz, Wirtschaftsaufsicht und subjektiver Konkurrentenschutz, 1971, S. 157; ähnlich ders., Paritätische Mitbestimmung und Grundgesetz, 1974, S. 110 f. 
rungsprozessen im Kompetenzgefüge bezeichnen läßt. Wie Eckart Klein ${ }^{113}$ gehaltvoll und ideenreich aufbereitet hat, dient der Kompensationsgedanke dazu, „Verlust bzw. Zugewinn von Kompetenzen und Rechten $z u$ rechtfertigen "; er stützt sich daher auf die Vorstellung einer weitreichenden Disponibilität von Kompetenzen und Rechten, und ihm vermag sogar der Charakter eines bereichsspezifischen organisatorischen Gestaltungsauftrags zuerkannt werden. Seine bekannteste Ausformung hat er in dem seit langem in die Lehre und Rechtsprechung eingegangenen Satz gefunden, daß Kompetenzverluste auf gemeindlicher Ebene durch Mitsprache- und Mitentscheidungsbefugnisse auf überörtlicher Ebene auszugleichen sind ${ }^{114}$. Der Rechtsgedanke findet sich jedoch recht vielfältig und verbreitet im Verfassungs- und Verwaltungsrecht als Erklärungs- und Begründungselement von Erscheinungen flexibler Kompetenz- und Rechtsabschichtungen wieder ${ }^{115}$.

Es dürften daher keine durchgreifenden Bedenken bestehen, den Kompensationsgedanken als rechtlichen Rückhalt, als Legitimationsbasis von regelungsersetzenden Absprachen zu begreifen. Was sich als plausible rechtskonstruktive Begründungsmöglichkeit anbietet, erweist sich indessen als eine in hohem Maße problembehaftete Argumentationsschiene, wie sofort erkennbar wird, wenn man das reiche Beispielsmaterial von Absprachen unter dem Aspekt betrachtet, inwieweit der Handlungsbeitrag des Privaten wirklich als ein Ausgleich des mit dem Regelungsverzicht des Verwaltungsträgers verbundenen Vollzugsdefizits angesehen werden kann oder einen solchen Ausgleich überhaupt herzustellen vermag.

Ohne ins Detail gehen zu können, läßt sich die Absprachepraxis insgesamt dahin kennzeichnen, daß der „Erfolg“ der von dem Privaten angebotenen Handlungen oder Unterlassungen regelmäßig weit hinter dem in der Aufgabenzuweisungsnorm avisierten und durch hoheitliche Regelung durchsetzbaren Standard der Gemeinwohlverwirklichung zurückbleibt, ja es in vielen Fällen an der funktionalen Aufeinanderbezogenbeit ${ }^{116}$ des administrativen Regelungsverzichts

113 E. Klein, Die Kompetenz- und Rechtskompensation, DVBl. 1981, S. 661 ff.

114 Vgl. dazu die Literatur- und Rechtsprechungsübersicht bei E.Klein, (Anm. 113), S. 661 in Fn. 4.

$115 \mathrm{Vgl}$. zur Lokalisierung des Kompensationsgedankens im Verfassungsrecht die Übersicht bei E. Klein, (Anm. 113), S. $661 \mathrm{ff}$.

${ }_{116} \mathrm{Vgl}$. E. Klein, (Anm.113), S.663, der zutreffend hervorhebt, daß in den Schwierigkeiten, über den Gesichtspunkt formaler Äquivalenz hinaus inhaltliche Äquivalenz i.S. materiell gleichrangiger Bedeutung zwischen verlorener und 
und des als Ausgleich gedachten privaten Handlungsbeitrags ermangelt. Das Erfordernis eines annähernden Ausgleichs zwischen staatlichem Regelungsverzicht und privatem Handlungsbeitrag wäre noch gegeben, wenn sich die Absprachepraxis insgesamt mit folgendem Grundbeispiel kennzeichnen ließe: „Wenn Du, Privatmann, die Immissionen Deines Betriebs um $5 \%$ verringerst, dann schließe ich, Verwaltungsträger, die Augen davor, daß die reduzierten Schadstoffimmissionen Deines Betriebes noch immer $10 \%$ über dem höchstzulässigen Grenzwert liegen. “ Läßt sich aber mit dem Kompensationsgedanken eine Absprachepraxis folgender Art legitimieren?: „Wenn Du, Privatmann, die Schaffung oder den Erhalt von 100 Arbeitsplätzen garantierst, so schließe ich, Verwaltungsträger, die Augen davor, daß die Immissionen Deines Betriebes die zulässigen Grenzwerte beträchtlich überschreiten." Bei dieser Sachlage fehlt es an der funktionalen Aufeinanderbezogenheit des administrativen Regelungsverzichts und des privaten Handlungsbeitrags, und damit ist der Möglichkeit, die Absprache mittels des Kompensationsgedankens zu rechtfertigen, der Boden entzogen.

Allein diese einfach gelagerte Sachverhaltsvariante verdeutlicht, daß der Rückgriff auf den Kompensationsgedanken zur Legitimierung von regelungsersetzenden Absprachen Fragen über Fragen aufwirft: Läßt sich für Absprachen eine Zulässigkeitsvoraussetzung des Inhalts formulieren, daß zwischen dem durch den Regelungsverzicht eintretenden Vollzugsdefizit und dem Handlungsbeitrag des Privaten ein Minimalausgleich herbeigeführt werden muß, und wie läßt sich dieser gegebenenfalls quantifizieren? Lassen sich regelungsverzichtsbedingte Vollzugsdefizite etwa im Bereich des Umweltschutzes mit privaten Handlungsbeiträgen kompensieren, die sich in erster Linie oder gar allein wirtschaftspolitisch auswirken? Nach welchen Maßstäben läßt sich bestimmen, welche Vollzugsdefizite durch welche Handlungserfolge kompensationsfähig sind? Wie ist es überhaupt mit der Verwendbarkeit des Kompensationsgedankens in komplexen Verwaltungsverfahren bestellt, in denen verschiedene, oft gegenläufige öffentliche Interessen zum Ausgleich gebracht werden müssen? Diese Fragen sind nur einige aus der Vielfalt praktischer und dogmatischer Anwendungsprobleme, die sich aus dem wohlwollenden Bemühen gegenüber der Verwaltung ergeben, regelungsersetzenden Absprachen

gewonnener Kompetenz- oder Rechtsposition auszumachen, die Gründe liegen, „die verfassungspolitisch zu höchster Zurückhaltung gegenüber dem Kompensationsmodell raten" (so Fn. 28). 
mit Privaten durch Rückgriff auf den Rechtsgedanken der Kompetenzkompensation eine Legitimationsbasis zu vermitteln.

Insgesamt bleibt festzuhalten, daß die Absprachepraxis zwischen Verwaltung und Privaten - von einzelnen Ausnahmen abgesehen weniger von funktionsgerechtem Ausgleichsbemühen als von einer an der Grenze des „Faulen“ stehenden - Kompromißbereitschaft der Verwaltung zeugt, und es besteht kein Anlaß, diesen Befund durch eine verfehlte Idealisierung von kooperationsrechtlichen und konsensualen Handlungsformen zu vernebeln.

\section{Abspracheverbot im Bereich gesetzlich oder grundrechtlich geschützter Teilhabe von Dritten am Verfahren administrativer Entscheidungsbildung}

Ein klares, rechtlich exakt konturiertes Abspracheverbot zwischen Verwaltung und Privaten läßt sich indessen dem geltenden Recht entnehmen, das dieser Handlungsform die praktisch wichtigsten, im Regelungsbereich der Erteilung von Begünstigungen liegenden Anwendungsräume verschließt: Indisponibel ist die Bindung an den normativen Auftrag des Verwaltungsträgers zur Durchsetzung des Gemeinwohls durch Regelung, wenn für deren Vornahme die Durchführung eines förmlichen Verwaltungsverfahrens im Sinne der $\$ \$ 63 \mathrm{ff}$. VwVfG gesetzlich vorgeschrieben ist oder sich dieses Erfordernis unmittelbar aus der Existenz grundrechtsgeschützter Teilhabe Dritter am Verfahren der behördlichen Entscheidungsbildung über den Regelungserlaß ergibt ${ }^{117}$. Die gesetzlich vorgeschriebene oder sich unmittelbar aus grundrechtsgesicherter Verfahrensteilhabe ergebende Formalisierung des Verfahrens administrativer Entscheidung über den Inhalt einer zu erlassenden Regelung entzieht dem Verwaltungsträger die Befugnis, sich mit dem Regelungsadressaten auf informellem Wege, d. h. unter Ausschluß der Anhörungs- und Mitspracheberechtigten, über den teilweisen Verzicht auf Durchsetzung von Ziel und Inhalt des gesetzlichen Handlungsauftrags und dafür zu erbringender Kompensationsleistungen ins Benehmen zu setzen. Wo gesetzlich vorgeschriebene oder grundrechtsgesicherte Teilhabe Dritter am Verfahren der administrativen Entscheidungsbildung besteht, driftet die regelungsersetzende Absprache mit den Privaten als Rechtsformmanipulation ins rechtliche Abseits, weil sie ersichtlich gerade dazu dient,

117 Vgl. dazu präzise G. Lübbe-Wolff, (Anm. 10), S. 297; ferner W. HoffmannRiem, Selbstbindungen, (Anm. 5), S.212; C. E. Eberle, (Anm. 10), S. 443; H.Baner, (Anm. 10), S. 254. 
sich den aus der Verfahrensbeteiligung Dritter ergebenden Hemmnissen zu entziehen ${ }^{118}$.

\section{Die dogmatischen Probleme der Anerkennung von \\ Kompensationsansprüchen bei Nichteinhaltung von Absprachen}

Informelle Absprachen begründen - ihrem Wesen gemäß - keine Rechtspflichten, weshalb ihre Nichteinhaltung durch den Verwaltungsträger oder den Privaten keinen Verstoß darstellt ${ }^{119}$. Aus diesem Grunde stößt die Behauptung, die Nichteinhaltung der Abrede durch die Verwaltung könne Amtshaftungsansprüche des Privaten begründen $^{120}$, auf schwerlich überwindbare dogmatische Hindernisse: Wie soll es möglich sein, einen Schadensersatzanspruch wegen Verletzung einer Amtspflicht zu bejahen, ohne in dieser einen Rechtsverstoß, d. h. rechtswidriges Handeln, zu erblicken? Dieses dogmatische Hindernis läßt sich auch nicht mit dem scheinplausiblen Argument überwinden, das Verbot widersprüchlichen Verhaltens begründe eine Amtspflicht zu „konsequentem Verhalten ${ }^{{ }^{1221}}$, denn dieses Argument stellt nichts anderes dar als eine verklausulierte Anerkennung rechtlicher Verbindlichkeit der Absprache, durch die ihr die Qualität eines öffentlichrechtlichen Vertrages verliehen wird. Gleichen Bedenken begegnet die Anerkennung vertrauensschutzrechtlicher oder plangewährleistungsrechtlicher Kompensationsansprüche des Privaten $^{122}$, weil kein Begründungsweg daran vorbeiführt, die Nichteinhaltung der Absprache als Verstoß gegen das Verbot widersprüchlichen Verhaltens einzustufen und damit die Einhaltung der Absprache in eine Rechtspflicht zu „erhöhen“. Auch insoweit tun sich also Probleme auf, die der Bewältigung noch harren.

118 Grundlegend zum grundrechtlichen Schutz konstituierter Verfahrensrechtspositionen G.Lübbe-Wolff, Die Grundrechte als Eingriffsabwehrrechte, 1988, S. $178 \mathrm{ff}$.

119 So zutreffend Ph. Kunig, (Anm. 10), S. 1201.

120 So Ph. Kunig, (Anm. 10), S. 1201; unbestritten ist nur, daß informale Verwaltungshandlungen selbst Rechtsgutverletzungen bewirken können, die Amtshaftungsansprüche auslösen; vgl. dazu F. Ossenbübl, (Anm. 97), ZHR Bd. 155 (1991), S. 329 ff.; G. Lübbe-Wolff, Rechtsprobleme behördlicher Umweltberatung, NJW 1987, S. 2705 ff. (2708f.).

121 Vgl. Ph. Kunig, (Anm. 10), S. 1201.

122 So vor allem $M$. Oldiges, (Anm. 10), S. $10 \mathrm{ff}$. 
Leitsätze des 1. Berichterstatters über:

\section{Verträge und Absprachen zwischen der Verwaltung und Privaten}

\section{Einleitung}

1. Der Lehre von den Handlungsformen der Verwaltung wird vielfach "dogmatische Insuffizienz" bescheinigt: sie vermöge nicht eine sachangemessene rechtsstaatliche Disziplinierung des beutigen Verwaltungshandelns zu gewäbrleisten und bedürfe einer dogmatischen Umformung.

2. Sozial- und verwaltungswissenschaftlichen Befassungen mit dem Phänomen des informellen Staatshandelns ist mit Vorsicht $z u$ begegnen.

a) Die verwendete Begrifflichkeit löst die dogmatische Substanz von Rechtsbegriffen auf, entziebt sich rechtlicher Präzisierung und stiftet nicht selten Verwirrung.

b) Die Tendenzen zum Ausbruch aus den Rechtsformen werden vielfach mit der durch Gesetzesflut und Regelungsübermaß verursachten Lähmung der Verwaltungsinitiative in Zusammenhang gebracht.

3. Die Ursachen für das Ausgreifen des informellen Verwaltungsbandelns liegen in der Einbuße der Steuerungskraft des Gesetzes, der vermehrten Selbststeuerung und Eigenverantwortung der Verwaltung und der daraus resultierenden Veränderung der Formen administrativer Regelungsaufgaben.

4. Auch in der Vergangenheit bat sich die Verwaltung vielfach der Instrumente mittelbarer oder faktischer Verbaltensbeeinflussung bedient, die als Realakte oder schlichte Verwaltungshandlungen qualifiziert wurden. Der Literatur läßt sich nicht entnehmen, was diese Handlungen von informellem Verwaltungshandeln unterscheidet.

5. Verträge und Absprachen zwischen Verwaltung und Privaten verbindet als Prototypen sogenannten kooperativen Verwaltungshandelns nicht nur eine instrumentelle Sachnäbe, vielmebr werfen die kooperativen Handlungsformen allesamt Probleme hinsichtlich ibrer Unterstellung unter die durch die verfassungsrechtlichen Legalitätskriterien errichteten normativen Handlungsbindungen auf. 
a) Die Zuerkennung der Befugnis zu privatvertraglichem Handeln ermöglicht der Verwaltung ersichtlich, die durch die gegenständliche Begrenzung der Verwaltung auf öffentliche Aufgaben bestebenden Handlungsschranken zu überwinden.

b) Die Befugnis der Verwaltung zum Abschluß subordinationsrechtlicher Verträge eröffnet die Möglichkeit, sich den in Gesetzmässigkeit und Verbältnismäßigkeit festgeschriebenen inbaltlichen Handlungsmaßstäben $\mathrm{zu}$ entziehen.

c) Die Probleme der informellen Absprachen liegen darin, daß sich die Verwaltung der Handlungsbindungen entledigt, die in der grundrechts-und rechtsschutzgebotenen Formung des Verwaltungshandelns angelegt sind.

\section{Teil: Die vertraglichen Handlungsformen der Verwaltung}

6. Die Handlungsformen der Verwaltung sind praktische Zweckschöpfungen, die einem ständigen Anpassungsdruck an die sich verändernden Aufgaben der Verwaltung unterliegen.

7. Die Rechtsform des Verwaltungshandelns ist das von der Rechtsordnung für eine bestimmte Handlung zur Verfïgung gestellte "Kleid".

a) Die Aussage, es bestebe eine Wahlfreibeit zwischen Handlungsund Rechtsformen der Verwaltung, ist obne Sinn.

b) Zwischen den Rechtsformen des Verwaltungshandelns bestebt ein rechtsvorbehaltloses Gebrauchsauswablermessen. Ein aus dem Verbältnismäßigkeitsgrundsatz abgeleiteter grundsätzlicher Vorrang vertraglicher Rechtsformen vor dem Verwaltungsakt besteht nicht.

8. Die zur Verfügung stebenden Rechtsformen des Verwaltungsbandelns unterliegen rechtskonstruktiven Anforderungen insofern, als ibnen keine befugnisbegründende Funktion zukommt. Die Kompetenzen eines Verwaltungsrechtsträgers sind abschließend in der seinen Handlungsauftrag begründenden Aufgabenzuweisungsnorm enthalten, so daß der Gebrauch der Rechtsformen keine anderen oder weitergebenden Handlungsbefugnisse des Verwaltungsträgers zur Entstebung bringen darf.

a) Die Aussage, daß sich die Verwaltung anstelle des Erlasses eines Verwaltungsaktes der privatvertraglichen Rechtsformen bedienen darf, ist dogmatisch unhaltbar, wenn oder soweit mit dem Gebrauch der Rechtsform rechtliche Befugnisse begründet werden, die nicht in der Aufgabenzuweisungsnorm enthalten sind. 
b) Die Konstruktion des subordinationsrechtlichen Vertrages ist deshalb problematisch, weil dem aus dem Zivilrecht stammenden Rechtsinstitut des Vertrages begriffsprägende oder typusbestimmende Elemente wesenseigentümlich sind, die bei Gebrauch des Rechtsinstitutes als Handlungsinstrument der Verwaltung zu einer Auflösung der Gesetzmäßigkeit und Verbältnismäßigkeit fübren.

\section{Der privatrechtliche Vertrag als Rechtsform}

9. Die Verwaltungsrechtsdogmatik verknüpft mit der Befugnis zum Gebrauch der privatrechtlichen Rechtsform die Herauslösung des begründeten Rechtsverbältnisses aus dem Geltungsregime des Öffentlichen Rechts.

10. Der Rückschluß von der privatrechtlichen Rechtsform der Verwaltungshandlung auf die privatrechtliche Qualität des begründeten Rechtsverbältnisses stellt ein folgenschweres Symptom verfassungskontroverser verwaltungsrechtsdogmatischer Theorie- und Systembildung dar.

a) Die Qualifizierung des durch Gebrauch der privatvertraglichen Rechtsform begründeten Rechtsverbältnisses als zwischen zwei Privatrechtssubjekten bestehender (privatrechtlicher) Vertrag gründet sich auf die staatstheoretische Prämisse, daß „der Staat über die Freibeit der Entstaatlicbung verfügt" (P. Laband).

b) Für den Verfassungsstaat des Grundgesetzes ist „die Unverfügbarkeit der Identität des Staates" (O. Mayer) als Adressat der Verfassungsbindungen kennzeichnend.

11. Die als Einheit verfaßte Staatsgewalt läßt die Ausgliederung einer Erscheinung von Staatlichkeit als Privatrechtssubjekt nicht zu.

12. Die Unterscheidung zwischen öffentlichem und privatem Recht kommt nicht in verschiedenen Rechtsformen, sondern in unterschiedlichen Rechtsmaßstäben des Verwaltungshandelns zum Ausdruck.

13. Juristische Personen des Öffentlichen Rechts sind nur in dem gesetzlich übertragenen Wirkungsbereich rechtlich existent.

a) Aus diesem Grunde ist die einem verselbständigten Verwaltungsträger zustehende "Rechtsfäbigkeit" niemals eine Vollrechtsfäbigkeit im Sinne des Bürgerlichen Rechts, sondern begriffsnotwendig eine auf den Kompetenzkreis bezogene Teilrechtsfähigkeit und als solche eine Rechtsfähigkeit des Öffentlichen Rechts. 
b) Rechtshandlungen eines verselbständigten Verwaltungsträgers außerhalb seines gesetzlichen Wirkungskreises entbebren schlechthin der Rechtswirksamkeit (ultra vires-Lebre).

14. Die gesetzliche Aufgabenzuweisungsnorm und darin eingeschlossene Handlungsermächtigung bestimmen abscbließend die Voraussetzungen und Grenzen der Befugnis eines Verwaltungsträgers, sich privatvertraglicher Rechtsformen zu bedienen; der dadurch zustandekommende Vertrag ist öffentlich-rechtlicher Natur.

\section{Der subordinationsrechtliche Vertrag als Rechtsform}

15. Der als Ersatz zum Erlaß eines Verwaltungsaktes konzipierte subordinationsrechtliche Vertrag stellt eine korrekturbedürftige dogmatische Feblkonstruktion dar.

a) Der Gedanke der Kooperation ist untauglich, das Wesen vertraglicher Rechtsbeziehungen zwischen Verwaltung und Privaten zu erklären.

b) Mangels rechtlicher Gleichordnung von Verwaltung und Privaten läßt sich die anstelle des Erlasses eines Verwaltungsaktes geschlossene "Zwangsvereinbarung" nicht als echter Vertrag qualifizieren.

16. Im Bereich rechtlicher Gleichordnung zwischen Verwaltung und Privaten ist der (koordinationsrechtliche) Verwaltungsvertrag wichtige, bereichsweise sogar einzig zulässige Rechtsform des Verwaltungshandelns. Dies gilt insbesondere für die Übertragung der Wabrnebmungskompetenz von Verwaltungsaufgaben auf Private.

\section{Teil: Die regelungsersetzenden Absprachen zwischen Verwaltung und Privaten}

17. Die Probleme einer sachangemessenen normativen Einbindung des informellen Verwaltungshandelns haben ibre Ursachen in der die gesamte verwaltungsrechtsdogmatische Systembildung tragenden Verknüpfung der Rechtsformen des Verwaltungshandelns mit den administrativen Regelungshandlungen.

a) Das allein dem individuellen Rechts- und Interessenschutz dienende Verwaltungsrecht hat kein "Interesse" an einer dogmatischen Durchformung rechtlich unverbindlicher und folgenloser Tatbandlungen.

b) Für Regelungen der Verwaltung bestebt ein Rechtsformvorbebalt in dem Sinne, daß diese nur in den zur Verfügung stehenden Rechtsformen vorgenommen werden dürfen. 
c) Der Rechtsformvorbehalt vermag die Durchsetzung der Maßstabsfunktion des Verwaltungsrechts gegenüber der Verwaltung nicht bei Rechtsformmanipulationen durch Vornahme regelungsersetzender Verwaltungshandlungen zu gewährleisten.

18. Informelles Verwaltungshandeln unterscheidet sich von schlichtem Verwaltungshandeln durch seine Eigenart als Handlungsersatz gegenüber an sich zulässiger Vornabme einer mit Rechtsverbindlichkeit ausgestatteten Regelung.

19. Durch den Verzicht auf die Setzung einer verbindlichen Rechtsfolge verfügt der Verwaltungsträger über seine Bindung an das Gesetz und nicht nur über den Einsatz von Instrumenten, die ihm zur Erfüllung der ihm übertragenen Aufgabe zur Verfügung steben.

20. Als einzige Möglichkeit der Legitimierung des administrativen Regelungsverzichts durch Absprache mit Privaten kommt der „Kompensationsgedanke" in Betracht.

a) Der Rechtsgedanke der Kompetenzkompensation läßt sich kennzeichnen als Ausgleichsmechanismus bei Vorgängen der Ab-. und Anwachsung von Inhaberschaften, insbesondere bei rechtlich nicht geregelten Wanderungsprozessen im Kompetenzgefüge.

b) Der Rückgriff auf den Rechtsgedanken der Kompetenzkompensation zur Legitimierung von Absprachen zwischen Verwaltung und Privaten wirft die Vielzahl ungelöster Probleme auf, die sich insbesondere aus dem Erfordernis der funktionalen Aufeinanderbezogenbeit des administrativen Regelungsverzichts und des als Ausgleich gedachten privaten Handlungsbeitrags ergeben.

21. Im Bereich gesetzlich oder grundrechtlich gescbützter Teilhabe von Dritten am Verfabren administrativer Entscheidungsbildung besteht ein Abspracheverbot.

22. Der Anerkennung von Kompensationsansprüchen des Privaten bei Nichteinhaltung der Absprache durch den Verwaltungsträger steben dogmatische Hindernisse entgegen, die bislang nicht ausgeräumt sind. 


\section{Verträge und Absprachen zwischen der Verwaltung und Privaten}

2. Bericht von Prof. Dr. Walter Krebs, Münster

Inhalt

A. Vorüberlegungen für eine Dogmatik des Verwaltungsvertrages ....................... 250

I. Bedeutung des Verwaltungsvertrages .......... 250

1. Einsatzbreite und Funktionenvielfalt ........ 250

2. Der Verwaltungsvertrag als Handlungs- und Rechtsform des kooperativen Staates . . . . . . . . . . 253

II. Aufgaben der Dogmatik des Verwaltungsvertrages . . . . 255

1. Eigenständigkeit des Rechtsinstituts „Verwaltungs-

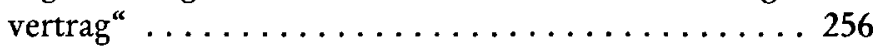

2. Rechtsdogmatische Annäherung des öffentlich-rechtlichen und zivilrechtlichen Verwaltungsvertrages . . . 257

3. Prozedurale Konzeption der Vertragsdogmatik ... . 258

4. Ausdifferenzierung der Vertragsdogmatik . . . . . 259

B. Rechtsfragen einer allgemeinen Vertragsdogmatik . . . . 260

I. Verfahren vor Vertragsschluß . . . . . . . . . . . 260

1. Verfahrensbindung des Verwaltungsträgers ..... 260

2. Vertragsgebote .................. 262

II. Vertragsschluß ...................... 263

1. Zulässigkeit des Vertragsschlusses . . . . . . . . 263

2. Wirksamkeit des Vertragsschlusses . . . . . . . 267

III. Rechtsstellung nach Vertragsschluß . . . . . . . . 269

1. Bindung wirksamer Verträge $\ldots \ldots \ldots \ldots \ldots . \ldots 269$

2. Anpassung an veränderte Umstände . . . . . . 271

IV. Annäherung des zivilrechtlichen und öffentlich-rechtlichen Verwaltungsvertrages ............... 273

1. Verwaltungsprivatrecht $\ldots \ldots \ldots \ldots \ldots \ldots \ldots 273$ 
2. Dogma der Wahlfreiheit .............. 275

3. Bestimmung der Rechtsnatur . . . . . . . . 276

C. Zur Leistungsfähigkeit einer Vertragstypologie . . . . . . 277

D. Schlußbemerkung $\ldots \ldots \ldots \ldots \ldots \ldots \ldots \ldots 280$ 
Walter Krebs

\section{A. Vorüberlegungen für eine Dogmatik des Verwaltungs- vertrages*}

\section{Bedeutung des Verwaltungsvertrages}

\section{Einsatzbreite und Funktionenvielfalt}

Es ist sicher kein Zufall, daß der Vorstand unserer Vereinigung den Verwaltungsvertrag gerade in diesem Jahr thematisiert. Seine erste allgemeine gesetzliche Anerkennung verschaffte ihm - auch in seiner öffentlich-rechtlichen Erscheinungsform - $\$ 121$ des schleswig-holsteinischen Landesverwaltungsgesetzes vom 18.4.1967'. Damit hat für den Verwaltungsvertrag das Jahr 1992 ein wenig Jubiläumscharakter, wenn er auch wesentlich älter als $25 \mathrm{Jahre} \mathrm{ist}{ }^{2}$. Dieses Alter spricht für eine gewisse Erfahrung, und die Verwaltungspraxis hat nicht nur in der Vergangenheit bereits hinlänglich Erfahrungen mit dem Verwaltungsvertrag gesammelt, sondern gewinnt noch ständig welche hinzu. Es gibt nicht nur vitale „Klassiker“, wie den Vertrag zur Ablösung der Stellplatzpflicht ${ }^{3}$, sondern auch fortlaufend neue Gestaltungen, wie etwa die - zum Teil flächendeckend eingesetzten Verträge, mit denen sich Grundstückseigentümer verpflichten, gegen einen Nachteilsausgleich bei der Bodennutzung bestimmte Maßnahmen zugunsten des Naturschutzes vorzunehmen, zu unterlassen oder zu dulden ${ }^{4}$. Der Verwaltungsvertrag hat sich nicht nur in Rechtsgebie-

* Nach der Absprache mit dem Herrn Erstberichterstatter konzentriere ich mich auf die Verträge zwischen der Verwaltung und Privaten. Ich nenne sie ungeachtet ihrer privatrechtlichen oder öffentlich-rechtlichen Rechtsform „Verwaltungsverträge".

1 Vgl. zuvor schon Art. 47-51, 202, 211 des Entwurfs einer Verwaltungsrechtsordnung für Württemberg, in: Verwaltungsrechtsordnung für Württemberg, Entwurf eines Gesetzes mit Begründung, 1931.

${ }^{2}$ Er reicht bis in das 19. Jahrhundert zurück, vgl. Maurer, Der Verwaltungsvertrag - Probleme und Möglichkeiten, in: Hill, Verwaltungshandeln durch Verträge und Absprachen, 1990, S. 15 (17) = DVBl. 1989, S. 798 (799ff.). Zur älteren Rechtspraxis auch Layer, Zur Lehre vom öffentlich-rechtlichen Vertrag. Eine Studie aus dem österreichischen Verwaltungsrecht, 1916, S. $25 \mathrm{ff}$.

${ }^{3}$ Er wurde schon unter der Geltung der Verordnung über Garagen und Einstellplätze (Reichsgaragenordnung - RGaO) vom 17. Februar 1939, RGBl. I, S. 219 ff. praktiziert. Aus jüngerer Zeit dazu Eblers, Die Zulässigkeit von öffentlich-rechtlichen Verträgen über die Ablösung der Stellplatz- oder Garagenbaupflicht, DVBl. 1986, S. 529 ff.; Ziegler, Zur Ablösung der Stellplatzpflicht, DÖV 1984, S. 831 ff., jew. m. w. N.

4 Ebersbach, Möglichkeiten und Grenzen des Vertragsnaturschutzes unter besonderer Berücksichtigung des Waldes, AgrarR 1991, S.63 f. (Tagungsbericht). 
ten, in denen er von jeher heimisch war, wie dem Städtebaurecht, weiter etabliert ${ }^{5}$. Er rückt auch in anderen Rechtsgebieten, wie z. B. im Sozialrecht ${ }^{6}$, zunehmend in das allgemeine Bewußtsein. Für das Umweltrecht wird auf seine breit gestreuten Einsatzmöglichkeiten hingewiesen ${ }^{7}$, und namentlich im Naturschutzrecht hat sich die Vertragspraxis mit dem Begriff "Vertragsnaturschutz" schon in einer eingebürgerten Terminologie niedergeschlagen ${ }^{8}$. Zur Erfüllung ihrer Aufgabe, das ehemals "volkseigene Vermögen“ in den ostdeutschen Bundesländern zu privatisieren, bedient sich die Treuhandanstalt des Verwaltungsvertrages?.

Die knappe und unvollständige Aufzählung ${ }^{10}$ vermittelt einen ersten Eindruck von der Einsatzbreite und Funktionenvielfalt dieses Handlungsinstrumentes. Es ist nicht nur zum eher mikroadministrati-

5 Dazu Schmidt-Aßmann, Vertragstypen der städtebaulichen Praxis, in: Schmidt-Aßmann/Krebs, Rechtsfragen städtebaulicher Verträge, 2.Aufl. 1992, S. $1 \mathrm{ff}$.; ders., Verwaltungsverträge im Städtebaurecht, in: Fschr. f. Gelzer, 1991, S. $117 \mathrm{ff}$; Krebs, Bauplanungs- und Bauordnungsrecht, in: Hill, Verwaltungshandeln durch Verträge und Absprachen, 1990, S. 77 ff.; Jäde, Neue Aspekte städtebaulicher Verträge, BayVBl. 1992, S. $549 \mathrm{ff}$.

- Vgl. insbesondere $\$ \$ 69 \mathrm{ff}$. SGB V v. 20. 12.1988 (BGBl. I, S. $2477 \mathrm{ff}$.), zuletzt geändert durch Einigungsvertrag v. 31.8.1990 (BGBl.II, S. 889 ff.) und durch das Erste Gesetz zur Änderung des Fünften Buches des Sozialgesetzbuches v. 22.3.1991 (BGBl. I, S. 792 ff.).

7 Kloepfer, Umweltrecht, 1989, $\$ 4$ Rdn. 246 (S. 204). Nicht nur zur vertraglichen Kooperation Rengeling, Das Kooperationsprinzip im Umweltrecht, 1989, S. $15 \mathrm{ff} . ;$ Beyer, Der öffentlich-rechtliche Vertrag, informales Handeln der Behörden und Selbstverpflichtungen Privater als Instrumente des Umweltschutzes, Diss. Köln 1986.

${ }^{8}$ Ebersbach, AgrarR 1991, S.63 f.; Rengeling/Gellermann, Kooperationsrechtliche Verträge im Naturschutzrecht, ZG 1991, S. 317 ff.; Gellermann/Middeke, Der Vertragsnaturschutz, NuR 1991, S. $457 \mathrm{ff}$; di Fabio, Vertrag statt Gesetz?, DVBI. 1990 , S. 338 (340).

9 Zu Rechtsfragen der Privatisierung vgl. Bleckmann/Erberich, Die Treuhandanstalt und ihre Unternehmen, in: Rädler/Raupach/Bezzenberger, Vermögen in der ehemaligen DDR, Losebl., Stand: 1992, bes. Rdn. $20 \mathrm{ff}$., $39 \mathrm{ff}$;; Weimar, Die Privatisierung der Aktiengesellschaften in den neuen Bundesländern, BB 1991, Beil. 3 zu Heft 3, S. 1 ff.; Fabrenbach, Das Privatisierungsverfahren nach dem Treuhandgesetz, DtZ 1990, S. $268 \mathrm{ff}$.

${ }_{10} \mathrm{Vgl}$. weiterführend zum Abgabenrecht Sontheimer, Der verwaltungsrechtliche Vertrag im Steuerrecht, 1987; Heun, Die Zulässigkeit öffentlich-rechtlicher Verträge im Bereich der Kommunalabgaben, DÖV 1989, S. 1053 ff.; zum Subventionsrecht jüngst, nicht nur zum schweizerischen Recht, Giacomini, Verwaltungsrechtlicher Vertrag und Verfügung im Subventionsverhältnis «Staat - Privater», 1992; allg. zum schweizerischen Recht Richli, Zu den Gründen, Möglichkeiten und Grenzen für Verhandlungselemente im öffentlichen Recht, ZBI. 1991, S. 381 (385ff.). 
ven Einsatz und zur Begründung zweiseitiger Rechtsverhältnisse tauglich, wie etwa bei der Berücksichtigung von Sonderwünschen bei der Verlegung eines Schmutzwasserkanals ${ }^{11}$, sondern auch zur Gestaltung "polygonaler" oder „mehrpoliger Rechtsverhältnisse ${ }^{{ }_{12} 2}$ und zur Wahrnehmung von Verwaltungsaufgaben von makroadministrativen Dimensionen. Plastisches Beispiel hierfür ist der Ende 1986 zwischen dem Land Rheinland-Pfalz, den kommunalen Spitzenverbänden im Land, der Industrie- und Handelskammer Ludwigshafen und der Landesvereinigung Rheinland-Pfälzischer Unternehmerverbände geschlossene sog. Grundvertrag zur Kooperation bei der Lösung der Altlastenproblematik ${ }^{13}$. Weniger spektakulär, dafür aber häufiger vorkommend ist im Städtebaurecht der Ersatz der amtlichen Umlegung durch eine freiwillige, also vertragliche ${ }^{14}$. Die Beispiele unterstreichen die Einschätzung eines Praktikers, nach der sich gerade bei „inhaltlich schwierigen und umfangreichen Regelungsmaterien " der Vertrag anbiete $^{15}$; der Vertrag bewährt sich demzufolge insbesondere zur Bewältigung komplexer Problemlagen ${ }^{16}$.

Der Verwaltungsvertrag vermag auch Rechtsverhältnisse unterschiedlicher zeitlicher Dimension zu erfassen. Er verrechtlicht nicht nur eine punktuelle Interessenkonvergenz zwischen Verwaltung und Bürger, wie im Fall eines kommunalen Grundstücksgeschäftes, sondern auch mittelfristige Beziehungen, wie etwa bei der Stadterneuerung mit Hilfe von Sanierungsträgern ${ }^{17}$. Er kann schließlich das

11 OVG Lüneburg v. 13. 8. 1991, NJW 1992, S. 1404.

12 Begrifflich ähnlich Scbmidt-Aßmann, Verwaltungsverantwortung und Verwaltungsgerichtsbarkeit, VVDStRL 34 (1976), S. 221 (236); ders., Zur Reform des Allgemeinen Verwaltungsrechts, in: Hoffmann-Riem/Schmidt-Aßmann, Reform des Allgemeinen Verwaltungsrechts - Grundfragen, 1993, S. 11 (45); Schnapp, Rechtsverhältnisse in der Leistungsverwaltung, DÖV 1986, S. 811 (817); Bauer, Subjektive öffentliche Rechte des Staates, DVBl.1986, S.208 (218); vgl. auch W. Martens, Wandlungen im Recht der Gefahrenabwehr, DÖV 1982, S. 89 (96):

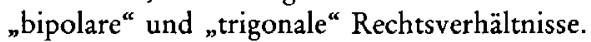

${ }_{13}$ Kloepfer (Fn. 7), \$4 Rdn. 247 (S. 205).

14 Vgl. BVerwG v. 6. 7. 1984, NJW 1985, S. 989 f.

15 Arnold, Die Arbeit mit öffentlich-rechtlichen Verträgen im Umweltschutz beim Regierungspräsidium Stuttgart, VerwArch. 80 (1989), S. 125 (139).

$16 \mathrm{Vgl}$. dazu den Praxisbericht von Offele, Bauplanungs- und Bauordnungsrecht, in: Hill, Verwaltungshandeln durch Verträge und Absprachen, 1990, S. 90 (93 ff.) und allg. auch Kunig, Alternativen zum einseitig-hoheitlichen Verwaltungshandeln, in: Hoffmann-Riem/Schmidt-Aßmann, Konfliktbewältigung durch Verhandlungen, Bd. I, 1990, S. 43 (46f.).

$17 \$ \$ 157 \mathrm{ff}$. BauGB v. 8.12.1986 (BGBl. I, S.2191 ff.) i.d.F. der Bekanntmachung v. 8.12.1986 (BGBl. I, S. 2253), zuletzt geändert durch Einigungsvertrag v. 31.8. 1990 (BGBl. II, S. 889 ff.). 
Instrument zur Begründung und Gestaltung von „Dauerrechtsverbältnissen "18 sein, wie die im SGB V vorgesehenen Verträge zwischen Krankenkassen und Leistungserbringern ${ }^{19}$ zeigen.

Die Skizze der Funktionenvielfalt des Verwaltungsvertrages soll mit dem Hinweis darauf abgeschlossen werden, daß der Vertrag in ganz unterschiedliche Verhältnisse zu den Instrumenten des hoheitlich-einseitigen Verwaltungshandelns treten kann. Seine Fähigkeit, Verwaltungsakte zu ersetzen, deutet schon $\$ 54$ S. 2 VwVfG an; das erwähnte Beispiel des Vertragsnaturschutzes zeigt, daß Verwaltungsverträge auch Normen - faktisch - ersetzen und ergänzen können ${ }^{20}$. Im Fall der „Planabreden“ dienen Verträge der Normvorbereitung ${ }^{21}$. Verallgemeinernd kann man in bezug auf das einseitig-hoheitliche Instrumentarium von einer "Ergänzungs- und Ersatzfunktion" des Verwaltungsvertrages sprechen.

\section{Der Verwaltungsvertrag als Handlungs- und Rechtsform des kooperativen Staates}

Die Verwaltungspraxis zeigt den Verwaltungsvertrag „im Trend“. Diese Einschätzung findet ihre auch theoretische Bestätigung in der neueren Diskussion um die staatliche Systemsteuerung ${ }^{22}$. Angesichts gewandelter und sich wandelnder Staatsaufgaben drängt sich die Frage nach der Notwendigkeit veränderter Handlungs- und Verfahrensmo-

${ }_{18}$ Schmidt-Aßmann, Reform (Fn. 12), S. 11 (45). Zu den Dauerrechtsverhältnissen der Leistungsverwaltung ausführlich Krause, Rechtsverhältnisse in der Leistungsverwaltung, VVDStRL 45 (1987), S. 212 (224ff.).

19 Z. B. $\ 109$ SGB V: Versorgungsverträge mit Krankenhäusern; $\$ 127$ SGB V: Verträge zur Versorgung mit Heilmitteln; $\$ \$ 132 \mathrm{ff}$. SGB V: Beziehungen zu sonstigen Leistungserbringern.

20 Gellermann/Middeke, NuR 1991, S. 457; di Fabio, DVBl. 1990, S. 338 (340 f.).

${ }^{21} \mathrm{Vgl}$. Krebs, Zulässigkeit und Wirksamkeit vertraglicher Bindungen kommunaler Bauleitplanung, VerwArch. 72 (1981), S. $49 \mathrm{ff}$.

${ }^{22}$ Schuppert, Konfliktmittlung bei Verhandlungen und Verwaltungsverfahren, in: Hoffmann-Riem/Schmidt-Aßmann, Konfliktbewältigung durch Verhandlungen, Bd. II, 1990, S.29 (30 ff.); ders., Grenzen und Alternativen von Steuerung durch Recht, in: Grimm, Wachsende Staatsaufgaben - sinkende Steuerungsfähigkeit des Rechts, 1990, S. 217 ff.; Ritter, Das Recht als Steuerungsmedium im kooperativen Staat, in: Grimm, ebd., S. 69 ff., jew. m. w. N.; Pitschas, Verwaltungsverantwortung und Verwaltungsverfahren, 1990, S. $48 \mathrm{ff}$., $582 \mathrm{ff}$;; Holznagel, Reform des allgemeinen Verwaltungsrechts, NVwZ 1992, S. $862 \mathrm{f}$. (Tagungsbericht); Richli, ZBBl. 1991, S. 381 (388 ff.). 
dalitäten des Staates, insbesondere der Verwaltung, auf ${ }^{23}$. Bei Einsicht in die je nach Bedingungsumfeld unterschiedliche, jedenfalls aber häufig begrenzte Steuerungskraft imperativer Befehle ${ }^{24}$ wächst das Bemühen um die Suche nach Verbesserung der Befolgungschancen hoheitlicher Anordnungen, aber auch um die nach Alternativen und Ergänzungen einseitigen staatlichen Handelns. Und vor dem Hintergrund begrenzter ,intellektueller, personeller und finanzieller Ressourcen ${ }^{* 25}$ des Staates richtet sich die Aufmerksamkeit auf die Einbindung gesellschaftlicher Kräfte in die staatliche Aufgabenwahrnehmung. Das Umweltrecht, aber besonders auch das Sozialrecht, liefert Anschauungsmaterial für diesen Befund.

Auch wenn man nicht meint, daß alle diese Fragen ihre zwangsläufige oder gar exklusive Antwort im Begriff des „kooperativen Staa-

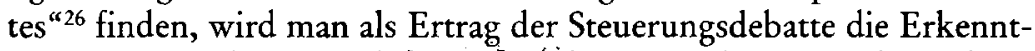
nis rezipieren können, daß Formen konsensualen Verwaltungshandelns ihren selbstverständlichen Platz im Arsenal staatlicher Steuerungstechniken eingenommen haben und dort zunehmend Gewicht erhalten.

Das lenkt fast naturgemäß die Aufmerksamkeit auf den Verwaltungsvertrag. Da einen Vertrag nur schließt, wer sich - zumindest bei Vertragsschluß - „verträgt“, ist Konsens nicht nur rechtliches, sondern bereits begriffliches Konstruktionsprinzip des Vertrages. Die Annahme der erhöhten Akzeptanz einer vertraglich getroffenen Ver-

${ }^{23}$ Vgl. Schuppert, in: Hoffmann-Riem/Schmidt-Aßmann (Fn. 22), S. 29 (33). Aufschlußreich auch der Titel des von Becker-Schwarze, Köck, Kupka und von Schwanenflügel hrsgg. Tagungsbandes zur Assistententagung Öffentliches Recht, 1991: "Wandel der Handlungsformen im Öffentlichen Recht“.

${ }^{24}$ Das vielzitierte Wort von der "Krise der regulativen Politik“ (Mayntz, Regulative Politik in der Krise?, in: Matthes, Sozialer Wandel in Europa, 1979, S. $55 \mathrm{ff}$.) und noch mehr das von der "Krise des regulativen Rechts ${ }^{\text {“ }}$ verleitet zu Mißverständnissen. Richtigstellend Schuppert, in: Grimm (Fn. 22), S. 217 (231).

${ }_{25}$ Ritter, in: Grimm (Fn. 22), S. 69 (73).

${ }^{26}$ Dazu z. B. Ritter, Der kooperative Staat, AöR 104 (1979), S. 389 ff.; Rengeling, Kooperationsprinzip (Fn. 7); J.J. Hesse, Aufgaben einer Staatslehre heute, in: Ellwein/J.J. Hesse/Mayntz/Scharpf, Jahrbuch zur Staats- und Verwaltungswissenschaft, Bd. I, 1987, S. 55 (68ff.); ders., Verhandlungslösungen und kooperativer Staat, in: Hoffmann-Riem/Schmidt-Aßmann, Konfliktbewältigung durch Verhandlungen, Bd.I, 1990, S.97ff.; Schrader, Das Kooperationsprinzip - ein Rechtsprinzip?, DÖV 1990, S.326ff. Vgl. auch Wirtenberger, Akzeptanz durch Verwaltungsverfahren, NJW 1991, S. 257 ff. Kritisch zum "kooperativen Staat" z. B. Lecheler, Verträge und Absprachen zwischen der Verwaltung und Privaten, BayVBI. 1992, S. 545 ff. 
waltungsentscheidung hat angesichts der einverständlichen Rechtserzeugung eine gewisse Plausibilität. Der Verwaltungsvertrag ist keine Zauberformel zur Bewältigung der „neuen Problemlagen“, bietet sich zu ihrem Abbau aber an. Aus Gründen der Akzeptanzsicherung ist er vielfach als rechtlicher Ersatz für eine einseitige hoheitliche Anordnung bedenkenswert. Allerdings sollte man seine eigentliche Bedeutung nicht in einer konsensualen Konkurrenz zum imperativen Befehl suchen. Sie liegt vielmehr dort, wo der Staat seine Aufgaben ohne freiwillige Mitwirkung organisierter oder nicht organisierter gesellschaftlicher Kräfte entweder gar nicht oder nicht in der angestrebten Art und Weise erfüllen könnte. Das begründet die Verwendungshäufigkeit des Vertrages im Städtebau, beim Umweltschutz und auf vielen Gebieten der sozialen Fürsorge.

Die in ihrer Bedeutung neu erkannten Handlungsmöglichkeiten des kooperativen Staates reichen sicher über den Abschluß eines Vertrages weit hinaus. Das weiter gesteckte Thema von heute, das die „Absprache ${ }^{« 27}$ einschließt, deutet dies an. Auch einseitige Verwaltungsentscheidungen können das Ergebnis eines Einverständnisses mit ihren Adressaten sein. Akzeptanzsuche und Konsensbildung finden innerhalb und außerhalb hoheitlicher Entscheidungsverfahren statt. Das Netz nicht-förmlicher Verwaltungshandlungen legt sich bisweilen quer über das System der rechtsförmlichen. Der Verwaltungsvertrag läßt sich somit im Schnittpunkt zweier Beziehungsgefüge ansiedeln: als Ausdrucksform des "kooperativen Staates" in dem des konsensualen Staatshandelns und als rechtsverbindliche Regelung in dem der rechtsförmlichen Verwaltungshandlungen. In dem einen Gefüge hat er seinen rechtlich herausgehobenen Stellenwert durch seine Rechtsform und Rechtsverbindlichkeit, und in dem anderen ist es der besondere Modus der Rechtserzeugung, der ihm dort seinen eigenen Platz zuweist. Die Verfügbarkeit einer leistungsfähigen Vertragsdogmatik erscheint von daher doppelt bedeutsam.

\section{Aufgaben der Dogmatik des Verwaltungsvertrages}

Das „Anforderungsprofil“ für die Dogmatik des Verwaltungsvertrages läßt sich schon aufgrund der bisherigen Überlegungen umreißen. Sie muß

27 Sie hat inzwischen Eingang in die Lehrbuchliteratur gefunden. Vgl. Maurer, Allgemeines Verwaltungsrecht, 8. Aufl. 1992, $\$ 15 \mathrm{Rdn} .13 \mathrm{ff}$. (S. $369 \mathrm{f}$.); Erichsen, Das Verwaltungshandeln, in: Erichsen/Martens, Allgemeines Verwaltungsrecht, 9. Aufl. 1991, $\$ 35$ Rdn. 1 (S. 419). 
- zum einen dem Verwaltungsvertrag helfen, ein wirkungsvolles Instrument der Verwaltung bei der Wahrnehmung ihrer Aufgaben zu sein,

- zum anderen die potentielle Einsatzbreite und die damit verbundene Funktionenvielfalt des Verwaltungsvertrages aufnehmen und

- schließlich die Gemeinsamkeiten der Verwaltungsverträge herausarbeiten, ohne die es eine Dogmatik „des“ Verwaltungsvertrages nicht gäbe.

Letzteres wird allerdings nur auf sehr hohem Abstraktionsniveau möglich sein. Das ist jedoch kein Spezifikum des Verwaltungsvertrages.

\section{Eigenständigkeit des Rechtsinstituts „Verwaltungsvertrag“}

Gemeinsam ist allen Verwaltungsverträgen, daß sie zur Wahrnehmung von Staatsaufgaben geschlossen werden. Schon das spricht für eine Emanzipation dieses Rechtsinstituts von dem des Zivilrechts. Normergänzung und Verwaltungsaktsersetzung, Konsenssuche und Akzeptanzsicherung sowie Partizipation an Verwaltungsaufgaben sind Assoziationsbegriffe, die mit dem Verwaltungsvertrag, nicht mit dem Vertrag unter Privaten, in Verbindung gebracht werden. Der Seitenblick auf das Parallelinstitut des französischen Verwaltungsrechts $^{28}$ erlaubt die Prognose, daß die Aufgabenstellung dem Recht des Verwaltungsvertrages ihr eigenes Gepräge geben wird.

Diese Prognose wird durch die rechtsdogmatische Überlegung bestärkt, daß die rechtliche Grundlage für den Verwaltungsvertrag auf seiten des Verwaltungsträgers eine entsprechende Kompetenz, auf seiten des Privaten die grundrechtlich geschützte Privatautonomie ist. Der Verwaltungsvertrag nimmt dem Privaten nicht seine Grundrechtsstellung und gibt der Verwaltung keine Freiheit ${ }^{29}$. Die Verwal-

28 Dazu Efstratiou, Die Bestandskraft des öffentlich-rechtlichen Vertrages. Eine vergleichende Untersuchung zum griechischen, französischen und insbesondere deutschen Verwaltungsvertragsrecht, 1987, bes. S. 87 ff.; Marzlin, Die Abgrenzung des öffentlich-rechtlichen Vertrages und des privatrechtlichen Vertrages der Verwaltung im französischen Recht unter vergleichender Berücksichtigung des deutschen Rechts, Diss. Mainz 1966; Jarass, Besonderheiten des französischen Verwaltungsrechts im Vergleich, DÖV 1981, S. 813 (820).

${ }_{29}$ Darüber, daß dem Staat keine Privatautonomie zusteht, dürfte Einigkeit bestehen, vgl. nur Maurer, Allg. VwR (Fn. 27), \$14 Rdn. 25 (S. 336); Bull, Allgemeines Verwaltungsrecht, 3. Aufl. 1991, $\$ 2$ Rdn. 73 (S. 29); Achterberg, Allgemeines Verwaltungsrecht, 2. Aufl. 1983, $\$ 1$ Rdn. 23 (S. 12); Eblers, Verwaltung und 
tung bleibt vielmehr auch dann in ihrer demokratisch geforderten Verantwortung, wenn sie ihre Entscheidung erst im Zusammenwirken mit dem Privaten rechtsverbindlich machen kann ${ }^{30}$.

Aus all dem folgt nicht die prinzipielle Untauglichkeit des Zivilrechts für seine Verwendung im Verwaltungsvertragsrecht. In dieser Hinsicht schließe ich mich der Auffassung an, die Herr Jarass vor zwei Jahren auf unserer Tagung geäußert hat. Danach ist die "These, das Privatrecht fördere die Freiheit des Bürgers, während das öffentliche Recht sie beschränke, ... sowenig hilfreich wie die umgekehrte Aussage, daß das öffentliche Recht dem Allgemeininteresse zum Durchbruch verhelfe, das Privatrecht dagegen nur Individualinteressen fördere"31. Die rechtsdogmatische Grundstruktur des Verwaltungsvertrages macht aber zum einen darauf aufmerksam, daß es nicht die mit dem Vertrag verbundene Freiheitsvorstellung, sondern die Rechtstechnizität zivilrechtlicher Ordnungsmodelle ist, die ihre Übernahme für die Zwecke des Verwaltungsvertrages ermöglicht. Die Privatrechtsnormen werden, wo nötig, modifiziert werden müssen ${ }^{32}$. Damit ist zum anderen schon der Hinweis gegeben, daß die öffentlichrechtlichen Spezifika den Verwaltungsvertrag nicht nur dort zum genuinen Institut des Verwaltungsrechts ausformen werden, wo das Zivilrecht keine adaptionsfähigen Modelle bereitstellt.

\section{Rechtsdogmatische Annäherung des öffentlich-rechtlichen und zivilrechtlichen Verwaltungsvertrages}

Die Verwaltung erfüllt auch dann ihre öffentlichen Aufgaben, wenn sie sich nicht des öffentlich-rechtlichen, sondern des zivilrechtlichen Vertrages bedient. Die Erfüllung von Staatsaufgaben mit Hilfe des

Verwaltungsrecht im demokratischen und sozialen Rechtsstaat, in: Erichsen/Martens, Allgemeines Verwaltungsrecht, 9.Aufl. 1991, $\$ 2$ Rdn. 66 (S.45); ders., Rechtsstaatliche und prozessuale Probleme des Verwaltungsprivatrechts, DVBI. 1983, S. 422 (424); Pietzcker, Der Staatsauftrag als Instrument des Verwaltungshandelns, 1978, S. 364.

30 Kunig/Rublack, Aushandeln statt Entscheiden?, Jura 1990, S. 1 (8 f.).

31 Jarass, Verwaltungsrecht als Vorgabe für Zivil- und Strafrecht, VVDStRL 50 (1991), S. 238 (241). Zu den „Charaktermerkmalen“ des Privatrechts im Verhältnis zum öffentlichen Recht vgl. auch Druey, Privatrecht als Kontaktrecht, JöR NF 40 (1991/1992), S. 149 ff. (insbes. S. 162 ff.).

32 Vgl. die Kataloge der anwendbaren Vorschriften und ihrer Modifikationen z. B. bei Bonk, in: Stelkens/Bonk/Leonhardt, VwVfG, 3. Aufl. 1990, $\$ 62$ Rdn. 11 ff. oder bei Kopp, VwVfG, 5. Aufl. 1991, $\$ 62$ Rdn. 4 ff., jew. m. N. auch zur Rspr. 
privatrechtlichen Vertrages erfolgt nicht nur "mittelbar", wie es z.B. von den fiskalischen Hilfsgeschäften gesagt wird ${ }^{33}$, sondern vielfach auch „unmittelbar", wie das erwähnte Beispiel der Privatisierungsgeschäfte der Treuhandanstalt eindrucksvoll belegt. Auch für den zivilrechtlichen Vertragsabschluß zwischen Verwaltungsträger und Privaten gilt dieselbe rechtsdogmatische Grundaussage wie für den verwaltungsrechtlichen Vertrag. Das spricht dafür, den zivilrechtlichen Vertrag zwischen Staat und Bürger dem öffentlich-rechtlichen Verwaltungsvertrag rechtsdogmatisch anzunähern. Die mit Rechtsunsicherheiten belastete Zäsur, zu der das Prozeß- und Verfahrensrecht zwingen, sollte sich nicht mehr als nötig in der Dogmatik des Verwaltungsvertrages niederschlagen. Systematisch ist der zivilrechtliche Vertrag zwischen Verwaltung und Privaten keine eigenständige Rechtsform des Verwaltungshandelns, kein aliud zum verwaltungsrechtlichen Vertrag, sondern eine Variante des Verwaltungsvertrages, der vom Begriff her beide Rechtsformen umschließen sollte ${ }^{34}$. Die für den Verwaltungsvertrag geltenden Grundregeln sollten daher prinzipiell rechtsformunabhängigen Charakter haben.

\section{Prozedurale Konzeption der Vertragsdogmatik}

Der Verwaltungsvertrag bringt die Kommunikationsbeziehung zwischen der Verwaltung und dem Bürger in eine Rechtsform. Diese Beziehung kann im Einzelfall sehr kurz, sie kann aber, wie die eingangs erwähnten „Dauerrechtsverhältnisse“ zeigen, auch von längerer Dauer sein. Das Verständnis des Verwaltungsvertrages als Ausdrucksmittel des kooperativen Staates erinnert daran, daß Akzeptanzsuche, Entscheidungsbildung und Konsenssuche prozeßhaft vonstat-

${ }^{33}$ Vgl. schon Siebert, Privatrecht im Bereich öfentlicher Verwaltung, in: Fschr. f. Niedermeyer, 1953, S.215 (221); Wolff, in: Wolff/Bachof, Verwaltungsrecht, Bd. I, 9. Aufl. 1974, $\$ 23$ II b (S. 108). Aus neuerer Zeit z. B. Ehlers, DVBl. 1983, S. 422 (423); Wilke/Schachtel, Probleme fiskalischer Betätigung der öffentlichen Hand, WiVerw. 1978, S. 95 (96).

${ }^{34}$ Ebenso Kreuzer, Der vertragswidrige Verwaltungsakt, 1988, S. 12. Terminologisch anders z.B. Maurer, in: Hill (Fn. 2), S. $15=$ DVBl. 1989, S.798, der allerdings auch fragt, ob der „verwaltungsprivatrechtliche Vertrag ... nicht im Verwaltungsvertrag aufgehen" sollte (in: Hill [a.a.O.], S. $37 \mathrm{ff}$. = DVBl. 1989, S. 798 [807]). Terminologisch anders auch Kawalla, Der subordinationsrechtliche Verwaltungsvertrag und seine Abwicklung, Diss. Konstanz 1984, S. 9; Lecheler, BayVB1. 1992, S. 545 mit Fn. 1; Schimpf, Der verwaltungsrechtliche Vertrag unter besonderer Berücksichtigung seiner Rechtswidrigkeit, 1982, S. 27. 
ten gehen ${ }^{35}$. Der Vertragsschluß ist daher nur ein rechtsförmlicher Ausschnitt aus einem Verwaltungsverfahren, das bereits vorher möglicherweise nicht einmal mit der Zielsetzung eines Vertragsschlusses - einsetzt und mit Vertragsschluß keinesfalls beendet sein muß. Die Dogmatik des Verwaltungsvertrages kann die Entwicklungsgeschichte der Verwaltungsaktsdogmatik in Rechnung stellen und von vornherein eine Verengung des Blicks auf die rechtsförmliche Entscheidung vermeiden ${ }^{36}$. Insofern gilt es, auch die rechtlichen „Vorund Nachwirkungen" des Vertragsschlusses zu bedenken. Damit liegt es nahe, die Vertragsdogmatik prozedural zu konzipieren und die öffentlich-rechtlichen Spezifika des Verwaltungsvertrages „phasenspezifisch" zu betrachten.

\section{Ausdifferenzierung der Vertragsdogmatik}

"Der“ Verwaltungsvertrag soll von „seinen“ allgemeinen Lehren ebenso geprägt werden, wie "die“ je unterschiedlichen Verträge von ihren jeweiligen Rechtsgebieten her ihren besonderen Charakter erhalten. Eine sinnvolle Vertragsdogmatik muß darauf Bedacht nehmen, daß die Ebene der konkreten Einsatzfelder des Vertrages die Impulse der allgemeinen Ebene aufnimmt, und umgekehrt müssen die besonderen Problemsituationen des konkreten Vertragseinsatzes auf der Ebene der allgemeinen Lehren reflektiert werden können ${ }^{37}$. Angesichts der schon angedeuteten Abstraktionshöhe der möglichen allgemeingültigen Aussagen über den Vertrag und angesichts der eingangs umrissenen Breite und Verschiedenartigkeit seiner konkreten Einsatzfelder besteht die Gefahr, daß die Distanz zwischen beiden Ebenen zu groß ist, um den notwendigen Austausch unter ihnen zu ermöglichen. Will man der Gefahr begegnen, sollte man überlegen, ob nicht in das ganze dogmatische Vertragsgebäude Zwischenebenen eingezogen

${ }^{35}$ Vgl. den Katalog von ,typenrechtlicher Steuerung" von Schuppert, in: Grimm (Fn. 22), S. 217 (232 f., insbes. S. 233: „Prozedurale Steuerung. Gemeint ist ... eine Steuerung durch Verfahren, insbesondere über Verfahren der Entscheidungs- und Konsensbildung").

${ }^{36}$ Grundlegend insofern Brohm, Die Dogmatik des Verwaltungsrechts vor den Gegenwartsaufgaben der Verwaltung, VVDStRL 30 (1972), S. 245 (253 ff.). Allgemein zur "Prozeßdimension staatlichen Entscheidens“ auch Pitschas, Verwaltungsverantwortung (Fn. 22), S. $158 \mathrm{ff}$. $\mathrm{Zu}$ den besonderen Problemen des „Dauerverhältnisses“ Krause, VVDStRL 45 (1987), S. 212 (224ff.).

${ }^{37} \mathrm{Vgl}$. zu den "Wechselbeziehungen“ zwischen "allgemeinem Verwaltungsrecht und seinen Referenzgebieten" Schmidt-Aßmann, Reform (Fn. 12), S. 11 (14, $26 \mathrm{ff}$.). 
werden sollten, die Vermittlungs- und Entlastungsfunktionen erfüllen. Vermittlung meint die Konkretisierung der allgemeinen Aussagen bei Berücksichtigung eines eingegrenzten Problemfeldes, aber auch die Abstrahierung von Spezialproblemen der konkreten Vertragspraxis. Damit werden zugleich beide dogmatischen Ebenen entlastet, weil die sektorale Verallgemeinerung von Vertragsregeln der Problemlösung im konkreten Fall hilft und die allgemeine Vertragsdogmatik vor einer Überfrachtung mit Einzelproblemen schützt. Fragen wie die, ob die Drittschutzregelung des $\$ 58 \mathrm{VwVfG}$ eine abschließende Lösung für alle einschlägigen Probleme sein kann, oder die, ob nicht die Bedeutung einiger Verwaltungsverträge Publikationserfordernisse begründet, lassen sich differenzierter und vor dem Hintergrund konkreter Sachbereiche problemnäher diskutieren.

Mit diesen Vorüberlegungen wende ich mich nun den Rechtsfragen einer allgemeinen Vertragsdogmatik zu.

\section{B. Rechtsfragen einer allgemeinen Vertragsdogmatik}

\section{Verfabren vor Vertragsschlu $\beta$}

\section{Verfabrensbindung des Verwaltungsträgers}

$\mathrm{Da}$ der Vertrag das Produkt eines gemeinsamen Verfahrens der Rechtserzeugung ist, muß sich die Andersartigkeit des Verwaltungsvertrages gegenüber dem Vertrag unter Privaten, insbesondere die Ungleichstellung der Vertragsparteien, bereits auf das Verfahren vor Vertragsschluß auswirken. Für den öffentlich-rechtlichen Verwaltungsvertrag haben die Verwaltungsverfahrensgesetze diese Konsequenz gezogen und den Vertrag dem Verwaltungsakt verfahrensrechtlich angenähert. $\$ 9 \mathrm{VwVfG}(\$ 8$ SGB X) stellt den „Abschluß eines öffentlich-rechtlichen Vertrages" als Ziel des Verwaltungsverfahrens dem "Erlaß eines Verwaltungsaktes" gleich, und $₫ 62 S .1 \mathrm{VwVfG}$ $(\$ 61$ S. 1 SGB X) verweist für den Vertrag auf die „übrigen Vorschriften" des Gesetzes. Über den Kanon der damit anzuwendenden Normen des $\mathrm{VwVfG}^{38}$, namentlich die über die Beratung, Belehrung und Auskunft, besteht weitgehend Einigkeit ${ }^{39}$, ebenso darüber, daß sich

${ }^{38}$ Ausführlich dazu Punke, Verwaltungshandeln durch Vertrag, o. J. (1989?), S. $46 \mathrm{ff}$.

39 Vgl. z.B. für die Anwendbarkeit des $\$ 3 \mathrm{VwVfG}$ (örtliche Zuständigkeit): Kopp, VwVfG (Fn. 32), \$62 Rdn. 2; Obermayer, VwVfG, 2. Aufl. 1990, $\$ 62$ Rdn. 7; Mollgaard, in: Knack, VwVfG, 3. Aufl. 1989, \$62 Rdn. 2; Ule/Laubinger, Verwaltungsverfahrensrecht, 3. Aufl. 1986, S.520; für die Anwendbarkeit der 
die Verantwortung der Behörde für ihre Entscheidung auch dann in ihrer Bindung an den Untersuchungsgrundsatz widerspiegelt, wenn sie im Konsens mit dem Bürger handelt ${ }^{40}$. Nach zutreffender h.L. erübrigt dieser allerdings die sonst obligatorische Anhörung ${ }^{41}$.

Aus Gründen des Verfahrensschutzes bedarf es daher nicht der Annahme, die Entscheidung der Behörde über den Vertragsschluß sei ein Verwaltungsakt ${ }^{42}$. Der Verwaltungsvertrag bietet gerade den Vorteil, Rechtsverhältnisse, auch solche auf Dauer, ohne Verlust an öffentlich-rechtlicher Disziplinierung des Verwaltungsträgers „umweglos" begründen und ausgestalten zu können. Die einst rechtsstaatlich motivierte Konstruktion, insbesondere privatrechtlichen Rechtsverhältnissen zwischen Verwaltung und Bürger eine öffentlich-rechtliche "Stufe" vorzuschalten ${ }^{43}$, ist für viele Fallgestaltungen entbehrlich geworden ${ }^{44}$.

Dem Drittschutz trägt $₫ 58$ Abs. 1 VwVfG dadurch Rechnung, daß er die Wirksamkeit eines in Rechte Dritter eingreifenden Vertrages von dessen Zustimmung abhängig macht. Die Norm entspricht dem zivilrechtlichen Grundsatz, daß es keine Verträge zu Lasten Dritter geben darf ${ }^{45}$. Diese materiellrechtliche Einbeziehung des Dritten in

$\iint 11,12$ VwVfG (Handlungs- und Beteiligtenfähigkeit) z. B. Bonk, in: Stelkens/ Bonk/Leonhardt (Fn. 32), $\$ 62$ Rdn. 5; Kopp, VwVfG (a.a. O.), $\$ 62$ Rdn. 2; für die Anwendbarkeit der $\$ \$ 20,21$ (ausgeschlossene Personen und Besorgnis der Befangenheit): vgl. Kopp, VwVfG (a.a.O.), $\$ 62$ Rdn. 2; Ule/Laubinger, Verwaltungsverfahrensrecht (a.a.O.), S. 520; Bonk, in: Stelkens/Bonk/Leonhardt (a. a. o.), $\$ 62$ Rdn. 5; für die Anwendbarkeit des $\$ 25$ VwVfG (Auskunft, Beratung): z. B. Meyer, in: Meyer/Borgs, VwVfG, 2. Aufl. 1982, $\$ 62$ Rdn. 4; Ule/Laubinger, Verwaltungsverfahrensrecht (a.a. O.), S. 521.

${ }^{40}$ Bonk, in: Stelkens/Bonk/Leonhardt (Fn.32), $\$ 62$ Rdn. 5; Obermayer, VwVfG (Fn. 39), \$62 Rdn. 26; Punke, Verwaltungshandeln (Fn. 38), S. 57 ff.

41 A. A. Kopp, VwVfG (Fn. 32), \$62 Rdn. 2.

42 So aber Kopp, Die Entscheidung über die Vergabe öffentlicher Aufträge und über den Abschluß öffentlichrechtlicher Verträge als Verwaltungsakte?, BayVBl. 1980, S. 609 ff.; Bleckmann, Subventionsrecht, 1978, S. 88; wie hier z. B. Eblers, Verwaltung in Privatrechtsform, 1984, S. 193; Friebe, Die Konkurrentenklage gegen einen öffentlich-rechtlichen Subventionsvertrag, DÖV 1980, S.673 (674 ff.).

${ }^{43}$ Von inzwischen rechtsgeschichtlicher Bedeutung H.P. Ipsen, Öffentliche Subventionierung Privater, DVBl. 1956, S.602 ff.; ders., Verwaltung durch Subventionen, VVDStRL 25 (1967), S. 257 (bes. 298).

${ }_{44}$ Zur Kritik Ossenbühl, Rechtliche Probleme der Zulassung zu öffentlichen Stadthallen, DVBl. 1973, S. 289 (292 f.).

${ }^{45}$ Dazu Hadding, in: Soergel, BGB, Bd. II, 12. Aufl. 1990, $\$ 328$ Rdn. $118 \mathrm{ff}$.; Heinrichs, in: Palandt, BGB, 52. Aufl. 1993, Einf. v. $\$ 328$ Rdn. 10; Gottwald, in: 
den Vertrag muß vertragsrechtliche "Vorwirkungen“ auf den Verfahrensschutz Dritter haben. Daraus folgt, daß die Verfahrensnormen über die obligatorische Hinzuziehung des Dritten $(\$ 13$ Abs. 2 S. $2 \mathrm{VwVfG}$ ) rechtsdogmatisch mit $\$ 58$ Abs. $1 \mathrm{VwVfG}$ abzugleichen sind. Soweit schon die vertragliche Verpflichtung der Behörde zu einer drittbelastenden Maßnahme dem Zustimmungsvorbehalt unterliegt ${ }^{46}$, ist der Dritte auch am Verfahren vor Vertragsschluß zu beteiligen.

Nur relativ wenig diskutiert wurde bislang die Beteiligung organisierter oder nicht organisierter Betroffener oder erweiterte Formen der Öffentlicbkeitsbeteiligung ${ }^{47}$. Allerdings ist eine Breiten- und Tiefenwirkung, die derartige Verfahrensöffnungen sinnvoll erscheinen ließe, nicht so typisch für das Vertragsrecht, daß sie notwendig Gegenstand des allgemeinen Vertragsrechts sein müßte. Deshalb sei zum einen diese Problematik hier als Merkposten festgehalten, weil wie eingangs gezeigt - derartige Vertragsdimensionen nicht ausgeschlossen sind. Zum anderen sei aber der allgemeine Hinweis erlaubt, daß ein Übermaß an Verfahrensbindungen in der Praxis Vermeidungsstrategien beflügelt und damit das Bemühen, der Verwaltung mit dem Vertrag ein ebenso rechtsstaatlich einwandfreies wie praktisch handhabbares Instrument an die Hand zu geben, konterkarieren kann.

\section{Vertragsgebote}

Eine allgemeine Rechtspflicht für die Behörde, dem Vertragshandeln Vorrang vor Handeln in hoheitlich-einseitiger Form zu geben, gibt es nicht. Sie hat über den Einsatz ihrer Handlungsformen nach pflichtgemäß ausgeübtem Ermessen zu entscheiden. Die ihr in $\$ 54$ $V_{w} V f G$ entsprechend eingeräumte Pflicht ist objektiv-rechtlich zu

Münchener Kommentar zum Bürgerlichen Gesetzbuch, Bd. II, 2. Aufl. 1985, $\$ 328$ Rdn. 97 ff.; Vollkommer, in: Jauernig, BGB, 6. Aufl. 1991, $\$ 328$ Anm. I. 3. d); vgl. zur verfassungsrechtlichen Fundierung dieses Grundsatzes BVerfG v. 23.4.1986, BVerfGE 73, S. 261 (270f.).

${ }_{46}$ H. M., vgl. z.B. Erichsen, in: Erichsen/Martens (Fn. 27), $\$ 27$ Rdn. 8 (S. 372 f.).

47 Zur Diskussion im "Vertragsnaturschutz" vgl. Gellermann/Middeke, NuR 1991, S. 457 (464 f.); di Fabio, DVBI. 1990, S. 338 (344f.); Rengeling/Gellermann, ZG 1991, S. 317 (332 f.). Zur Diskussion bei "Planungsabreden“"vgl. schon Degenhart, Vertragliche Bindungen der Gemeinde im Verfahren der Bauleitplanung, BayVBl. 1979, S. 289 (295). 
deuten ${ }^{48}$. Auch aus dem Übermaßverbot läßt sich kein allgemeines Vertragsgebot für die Fälle herleiten, in denen die Betroffenen bereit sind, ihnen andernfalls durch Verwaltungsakt auferlegte Verpflichtungen freiwillig zu übernehmen ${ }^{49}$. Auch wenn es ein allgemeines, rechtliches Subsidiaritätsprinzip zugunsten des Vertrages nicht gibt, kann es in einzelnen Fällen - z. B. in einigen Vorschriften des Städtebaurechts ${ }^{50}$ oder des nordrhein-westfälischen Naturschutzrechts ${ }^{51}$ - vom Gesetzgeber angeordnet sein. Darüber hinaus kann u. U. die Zulässigkeit eines hoheitlichen Verfahrens an der sachlich nicht begründbaren Verweigerungshaltung der Gemeinde gegenüber der Vertragslösung scheitern $^{52}$. Schließlich kann der durch den allgemeinen Gleichheitssatz ausgelöste Selbstbindungsmechanismus $s^{53}$ Kontrahierungszwänge für den Verwaltungsträger begründen, der vom Vertrag "flächendekkend" Gebrauch macht.

\section{Vertragsschluß}

Die rechtswissenschaftliche Diskussion des Verwaltungsvertrages hat sich bislang auf die vielen Rechtsfragen der Zulässigkeit des Vertragsschlusses, seiner Wirksamkeit und seiner Rechtsfolgen konzentriert. Das erlaubt mir, auf den Ertrag dieser Bemühungen zurückzugreifen, und erleichtert mir den Zwang, selektiv vorzugehen.

\section{Zulässigkeit des Vertragsschlusses}

So ist heute Allgemeingut, daß der Verwaltungsvertrag seine rechtliche Eigenart wesentlich durch den Verfassungsgrundsatz der

${ }_{48}$ Ebenso Punke, Verwaltungshandeln (Fn. 38), S. 94. Vgl. generell gegen einen Anspruch auf Durchführung eines bestimmten Verwaltungsverfahrens, auch wenn dieses objektiv-rechtlich geboten ist, Hill, Verfahrensermessen der Verwaltung, NVwZ 1985, S. 449 (452).

49 Zutreffend Scherzberg, Grundfragen des verwaltungsrechtlichen Vertrages, JuS 1992, S. 205 (209); vgl. auch Kunig/Rublack, Jura 1990, S. 1 (11); Erichsen, in: Erichsen/Martens (Fn.27), $\$ 27$ Rdn. 3 (S.369f.) m. Fn.14a; zum Teil a.A. Reckers, Gesetzwidrige und gesetzesabweichende Regelungen in Verwaltungsverträgen zwischen Bürger und Staat, Diss. Tübingen 1988, S. $82 \mathrm{ff}$.; differenzierend $d i$ Fabio, DVBl. 1990 , S. 338 (345 f.).

so $\$ \$ 27$ I, 87 II, 110 I BauGB.

51 \$4 I des Gesetzes zur Sicherung des Naturhaushalts und zur Entwicklung der Landschaft (Landschaftsgesetz-LG) v. 18.2.1975 (GV NW 1975, S. 190) i.d.F. der Bekanntmachung v. 26.6.1980 (GV NW 1980, S.734).

52 BGH v. 2.4.1981, NJW 1981, S.2124: gemeindliche Beteiligungsverpflichtung an einer freiwilligen Umlegung.

${ }_{53}$ Erichsen, in: Erichsen/Martens (Fn. 27), \$32 Rdn. 5 (S. 409). 
Gesetzmäßigkeit der Verwaltung erfährt und daß für das Vertragshandeln der Verwaltung der Gesetzesvorrang lediglich beim Vergleichsvertrag abgeschwächt, im übrigen aber uneingeschränkt gilt ${ }^{54}$. Attraktiv ist der Verwaltungsvertrag für die Verwaltung auch nicht als "Fluchthelfer" aus der rechtlichen Bindung, weil diese Flucht rechtlich ohnehin nicht gelingen kann. Besondere Attraktion gewinnt der Vertrag für die Verwaltung vielmehr aus den mit seiner Hilfe erweiterten Gestaltungschancen. Die Kooperation mit dem Bürger bietet Möglichkeiten zur Verfolgung, Erreichung oder Optimierung von Verwaltungszielen, die dem einseitigen hoheitlichen Verwaltungshandeln nicht in gleicher Weise eröffnet sind.

Ein solcher Einsatz des Vertrages setzt entsprechende Entscheidungsspielräume der Verwaltung voraus. Rechtsdogmatisch ist damit nach dem rechtlichen Entscheidungsrabmen für das Vertragshandeln gefragt. Er wird durch eine Reihe rechtlicher Restriktionen gebildet, die sich - grob gegliedert - in vier Gruppen einteilen und daraufhin untersuchen lassen, ob und inwieweit sie einem Vertragsschluß entgegenstehen. Ihr prinzipieller Aussagegehalt gilt für den privatrechtlichen und öffentlich-rechtlichen Verwaltungsvertrag gleichermaßen.

Erstens sind es mögliche Vertragsformverbote. Ihre Diskussion hat allerdings erwiesen, daß sie bereichsspezifisch unterschiedlich ${ }^{55}$, insgesamt aber recht selten vorkommen ${ }^{56}$. Die gesetzliche Bereitstellung einer Rechtsform hoheitlichen Handelns kann, muß aber keine Indizwirkung für ein Vertragsformverbot haben ${ }^{57}$. Der Hinweis des $\$ 54$ S. 2 VwVfG auf den alternativen Einsatz von Verwaltungsakt und

${ }^{54}$ Erichsen, in: Erichsen/Martens (Fn. 27), \$27 Rdn. 9 (S. 373); Scherzberg, JuS 1992, S. 205 (210); Schenke, Der rechtswidrige Verwaltungsvertrag nach dem VwVfG, JuS 1977, S. 281 (285); Maurer, in: Hill (Fn. 2), S. 15 (31) = DVBl. 1989, S. 798 (804); Ule/Laubinger, Verwaltungsverfahrensrecht (Fn.39), S.519; Kopp, VwVfG (Fn. 32), $\$ 54$ Rdn. 24; Schimpf, Vertrag (Fn. 34), S. 136.

${ }_{55}$ Relativ vertragsfeindlich ist z. B. das Steuer-, zum Teil auch das Abgabenrecht, vgl. zum Problem- und Meinungsstand Heun, DÖV 1989, S. 1053 ff. m. zahlr. N. sowie Ress, Begriff, Wesen und Funktion des öffentlich-rechtlichen Vertrages, Revue européenne de droit public 1989, S. 279 (297f.) m. Beispielen.

${ }^{56}$ Ein Beispiel ist die Beamtenernennung, vgl. Meyer, in: Meyer/Borgs (Fn. 39), $\$ 54 \mathrm{Rdn} .70 ;$ Maurer, Allg. VwR (Fn. 27), \$14 Rdn.26 (S. 337). Weitere Beispiele bei Ress, Revue européenne de droit public 1989, S. 279 (297f.).

57 Schimpf, Vertrag (Fn. 34), S. 176; Meyer, in: Meyer/Borgs (Fn. 39), \$54 Rdn. 70; Scherzberg, JuS 1992, S. 205 (208); Kunig, Verträge und Absprachen zwischen Verwaltung und Privaten, DVBl. 1992, S. 1193 (1196). Vgl. dazu auch Tschaschnig, Die Nichtigkeit subordinationsrechtlicher Verträge nach dem Verwaltungsverfahrensgesetz, 1984, S. $146 \mathrm{ff}$. 
Vertrag ist insofern aufschlußreich. Soweit sich die Rechtsordnung dem Vertragsschluß widersetzt, widerspricht sie in der Regel dem Inhalt des Vertrages, nicht seiner Verwendung an sich.

Zweitens kann die Einschlägigkeit des Gesetzesvorbehalts bei fehlender gesetzlicher Ermächtigung die behördliche Vertragsinitiative lähmen. Seine Problematik schien sich zunächst mit dem Erlaß der Verwaltungsverfahrensgesetze erledigt zu haben. Die Materialien des VwVfG des Bundes halten die Frage nach einer gesetzlichen Ermächtigung mit der Regelung des $\$ 54 \mathrm{VwVfG}$, wonach die Verwaltung öffentlich-rechtliche Verträge schließen kann, für beantwortet ${ }^{58}$. Bis heute entnimmt die h.M. dem Gesetzesvorbehalt kaum Restriktionen für das Vertragshandeln ${ }^{59}$. Ihr ist modifiziert zuzustimmen. Sie läßt sich zwar nicht damit begründen, daß $₫ 54 \mathrm{VwVfG}$ die geforderte Ermächtigung sei ${ }^{60}$ oder $\$ \$ 54 \mathrm{ff}$. VwVfG Ersatzfunktionen übernäh$m^{6}{ }^{61}$. Als Verfassungsgrundsatz läßt sich der Gesetzesvorbehalt nicht einfachgesetzlich abbedingen, und ihm genügen nur bereichs-

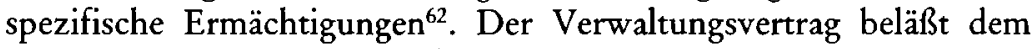
privaten Vertragspartner aber prinzipiell seine privatautonome Rechtsstellung, so daß sich aus seiner Sicht der Vertragsschluß in der Regel nicht als ein den Gesetzesvorbehalt auslösender Grundrechtseingriff, sondern als Freiheitsgebrauch darstellt ${ }^{63}$.

$\mathrm{Zu}$ wenig beachtet wird allerdings die objektiv-rechtliche Komponente des Gesetzesvorbehalts, die - unabhängig vom Konsens des Privaten - zum Schutz der Führungsrolle des Parlaments eine gesetzgeberische Entscheidung erfordern kann $^{64}$. Das so begründete

${ }^{58}$ BT-Drucks. 7/910, S. $78-$ Begründung zu $\$ 50$ des Entwurfs (entspricht $\$ 54$ $\mathrm{VwVfG})$.

${ }^{59} \mathrm{Vgl}$. etwa Maurer, Allg. VwR (Fn. 27), $\$ 14$ Rdn. 26 (S.337); Bonk, in: Stelkens/Bonk/Leonhardt (Fn. 32), \$54 Rdn. 45; Meyer, in: Meyer/Borgs (Fn. 39), $\$ 54$ Rdn. 67; Ule/Laubinger, Verwaltungsverfahrensrecht, (Fn. 39), S.517. Restriktiv demgegenüber Schimpf, Vertrag (Fn. 34), S. $169 \mathrm{ff}$.

60 Z. B. Ress, Revue européenne de droit public 1989, S. 279 (282); Maurer, Allg. VwR (Fn. 27), $\$ 14$ Rdn. 26 (S. 337).

${ }^{61} \mathrm{Vgl}$. Erichsen, in: Erichsen/Martens (Fn. 27), $\$ 27 \mathrm{Rdn} .10 \mathrm{ff}$. (S. $375 \mathrm{ff}$.). Für das Subventionsrecht soll nach Henke, Recht der Wirtschaftssubventionen als allgemeines Vertragsrecht, 1979, S. 56f. \$56 VwVfG „Ersatzfunktionen“ übernehmen.

62 Scherzberg, JuS 1992, S. 205 (211).

${ }^{63}$ Göldner, Gesetzmäßigkeit und Vertragsfreiheit im Verwaltungsrecht, JZ 1976, S. 352 (355); Maurer, in: Hill (Fn. 2), S. 15 (33) = DVBl. 1989, S. 798 (805); Krebs, Der städtebauliche Vertrag im Gefüge der allgemeinen Vertragslehre des Verwaltungsrechts, in: Schmidt-Aßmann/Krebs, Rechtsfragen städtebaulicher Verträge, 2. Aufl. 1992, S. 185 ff.; Scherzberg, JuS 1992, S. 205 (211).

${ }_{64}$ Dazu Krebs, in: Schmidt-Aßmann/Krebs (Fn. 63), S. $189 \mathrm{ff}$. 
Anwendungsfeld des Gesetzesvorbehalts kann derzeit aber nur als das Problem formuliert werden, ob nicht die quantitative oder qualitative Dimension einer staatlichen Aufgabe eine gesetzliche Vorordnung des Verwaltungshandelns verlangt, für das Vertragshandeln insbesondere die Vorgabe vertraglicher Mindestinhalte. Um das Gemeinte weniger vage am konkreten Beispiel deutlich zu machen: Die gesetzlichen Vorgaben für den Sanierungsträgervertrag im Städtebaurecht ${ }^{65}$ oder für das Vertragshandeln im Kassenarztrecht ${ }^{66}$ sind positive Beispiele für das Bemühen, demokratischen und rechtsstaatlichen Anliegen des Gesetzesvorbehalts gerecht zu werden.

Als Eckdaten des rechtlichen Vertragsrahmens insgesamt bedeutsamer sind allerdings - drittens - die Maßgaben der $\int \mathbb{S} 54 f f$. VwVfG. Sie sind unmittelbar zwar nur auf den offentlich-rechtlichen Vertrag anwendbar. Die dadurch theoretisch mögliche Differenz zur Zulässigkeit des zivilrechtlichen Vertrages ist allerdings im Hinblick auf die inhaltlichen Anforderungen nicht hoch zu veranschlagen. So ist die für Austauschverträge einschlägige Norm des $\$ 56$ VwVfG ein Produkt des Zusammenspiels von Maßgaben des Übermaßverbotes ${ }^{67}$ und des Koppelungsverbotes ${ }^{68}$, also von Grundsätzen, die ebenso bundesrechtlich einheitlich wie rechtsformunabhängig gelten.

In den Vorgaben des $₫ 56 \mathrm{VwVfG}$ spiegelt sich die Eigenart des Verwaltungsvertrages besonders auffällig wider: Die privatautonome Rechtsstellung des Bürgers erlaubt ihm, sich aus welchem Grund auch immer bis an die Grenze von Sittenwidrigkeit und Treu und Glauben zu verpflichten ${ }^{69}$, die Verwaltung ist hingegen an das „Angemessen-

$65 \$ \$ 157 \mathrm{ff}$. BauGB.

66 Insbes. $\$ \$ 69 \mathrm{ff}$. SGB V.

67 Es kommt im „Angemessenheitsgebot" zum Ausdruck, vgl. Kopp, VwVfG (Fn. 32), $\$ 56$ Rdn. 13; Erichsen, in: Erichsen/Martens (Fn. 27), $\$ 27$ Rdn. 13 (S. 376); Scherzberg, JuS 1992, S. 205 (212); VGH München v. 11.4.1990, NVwZ 1990, S. 979 (981).

68 Zum Koppelungsverbot schon Menger, Zum Koppelungsverbot bei öffentlich-rechtlichen Verträgen, VerwArch. 64 (1973), S. 203 ff.; zur Rspr. des pr. OVG und des Reichsgerichts vgl. die Nachw. bei Erichsen, in: Erichsen/Martens (Fn. 27), \$27 Rdn. 14 (S. 377); aus der jüngeren Rspr. vgl. z. B. BGH v. 21.11. 1957, BGHZ 26, 84 (86ff.); BVerwG v. 13.7.1979, NJW 1980, S.1294ff.; BVerwG v. 15. 12.1989, BVerwGE 84, S.236 (241) = JZ 1990, S. 591 (593) m. Anm. Ehlers; VGH München v. 11.4.1990, NVwZ 1990, S. 979 (981); OVG Münster v. 19.8.1988, NJW 1989, S. 1879 (1880).

69 Das wird auch für den Abschluß von Verwaltungsverträgen angenommen, vgl. Rengeling/Gellermann, ZG 1991, S. 317 (331); Pieroth/Schlink, Grundrechte, Staatsrecht II, 8. Aufl. 1992, Rdn. 165. Ob die Auffassung überzeugt, kann angesichts der Bindung der Behörde dahinstehen. 
heitsgebot" und das "Sachzusammenhangsgebot" gebunden. Das Gebot der Angemessenheit der Gegenleistung des Bürgers beläßt der vertragschließenden Behörde allerdings hinreichende Entscheidungsspielräume. Inwieweit das Sachzusammenhangsgebot diese einengt, entscheidet letztlich das Fachgesetz, das zur Konkretisierung des Begriffs „sachlicher Zusammenhang" herangezogen werden muß ${ }^{70}$.

Diese Beziehung verdeutlicht zugleich, daß - viertens - in der Regel das Ausmaß der fachgesetzlichen Vorordnung über den eigentlichen Umfang des rechtlichen Rahmens vertraglichen Verwaltungshandelns Auskunft gibt. Der Bereich rechtlich strikt gebundenen Gesetzesvollzuges schließt das Vertragshandeln zwar nicht notwendig aus. Die Chance, mit Hilfe des Vertrages Aufgaben auch jenseits der Eingriffsschwelle für einseitiges Handeln wahrzunehmen, bietet sich aber insbesondere in Bereichen an, in denen der Gesetzgeber das Verwaltungshandeln nur durch Zuständigkeitsnormen, Aufgabenzuweisungen und Zweckvorgaben dirigiert ${ }^{71}$. Auch das erklärt, warum das Umweltrecht für den Einsatz von Verträgen reizvoller ist als etwa das Steuerrecht.

\section{Wirksamkeit des Vertragsschlusses}

Die Verwaltungsaktsdogmatik verdankt ihre Identität - und ihren Erfolg - wesentlich der kunstvollen Abstimmung von Wirksamkeits-, Bestandskrafts-, Anfechtungs- und Aufhebungsregeln. Das Vertragsrecht ist, zumindest unter diesem Gesichtspunkt, wesentlich einfacher strukturiert. Von den Besonderheiten des $\$ 126 \mathrm{Abs} .3 \mathrm{Lan-}$ desverwaltungsgesetz Schleswig-Holstein abgesehen fehlen dem Verwaltungsaktsrecht vergleichbare Anfechtungsregelungen. Das verlagert notwendig den Schwerpunkt der Dogmatik auf die Rechtsfragen der Wirksamkeit des Vertragsschlusses. Sie sind zum Teil abgeklärt, zum Teil auf der Ebene des allgemeinen Vertragsrechts nicht völlig abklärbar.

Einigkeit besteht heute darüber, daß die differenzierenden Regelungen des $₫ 59 \mathrm{VwVfG}$ erkennen lassen, daß nicht jeder Rechtsfehler zur Unwirksamkeit des Vertrages führen soll ${ }^{72}$. Weitestgehend Einig-

70 Schmidt-Aßmann, in: Fschr. f. Gelzer (Fn. 5), S. 117 (124).

71 Vgl. anschaulich die Prüfung von $\$ 1$ III und VI BauGB durch den VGH München v. 11.4.1990, NVwZ 1990, S. 979, sowie - allgemein - Schmidt-Aßmann, in: Fschr. f. Gelzer (Fn. 5), S. 117 (124): „Gesetzesdirigierte Vertragsgestaltung“.

72 Vgl. nur Ule/Laubinger, Verwaltungsverfahrensrecht (Fn. 39), S.541; Kopp, VwVfG (Fn. 32), $\$ 59$ Rdn. 2; Stelkens, Verwaltungsverfahren, 1991, Rdn.661; Kunig, DVBl. 1992, S. 1193 (1200). 
keit besteht inzwischen darüber, daß die Norm gleichwohl einer verfassungsrechtlichen Prüfung standhält ${ }^{73}$, und kaum noch bestritten ist derzeit, daß der Verweis des $\$ 59$ Abs. 1 VwVfG auf die Vorschriften des Bürgerlichen Gesetzbuches auch die Regelung des $\$ 134$ BGB über die Nichtigkeit von Verträgen umfaßt, die gegen ein gesetzliches Verbot verstoßen ${ }^{74}$. $\$ 134$ BGB gilt daher für den privatrechtlichen wie öffentlich-rechtlichen Vertrag gleichermaßen und avanciert derge-

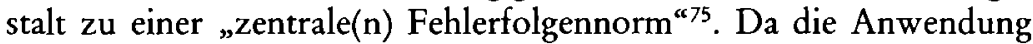
von $\$ 134 \mathrm{BGB}$ nicht dazu führen darf, die von $\$ 59 \mathrm{VwVfG}$ gewollte Differenzierung zu nivellieren, stellt sich die Frage, welcher Rechtsverstoß eine „qualifizierte Art des Konflikts" (Weyreuther ${ }^{76}$ ) darstellt. $\$ 134$ BGB verweist hierfür auf das Sachgesetz, so daß eine Antwort auf die Frage nur bei Zusammenschau von $\$ 59$ VwVfG i.V. m. $\$ 134$ BGB und der einschlägigen, kollidierenden Rechtsnorm gegeben werden kann ${ }^{77}$. Das allgemeine Vertragsrecht enthält für dieses Interpretationsproblem aber Vorgaben:

Zum einen berechtigt die Eigenart des Verwaltungsvertrages zur Skepsis vor der Übernahme von Topoi, die die Zivilrechtslehre ${ }^{78}$ zur

${ }_{73}$ Z.B. Punke, Verwaltungshandeln (Fn. 38), S. 190; Efstratiou, Bestandskraft (Fn. 28), S. 254 ff.; trotz diskutierter Bedenken im Ergebnis auch Reckers, Regelungen (Fn. 49), S. 159; Ule/Laubinger, Verwaltungsverfahrensrecht (Fn. 39), S. 541. Vgl. hierzu ausführlicher auch Krebs, in: Schmidt-Aßmann/Krebs (Fn.63), S. 206 ff. m. N.

${ }_{74}$ Z.B. Schmidt-Aßmann, in: Fschr. f. Gelzer (Fn. 5), S. 117 (125); Kopp, VwVfG (Fn. 32), \$59 Rdn.7ff.; Möllgaard, in: Knack (Fn. 39), \$59 Rdn. 3.1; Bramsche, Rechtsfolgen verwaltungsvertraglicher Gesetzesverstöße, 1986, S. 10 ff.; Schimpf, Vertrag (Fn.34), S.284ff.; aus der Rspr. z.B. VGH München v. 11.4.1990, NVwZ 1990, S. 979 (980); VGH Mannheim v. 18.10.1990, NVwZ 1991, S. 583 (585); für Unanwendbarkeit Blankenagel, Folgenlose Rechtswidrigkeit öffentlich-rechtlicher Verträge?, VerwArch. 76 (1985), S. 276 (282ff.); vgl. hierzu auch Bleckmann, Verfassungsrechtliche Probleme des Verwaltungsvertrages, NVwZ 1990, S. $601 \mathrm{ff}$.

${ }^{75}$ Scbmidt-Aßmann, in: Fschr. f. Gelzer (Fn. 5), S. 117 (125).

76 Weyreutber, Ablösungsverträge, entgegenstehende Rechtsvorschriften und gesetzliche Verbote, in: Fschr. f. Reimers, 1979, S.379 (383); ähnlich OVG Lüneburg v. 12.1.1988, NJW 1988, S. 2126 (2127), das einen „qualitativen Rechtsverstoß " fordert; kritisch Ress, Revue européenne de droit public 1989, S. 279 (283 m. Fn. 10).

77 Vgl. auch BVerwG v. 23.8.1991, NJW 1992, S. 1642 (1643): „Ob eine Regelung, die durch verwaltungsrechtlichen Vertrag getroffen wird, an einem zur Nichtigkeit führenden Mangel leidet, entscheidet zum einen das allgemeine Vertragsrecht und zum anderen das jeweils einschlägige Fachrecht."

${ }_{78} \mathrm{Vgl}$. insbesondere Canaris, Gesetzliches Verbot und Rechtsgeschäft, 1983. 
Anwendung von $\$ 134$ BGB entwickelt hat. So wird etwa die allgemeine Regel, daß ein gesetzliches Verbot, das sich nur gegen einen Geschäftspartner richtet, nicht zur Nichtigkeit des Geschäftes führe ${ }^{79}$, angesichts der besonderen Rechtsbindung der Verwaltung für den Verwaltungsvertrag keine Gültigkeit beanspruchen können. Auch wird man den angesprochenen, besonderen Stellenwert des Verfahrens in eine differenzierende Diskussion der einschlägigen Vorschriften einbringen müssen.

Zum anderen ist ganz allgemein zu vergegenwärtigen, daß $\$ 59$ VwVfG das Ergebnis einer Abwägung zwischen den Verfassungsprinzipien der Gesetzmäßigkeit der Verwaltung, der Rechtssicherheit und auf seiten des Privaten - des Vertrauensschutzes darstellt. Diese Abwägung ist vom Gesetzgeber in $\$ 59$ Abs. 2 VwVfG konkretisiert worden und für den offenen Tatbestand des $\$ 59 \mathrm{Abs.} 1 \mathrm{VwVfG} \mathrm{i}$. V.m. $\$ 134$ BGB vom Rechtsanwender selbst fortzuführen. Er hat daher insbesondere den Stellenwert der von der kollidierenden Norm geschützten Interessen zu ermitteln. Dieser Vorgang kann durch im einzelnen noch zu entwickelnde Kriterien erleichtert werden. Beispiele sind die Bedeutung einer Norm für das Verfahren oder der Stellenwert einer Vorschrift in ihrem Regelungszusammenhang ${ }^{80}$. Auch kann der normativ intendierte Schutz von Drittinteressen, die zwar keine Zustimmungsbedürftigkeit der Betroffenen nach $₫ 58$ Abs. $1 \mathrm{VwVfG}$ auslösen, aber so wichtig sind, daß sie auch im Verwaltungsvertrag nicht unbeachtet bleiben dürfen ${ }^{81}$, für ein gesetzliches Verbot sprechen.

Die als Abwägungsprozeß strukturierte Anwendung des $\$ 134$ BGB wird nicht ohne Restbestände an Rechtsunsicherheit auskommen. Das mag man bedauern oder als Chance flexibler Problemlösung begrüBen. Jedenfalls ist das Phänomen der „Abwägung“ kein Spezifikum des Vertragsrechts.

\section{Rechtsstellung nach Vertragsschlu $\beta$}

\section{Bindung wirksamer Verträge}

Die gesetzgeberische Entscheidung zugunsten relativer Fehlerresistenz des Verwaltungsvertrages würde desavouiert, wenn sich die

${ }^{79}$ BGH v. 22. 5. 1978, BGHZ 71, S. 358 (360), allerdings mit dem Hinweis auf die Unentbehrlichkeit der teleologischen Interpretation im Einzelfall.

so Schmidt-Aßmann, in: Fschr.f. Gelzer (Fn. 5), S. 117 (126); vgl. auch Efstration, Bestandskraft (Fn. 28), S. 233.

81 Anschaulich BVerwG v. 23. 8. 1991, NJW 1992, S. 1642 (1643 f.). 
Verwaltung vom rechtswidrigen, aber gleichwohl wirksamen Vertrag ohne weiteres lösen ${ }^{82}$, die Erfüllung des vertraglich Geschuldeten verweigern ${ }^{83}$ oder die vertragsgemäß erbrachte Leistung zurücknehmen dürfte. Aus entwicklungsgeschichtlicher Sicht hat der Gesetzgeber den Verwaltungsvertrag aufgewertet und ihn rechtsdogmatisch dem Verwaltungsakt angenähert. Dem Verwaltungsakt ähnlich konkretisiert und individualisiert er „auf der Grundlage und in Grenzen des Gesetzes" die Rechtslage ${ }^{84}$. Seine gesetzgeberisch intendierte Funktion besteht darin, rechtsverbindlich festzulegen, was im Einzelfall „Rechtens sein soll“85. Der Rechtsquellencharakter, der dem Verwaltungsvertrag damit zukommt, führt dazu, daß er für die rechtliche Bewertung der auf seiner Grundlage erfolgten Handlungen und Entscheidungen maßgeblich ist. Der vertragswidrig erlassene Verwaltungsakt ist damit rechtswidrig, der vertragsgemäße hingegen rechtmäßig selbst dann, wenn er gegen Rechtsnormen verstößt, die die Wirksamkeit des Vertrages unberührt gelassen haben.

Diese Rechtsauffassung ist nicht unbestritten ${ }^{86}$, wird aber eher zunehmend geteil ${ }^{87}$. Der rechtsstaatlich motivierten Kritik $^{88}$ sei entgegengehalten, daß qualifizierte Rechtsverstöße diese Rechtsfolge nicht auszulösen vermögen, die Relativierung von Rechtsfehlern kein singuläres Phänomen ist und auch der rechtswidrige Verwaltungsakt

${ }^{82}$ Vgl. dazu Blankenagel, VerwArch. 76 (1985), S. 276 (292 ff.), der bei rechtswidrigen, aber nicht nichtigen Verträgen ein Rücktrittsrecht nach $₫ 62 \mathrm{VwVfG}$ i.V.m. $\$ \$ 346 \mathrm{ff}$. BGB annimmt.

${ }^{83}$ So für sog. „Zusageverträge“ Bullinger, Leistungsstörungen beim öffentlichrechtlichen Vertrag, DÖV 1977, S.812 (815), der dem Verwaltungsträger die Möglichkeit geben will, die Erfüllung eines rechtswidrigen, aber wirksamen Vertrages zu verweigern und den Vertrauensschaden des privaten Vertragspartners in Geld auszugleichen.

${ }^{84}$ P. Kirchbof, Mittel staatlichen Handelns, in: Isensee/Kirchhof, Handbuch des Staatsrechts der Bundesrepublik Deutschland, Bd. III, 1988, $\$ 59$ Rdn. 152 (S. 184).

${ }^{85}$ O. Mayer, Deutsches Verwaltungsrecht, Bd.I, 3. Aufl. 1924, S. 93 für den Verwaltungsakt.

${ }_{86} \mathrm{Vgl}$ z. B. Henke, Allgemeine Fragen des öffentlichen Vertragsrechts, JZ 1984, S. 441 (445); Maurer, in: Hill (Fn. 2), S. 15 (27) = DVBl. 1989, S. 798 (803).

87 Im Ergebnis ebenso z. B. Erichsen, in: Erichsen/Martens (Fn. 27), $\$ 27$ Rdn. 8, 25 (S. 372, 382); Fluck, Die Erfüllung des öffentlich-rechtlichen Verpflichtungsvertrages durch Verwaltungsakt, 1985, S.65; Meyer, in: Meyer/Borgs (Fn. 39), $\$ 54$ Rdn. 3; Knuth, Konkurrentenklage gegen einen offentlichrechtlichen Subventionsvertrag - OVG Münster, NVwZ 1984, 522, JuS 1986, S. 523 (524); Kunig, DVBl. 1992, S. 1193 (1200).

${ }_{88}$ Maurer, Abgestufte Rechtsfolgen bei Gesetzesverstößen der Verwaltung?, in: Hill, Zustand und Perspektiven der Gesetzgebung, 1989, S. 233 (248): „...m. E. rechtsstaatlich nicht mehr haltbar". 
aus unterschiedlichen Gründen unaufhebbar und damit maßgeblicher Bewertungsmaßstab für das auf seiner Grundlage Geleistete bleiben kann.

\section{Anpassung an veränderte Umstände}

Dem wirksamen Verwaltungsvertrag eignet - wie jeder rechtlichen Regelung - eine gewisse Statik. Sie ist prinzipiell wegen der Verläßlichkeit des einverständlich als rechtsverbindlich Gewollten unentbehrlich. Bei auf Dauer angelegten Rechtsbeziehungen kann die Starrheit der Regelung aber zum Problem werden. Seit der „Augenblicksaufnahme" des Vertragsschlusses können sich die tatsächlichen oder rechtlichen Verhältnisse, oder auch deren Einschätzung durch die Vertragsparteien, geändert haben. Folge einer solchen Änderung kann sein, daß auf der Basis der bisherigen Regelung die Erreichung der Vertragszwecke gefährdet oder ausgeschlossen ist, der im Vertrag abgestimmte Interessenausgleich in eine Schieflage gerät oder öffentliche Interessen bedroht erscheinen.

Der so mögliche Anpassungsbedarf ist bekanntlich weder ein spezifisches noch neues Problem des Verwaltungsvertrags. Seine Behandlung hat insbesondere in der Zivilrechtslehre eine weit zurückreichende Tradition ${ }^{89}$. Das verleiht der Einschätzung eines zivilrechtlichen Kollegen besonderes Gewicht, nach der die Vertragsparteien „zuerst berufen (sind), Anpassungsprobleme im Vertrag präventiv zu lösen und zwar unterhalb der hohen Eingreifschwellen gesetzlicher

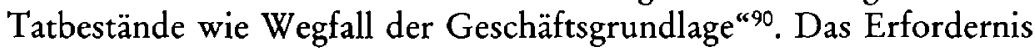
einer verwaltungsvertraglichen Kautelarjurisprudenz muß daher besonders betont werden.

Die soeben zitierte Mahnung ist um so ernster zu nehmen, als mit den Lehren von der clausula rebus sic stantibus und vom Wegfall der Geschäftsgrundlage ${ }^{91}$, in welcher Verbindung auch immer, für die Rechtspraxis alles andere als abgeklärte und dogmatisch griffige Instrumente zur Verfügung stehen. Die schon lange vor Erlaß der

${ }^{89}$ Ein knapper Abriß der geschichtlichen Entwicklung findet sich bei Stern, Die clausula rebus sic stantibus im Verwaltungsrecht, in: Fschr. f. Mikat, 1989, S. 775 ff. m.w. N. Zur Entwicklung im öffentlichen Recht vgl. auch Efstratiou, Bestandskraft (Fn. 28), S. $291 \mathrm{ff}$. Vgl. auch Tober, Die „clausula rebus sic stantibus“ bei verwaltungsrechtlichen Verträgen, 1970.

${ }^{90}$ Horn, Vertragsbindung unter veränderten Umständen, NJW 1985, S. 1118 (1119).

${ }^{91} \mathrm{Zu}$ ihrer Unterscheidung Stern (Fn. 89), S. 775 ff.; für das Staatsvertragsrecht vgl. BVerfG v. 30.1.1973, BVerfGE 34, S. 216 (229f.). 
Verwaltungsverfahrensgesetze bestehende Einigkeit über ihre Geltung auch im öffentlichen Recht bewegt sich auf einem Abstraktionsniveau $^{92}$, das ihre praktische Umsetzung zu einem unsicheren Geschäft werden läßt. Angesichts der in der Zivilrechtslehre ebenso alten wie noch nicht beendeten Auseinandersetzung in Grundsatz- wie in Einzelfragen ${ }^{93}$ ist dies kein überraschender Befund und begründet die Vermutung, daß die gesetzliche Positivierung die Probleme noch nicht abschließend geklärt hat.

In $₫ 60 \mathrm{VwVfG}$ kommt die im öffentlichen Recht hinzutretende Schwierigkeit zum Ausdruck, wie die Ungleichheit der Vertragspartner des Verwaltungsvertrages bei der Umsetzung der clausula-Lehren vom Zivilrecht in das Verwaltungsvertragsrecht zu berücksichtigen ist $^{94}$. Sie wird in der unsicheren Einschätzung des $\$ 60$ Abs. 1 Satz 2 VwVfG sichtbar. Nach dieser Vorschrift hat die Behörde ein besonderes Kündigungsrecht, „um schwere Nachteile für das Gemeinwohl zu verhüten oder zu beseitigen". Es ist umstritten, ob die Norm die Lehre von der „erweiterten Anwendung“ des „clausula“-Grundsatzes umsetzen will ${ }^{95}$ oder gegenüber der Regelung des $\$ 60$ Abs. 1 Satz 1 VwVfG - also dem "clausula"-Grundsatz - eigenständigen Charakter besitzt ${ }^{96}$. Zur Entzerrung der dogmatischen Probleme ${ }^{97}$ sollte man letzterer Auffassung folgen und in der Regelung des $\$ 60$ Abs. 1 Satz 2 $\mathrm{VwVfG}$ eines der öffentlich-rechtlichen Spezifika sehen, die das ganze Verwaltungsvertragsrecht charakterisieren. Die Ungleichstellung der Vertragsparteien und die Uneigennützigkeit des behördlichen Vertragsschlusses drücken sich in der Befugnis des Verwaltungsträgers aus, in Sonderfällen zugunsten des öffentlichen Interesses einseitig in die vertragliche Regelung einzugreifen. Als Eingriff ist der Einsatz

$92 \mathrm{Vgl}$. den ausführlichen Literaturbericht bei Efstratiou, Bestandskraft (Fn. 28), S. $310 \mathrm{ff}$.

93 Dazu Schmidt, in: Staudinger, BGB, 12. Aufl. 1983, \$242 Rdn. 833 ff.; Roth, in: Münchener Kommentar zum Bürgerlichen Gesetzbuch, Bd.II, 2. Aufl. 1985, $\$ 242 \mathrm{Rdn} .465 \mathrm{ff}$.

94 Dazu etwa Fiedler, Zum Wirkungsbereich der clausula rebus sic stantibus im Verwaltungsrecht, VerwArch. 67 (1976), S. 125 (144ff.).

95 Bonk, in: Stelkens/Bonk/Leonhardt (Fn. 32), \$60 Rdn. 19; Bullinger, DÖV 1977, S. 812 (821): „Sonderfall der clausula rebus sic stantibus“.

96 Meyer, in: Meyer/Borgs (Fn. 39), $\$ 60$ Rdn. 19; Kawalla, Verwaltungsvertrag (Fn. 34), S. 143; Kokott, Entschädigungsfragen bei der Ausübung des einseitigen Kündigungsrechts der Behörde beim öffentlich-rechtlichen Vertrag ( $\$ 60$ Abs. 1 Satz 2 VwVfG), VerwArch. 83 (1992), S. 503 (508 f.) m. w. N. zum Meinungsstand.

${ }^{7} \mathrm{Vgl}$. auch Efstratiou, Bestandskraft (Fn.28), S. 346 und auch schon Fiedler, VerwArch. 67 (1976), S. 125 (144ff.). 
dieses Instruments an die Restriktionen des Übermaßverbotes gebunden $^{98}$ und kann Entschädigungsansprüche auslösen, die analog zur entsprechenden Regelung beim Widerruf von begünstigenden Verwaltungsakten ( $\$ 49 \mathrm{Abs.} 5 \mathrm{VwVfG}$ ) zu begründen sind 9 .

\section{Annäberung des zivilrechtlichen und öffentlich-rechtlichen Verwaltungsvertrages}

\section{Verwaltungsprivatrecht}

Das hier vorgebrachte Anliegen einer rechtsdogmatischen Annäherung von zivilrechtlichem und öffentlich-rechtlichem Verwaltungsvertrag ist keine völlig neue Erfindung, sondern eine Fortführung des Grundgedankens, der der Lehre vom Verwaltungsprivatrecht zugrunde liegt. Aus Münster kommend zitiere ich gerne einen ihrer Gründungsväter ${ }^{100}$, Hans Julius Wolff. Er schrieb 1956 in der ersten Auflage seines Lehrbuchs: „Geht ein Subjekt öffentlicher Verwaltung Privatrechtsverhältnisse ... ein, um in privatrechtlichen Formen ... unmittelbar öffentliche Verwaltungs- (...) Zwecke zu verfolgen, so gilt ein Verwaltungsprivatrecht, dessen Besonderheit u.a. darin besteht, daß die Träger der Verwaltung ... etlichen öffentlich-rechtlichen Bindungen unterliegen "101. Diese Lehre ist in der Vergangenheit viel, und häufig zu Recht, kritisiert worden ${ }^{102}$. Insbesondere trifft die Kritik, die darauf abhebt, daß es „im Bereich nicht obrigkeitlicher staatlicher Tätigkeit ... keine per se öffentlichen Aufgaben oder

${ }_{98}$ Meyer, in: Meyer/Borgs (Fn. 39), $\$ 60$ Rdn. 19.

99 Kopp, VwVfG (Fn. 32), $\$ 60$ Rdn. 19; Maurer, Allg. VwR (Fn. 27), $\$ 14$ Rdn. 54 (S.356); Meyer, in: Meyer/Borgs (Fn. 39), \$60 Rdn. 23; Kawalla, Verwaltungsvertrag (Fn. 34), S. 147; Littbarski, Der Wegfall der Geschäftsgrundlage im öfentlichen Recht. Zugleich ein Beitrag zur Auslegung des $₫ 60$ Abs. 1 VwVfG, 1982, S. 57. A. A. Kokott, VerwArch. 83 (1992), S. 503 (513 ff.), die $₫ 60$ Abs. 1 Satz 2 VwVfG mangels ausdrücklicher Entschädigungsregelung wegen Verstoßes gegen die Junktimklausel des Art. 14 Abs. 3 Satz 2 GG für nichtig hält.

${ }_{100}$ Als weiterer Gründer gilt Siebert, in: Fschr. f. Niedermeyer (Fn. 33), S. $215 \mathrm{ff}$.

101 Verwaltungsrecht I, 1956, $\$ 23$ I (S.73), fast ebenso noch in: Wolff/Bachof, Verwaltungsrecht I, 9. Aufl. 1974, $\$ 23$ I (S. 108).

102 Z. B. Erichsen, in: Erichsen/Martens (Fn. 27), $\$ 32$ Rdn. 3 (S. 408); Rüfner, Formen öffentlicher Verwaltung im Bereich der Wirtschaft, 1967, S.389f., 397; Zuleeg, Dic Anwendungsbereiche des öffentlichen Rechts und des Privatrechts, VerwArch. 73 (1982), S. 384 (397); Emmerich, Die Fiskalgeltung der Grundrechte, namentlich bei erwerbswirtschaftlicher Betätigung der öffentlichen Hand BGHZ 52, 352 und BGH, Betr. 1969, 1791, JuS 1970, S. 332 (335). 
Verwaltungszwecke gibt“103. Der Begriff der „unmittelbaren Wahrnehmung öffentlicher Aufgaben" ist zu diffus, um ein tauglicher rechtlicher Anknüpfungspunkt für öffentlich-rechtliche Bindungen zu sein. Gleichwohl bleibt das Anliegen der Lehre, den Staat auch bei privatrechtlicher Aufgabenerfüllung öffentlich-rechtlich zu disziplinieren, unvermindert berechtigt.

Es kann dergestalt aufgegriffen werden, daß die Lehre vom Verwaltungsprivatrecht von ihrer „Aufgabenorientierung" auf eine „Normorientierung " umgestellt wird. Die jeweilige Rechtsnorm selbst entscheidet über ihren Anwendungsbereich und ist daraufhin zu untersuchen, ob sie ihre Anwendung von der Rechtsform des Verwaltungshandelns abhängig macht. Das ist vielfach, wie etwa bei den Grundrechten ${ }^{104}$, nicht der Fall. Umgekehrt erlauben auch nicht alle Privatrechtsnormen eine „Flucht aus dem Privatrecht", sind also auch bei öffentlich-rechrlichem Vertragshandeln anzuwenden ${ }^{105}$.

Ausweislich ihrer Eingangsbestimmungen ${ }^{106}$ sind die Vorschriften der Verwaltungsverfahrensgesetze unmittelbar nur auf die „öffentlichrechtliche Verwaltungstätigkeit der Behörden“ anwendbar. Sie gelten also rechtsformabhängig. Es wurde aber schon darauf hingewiesen, daß z. B. das "Angemessenheits-“ und das „Sachzusammenhangsgebot" des $\$ 56$ Abs. 1 VwVfG durch bundesrechtliche Grundsätze vorgeprägt sind, die - wie in diesem Fall das Übermaßverbot und das Koppelungsverbot - rechtsformunabhängig gelten ${ }^{107}$. Die analoge Anwendung wesentlicher Verfahrensbestimmungen der Verwaltungs-

${ }^{103}$ Erichsen, in: Erichsen/Martens (Fn. 27), $\$ 32$ Rdn. 3 (S. 408); vgl. auch Rüfner, Formen (Fn. 102), S. 397.

104 Zur „Fiskalgeltung der Grundrechte“ vgl. Eblers, Privatrechtsform (Fn. 42), S. 212 ff.; Jarass, in: Jarass/Pieroth, GG, 2. Aufl. 1992, Art. 1 Rdn. 18; Hesse, Grundzüge des Verfassungsrechts der Bundesrepublik Deutschland, 18. Aufl. 1991, $\$ 11$ I Rdn. 348 (S. 146); Erichsen, in: Erichsen/Martens (Fn. 27), $\$ 32$ Rdn. 4 (S. 409).

105 Hier ist manches noch ungeklärt. Zur Anwendbarkeit des AGB-Gesetzes auf öffentlich-rechtliche Verträge vgl. OVG Münster v. 19. 8. 1988, NJW 1989, S. 1879 (1880); Stober, Zur Anwendung des AGB-Gesetzes auf die öffentliche Hand, DÖV 1977, S. 398 (399 f.); Schimpf, Vertrag (Fn. 34), S. 325 f.; Ehlers, Privatrechtsform (Fn. 42), S. 352 ff. Zur Bindung von Verwaltungsträgern an das Wettbewerbsrecht Pietzcker, Rechtsbindungen der Vergabe öffentlicher Aufträge, AöR 107 (1982), S. 61 (74ff.); Scholz, Wettbewerbsrechtliche Klagen gegen Hoheitsträger: Ziviloder Verwaltungsrechtsweg?, NJW 1978, S. 16 (17); Emmerich, JuS 1970, S. 332 (336f.); Ehlers, Privatrechtsform (Fn. 42), S. 361 ff. m. N.

106 \$1 I VwVfG-Bund; \$1 I VwVfG NW; \$1 I SGB X.

107 Das folgt für das Übermaßverbot aus der grundrechtlichen Fundierung, vgl. Krebs, in: v. Münch/Kunig, GG, Bd. I, 4. Aufl. 1992, Art. 19 Rdn. 24. Im Hinblick auf das Koppelungsverbot vgl. oben unter B. Il. 1. (S. 266). 
verfahrensgesetze auf den Privatrechtsvertrag ist in der Vergangenheit ebenso diskutiert worden ${ }^{108}$ wie z.B. die Übertragung des Schriftformerfordernisses ( $\$ 57 \mathrm{VwVfG}$ ) auf bestimmte zivilrechtliche Verwaltungsverträge ${ }^{109}$. Soweit die Bestimmungen der Verwaltungsverfahrensgesetze Verfassungsgebote umsetzen, ist zumindest deren verfassungsrechtliche Grundaussage auch bei der Verwendung der Privatrechtsform für die Verwaltung verbindlich ${ }^{110}$. Zieht man eine Gesamtbilanz ${ }^{111}$, so steht der privatrechtliche dem öffentlich-rechtlichen Verwaltungsvertrag in den rechtsstaatlichen Standards näher, als man argwöhnen könnte.

\section{Dogma der Wablfreibeit}

Geht man von dieser Annahme aus, verliert der Streit um die Wablfreibeit der Verwaltung zwischen öffentlich-rechtlichen und privatrechtlichen Handlungsformen an Brisanz und das entsprechende Dogma den Charakter einer "Gretchenfrage“. An der Überzeugungskraft des Grundsatzes bestehen ohnehin Zweifel. Zwar soll nicht in Abrede gestellt werden, daß die Verwaltung die Wahl über den Vertragsgegenstand haben und damit auch zivilrechtliche Verträge schließen kann. Fraglich erscheint aber, ob ihr bei getroffener Wahl über den Vertragsgegenstand noch eine Entscheidung über die Rechtsform bleibt. Bei Lektüre der einschlägigen Entscheidungen der Gerichte fällt jedenfalls auf, daß diese gerade nicht danach fragen, wofür sich die Verwaltung denn „entschieden“ habe, sondern danach, ob der gewählte Vertragsgegenstand öffentlich- oder privatrechtlich ist $^{112}$. Wenn aber die Rechtsnatur eines Vertrages objektiv, d.h.

108 Von Zezschwitz, Rechtsstaatliche und prozessuale Probleme des Verwaltungsprivatrechts, NJW 1983, S. 1873 (1881).

109 Für städtebauliche Verträge Schmidt-Aßmann, in: Fschr. f. Gelzer (Fn. 5), S. 117 (128).

110 Krebs, in: Schmidt-Aßmann/Krebs (Fn. 64), S. 156 f. Zum Teil werden Verfahrensregelungen des VwVfG auch entweder als Ausdruck allgemeiner Rechtsgedanken oder im Analogieschluß auf den privatrechtlichen Vertragsabschluß übertragen, vgl. Ehlers, Privatrechtsform (Fn. 42), S.226. Als übertragbar werden von Eblers, DVBl.1983, S. 422 (425 ff.) die $\$ \$ 14,20,21,24,25,28,30,40 \mathrm{VwVfG}$ angesehen. Vgl. auch den Katalog bei von Zezschwitz, NJW 1983, S. 1873 (1881): $\$ \$ 16,20,21,24 \mathrm{II}, 25,28,29,30,51 \mathrm{VwVfG}$.

111 Krebs, in: Schmidt-Aßmann/Krebs (Fn. 64), S. $134 \mathrm{ff}$.

112 BVerwG v. 15.12.1989, BVerwGE 84, S. $236(238)=\mathrm{JZ} 1990$, S. $591 \mathrm{ff}$. m. Anm. Ehlers; BGH v. 25.6.1991, NJW 1992, S.1561 (1562); BGH v. 12.11.1991, DVBl. 1992, S.615ff.; OVG Münster v. 23.5.1990, NwVBl.1991, S.14; OVG Münster v. 19.8.1988, NJW 1989, S.1879; OVG Lüneburg v. 12. 1. 1988, NJW 1988, S.2126; OLG Hamm v. 28.9.1990, BauR 1991, S. 653 ff. 
unabhängig von den Vorstellungen der Vertragsparteien bestimmt wird $^{113}$, ist der Grundsatz der Wahlfreiheit zumindest relativiert.

Aus rechtspraktischer Sicht sollte er im Hinblick auf die Handlungsformen ohnehin nicht überschätzt werden, weil deren öffentlichrechtliche Bindung nicht zur Disposition steht. Bedeutsamer bleibt das Dogma im Hinblick auf die Organisationsformen, weil die Verwendung der Privatrechtsform hier z.B. manche Fessel des Haushaltsrechts lockern kann ${ }^{114}$. Das allerdings ist nicht mein Thema, und ich erwähne es nur, weil sich nach allgemeinem Dafürhalten Privatrechtssubjekte, außer im Fall der Beleihung, der öffentlich-rechtlichen Handlungsformen nur bei Vorliegen einer besonderen gesetzlichen Ermächtigung bedienen dürfen ${ }^{115}$. Da die Verwaltung auch in privatrechtlicher Organisationsform Verwaltung bleibt, ist der privatrechtliche Verwaltungsvertrag derzeit schon aus diesem Grund unentbehrlich.

\section{Bestimmung der Rechtsnatur}

Solange öffentlich-rechtliche und privatrechtliche Verwaltungsverträge denkbar sind, wird die Bestimmung der Rechtsnatur der Verwaltungsverträge ein Problem ${ }^{116}$ bleiben. Praktischer Beleg für diese These sind die vielen Judikate zu dieser Rechtsfrage - auch aus jüngster Vergangenheit ${ }^{117}$. Rechtsdogmatisch beruht sie auf der Überlegung, daß bei einem Dualismus der Rechtsformen und gleichzeitiger öffentlich-rechtlicher Bindung aller Verwaltungsverträge eine alle

${ }_{113}$ Scherzberg, JuS 1992, S. 205 (206); Maurer, Allg. VwR (Fn. 27), $\$ 14$ Rdn. 9 (S. 322).

114 Eblers, Privatrechtsform (Fn. 42), S. 309 ff.

115 Im Hinblick auf verwaltungsrechtliche Verträge vgl. schon Apelt, Der verwaltungsrechtliche Vertrag, 1920, S.53; aus neuerer Zeit z. B. Kopp, VwVfG (Fn. 32), \$54 Rdn. 10, 33; Möllgaard, in: Knack (Fn. 39), \$54 Rdn. 4.1; Erichsen, in: Erichsen/Martens (Fn. 27), $\$ 25$ Rdn. 9 (S.365). Vgl. auch Gern, Zur Möglichkeit öffentlich-rechtlicher Verträge zwischen Privaten, NJW 1979, S. 694 (695); Schimpf, Vertrag (Fn. 34), S. $71 \mathrm{ff}$.

116 Vgl. zu dieser Problematik z.B. Punke, Verwaltungshandeln (Fn.38), S. $26 \mathrm{ff}$;; Pestalozza, Formmißbrauch des Staates, 1973, S.180 ff.; Gern, Neue Aspekte der Abgrenzung des öffentlich-rechtlichen vom privatrechtlichen Vertrag, VerwArch. 70 (1979), S. $219 \mathrm{ff}$; Lange, Die Abgrenzung des öffentlichrechtlichen vom privatrechtlichen Vertrag, NVwZ 1983, S. 313 ff.; Christ, Die Verwaltung zwischen öffentlichem und privatem Recht - Erörtert am Beispiel von Realakt und Vertrag, 1984; Neumann, Dogmatische und prinzipiengeleitete Argumente bei der Abgrenzung von Verwaltungsverträgen, DÖV 1992, S. $154 \mathrm{ff}$.

117 Vgl. dazu die Nachw. Fn. 112. 
Zweifelsfälle erfassende, trennscharfe Abgrenzungsformel nicht gelingen kann. Die Frage nach der privatrechtlichen oder öffentlichrechtlichen Rechtsnatur des Vertrages zielt - materiell-rechtlich nicht auf eine „Entweder-Oder-Entscheidung“, sondern fragt nach dem quantitativen Ausmaß der öffentlich-rechtlichen Vorordnung des Vertrages. Sie ist also eine Frage der rechtlichen Bewertung. In Zweifelsfällen kommt es darauf an, ob das Wertungsmodell, das für die inhaltliche Beurteilung des Vertrages heranzuziehen ist, ausschlaggebend vom privaten oder vom öffentlichen Recht geprägt ist.

\section{Zur Leistungsfähigkeit einer Vertragstypologie}

Die Beschäftigung mit den allgemeinen Lehren des Vertragsrechts hat den bereits geäußerten Verdacht ihres hohen Abstraktionsniveaus nicht ausräumen können. Das rechtfertigt, den Gedanken einer dogmatischen Zwischenebene wieder aufzunehmen. Will man ihn umsetzen, wird man von den konkreten Fallgestaltungen der Vertragspraxis die Besonderheiten der jeweiligen Einsatzbereiche abstrahieren, sie also vertypen ${ }^{118}$. Die Kriterien dieses Abstraktionsverfahrens hängen vom Erkenntnisinteresse ab. Die nachfolgend zur Diskussion gestellte Typisierung ist von den eingangs angestellten Überlegungen geleitet. Es geht zum einen um die Abbildung der geschilderten Einsatzbreite und Funktionenvielfalt des Verwaltungsvertrages und den Versuch ihrer systematischen Erfassung. Zum anderen soll im Katalog der Vertragstypen zum Ausdruck kommen, daß im Verwaltungsvertrag das klassisch liberale Trennungsmodell von Staat und Gesellschaft zwar nicht aufgehoben ist, aber relativiert wird - weshalb dem Verwaltungsvertrag ja solange Skepsis entgegengeschlagen ist. Dieser Überschneidungsbereich ist breit und nuancenreich. Die Praxis der Verwaltungsorganisation ${ }^{119}$ macht diesen Befund augenfälliger als die der Handlungsformen; er findet seinen Ausdruck aber auch bei dem Gebrauch des Verwaltungsvertrages. Hält man sowohl die Funktionenvielfalt des Vertrages als auch die Nähe oder Ferne zur klassischen Hoheitsverwaltung für rechtsdogmatisch relevant,

${ }^{118}$ Das Erfordernis einer "Typologie“ des Verwaltungsvertrages betont auch Maurer, in: Hill (Fn. 2), S. 15 (24) = DVBl. 1989, S. 798 (802).

${ }^{119}$ Dazu Schuppert, Die Erfüllung öffentlicher Aufgaben durch verselbständigte Verwaltungseinheiten, 1981. Vgl. auch Krebs, Verwaltungsorganisation, in: Isensee/Kirchhof, Handbuch des Staatsrechts der Bundesrepublik Deutschland, Bd. III, 1988, $\$ 69$ Rdn. 5 ff. (S. 570 ff.). 
liegt es nahe, einen skalenartigen Katalog zu erstellen. Das erklärt folgende Reihung:

- (1.) Verträge im Rahmen erwerbswirtschaftlicher Betätigung

- (2.) Beschaffungs-/Privatisierungsverträge

- (3.) Verträge zur gemeinsamen Erfüllung öffentlicher Aufgaben („Kooperationsverträge“)

- (4.) Verträge zur Vorbereitung, Erleichterung und Ergänzung von Hoheitsakten

- (5.) Hoheitsaktersetzende Verträge

Der Katalog erhebt keinen Anspruch auf Vollständigkeit (er erfaßt z.B. nicht alle Vertragstypen der Leistungsverwaltung ${ }^{120}$ ), ist in sich möglicherweise weiter differenzierungsbedürftig (z. B. bei den „Kooperationsverträgen“), reicht aber, um das vorgebrachte Anliegen zu verdeutlichen.

Eine Vertragstypologie erfüllt zunächst heuristische Funktionen, dient also der Problemsensibilisierung, der Relativierung von Problemen und der Vorbereitung von Problemlösungen. So wird zum Beispiel deutlich, daß der Geltungsumfang des allgemeinen Vertragsrechts in seinem Randbereich fraglich wird, bzw. daß die allgemeinen Lehren die Verträge im Rahmen erwerbswirtschaftlicher Betätigung bislang nur begrenzt erreichen. Weiterhin wird angesichts der so vergegenwärtigten Bandbreite des Vertragshandelns die Diskussion darüber, ob denn nun der Verwaltungsakt oder der Vertrag das geeignetere Handlungsinstrument der Verwaltung sei, erheblich relativiert. Und schließlich wird die These, daß die Grenzlinie, die die Unterscheidung von öffentlichem und privatem Recht markiert, keine problemadäquate Rechtfertigung für eine dieser Linie entsprechende Trennung unterschiedlicher Vertragsdogmatiken abgibt, eher bekräftigt als abgeschwächt.

Der heuristischen Funktion der Typologie schadet es im übrigen nicht, wenn einzelne Verträge mehrfach subsumtionsfähig sind. Die genannten Typen haben nicht die Trennschärfe von Rechtsbegriffen. Dies wäre nur bei Steigerung des Abstraktionsgrades zu erreichen. Gleichwohl erfüllt eine Vertragstypologie auch die rechtsdogmatische

120 Vgl. Fleiner-Gerster, Rechtsverhältnisse in der Leistungsverwaltung, VVDStRL 45 (1987), S. 152 (160 ff.): „Typologische Unterschiede der Rechtsverhältnisse der Leistungsverwaltung “; dens., Probleme des öffentlichrechtlichen Vertrages in der Leistungsverwaltung, ZBl. 1989, S. 185 (189ff.) - überarbeitete Fassung des zuvor zitierten Berichts. 
Mittlerfunktion, von der schon die Rede war ${ }^{121}$. Das soll - abschließend - an zwei Anwendungsfällen aufgezeigt werden.

Das allgemeine Vertragsrecht formuliert die Voraussetzung für das besondere Kündigungsrecht des Verwaltungsträgers sehr vage, wenn es die Verhütung oder Beseitigung schwerer Nachteile für das Gemeinwohl verlangt ( $\$ 60$ Abs. 1 S. 2 VwVfG; $\$ 59$ Abs. 1 S. 2 SGB X). $\$ 110$ Abs. 1 i. V. m. $\$ 109$ Abs. 3 SGB V fordern demgegenüber ganz konkret für die Kündigung von Versorgungsverträgen mit Krankenhäusern u. a., daß keine Gewähr mehr für eine leistungsfähige und wirtschaftliche Krankenhausbehandlung geboten wird. Diese Voraussetzung abstrahierend und den Grundsatz des allgemeinen Vertragsrechts konkretisierend ${ }^{122}$ wäre für die Kündigung von Verträgen zur gemeinsamen Erfüllung öffentlicher Aufgaben die Bedeutung dieser Aufgabe für die Allgemeinheit und das Ausmaß der Gefährdung ihrer Wahrnehmung ausschlaggebend.

Der Vertragstyp „Beschaffungs- und Privatisierungsvertrag“ vergegenwärtigt ein besonderes Schutzbedürfnis für konkurrierende Dritte, die nicht den Zuschlag erhalten. Ein repressiver, nach Vertragsschluß einsetzender Schutz wird der wirtschaftlichen Situation häufig nicht gerecht werden. Von daher läßt sich auch für diesen Vertragstyp verallgemeinernd die Notwendigkeit eines besonderen Verfahrensschutzes feststellen. Dieser Notwendigkeit werden die Grundsätze des allgemeinen Vertragsrechts kaum gerecht werden können, und es wäre zu prüfen, ob und für welche Fallgestaltungen die Vorschriften z. B. des Haushaltsrechts ${ }^{123}$ oder EG-Rechts ${ }^{124}$ verallgemeinerungsfähige Verfahrensstandards enthalten.

Mit dieser Überlegung ist aber schon darauf hingewiesen, daß die Leistungsfähigkeit einer dogmatischen „Zwischenebene“ und damit auch die der allgemeinen Vertragslehren nicht zuletzt auf den Ertrag der Vertragsdogmatik der jeweiligen Einzelbereiche angewiesen ist.

121 Vgl. oben unter A. II. 4 (S.259 f.).

122 Vgl. schon Fiedler, VerwArch.67 (1976), S. 125 (151): „»Öffentliches Interesse « ist weiter zu konkretisieren nach dem jeweiligen Vertragstypus und seiner Funktion innerhalb eines jeweils verschiedenen Sach- und Rechtszusammenhangs" (Hervorhebung im Original).

${ }^{123}$ Pietzcker, AöR 107 (1982), S. 61 (insbes. S. 80 ff.).

124 Vgl. dazu Pietzcker, AöR 107 (1982), S. 61 (64ff.); Schmittmann, Die EGRechtsmittelrichtlinie zur Vergabe öffentlicher Liefer- und Bauaufträge, EuZW 1990, S. $536 \mathrm{ff}$. 


\section{Schlußbemerkung}

Diese letzte Bemerkung sollte nun aber keineswegs dahingehend fehlverstanden werden, der Verwaltungsvertrag sei rechtsdogmatisch völlig unausgereift. Im Gegenteil: Die Annahme, er bedürfe nun der vermehrten dogmatischen Feinarbeit „im Besonderen“, schließt die Annahme eines gewissen Reifegrades „im Allgemeinen“ ein. In seinem Jubiläumsjahr präsentiert sich der Verwaltungsvertrag insgesamt in einem Zustand, der ihm schönste Aussichten ${ }^{125}$ für seine weitere Entwicklung verspricht.

125 Pessimistisch für die Schweiz Richli, ZBl. 1991, S. 381 (399): „Der öffentlichrechtliche Vertrag wird in näherer Zukunft schwerlich einen Platz an der Sonne erringen." 
Leitsätze des 2. Berichterstatters über:

\section{Verträge und Absprachen zwischen der Verwaltung und Privaten}

1. Terminologische Vorbemerkung: Der Begriff des „Verwaltungsvertrages" umfaßt nachfolgend sowohl die öffentlich-rechtlichen als auch die privatrechtlichen Verträge zwischen Verwaltung und Privaten.

A. Vorüberlegungen für eine Dogmatik des Verwaltungsvertrages

I. Bedeutung des Verwaltungsvertrages

2. Die Verwendung des Verwaltungsvertrages in der Verwaltungspraxis zeigt seine Einsatzbreite und Funktionenvielfalt. In vielen Rechtsgebieten ist er ein selbstverständliches Handlungsinstrument der Verwaltung geworden. Er bewährt sich insbesondere zur Bewältigung komplexer Problemlagen. Im Verbältnis zum einseitig-hoheitlichen Verwaltungsinstrumentarium hat er eine Ergänzungs- und Ersatzfunktion.

3. Der durch die Verwaltungspraxis vermittelte Eindruck zunehmender Verwendung des Verwaltungsvertrages wird durch die theoretische Diskussion um die staatliche Systemsteuerung bestätigt. Sie hat die Ergänzungsbedürftigkeit des einseitigen Staatshandelns durch Handlungsformen des "kooperativen Staates" aufgezeigt.

4. Mit dem Verwaltungsvertrag als Ausdruck des Einverständnisses von Verwaltung und Bürger kann die Akzeptanz von Verwaltungsentscheidungen verbessert werden. Die eigentliche Bedeutung des Verwaltungsvertrages liegt aber nicht in der Alternative zum imperativen Befehl, sondern in den durch ibn gesteigerten Handlungsmöglichkeiten der Verwaltung.

5. Der Verwaltungsvertrag verbindet das Beziehungsgefüge der konsensualen mit dem der rechtsförmlichen und rechtsverbindlichen Verwaltungshandlungen. Das unterstreicht die Notwendigkeit einer leistungsfähigen Vertragsdogmatik. 


\section{Aufgaben der Dogmatik des Verwaltungsvertrages}

6. Der Verwaltungsvertrag ist zum einen dadurch gekennzeichnet, daß der Staat mit ibm seine Aufgaben erfüllt, und zum anderen dadurch, daß sich die Rechtsstellungen beider Vertragsparteien grundsätzlich voneinander unterscheiden. Beide Gesichtspunkte sprechen dafür, den Verwaltungsvertrag vom Parallelinstitut des Zivilrechts zu emanzipieren und zum genuinen Institut des Verwaltungsrechts auszuformen.

7. In ihrer rechtsdogmatischen Grundstruktur sind öfentlich-rechtlicher und privatrechtlicher Verwaltungsvertrag gleich. Sie sind daber in dem Sinne einander rechtsdogmatisch anzunähern, daß für sie dieselben rechtsstaatlichen Standards gelten.

8. Der Vertragsschluß ist der rechtsförmliche Ausschnitt aus einem prozeßhaft verlaufenden Geschehen. Die Dogmatik des Verwaltungsvertrages sollte daher prozedural konzipiert werden, um seine öffentlich-rechtlichen Spezifika "phasenspezifisch" $z$ u analysieren.

9. Angesichts des großen Abstraktionsgefälles zwischen den allgemeinen Lebren und den besonderen Einsatzfeldern des Verwaltungsvertrages bedarf es "dogmatischer Zwischenebenen", die den Austausch zwischen allgemeiner und Bereichsdogmatik des Verwaltungsvertragsrechts ermöglichen.

\section{B. Rechtsfragen einer allgemeinen Vertragsdogmatik}

\section{Verfabren vor Vertragsschlu $\beta$}

10. Die Verwaltungsverfahrensgesetze stellen die verfahrensrechtlichen Schutzbestimmungen, die für den Erlaß eines Verwaltungsaktes gelten, auch für das Verfabren zur Verfügung, das in den Abschluß eines verwaltungsrechtlichen Vertrages mündet. Der Verfabrensschutz des Dritten muß zumindest seiner materiell-rechtlichen Rechtsstellung entsprechen.

11. Ein allgemeines, rechtliches Subsidiaritätsprinzip zugunsten des Verwaltungsvertrages läßt sich nicht begründen. In Einzelfällen kann ein Vorrang des Vertragshandelns aber normativ angeordnet sein.

\section{Vertragsschluß}

12. Die den rechtlichen Entscheidungsrahmen für das Vertragshandeln bildenden Restriktionen lassen sich im wesentlichen in vier Gruppen einteilen und daraufbin befragen, welche Entscheidungsspielräume sie der Verwaltung lassen. Es sind Vertragsformverbote, Not- 
wendigkeiten gesetzlicher Ermäcbtigung, Maßgaben der $\iint 54 f f$. $V w V f G$ und fachgesetzliche Vorgaben.

13. Vertragsformverbote und der Gesetzesvorbehalt lähmen Vertragsinitiativen der Verwaltung nur ausnabmsweise. Die Maßgaben der $\iint 54 f f$. VwVfG bedürfen z.T. der Konkretisierung durch das Fachgesetz, das wesentlich über die Einsatzmöglichkeiten des Verwaltungsvertrages entscheidet.

14. Der offene Tatbestand des ( 599 Abs. 1 VwVfG i.V.m.) $\$ 134$ $B G B$ ist durch eine Abwägung zwischen den normgeschützten Interessen und dem Bestandsinteresse am Vertrag zu konkretisieren. Dieser Abwägungsvorgang ist durch einen noch $z u$ entwickelnden Kriterienkatalog zu stabilisieren.

\section{Rechtsstellung nach Vertragsschluß}

15. Die von den Verwaltungsverfabrensgesetzen intendierte Funktion des Verwaltungsvertrages besteht darin, rechtsverbindlich festzulegen, was im Einzelfall „Rechtens sein soll ${ }^{\star}$. Die rechtliche Beurteilung eines vertraglich geschuldeten Verwaltungsakts richtet sich daber nach den Maßgaben des wirksamen Vertrages.

16. Rechtliche oder tatsächliche Veränderungen nach Vertragsschluß können für den Verwaltungsvertrag einen Anpassungsbedarf begründen. Ihm ist in erster Linie präventiv durch Vertragsgestaltung Rechnung zu tragen.

17. Die gesetzliche Anpassungsregelung des $\$ 60$ Abs. 1 VwVfG leidet unter der rechtsdogmatischen Unsicherbeit über die Lebren von der clausula rebus sic stantibus und vom Wegfall der Geschäftsgrundlage. Das besondere Kündigungsrecht des Verwaltungsträgers in $\mathbb{1} 60$ Abs. 1 S. 2 VwVfG ist kein Unterfall des "clausula-Grundsatzes", sondern hat rechtsdogmatisch eigenständigen Charakter.

\section{Annäherung des zivilrechtlichen und öffentlich-rechtlichen Verwaltungsvertrages}

18. Die Annabme der rechtsdogmatischen Annäherung von öffentlich-rechtlichen und privatrechtlichen Verwaltungsverträgen nimmt das Anliegen auf, das der Lebre vom Verwaltungsprivatrecht zugrunde liegt. Diese Lehre ist allerdings von ibrer „Aufgabenorientierung "auf eine "Normorientierung" umzustellen. Soweit die rechtsformabhängigen Maßgaben der Verwaltungsverfabrensgesetze Verfassungsgebote konkretisieren, ist zumindest deren verfassungsrechtlicher Normgehalt auch für den privatrechtlichen Verwaltungsvertrag verbindlich. 
19. Bei rechtsdogmatischer Annäherung von öffentlich-rechtlichen und privatrecbtlichen Verwaltungsverträgen verliert das Dogma der Formenwablfreiheit der Verwaltung materiell-rechtlich an Bedeutung. Es wird obnehin relativiert, wenn die Rechtsnatur des Verwaltungsvertrages von seinem Gegenstand ber, also objektiv, beurteilt wird.

20. Bei Dualismus der Handlungsformen und gleichzeitiger öffentlich-rechtlicher Bindung aller Verwaltungsverträge ist die Bestimmung der Rechtsnatur des Vertrages eine Wertungsfrage, so daß eine trennscharfe Abgrenzungsformel nicht gelingen kann. In Zweifelsfällen kommt es darauf an, ob das für den Vertrag maßgebliche normative Wertungsmodell ausschlaggebend vom privaten oder öffentlichen Recht geprägt ist.

\section{Zur Leistungsfäbigkeit einer Vertragstypologie}

21. Zur Schaffung einer "dogmatischen Zwischenebene" (Leitsatz 9) bietet sich die Bildung einer Vertragstypologie an.

22. Mit einem Katalog von Vertragstypen kann der Versuch unternommen werden, die Einsatzbreite und Funktionenvielfalt des Verwaltungsvertrages zu erfassen. Will man gleichzeitig die Verwendung des Verwaltungsvertrages im Überschneidungsbereich von Staat und Gesellschaft verdeutlichen, ergibt sich eine skalenartige Reibung (ohne Anspruch auf Vollständigkeit):

- (1.) Verträge im Rabmen erwerbswirtschaftlicher Betätigung

- (2.) Beschaffungs-/Privatisierungsverträge

- (3.) Verträge zur gemeinsamen Erfüllung öffentlicher Aufgaben („Kooperationsverträge“)

- (4.) Verträge zur Vorbereitung, Erleichterung und Ergänzung von Hobeitsakten

- (5.) Hobeitsaktersetzende Verträge

23. Eine Vertragstypologie kann nicht nur heuristische Funktionen, sondern auch "rechtsdogmatische Mittlerfunktionen" erfüllen. Abstrakte Aussagen des allgemeinen Vertragsrechts können sektoral konkretisiert, konkrete Regeln des Einzeleinsatzes des Vertrages können für einen Vertragstyp verallgemeinert werden. 


\title{
Verträge und Absprachen zwischen der Verwaltung und Privaten in Frankreich
}

\author{
3 a. Landesbericht von Prof. Dr. Christian J. Autexier, Saarbrücken
}

Für die französische Rechtswissenschaft stellt sich weniger die Frage, ob und inwieweit die Verwaltung, anstelle einseitig-hoheitlichen Handelns, mit Privaten paktieren darf oder soll', als die Frage nach der Behandlung solcher Pakte durch die Verwaltungsgerichtsbarkeit ${ }^{2}$.

1 Es entspricht allgemeiner Ansicht, daß die Vielfalt der Institute des französischen Verwaltungsrechts, die mit dem Beiwort „vertraglich“ oder „vereinbarungs-

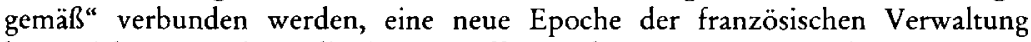
kennzeichnen; an die Stelle der Eingriffsverwaltung ist eine Verwaltung getreten, „die durch Verhandlungen und Übereinkünfte zwischen der öffentlichen Gewalt und den Bürgern gestaltet wird" (A. de Laubadère, Administration et contrat, Mélanges Brethe de la Gressaye, Brière éd., Bordeaux 1967, S. 453-467, Neudruck in: Pages de doctrine, LGDJ, Paris 1980, Bd. 2, S. 239-252).

2 Aus der umfangreichen Bibliographie zur Thematik sind neben den klassischen Handbüchern des Verwaltungsrechts (z. B. René Chapus, Droit administratif général und Droit du contentieux administratif; André de Laubadère, Pierre Delvolvé und Franck Moderne, Traité des contrats administratifs; Jean Rivero, Droit administratif; Georges Vedel und Pierre Delvolvé, Droit administratif) vor allem folgende Werke hervorzuheben:

A. Monographien: Yves Madiot, Aux frontières du contrat et de l'acte administratif unilatéral: recherches sur la notion d'acte mixte en droit public français, LGDJ, Paris 1971; Dominique Pouyaud, La nullité des contrats administratifs, LGDJ, Paris 1991; Charles-Louis Vier, Le procédé contractuel dans l'administration économique, thèse Paris II, 1972.

B. Aufsätze: Denys de Béchillon, Le contrat comme norme dans le droit public positif, in: RFDA 1992, S. 15 ff.; Jacques Caillosse, Sur la progression en cours des techniques contractuelles d'administration, in: Loïc Cadiet, Le droit contemporain des contrats, Economica, Paris 1987, S. 89 ff.; Raphaël Romi, La renégociation par le juge des actes négociés en actes unilatéraux, archaïme paradoxal on technique d'avenir? in: AJDA 1989, S. $9 \mathrm{ff}$; Didier Truchet, Le contrat administratif, qualification juridique d'un accord de volontés, in: Loïc Cadiet, Le droit contemporain des contrats, Economica, Paris 1987, S. 185 ff.; Prosper Weil, Le renonveau de la 
Tatsächlich sind die Beispiele für einseitige Rechtsakte, deren Inhalt zwischen Verwaltung und daraus Berechtigten und Verpflichteten bzw. ihren Vertretern (insbesondere Berufs- und Gewerkschaftsverbände) ausgehandelt worden ist, zahlreich ${ }^{3}$. Diese Praxis entspricht der heute in Gesellschaft und Verwaltung verbreiteten Annahme, die Effektivität hoheitlichen Handelns hänge von seiner Akzeptanz ab, die ihrerseits auf dem vorher erzielten Konsens beruhe. Die französischen Schlagwörter lassen sich in etwa mit "kooperativem Verwaltungshandeln", „Wandlung zu einem Staat des Aushandelns“ oder „ausgehandelten einseitigen Rechtsakten“ wiedergeben".

théorie du contrat administratif, in: Mélanges Stassinopoulos, LGDJ, Paris 1974, S. $217 \mathrm{ff}$.

C. Rechtsprechung: CE 2.3.1973, Syndicat national du commerce en gros des équipements, pièces pour vébicules ou outillages, Leb. 181 = AJDA 1973, S. 323 mit Bericht Braibant, Anm. Ch.-L. Vier, AJDA 1973, S. 326; CE 23.3. 1973, Fédération du personnel de la défense nationale, Leb.247; CE 23.10.1974, Sieur Valet et association pour la défense des intérêts professionnels de la boucherie du bassin parisien, Leb. 500 = AJDA 1975, S. 363 mit Anm. Ch.-L. Vier; CE S. 18. 10.1974, Confédération nationale des auxiliaires médicaux, Leb. 495 = AJDA 1974, S. 535 mit chron. Franc et Boyon = Dr. soc. 1974, S. 335 mit Anm. F. Moderne; CE S. 18.2.1977, Hervouet, Leb. 98 = AJDA 1977, S. 255 mit chron. Nauwelaers et Fabius; CE 20.1.1978, Syndicat national de l'enseignement technique agricole public, Leb. 23, chron. Renaud Denoix de Saint-Marc AJDA 1979, S. 37; CE S.9.10.1981, Syndicat des médecins de la Haute-Loire, Leb. $360=$ AJDA 1982, S. 364 und chron. Tiberghien et Lasserre S. 357; CE 8.3.1985, Les amis de la terre, Leb. 73 = AJDA 1985, S. 382 = RFDA 1985, S. 363 mit Bericht Jeanneney.

${ }_{3}$ Y.Madiot (a.a.O.) untersucht folgende Kategorien, die er als gemischte Rechtsakte bezeichnet: Kollektivvereinbarungen (Tarifverträge, Kollektivvereinbarungen im Bereich der Landwirtschaft, Abkommen zwischen Ärzteverbänden und Krankenversicherungsträgern, ...) und Einzelvereinbarungen (zwischen Konzessionsgeber und Konzessionsnehmer, zwischen Siedlungsbetreibern und -eigentümern, zwischen dem Staat und Privatschulen, ...). Diese Kategorien umfassen allerdings nur einen Teil der in diesem Bericht behandelten Rechtsakte.

${ }^{4}$ Im Mittelpunkt dieses Berichts stehen Rechtsakte, die zwischen der Verwaltung und Privaten ausgehandelt werden. Es ist klar, daß der Anwendungsbereich konsensualer Verfahren viel breiter ist. Jean Rivero beschreibt sie in seinem Verwaltungsrechtshandbuch (a. a. O.) folgendermaßen: „Die Verwaltung bedient sich ihrer, um das Verhalten der Privaten in einer Weise zu beeinflussen, daß es dem Allgemeininteresse entspricht: Sie gewährt ihnen Vorteile verschiedener Art als Gegenleistung für die eingegangenen Verpflichtungen. Dies gilt für die Beziehungen zwischen dem Staat und den Privatschulen (...). Wichtiger noch, und höchst verschiedenartig, sind Verträge im Bereich der Wirtschaft, die entweder mit Berufsverbänden für einen ganzen Wirtschaftszweig oder mit einzelnen Privatunternehmen abgeschlossen werden und darauf abzielen, deren Tätigkeit in eine mit der Ausführung der wirtschaftlichen Planung oder der Raumordnungsplanung in 
Diese Praxis informalen Verwaltungshandelns findet vor allem Anwendung im Bereich des Wirtschaftsverwaltungsrechts, des Berufsrechts, des Baurechts, aber auch im Bereich des Umwelt- und Beamtenrechts.

Solche Pakte lösen beim Juristen Unbehagen aus, weil sie in vielfältiger und atypischer Gestalt in Erscheinung treten: in Form einer Versprechung, in Form einer durch einseitigen Hoheitsakt bestätigten Vereinbarungsurkunde oder in Form eines Übereinkommens.

1. Ein Beispiel einer Versprechung: Ein Berufsverband, in diesem Fall der Nationale französische Dachverband der Metzger, verpflichtet sich nach Verhandlungen mit dem Wirtschaftsminister, bestimmte Kalkulationsmaßstäbe zur Berechnung der Höchstpreise für Fleischwaren zugrunde zu legen. Nach Hinterlegung der Zusage des Berufsverbands wird diese durch ministeriellen Erlaß bestätigt, der zugleich ihre Anwendung und Durchführung für den Einzelhändler regelt (Besteuerung der Preise derjenigen, die der Verpflichtung nicht beitreten). Es ist offensichtlich, daß es sich bei dem hier verwirklichten Pakt, „nicht um eine vertragliche Verpflichtung handelt, sondern um eine einseitige Festsetzung mit Verordnungscharakter, die im Einvernehmen mit dem Nationalen französischen Dachverband der Metzger getroffen wurde“".

2. Ein Beispiel einer durch einseitigen Hoheitsakt bestätigten Vereinbarungsurkunde: Die am 28. Oktober 1971 zwischen dem Berufsverband der Ärzte und den Sozialversicherungsträgern abgeschlossene convention nationale regelt namentlich die Voraussetzungen eines "Ausschlusses“ der Ärzte im Falle wiederholter und gravierender Überschreitungen der tariflichen Sätze. Die zwischen der nationalen Krankenkasse und den Berufsverbänden abgeschlossenen Vereinbarungen sind normalerweise öffentlich-rechrliche Verträge ${ }^{6}$; anders aber die convention nationale von 1971: Sie wurde durch ministeriellen Erlaß vom 29. Oktober 1971 bestätigt. Diese Bestätigung verleiht

Einklang stehende Richtung zu lenken. Derselben konsensualen Verfahren mit derselben Zielsetzung bedient sich der Staat in seinen Beziehungen zu öffentlichen Unternehmen (contrats de programme), zu Zusammenschlüssen von Gebietskörperschaften (...) oder gar zu einzelnen Gemeinden. Man erkennt, daß mit diesen verschiedenen Verfahren eine Handlungsform der Verwaltung entsteht, in der die vertragliche Übereinkunft einen immer bedeutenderen Platz einnimmt. Die Eigenarten und die rechliche Einstufung dieser verschiedenen Verträge sind jedoch noch unbestimmt und unbeständig."

${ }^{5}$ CE 23. 10.1974, Sieur Valet u. a., a.a.O.

${ }^{6} \mathrm{CE}$ S. 18.10.1974, Confédération nationale des auxiliaires médicaux, a. a. O. 
- so die Rechtsprechung - den Bestimmungen der Vereinbarung, und zwar ausgerechnet denjenigen, die rein vertraglichen Charakters sind, weil sie über die gesetzlichen Vorgaben des Code de la Santé hinausgehen, verordnungsgleiche Rechtswirkungen?

3. Beispiele für anscheinend reine Übereinkommen: An dieser Stelle seien zwei Beispiele ausgewählt, in denen es nicht um Berufsverbände, sondern Privatpersonen bzw. - genauer - Privatunternehmen geht.

Das erste Beispiel betrifft zwischen einem Minister und stark umweltgefährdenden Unternehmen abgeschlossene Abkommen. Die schwache Position, in der sich die ersten Umweltschutzbehörden den großen, stark emittierenden Industriezweigen oder Großunternehmen wie Péchiney-Ugine-Kublmann gegenüber befanden, veranlaßte die ersten französischen Umweltminister, nach Aktionsformen $\mathrm{zu}$ suchen, die durch Anreize Akzeptanz schaffen, anstatt durch einseitiges Handeln, die Nichtbeachtung festgesetzter Immissionswerte oder gar die Drohung mit Massenentlassungen zu provozieren. Dies führte, ohne ausdrückliche gesetzliche Ermächtigung, zu den sogenannten Branchen-Abkommen, auf Grund derer Unternehmen subventioniert wurden, die sich zu einer progressiven Reduzierung des Schadstoffausstoßes innerhalb eines bestimmten Zeitrahmens verpflichteten. In seiner Entscheidung vom 8. März 1985 hat der Conseil d'Etat unter diese Praxis einen Schlußstrich gezogen, indem er auf Klage eines Umweltschutzverbandes, wenn auch nicht die Abkommen an sich, so doch die ministeriellen Entscheidungen über den Abschluß der drei letzten Abkommen mit dem Unternehmen PUK für nichtig erklärt hat ${ }^{8}$.

Zuletzt sei das Beispiel der sogenannten „Steuerverträge“ genannt: Der Gesetzgeber hatte die Finanzverwaltung ermächtigt, Unternehmen, die sich zu planungskonformen Investitionen verpflichteten, eine Senkung des Steuersatzes bzw. der Bemessungsgrundlage der Körperschaftsteuer zu gewähren. Es wird noch zu zeigen sein, wie

7 CE S. 18.2.1977, Hervouet und CE S. 9.10.1981, Syndicat des médecins de la Haute-Loire, a.a.O.; s. a.: Louis Dubouis, Le contentieux des rapports entre les médecins et la sécurité sociale, in: EDCE ${ }^{\circ} 32$ [1980-1981], S.75-97.

${ }^{8}$ CE 8.3.1985, Les amis de la terre, a. a. O.; s.a.: Christian Autexier, Die Branchenabkommen in Frankreich, Dokumentation zur 7. wissenschaftlichen Fachtagung der Gesellschaft für Umweltrecht, 1984, Erich Schmidt Verlag, Berlin 1984, S. 195-244. Dieser Aufsatz befaßt sich mit der erstinstanzlichen Entscheidung des Verwaltungsgerichts Paris vom 27. März 1980, die durch die zitierte Entscheidung des Conseil d'Etat aufgehoben wurde. 
der Verwaltungsrichter seine Ablehnung begründet hat, diese in vertraglichem Gewande eingekleideten Pakte als echte Verträge zu qualifizieren.

Diese Beispiele lassen bereits die Grundtendenz des französischen Verwaltungsrichters erkennen, weiterhin der klassischen juristischen Analyse vor soziologisch-politischen Ansätzen den Vorzug zu geben. Er gebraucht bewährte und einfache Instrumente, die ich im folgenden ersten Teil kurz vorstellen werde. In einem zweiten Teil werde ich sodann darauf kommen, daß dieser auf den ersten Blick strenge Ansatz paradoxerweise, dank einer Praxis der Requalifizierung der Absprachen in einseitige Rechtsakte, zu einem stärkeren Schutz ihres Gehaltes führt.

\section{Die Vorgehensweise der Verwaltungsrechtsprechung}

Der französische Verwaltungsrichter differenziert zwischen dem konsensualen Gehalt der Absprache und ihrer instrumentalen Erscheinungsform: Ein einseitiger Rechtsakt wird nicht allein dadurch zu einem Vertrag, daß er auf einer Verhandlung zwischen der Verwaltung und seinen Adressaten beruht (A); darüber hinaus ist der Verwaltung in bestimmten Bereichen der vertragliche Weg verwehrt (B).

\section{A. Das rechtlich unwirksame negatium}

Für den Richter ist das negotium meistens ohne rechtliche Relevanz. Es lassen sich mindestens drei Fallgruppen unterscheiden, in denen eine im vorhinein erfolgte Abstimmung zwischen der Verwaltung und einem Privaten keinen Einfluß auf die rechtliche Qualifizierung des instrumentum hat.

1. Der einfachste Fall ist derjenige, in dem ein Privater - meistens im Bereich der Wirtschaftsverwaltung - sich einseitig verpflichtet, sich um ein bestimmtes Verhalten zu bemühen: exportorientiert zu wirtschaften oder Preissteigerungen in Grenzen zu halten. Es versteht sich, daß in einem derartigen Fall - trotz vertragsähnlicher Terminologie - kein echter Vertrag vorliegt, sondern nur eine „schlichte Verhaltensversprechung " mehr moralischen als rechtlichen Wertes".

${ }^{9}$ A. de Laubadère, Droit public économique, Dalloz, Paris 1944, S. 438. „Was steht in diesen ,Verträgen'? Im allgemeinen enthalten sie das Protokoll der Übereinstimmung zwischen den Absichten der Partner; die Angabe des Willens jedes 
2. Daneben gibt es Fälle, in denen im Vorfeld der Inhalt eines einseitigen Rechtsakts mit den Berechtigten und Verpflichteten bzw. ihren Vertretern ausgehandelt wird. Üblich ist diese Vorgehensweise im Wirtschaftsverwaltungs-, Berufs- und Beamtenrecht ${ }^{10}$. Die Beteiligung an der Aushandlung verleiht der endgültigen Entscheidung keinen vertraglichen Charakter, da für letztere die Exekutive allein und einseitig zuständig bleibt ${ }^{11}$.

3. Ferner gibt es Fälle, in denen der Adressat einer Entscheidung eine Verpflichtung eingeht, deren einzige Wirkung die Anwendbarkeit begünstigender gesetzlicher Vorschriften ist. Solche Verpflichtungen werden herkömmlicherweise als conditio juris ausgelegt und haben keinen vertraglichen Charakter ${ }^{12}$. Dies gilt insbesondere für die sogenannten „Steuerverträge“: Der Staat gewährt einseitig Steuerermäßigungen als Anreiz für Investitionen, die der Plan im Interesse der Nation vorgeschlagen hat $^{13}$.

\footnotetext{
Partners, konkret etwas zu unternehmen, insbesondere im finanziellen Bereich, um das vereinbarte Ziel zu erreichen; eine bestimmte Anzahl Versprechungen. Sie enthalten dagegen kaum, oder sogar überhaupt nicht, das grundlegende Merkmal des Vertrags, nämlich das Bestehen und die Begründung gegenseitiger Rechte und Pflichten der Vertragsparteien." (M.Rougevin-Baville u.a., Leçons de droit administratif, Hachette, Paris 1989, S. 177).

${ }^{10}$ Ein typisches Beispiel stellt Art. 9 des Generalstatuts für den öffentlichen Dienst vom 13.7.1983 dar: „Die Beamten wirken (...) an den Entwürfen der Einzelstatute und an der Überprüfung von Einzellaufbahnentscheidungen mit."; vgl. Christian Autexier, Das Recht des öffentlichen Dienstes in den Mitgliedstaaten der EG, Landesbericht Frankreich (Speyer, 21./22. September 1992, 100 S., in Druck).

${ }^{11}$ So hat z. B. ein Übereinkommen vom 27.5.1968 zwischen der Regierung und den Gewerkschaften keine Rechtswirkung: CE 23.5.1973, Fédération du personnel de la Défense nationale, a. a. O.

12 Für eine Analyse solcher Bedingungen, vgl. L. Duguit, Traité de droit constitutionnel, 1927, Bd. I, S. 320 u. 409: „Zwei oder mehr Personen treten in Kontakt und einigen sich in einem bestimmten Punkt, aber in der Folge dieser Einigung entsteht keine subjektive Rechtsposition, keine Einzelbeziehung zwischen Gläubiger und Schuldner. Dagegen entsteht eine feste Regel, oder eine objektive Rechtssituation, ein objektives Rechtsverhältnis. Dieser Rechtsakt hat die Form eines Vertrages, dem Inhalt nach ist er es nicht."

${ }^{13} \mathrm{Zu}$ den "Steuerverträgen “: J. Delmas Marsalet, Le contrôle juridictionnel des interventions économiques de l'Etat, in: EDCE 1969, S. 133; E. Ebrard, Les avantages fiscaux sur agréments administratifs, in: Rev. sc. fin. 1967, S. 41; M. R. Simmonet, Le contrôle juridictionnel des incitations fiscales, in: AJDA 1968, S.275; G. Timsit, Les contrats fiscaux, in: D. 1964, chron. S. 15; G. Tourné, Les agréments fiscaux, 1970. Mehr als 10000 "Steuerverträge“ wurden auf der Grundlage verschiedenster Bestimmungen Ende der 50er und Anfang der 60er Jahre geschlossen.
} 


\section{B. Das unzulässige instrumentum}

In den meisten dieser Fälle scheidet der Vertrag als verbotenes instrumentum aus: Hier sprechen die Verwaltungsgerichte der Verwaltung schlichtweg das Recht ab, einen Vertrag mit einem Privaten zu schließen. Dieses Verbot wird als Gebot des ordre public betrachtet und kann auf zweierlei Gründen beruhen: Entweder lassen die den Bereich regelnden Gesetze und Verordnungen vertragliche Abweichungen nicht zu, oder es handelt sich um ein als "vertragsfeindlich" ${ }^{14}$ angesehenes Rechtsgebiet.

1. Ein 1991 erschienenes Werk über die Nichtigkeit öffentlichrechlicher Verträge ${ }^{15}$ gibt eine Typologie der häufigsten Fälle, in denen normative Vorgaben das Verbot vertraglicher Vereinbarungen zur Folge haben. Im Rahmen dieses Berichts können nur einige Beispiele genannt werden:

- das Verbot für juristische Personen des öffentlichen Rechts, sich einer Schiedsgerichtsbarkeit zu unterwerfen ${ }^{16}$;

E. Ebrard definierte sie als „widerruflichen und individuellen Steuervorteil, der mit einem wirtschaftlichen Ziel gewährt wird“. Die Entscheidung über die Gewährung oder Verweigerung der Bewilligung traf die Verwaltung im Anschluß an eine Prüfung der Akten; die Verwaltung verfügte immer über einen Ermessensspielraum. Nach G. Timsit liegt eine Willensübereinstimmung vor, jedoch keine gegenseitigen Leistungen. Verpflichtungen geht nur das Unternehmen ein; die Verwaltung wendet lediglich gesetzliche Bestimmungen auf einen konkreten Sachverhalt an. In einer Stellungnahme vom 4.11.1959 (BOCD 16.5.1962, S. 383) signalisierte der Conseil d'Etat, daß die Verwaltung die Gewährung zurücknehmen kann, wenn das Unternehmen nicht mehr die darin festgelegten Bedingungen erfüllt. In einem Streitverfahren entschied er dann 1967, daß „das Unternehmen im Falle einer Nichterfüllung seiner Verpflichtungen und Obliegenheiten alle oder einen Teil der mit der Bewilligung verbundenen Steuervorteile verlieren kann“ (CE 10.3.1967, Ministère de l'Economie et des Finances c. Société Samat et Cie, AJDA 1967, S. 280, mit Bericht Galmot). In seinem Bericht hatte M. Galmot den "Steuervertrag“ als einen bedingten Verwaltungsakt analysiert, d.h. eine auflösende Bedingung angenommen, die in der Nichteinhaltung der Verpflichtungen durch das antragstellende Unternehmen besteht.

$14^{~ " M a t i e ̀ r e s ~ r e ́ f r a c t a i r e ~ a u ~ c o n t r a t ~}{ }^{*}$. Der Ausdruck stammt von Dominique Pouyaud, a.a.O., S. 183.

15 Ebd., S. $183 \mathrm{ff}$.

${ }_{16}$ Vorbehaltlich einer gegenteiligen gesetzlichen Bestimmung und abgesehen vom Sonderfall internationaler privatrechtlicher Verträge sowie der Auslegung und Anwendung der mit ausländischen Gesellschaften geschlossenen Verträge über Vorhaben von nationalem Interesse (Art. 9 des Gesetzes vom 19.8.1986 - Disneyland -). Wenn ein Verwaltungsgericht angerufen wird, erklärt es sich für zuständig 
- das Verbot für juristische Personen des öffentlichen Rechts, vertraglich vom Beamtenstatut abweichende Regelungen zu vereinbaren: „Die durch Gesetze und Verordnungen geregelte Rechtsstellung der Beamten kann nicht durch vertragliche Vereinbarungen abgeändert werden " ${ }^{17}$;

- das Verbot, öffentliches Eigentum zu verkaufen, solange dieses noch nicht seiner Bestimmung entzogen ist, oder öffentliches Eigentum mit einem dinglichen Recht zu belasten ${ }^{18}$;

- usw.

2. Jenseits solcher Verbote, die sich jeweils aus einer Rechtsnorm ergeben, sind für die Rechtsprechung vertragliche Vereinbarungen in rein hoheitlichen Bereichen gänzlich ausgeschlossen. Hier würde ein Vertrag gegen einen der Leitgedanken des französischen öffentlichen Rechts verstoßen: Einer Behörde, der eine Zuständigkeit oder hoheitliche Befugnis übertragen wurde, ist es nicht gestattet, auf deren Wahrnehmung zu verzichten. Diese Befugnis wurde ihr im Interesse der Allgemeinheit verliehen zur Erfüllung der Aufgaben, die ihr gemäß der staatlichen und politischen Ordnung obliegen. Folglich hat die Verwaltung keine Wahl zwischen vertraglicher Vereinbarung und einseitiger Handlung. Zwei klassische Zitate angesehener Mitglieder des Conseil d'Etat verdeutlichen die theoretische Grundlage.

Zum einen der Bericht von Guy Braibant zu einer Entscheidung vom 2. März 197319: „In Angelegenheiten, die die Wirtschaftspolitik und die öffentliche Ordnung berühren, wie z.B. die Regelung des Außenhandels, der Devisenkontrolle oder der Preispolitik, darf die Verwaltung weder durch Vertrag auf die ihr gesetzlich verliehene Verordnungsbefugnis verzichten noch über die Strafgewalt disponieren. Weder darf sie darauf verzichten, polizeiliche Maßnahmen zu treffen, noch darf sie ihre Befugnisse ganz oder teilweise auf Berufsverbände oder Unternehmen übertragen.“

und mißt einer Schiedsvereinbarung oder einer Schiedsgerichtsklausel in einem öffentlich-rechtlichen oder privatrechtlichen - Vertrag keinerlei Rechtswirkung bei (ebd., S. 188-192).

17 CE 25. 10.1929, Portebois, Leb. 930. Vgl. Pouyaud, a. a. O., S. $206 \mathrm{ff}$.

18 CE 16.5.1985, Société Eurolat, Leb. 141 = Petites Affiches 23.10.1985 mit Anm. Llorens = RDP 1985, S. $1700=$ RFDA 1986, S. 21 mit Bericht B. Genevois = DA 1985 n $^{\circ} 290$ = AJDA 1985, S.620 mit Anm. Fatome und Moreau.

${ }_{19}$ Syndicat national du commerce en gros des équipements, pièces pour vébicules ou outillages, a. a. O. 
Zum anderen der Bericht von Renaud Denoix de Saint Marc zu einer Entscheidung vom 20. Januar $1978^{20}$ : „Allgemein gilt, daß eine Verwaltungsbehörde dann, wenn ihr per Gesetz eine Verordnungsbefugnis verlieren wurde, verpflichtet ist, sich einseitiger Rechtsakte zu bedienen, und nicht statt dessen Vereinbarungen zu treffen. Es darf in der Tat nicht vorkommen, daß Bürger hier vertragliche Rechte gegen die Verwaltung geltend machen können. Vielmehr muß diese die Freiheit behalten, eine Verordnungsregelung, wie und wann sie es für angebracht hält, zu verändern: Niemand kann einen Anspruch auf die Beibehaltung einer Verordnungsregelung haben."

Dieser Grundsatz gilt auf dem Gebiet des Steuerrechts, der allgemeinen Ordnungspolizei ${ }^{21}$ und der sektoriellen Verwaltungspolizei, z. B. im Bereich der Wirtschafts- und Gewerbeaufsicht ${ }^{22}$ oder der umweltgefährdenden Bauten und Anlagen ${ }^{23}$.

\section{Die richterliche Politik der Bewahrung des Vereinbarten}

Wenn ich an dieser Stelle das Bisherige zusammenfaßte, so könnte ich von einem stark ausgeprägten Mißtrauen der französischen Verwaltungsgerichte gegenüber kooperativem Verwaltungshandeln sprechen.

Jedoch wäre dieser Schluß verfrüht. Würden die Gerichte konsequent so vorgehen, müßten sie die meisten Vereinbarungen und Pakte für nichtig erklären. Die jüngst erschienenen Untersuchungen stimmen demgegenüber darin überein, daß Nichtigkeitserklärungen letztlich nicht sehr häufig sind ${ }^{24}$. Im Vorwort zur Dissertation von Mme Pouyaud bestätigt Alex Weil, daß sich geradezu eine "richterliche Politik der Bewahrung des Vereinbarten" herausgebildet hat. Der Grundsatz „Alles ist besser, als die Nichtigkeit zu erklären“, scheine eine goldene Regel der Rechtsprechung zu $\operatorname{sein}^{25}$. D.h., die in den Verwaltungsvereinbarungen und -pakten zum Ausdruck gekommenen Willensübereinstimmungen sind derart komplexe und austarierte Gebilde, daß der Richter nur bei Vorliegen ganz entscheidender Gründe zur schwersten Sanktion, der Nichtigkeitserklärung, greift.

20 Syndicat national de l'enseignement technique agricole public, a. a. O.

${ }_{21}$ CE 17.6. 1932, Ville de Castelnaudary, Leb. 595.

22 CE 23.10.1974, Sieur Valet u. a., a. a. O.

${ }^{23} \mathrm{CE}$ 8. 3.1985, Les amis de la terre, a. a. O.

${ }^{24}$ Pouyaud, a. a. O., v. a. S. 287-288.

25 Pouyaud, a. a. O., S. 12. 
Nach Alex Weil liegt der Grund hierfür darin, daß die politischen und gesellschaftlichen Folgen einer Vernichtung des Verhandlungsergebnisses oft zu gravierend wären. Um diese zu vermeiden, nehmen die Gerichte häufig an, daß ein einseitiger Rechtsakt ergangen ist, der dem Pakt oder der Versprechung des Partners der Verwaltung Rechtswirkung verliehen hat. Läßt sich ein einseitiges Verwaltungshandeln neben dem vertraglichen instrumentum nur schwer ausmachen, versuchen die Gerichte, letzteres als einseitigen Rechtsakt zu qualifizieren bzw. zu requalifizieren.

\section{A. Die Technik der Requalifizierung ${ }^{26}$}

Prima facie erscheint die Technik der Requalifizierung insoweit widersinnig, als sie die Anfechtbarkeit der Vereinbarung erleichtert. Die Aufhebung von Verwaltungsverträgen im Streitverfahren ist nämlich weitaus schwerer möglich als die einseitiger Rechtsakte: Allein die Vertragsparteien können Klage auf Feststellung der Nichtigkeit eines Vertrages erheben. Die Requalifizierung einer Vereinbarung als einseitiger Rechtsakt eröffnet demgegenüber Dritten die Möglichkeit eines recours pour excès de pouvoir, einer Art Anfechtungsklage, deren Zulässigkeit geringen Anforderungen - insbesondere hinsichtlich der Klagebefugnis - unterliegt.

Auf der anderen Seite ermöglicht die Requalifizierung als einseitiger Rechtsakt, Teile der Vereinbarung als objektives Recht zu betrachten. Als solche, seien es konkrete oder abstrakt-generelle einseitige Rechtsakte, lassen sie sich nicht nur von allen Betroffenen anfechten. Sie können darüber hinaus, soweit sie abstrakt-generelle Normen darstellen, zum Prüfungsmaßstab der Rechtmäßigkeit weiterer Akte werden.

Die französischen Verwaltungsgerichte sind seit langem damit vertraut, hoheitlich-einseitige Elemente aus Verwaltungsverträgen abzuspalten:

- Nach der Theorie der Trennbarkeit sind recours pour excès de pouvoir gegen einseitige Entscheidungen, die sich auf den Vertragsabschluß oder seine Durchführung beziehen, zulässig ${ }^{27}$;

${ }^{26}$ Diese Technik ist Gegenstand einer interessanten Studie von Raphaël Romi, a. a. O.

${ }^{27}$ Die Theorie der Trennbarkeit im Recht der Verwaltungsverträge entwickelte der Conseil d'Etat beginnend mit den Entscheidungen vom 11.12.1903 (Commune 
- die Theorie der hoheitlich-einseitigen Klauseln verleiht - insbesondere im Bereich der Gemeindienste ${ }^{28}$ - gewissen Bestimmungen in Beleihungsverträgen einen hoheitlich-einseitigen Charakter, sofern „sie sich auf die Organisation der Gemeindienste beziehen"29.

Dies läßt sich jedoch aus Gründen, auf die ich hier nicht näher eingehen $\mathrm{kann}^{30}$, nur schlecht auf Pakte des informalen Verwaltungshandelns übertragen ${ }^{31}$. Daher hat der Conseil d'Etat in den eingangs zitierten Fällen weniger eine analytische Trennung zwischen Elementen vertraglichen und hoheitlich-einseitigen Charakters versucht, als eine synthetische Betrachtungsweise bevorzugt und a priori das $\mathrm{Ge}-$

de Gorre) und vom 4.8.1905 (Martin). Die Vertragsparteien und auch Dritte können aus Gründen der Verletzung objektiven Rechts alle Entscheidungen anfechten, die mit dem Vertrag verbunden sind: die Entscheidung über den Vertragsabschluß oder über seine Genehmigung, bestimmte - abtrennbare Ausführungsentscheidungen. Letztendlich ist der recours pour excès de pouvoir nur gegen den Vertrag i. e.S. unzulässig (abgesehen vom Sonderfall der Präfektenklage gegen Verträge der Gebietskörperschaften im Rahmen der Rechtsaufsicht gemäß dem Gesetz vom 2.3.1982).

${ }^{28}$ Das Wort „Gemeindienst“ als Übersetzung für service public soll sowohl den funktionalen als auch den institutionellen Gehalt dieses Schlüsselbegriffs zum Ausdruck bringen. Der service public ist neben der puissance publique das Kriterium für die Geltung des Verwaltungsrechts und zugleich die Zuständigkeit der Verwaltungsgerichtsbarkeit.

${ }^{29}$ Einige Vereinbarungsbestimmungen haben „hoheitlich-einseitigen Charakter", „weil sie sich auf die Organisation von Gemeindiensten beziehen“, und „werden folglich als einseitige Rechtsakte angesehen“. Diese Erweiterung betrifft nicht die „besonderen Lastenverzeichnisse“ in Beleihungsverträgen. Siehe hierzu die Darstellung der Theorie der hoheitlich-einseitigen Klauseln nach Georges Vedel und Pierre Delvolvé im Beitrag von Raphaël Romi (a.a.O.) und insbesondere die Nachweise aus Rechtsprechung und Lehre in seinen Anm. 8-13.

${ }^{30}$ Nach der Theorie der Trennbarkeit ist eine Klage pour excès de pouvoir der Vertragsparteien, mit dem die gerichtliche Überprüfung des Vertrages als solchem begehrt wird, unzulässig. „Die Aufhebung einer der abtrennbaren Entscheidungen durch den recours pour excès de pouvoir führt nicht zur Aufhebung des Vertrags als solchem. Sie kann nur von einer der Vertragsparteien begehrt werden, und zwar mit einem recours de plein contentieux. Die Theorie der hoheitlich-einseitigen Klauseln kann ihrerseits zahlreiche Zulässigkeitsprobleme aufwerfen“ (s. Romi, a.a.O., S. 11).

${ }^{31}$ Die Theorie der Trennbarkeit wird aber auf Auflagen zu baurechtichen Genehmigungen angewandt, s. CE S. 12.2.1988, Ministre de l'Urbanisme et du Logement, AJDA 1988, S. 363 und chron. S. 331. 
samte als einseitigen Rechtsakt angesehen ${ }^{32}$, um allenfalls in einem zweiten Schritt bestimmte eindeutig vertragliche Klauseln auszusondern.

\section{B. Die Vorteile der Requalifizierung}

Das Verfahren der Requalifizierung hat offensichtlich den Vorteil, daß für die rechtliche Beurteilung der Pakte informalen Verwaltungshandelns nicht auf eine dogmatische Konstruktion sui generis zurückgegriffen werden muß. Die klassische Einteilung in einseitige konkrete oder abstrakt-generelle - und zweiseitige - offentlichrechtliche oder privatrechtliche - Rechtsakte wird nicht angetastet. Allerdings nimmt der Richter, in den Fällen, in denen die Requalifizierung nicht eindeutig gesetzlich vorgesehen ist ${ }^{33}$, einen großen Beurteilungsspielraum in Anspruch. Hierdurch erhält die Materie einen unverkennbar kasuistischen Charakter. Diese Freiheit des Richters entspricht indes dem Wesen des französischen Verwaltungsrechts, das seit der grundlegenden Entscheidung im Fall Blanco 1873 durch seinen richterrechtlichen Charakter gekennzeichnet ist.

Vier weitere Überlegungen sprechen für die richterliche Requalifizierung:

1. Die Requalifizierungtechnik läßt Anpassungen zu: Sie ermöglicht dem Richter, gegebenenfalls den Vereinbarungscharakter derjenigen Bestimmungen zu bewahren, die nur inter partes gelten sollen, indem er sie von der Requalifizierung ausnimmt ${ }^{34}$.

32 Der synthetische Charakter der Vorgehensweise wird besonders deutlich im Urteil Valet (CE 23. 10. 1974, a. a. O.): „Da weder dieser Erlaß noch die Verbandszusage, die er zur Anwendung bringt und deren Bestimmungen Teil des Erlasses werden, eine vertragliche Verpflichtung der Verwaltung darstellen, sondern eine einseitige Entscheidung mit Verordnungscharakter, die in Übereinstimmung (mit dem Berufsverband) getroffen wurde."

33 Wie z. B. in Art. 9 des Generalstatuts der Beamten.

${ }^{34}$ In seinem Urteil vom 9.10.1981 - Syndicat des médecins de la Haute-Loire et autres - erkannte der Conseil d'Etat nicht allen Bestimmungen der zwischen den Sozialversicherungsträgern und dem Berufsverband der Ärzte abgeschlossenen convention nationale von 1971 (vgl. o. Nr. 2 der Einleitung) Verordnungscharakter zu. Für Tiberghien und Lasserre liegt die ratio in der Unterscheidung zwischen denjenigen Bestimmungen, die sich auf die Organisation des Gemeindienstes des Gesundheitswesens beziehen (requalifizierbare Bestimmungen), und den, auf die Wahrung des Selbstverständnisses des Berufsstandes gerichteten gegenseitigen Verpflichtungen der Parteien - im konkreten Fall die nationale Krankenkasse und der Verband der praktischen Arzte (Chron. Tiberghien et Lasserre, in: AJDA 1982, S. 358). 
2. Ein weiterer praktischer Vorteil der Requalifizierung besteht darin, daß Bestimmungen des Paktes auch Dritten gegenüber wirksam werden können ${ }^{35}$. Der Klageweg des recours pour excès de pouvoir wird ihnen eröffnet; sie können sich aber auch auf deren Rechtmäßigkeit berufen, und zwar als seien sie Verordnungsregelungen (Dekret oder Ministererlaß). Die richterliche Kontrolle wird also sowohl im Interesse der Betroffenen als auch im Interesse der Allgemeinheit erweitert.

3. Die Requalifizierung kommt auch der Verwaltung zugute, die bei veränderter Rechts- und Sachlage den Pakt durch einseitigen Rechtsakt abändern oder aufheben kann, da er „keine vertragliche Verpflichtung der Verwaltung darstellt ${ }^{\text {c36 }}$.

4. At last, ein Vorteil von nicht zu unterschätzender Bedeutung: Die Requalifizierung führt zu einer faktischen Aufwertung der requalifizierten Pakte: Ihre doppelte Herkunft, die vertragliche und die cinseitige, verleiht ihnen eine doppelte politische Legitimität: die des Konsenses und die des hoheitlichen Handelns.

35 „Der Zweck und die Rechtfertigung der Requalifizierung ist vor allem das Erreichen dieses praktischen Ergebnisses" (Romi, a. a. O., S. 14).

${ }^{36}$ CE 23. 10.1974, Sieur Valet u. a., a. a.O. 


\title{
Verträge und Absprachen zwischen der Verwaltung und Privaten in Österreich
}

\author{
3 b. Landesbericht von Prof. Dr. Johannes Hengstscbläger, Linz
}

Es ist mir natürlich nicht möglich, innerhalb der vorgegebenen Zeit von einer Viertelstunde alle mit dem heutigen Thema angesprochenen Rechtsprobleme zu behandeln. Daher sehe ich mich genötigt, Schwerpunkte zu setzen.

Nur mit wenigen Kernaussagen möchte ich die privatrechtlichen Verträge zwischen Verwaltung und Rechtsunterworfenen streifen.

Die Art. 17 und 116 Abs. 2 unseres Bundes-Verfassungsgesetzes ${ }^{1}$ räumen den Gebietskörperschaften umfassende Privatrechtsfähigkeit $e^{2}{ }^{2}$. Das Kernproblem, welches von einer Reihe weiterer Rechtsfragen begleitet wird - wie etwa jener nach der Zulässigkeit von Selbstbindungsgesetzen und außenwirksamen Normen sowie von transkompetentem Verwaltungshandeln, nach der Bindung an die Grundrechtsordnung, nach der Haftung für zugefügtes Unrecht, etc. - , liegt in der Bewältigung des naturgegebenen Spannungsverhältnisses zum strikten Legalitätsprinzip des Art. 18 B-VG.

Diesbezüglich werden in der Lehre alle denkbaren Lösungsvarianten angeboten. Der Bogen spannt sich vom Postulat einer strengen Gesetzesgebundenheit ${ }^{3}$ über differenzierte Sichtwei-

1 Bundes-Verfassungsgesetz in der Fassung von 1929, BGBl. 1/1930 (Wiederverlautbarung des mehrfach novellierten Gesetzes vom 1. Oktober 1920, womit die Republik Österreich als Bundesstaat eingerichtet wird [Bundes-Verfassungsgesetz]), zuletzt geändert durch BGBl. 470/1992.

2 Vgl. etwa Bruno Binder, Der Staat als Träger von Privatrechten, Wien - New York 1980, $135 \mathrm{ff}$.

${ }^{3}$ Eine strenge Gesetzesgebundenheit der Privatwirtschaftsverwaltung wurde hauptsächlich zu Beginn der Mitte der 50er Jahre eingeleiteten Problematisierung dieses Themas gefordert; vgl. vor allem Hans Klecatsky, Allgemeines österreichisches Verwaltungsrecht. Eine Buch- und Lagebesprechung, JBl. 1954, 473, 503; und ders., Die Köpenickiade der Privatwirtschaftsverwaltung, JBl. 1957, 333; sowie weiters auch Alfred Kobzina, Der Staat als Privatwirtschaftssubjekt, ÖJ 1961, 421; und Edwin Loebenstein, Das Förderungswesen unter dem Blickwinkel des 
$\operatorname{sen}^{4}$ bis hin zur weitestgehenden Freiheit staatlicher Privatwirtschaftsverwaltung, welche vor allem die Praxis in Anspruch nimmt ${ }^{5}$.

Eine allseits befriedigende Antwort wurde bis heute nicht gefunden und ist in Wahrheit auch nicht möglich, weil unsere Bundesverfassung für die Bewältigung des angesprochenen Spannungsverhältnisses keine tauglichen Anhaltspunkte enthält. Vielmehr trifft der ehrliche Befund von Richard Novak zu, daß das Problem der Privatwirtschaftsverwaltung der Lösung durch den Verfassungsgesetzgeber harrt ${ }^{6}$.

Als interessanter und dogmatisch ergiebiger erweisen sich jene Probleme, welche sich um den sogenannten verwaltungsrechtlichen Vertrag ranken. Dieser bereitet im österreichischen Rechtssystem deshalb besondere Schwierigkeiten, weil er als Gesetzesbegriff nir-

Legalitätsprinzips, 2. OJT 1964, II/3, 7 (33 ff.), der mit diesem Referat die Lehre von Art. 17 B-VG als Kompetenznorm für die sogenannten Selbstbindungsgesetze des Bundes und der Länder begründete.

Auch Ludwig Adamovich, Handbuch des österreichischen Verfassungsrechts ${ }^{6}$, Wien - New York 1971, 101 stellt noch kurz und bündig fest: „Der Grundsatz des Art. 18 Abs. 1 B-VG gilt uneingeschränkt auch für den Bereich der Privatwirtschaftsverwaltung."

${ }^{4} \mathrm{Vgl}$. etwa Bruno Binder, Staat, $255 \mathrm{ff}$.; ders., Wirtschaftsrecht, Wien - New York 1992, Rdn.0517f.; Franz Bydlinksi, Die privatwirtschaftliche Tätigkeit des Staates in privatrechtlicher Sicht, JBl. 1968, 9 (insbes. 15 ff.); Ludwig Fröbler/Peter Oberndorfer, Das Wirtschaftsrecht als Instrument der Wirtschaftspolitik, Wien New York 1969, 84 ff.; Gerhardt Plöchl, Der Staat als Wirtschaftssubjekt und seine Stellung zur Wirtschaft, 5.ÖJT 1973 I/3 A, 24 und $27 \mathrm{ff.;} \mathrm{Bernbard} \mathrm{Raschaner,}$ Verfassungsrechtliche Fragen der Wohnbauförderung, in: Beiträge zum Wirtschaftsrecht (Wenger-FS), Wien 1983, 121 (124ff.); und wohl auch Robert Walter/ Heinz Mayer, Grundriß des österreichischen Bundesverfassungsrechts', Wien 1992, Rdn. 570.

$5 \mathrm{Vgl}$. etwa Walter Antoniolli/Friedrich Koja, Allgemeines Verwaltungsrecht ${ }^{2}$, Wien 1986, 225 ff.; Karl Korinek, Das Konzept der Regierungsvorlage zu einem Vergabegesetz und seine rechtsstaatliche sowie bundesstaatliche Bedeutung, in: Karl Korinek / Heinz Peter Rill (Hrsg.), Zur Reform des Vergaberechts, Wien 1985, 1 (5f.); Heinz Peter Rill, Gliedstaatsverträge, Wien - New York 1972, $291 \mathrm{ff}$.; ders., Demokratie, Rechtsstaat und staatliche Privatwirtschaftsverwaltung, in: Beiträge zum Wirtschaftsrecht (Wenger-FS), Wien 1983, 57 (63ff.); sowie Heinz Schäffer, Die sogenannte Privatwirtschaftsverwaltung und das Gesetz, in: Allgemeines Verwaltungsrecht (Antoniolli-FS), Wien 1979, 253 (262 ff.).

Auch der VfGH hat nunmehr - ausdrücklich in bezug auf Gemeinden festgestellt, daß deren Privatrechtssphäre durch die Gesetze nicht erst geschaffen, sondern nur allenfalls beschränkt ist; vgl. das Erkenntnis Slg. 11.873/1988.

6 Richard Novak, Die Problematik der Abgrenzung der Hoheitsverwaltung von der sogenannten Privatwirtschaftsverwaltung, in: Allgemeines Verwaltungsrecht (Antoniolli-FS), Wien 1979, 61 (74). 
gends expressis verbis vorkommt. Es finden sich allerdings Phänomene, insbesondere im Steuerrecht, die von der herrschenden Lehre als verwaltungsrechtliche Verträge bezeichnet werden.

Dies vorweg festzuhalten, erscheint aus prinzipiellen Gründen erforderlich: Daraus, daß „verwaltungsrechtlicher Vertrag" kein verbum legale ist, folgt für die rechtsdogmatische Behandlung, daß nicht am Begriff und dessen Interpretation angesetzt werden kann, sondern daß im Mittelpunkt der Erörterung jene rechtlichen Phänomene stehen müssen, die von der Lehre zutreffenderweise mit dem Terminus „verwaltungsrechtlicher Vertrag“ apostrophiert werden.

Was wird nun in Österreich unter dem Begriff „verwaltungsrechtlicher Vertrag" verstanden? Charakteristisch für diese Rechtsfigur ist zweierlei:

1. Das Vertragselement, nämlich daß durch übereinstimmende Willenserklärungen der Beteiligten Rechte und Pflichten gestaltet werden ${ }^{7}$, und

2. die boheitliche Komponente, nämlich daß einer der Vertragspartner die Verwaltung ist und daß diese mit dem ihr eigentümlichen imperium auftritt. Ob sie beim vertraglichen Handeln als Hoheitsträger oder im Rahmen des Privatrechts tätig wird, bestimmt allein das Gesetz, das den betroffenen Staatsakt in den Bereich der Hoheitsverwaltung verweist oder nicht.

Hoheitliches Staatshandeln bedarf aufgrund des Totalvorbebalts in Art. 18 Abs. 1 B-VG einer hinreichenden gesetzlichen Grundlage, die nicht nur den Inhalt des Rechtsaktes, sondern auch die Zuständigkeit und das Verfahren bei seiner Erlassung festlegt ${ }^{8}$. Dies bedeutet für den verwaltungsrechtlichen Vertrag, der von der Verwaltung ex definitione im hoheitlichen Bereich abgeschlossen wird, daß er eine diesen drei Anforderungen genügende gesetzliche Grundlage benötigt.

7 Vgl. die Definition des rechtswissenschaftlichen Begriffes „Vertrag“ bei Heinz Peter Rill, Gliedstaatsverträge, $34 \mathrm{f.:} \mathrm{„Der} \mathrm{Vertrag} \mathrm{ist} \mathrm{ein} \mathrm{rechtsnormerzeugender}$ Tatbestand, der in der gegenseitigen, auf rechtliche Wirkung abzielenden Willensübereinkunft mehrerer Rechtssubjekte besteht, die auf ein Verhalten dieser gerichtet ist, oder der in solch einer Willensübereinkunft besteht, die überdies auch auf die Berechtigung dritter Rechtssubjekte gerichtet sein kann."

${ }^{8} \mathrm{Vgl}$. statt vieler etwa Ludwig Adamovich/Bernd-Christian Funk, Österreichisches Verfassungsrecht ${ }^{3}$, Wien - New York 1985, 241; Walter Antoniolli/Friedrich Koja, Verwaltungsrecht, 214; und Robert Walter/Heinz Mayer, Grundriß Bundesverfassungsrecht, Rdn.573; für die Rspr. vgl. etwa VfSlg. 5924/1969; und die Entscheidung des OGH vom 10.7.1991, 1 Ob. 30/91, abgedruckt in den JBl. 1992, $35 \mathrm{ff}$. 
Probleme ergeben sich schon bezüglich der Determinierung des Vertragsinbalts. Auf den ersten Blick mag es nämlich scheinen, daß vertragliche Einigungen, zu deren Wesenselementen die Abschlußfreiheit und die Gestaltungsfreiheit zählen, mit einer strikten Gesetzesbindung unvereinbar sind?.

Bei näherem Hinsehen zeigt sich jedoch, daß die von Art. 18 B-VG geforderte rechtliche Determinierung durchaus auch Spielräume für die Verwaltung eröffnet, die einen Vertragsabschluß nicht von vornherein sinnlos machen. So ergibt sich etwa aus Art. 130 Abs. 2 B-VG, der von der Zulässigkeit von Ermessensentscheidungen ausgeht, daß der Gesetzgeber - wenn auch in bestimmten Grenzen - von einer strikten Bindung der Verwaltung absehen kann. Aber auch sonst haben Lehre und Judikatur mittlerweile anerkannt, daß die Anforderungen an die Bestimmtheit der Gesetze nicht überspannt werden dürfen, sondern die geforderte Determinierungsdichte auch von der Sachgesetzlichkeit des Regelungsgegenstandes abhängt ${ }^{10}$.

Während sich der Gesetzgeber somit unter dem Aspekt des Art. 18 B-VG hinsichtlich der inhaltlichen Gestaltung verwaltungsrechtlicher Verträge mit der Einräumung eines Handlungsspielraumes nach Art des Ermessens begnügen kann, muß die Ermächtigung, einen Vertrag abzuschließen, immer ausdrücklich geregelt sein. Der Gesetzgeber hat also den verwaltungsrechtlichen Vertrag - bei sonstiger Unzulässigkeit - als spezielle Form obrigkeitlichen Handelns einzuführen ${ }^{11}$.

9 Theo Öblinger, Das Problem des verwaltungsrechtlichen Vertrages, Salzburg - München 1974, 36 spricht von einer gewissen, psychologisch gefärbten Spannung zwischen den beiden Rechtsfiguren "Legalitätsprinzip“ und „verwaltungsrechtlicher Vertrag“.

$10 \mathrm{Vgl}$. etwa Walter Antoniolli/Friedrich Koja, Verwaltungsrecht, $218 \mathrm{f}$;; Bruno Binder, Staat, 263 ff.; ders., Wirtschaftsrecht, Rdn. 0518; Ludwig Fröbler/Peter Oberndorfer, Die Gemeinde im Spannungsfeld des Sozialstaates, Linz 1970, $45 \mathrm{ff}$.; dies., Österreichisches Raumordnungsrecht, Linz 1975, 30 ff.; sowie Theo Öhlinger, Problem, 15 ff.; für die Rspr. vgl. etwa VfSlg. 8212/1977 und VfSlg. 8813/1980.

Zutreffend weist allerdings Ludreig Adamovich, Hoheitsverwaltung und Gesetz, in: Allgemeines Verwaltungsrecht (Antoniolli-FS), Wien 1979, 77 (86) darauf hin, daß den auf sachgebundene Differenzierung zielenden Postulaten mit einer gewissen Skepsis begegnet werden muß, zumal es kaum eine Verwaltungsmaterie gibt, für die man nicht mit irgendeiner Begründung Eigenheiten behaupten könnte, die einer strikten Anwendung des Legalitätsprinzips entgegenstehen.

11 Ermächtigt der Gesetzgeber die Verwaltung zu hoheitlichem Handeln, ohne besondere Handlungsformen vorzusehen, so steht den Behörden grundsätzlich nur das Instrument der Erlassung eines Bescheides zur Verfügung, da dieser in der Verfassung als Prototyp hoheitlichen Handelns verankert ist. 
$\mathrm{Ob}$ dies dem einfachen Gesetzgeber von Verfassungs wegen zusteht, ist fraglich, weil der verwaltungsrechtliche Vertrag in der Verfassung als Rechtsformkategorie nicht aufscheint. Geht man davon aus, daß das Bundes-Verfassungsgesetz die Formen obrigkeitlichen Verwaltungshandelns abschließend festlegt, käme er von vornherein nicht in Betracht.

In diesem Sinne hat etwa Heinz Mayer versucht, den öffentlichrechtlichen Vertrag, insbesondere wie er im Steuerrecht vorkommt, als antragsbedürftigen Bescheid im Sinne des Sechsten Hauptstücks des Bundes-Verfassungsgesetzes zu deuten. Steuervorschreibungen gehörten jedenfalls der Hoheitsverwaltung und nicht dem Privatrecht an. Als hoheitlicher Akt käme, da von der Geschlossenheit des Rechtsquellensystems auszugehen sei, nur der Bescheid in Betracht. Dieser sei zwar am Modell beteronomer Rechtserzeugung orientiert, habe aber auch eine starke autonome Komponente, nämlich immer dann, wenn seine Erlassung eines Antrags bedarf. Einer Deutung als autonom initiierter Bescheid, der der Justitiabilität der Gerichtshöfe öffentlichen Rechts unterliegt, stünde daher von Verfassungs wegen nichts im Wege ${ }^{12}$.

Die herrschende Lehre und letztlich auch der Verfassungsgerichtshof sind dieser These nicht gefolgt. Zum einen wurde eingewendet, daß sie den Wesensunterschied zwischen Vertrag und Bescheid verkennt, welcher darin besteht, daß beim antragsbedürftigen Bescheid das Fehlen der gesetzlich vorgesehenen Mitwirkung des einzelnen lediglich zur Rechtswidrigkeit führt, während bei Verträgen die fehlende Willenseinigung die absolute Nichtigkeit bewirkt ${ }^{13}$. Zum anderen läßt sich dagegen aber auch der grundsätzliche Einwand ins Treffen führen, daß das Rechtsquellensystem zwar binsichtlich generell-abstrakter Normen - abgesehen von wenigen, zum Teil nicht

12 Heinz Mayer, Der öffentlich-rechtliche Vertrag im österreichischen Abgabenrecht, JBl. 1976, 632 (636f.).

${ }_{13}$ Anders ausgedrückt, mit den Worten von Walter Antoniolli/Friedrich Koja, Verwaltungsrecht, 499: „Fehlt die Mitwirkung der Partei, so bedeutet dies bei einem Vertrag Nichtigkeit, bei einem Bescheid hingegen Aufbebbarkeit."

Auch andere Autoren betonen diesen Wesensunterschied von Bescheid einerseits und Vertrag andererseits; vgl. etwa Werner Doralt, Der verwaltungsrechtliche Vertrag, in: Allgemeines Verwaltungsrecht (Antoniolli-FS), Wien 1979, 205 (209f.); Bernd-Christian Funk, Verwaltungshandeln und Verwaltungsakt, in: Allgemeines Verwaltungsrecht (Antoniolli-FS), Wien 1979, 157 (161); und Ingrid Nowotny, Zur Möglichkeit der Einführung des verwaltungsrechtlichen Vertrages in die österreichische Rechtsordnung, ÖJZ 1973, 57 (61 [Fn. 62]). 
unbedeutsamen Ausnahmen wie den Kollektivverträgen - geschlossen sei, dies aber für individuelle Staatsakte nicht gelte.

Ein Blick auf den Telos, der hinter dem Postulat nach möglichster Geschlossenheit des Rechtsquellenkataloges steht, macht deutlich, daß diese - in Österreich herrschende - Unterscheidung zwischen generellen und individuellen Normen durchaus gerechtfertigt erscheint.

Die Regelung, von wem und in welcher Form generell-abstrakte Normen, insbesondere Gesetze, erzeugt werden, verkörpert die Systementscheidung unserer Verfassung über die'Ausübung staatlicher Macht und ist somit zentraler Bestandteil des demokratischen Prinzips. Diese, auf höchster Ebene festgelegte Konstruktion ist vom Schöpfer der Bundesverfassung so und nicht anders gewollt und einer Modifikation durch den einfachen Gesetzgeber nicht zugänglich. Jedermann bindende Normen können nur auf dem in der Verfassung vorgesehenen Weg erlassen werden. Diesbezüglich ist der Rechtsquellenkatalog im Bundes-Verfassungsgesetz abschließend festgelegt und durch den einfachen Gesetzgeber ohne Verletzung der darin zum Ausdruck kommenden demokratischen Grundstruktur nicht ergänzbar $^{14}$.

Eng mit dieser prinzipiellen Feststellung zusammen hängt auch die Frage der Rechtmäßigkeitskontrolle generell-abstrakten Staatshandelns. Nach dem Konzept der österreichischen Bundesverfassung wird es einzig und allein dem Verfassungsgerichtshof zugestanden, die den Volkswillen repräsentierenden allgemeinen Anordnungen bei Widerspruch zu höherrangigen Bestimmungen rechtsverbindlich zu beseitigen ${ }^{15}$. Die Kompetenzen des Höchstgerichtes sind jedoch nach einhelliger Ansicht hinsichtlich der prüfbaren Rechtsquellen in der

\footnotetext{
14 Vgl. dazu ausführlich unter Anführung weiterer Literatur und Judikatur Heinz Scbäffer, Rechtsquellen und Rechtsanwendung, 5. ÖT 1973 I/1 B, $34 \mathrm{ff}$. Zutreffend weist Heinz Schäffer, a. a.O., $40 \mathrm{f}$. auch darauf hin, daß der Verfassungsgesetzgeber selbst zu erkennen gibt, daß er die Bestimmungen des BundesVerfassungsgesetzes über die Erzeugung genereller Normen grundsätzlich als abschließend betrachtet; vgl. diesbezüglich etwa die EB zur RV betreffend die Anfügung eines Abs. 2 an Art.9 B-VG (427 BlgNR, 15.GP), denen sich der Nationalrat durch die Verabschiedung der B-VG-Novelle 1981, BGBl.350/1981, offensichtlich anschloß.

15 Die Justitiabilität genereller Normen macht einen wesentlichen Bestandteil des rechtsstaatlichen Prinzips der österreichischen Bundesverfassung aus; vgl. näher Johannes Hengstschläger, Totaländerung der Verfassung durch Gesetzessanierung? in: Staatsrecht in Theorie und Praxis (Walter-FS), Wien 1991, 215
} 
Verfassung taxativ festgeschrieben, das heißt auch sie stehen dem einfachen Gesetzgeber nicht zur Disposition ${ }^{16}$.

Es könnte nun natürlich erwogen werden, eine neue Normkategorie zu schaffen, deren Rechtmäßigkeit von keiner zentralen Stelle überprüft wird. Da die Aufhebungskompetenz des Verfassungsgerichtshofes aber nicht bloß dem Zweck der Kontrolle ordnungsgemäßen Verhaltens der staatlichen Machtträger dient, sondern auch die entscheidende Basis für den Konträrschluß bildet, daß derartige Anordnungen selbst bei Feblerbaftigkeit bis zur Beseitigung durch das Höchstgericht gültig und wirksam sind, hätte ein solches Vorgehen normtheoretisch zur Folge, daß Bestimmungen der betreffenden Kategorie von jedermann hinsichtlich ihrer Rechtswidrigkeit geprüft werden müßten und bei Vorliegen eines Fehlers absolut nichtig wären. Die daraus resultierende Rechtsunsicherheit wäre für die Praxis unerträglich und mit dem Rechtsstaatsprinzip österreichischer Prägung nicht vereinbar ${ }^{17}$. Es ist somit letztlich davon auszugehen, daß die Geschlossenheit des Rechtsquellensystems bezüglich generellabstrakter Normen auch aus rechtsstaatlichen Erwägungen grundsätzlich zu bejahen ist.

Individuell-konkrete Rechtsakte der Verwaltung sind hingegen auf einer anderen Ebene der Verfassung angesiedelt. Sie haben aufgrund der Entscheidung des Verfassungsgesetzgebers für ein striktes Legalitätsgebot primär nicht die Aufgabe der Rechtserzeugung, sondern der Vollziehung, das heißt die Funktion, die vom demokratisch legitimierten Gesetzgeber getroffenen allgemeinen Anordnungen auf den Einzelfall anzuwenden. Es ist dem einfachen Gesetzgeber von Verfassungs wegen übertragen, das heißt er ist ermächtigt und verpflichtet

(235 ff.) mit weiteren Literaturhinweisen. In der Zuständigkeit des VfGH zur Kontrolle genereller Normen wird daher auch der Kern der Funktion dieses Gerichtshofes als eines „Hüters der Verfassung“ gesehen; vgl. Ludwig Adamovich/ Bernd-Christian Funk, Verfassungsrecht, 334.

${ }_{16}$ Vgl. statt vieler etwa Ludwig Adamovich/Bernd-Christian Funk, Verfassungsrecht, 336; und Robert Walter/Heinz Mayer, Grundriß Bundesverfassungsrecht, Rdn. 1050.

${ }^{17}$ Der Umstand, daß die Verfassung selbst gewisse Ausnahmen von diesem Grundsatz der Sicherheit über den Bestand an geltenden generell-abstrakten Normen macht - so bewirken etwa Fehler bei der Kundmachung von Gesetzen und Verordnungen gemäß Art. 89 Abs. 1 B-VG deren absolute Nichtigkeit - ändert an den angestellten Überlegungen nichts; zum Spannungsverhältnis derartiger Durchbrechungen des Prinzips des Fehlerkalküls zum rechtsstaatlichen Baugesetz der österreichischen Verfassungsrechtsordnung vgl. Johannes Hengstschläger, Totaländerung, $237 \mathrm{ff}$. 
zugleich, nicht nur die materiellen Bestimmungen und die subjektiven Ansprüche des einzelnen zu regeln, sondern auch die Form und Prozedur, in der diese verwirklicht werden. Dabei eröffnet die Verfassung dem einfachen Gesetzgeber einen relativ großen Spielraum.

Für den verwaltungsrechtlichen Vertrag ist nun entscheidend, ob es dabei dem einfachen Gesetzgeber auch anheimgestellt ist, neue Rechtssatztypen einzuführen, oder ob er sich auf jene, die in der Verfassung ausdrücklich angesprochen sind, beschränken muß. Vergegenwärtigt man sich noch einmal den Telos des individuellen Verwaltungshandelns - also die Rechtsverwirklichung -, so gibt es vorerst keinen Grund, neue Rechtssatzformen a priori auszuschließen. Voraussetzung ist allerdings, daß sie diesem Zweck dienen und jene Grundsätze akzeptieren, welche die Verfassung für die Rechtskonkretisierung durch Verwaltungsorgane postuliert.

Das Bundes-Verfassungsgesetz verlangt für hoheitliches individuell-konkretes Verwaltungshandeln neben der bereits erwähnten, dem Art. 18 B-VG entsprechenden Gesetzesbindung insbesondere einen hinreichenden Rechtsschutz des einzelnen. Dabei muß es der Betroffene in der Hand haben, die ihm von der Rechtsordnung eingeräumten Berechtigungen letztlich - eventuell nach einem verwaltungsinternen Instanzenzug - bei einem der beiden Gerichtshöfe des öffentlichen Rechts zu erstreiten. Diese im Sechsten Hauptstück der Bundesverfassung getroffene Systementscheidung kommt insbesondere im Wortlaut ihres Art. 129 klar zum Ausdruck, der den Verwaltungsgerichtshof expressis verbis zur Sicherung der Gesetzmäßigkeit der gesamten öffentlichen Verwaltung beruft ${ }^{18}$.

Bei den Gerichtshöfen öffentlichen Rechts können von den individuell-konkreten Akten nach geltender Rechtslage ausschließlich Bescheide geprüft werden. Um der verfassungsgesetzlichen Forderung nach hinreichenden Rechtsverfolgungsmöglichkeiten zu genügen, muß der einfache Gesetzgeber bei der Ausgestaltung neuer Rechtsquellen folglich darauf bedacht sein, sie so zu konstruieren, daß sie letztlich in einen Bescheid münden und auf diese Weise an den

18 Seit der B-VG-Novelle 1988, BGBl.685/1988, mit der die unabhängigen Verwaltungssenate in das verfassungsrechtliche Rechtsschutzsystem eingebaut wurden, lautet Art. 129 B-VG: „Zur Sicherung der Gesetzmäßigkeit der gesamten öffentlichen Verwaltung sind die unabhängigen Verwaltungssenate in den Ländern und der Verwaltungsgerichtshof in Wien berufen. " Diese Verfassungsänderung ist jedoch für die folgenden Überlegungen ohne Belang. 
Verwaltungs- oder Verfassungsgerichtshof herangetragen werden können ${ }^{19}$.

Was bedeutet dies nun konkret für den verwaltungsrechtlichen Vertrag?

Zunächst ist festzuhalten, daß alle Versuche in der Literatur, die Zuständigkeitsbestimmungen im Sechsten Hauptstück des BundesVerfassungsgesetzes bezüglich der individuell-konkreten Normen extensiv zu interpretieren und unter den dort verwendeten Bescheidbegriff nicht nur den - vor allem in den österreichischen Verwaltungsverfahrensgesetzen konkretisierten - Bescheid im engeren Sinn zu subsumieren, sondern auch den verwaltungsrechtlichen Vertrag, bislang nicht überzeugen konnten.

So hat etwa Theo Öblinger mit tiefschürfenden Überlegungen nachzuweisen versucht, daß die Grenzen des tradierten Verständnisses des Bescheidbegriffes zu eng seien und eine Brücke in Richtung einer echten Bereicherung der öffentlich-rechtlichen Verwaltungsinstitutionen nicht nur von großem praktischen Nutzen, sondern auch verfassungsrechtlich begründbar wäre. Im Kern stützt er seine These auf die in $\$ 8$ des Allgemeinen Verwaltungsverfahrensgesetzes verankerte Parteistellung, die seiner Meinung nach die „positivrechtliche Überwindung der Deutung des Verwaltungsrechtsverhältnisses als strikte Über- und Unterordnung zwischen Staat und einzelnem und darüber hinaus auch die Überwindung der Konzeption des Verwaltungsaktes als Ergebnis eines streng heteronomen Prozesses“ bedeutet $^{20}$. „Der einzelne ist nicht mehr bloßer Adressat der Verwaltung, seine Beteiligung ist vielmehr gesetzliche Voraussetzung für das rechtmäßige Zustandekommen und, im Hinblick auf die Kontrolle dieser Voraussetzungen durch die Gerichtshöfe des öffentlichen Rechts, auch für den endgültigen Bestand eines Verwaltungsaktes. “21 $\mathrm{Da}$ dieser Begriff der Parteistellung nicht nur als wesentliches Element des Verwaltungsverfahrens im engeren Sinn zu werten sei, sondern auch den verfassungsrechtlichen Bescheidbegriff entscheidend mitdetermi-

19 Aus der Diktion des Art. 129 B-VG, der die "gesamte öfentliche Verwaltung" erfaßt, während die folgenden Artikel der Verfassung nur auf bestimmte Hoheitsakte abstellen, wird übrigens auch abgeleitet, daß es dem Staat nicht völlig freistehen könne, durch ein Ausweichen auf privatrechtliche Handlungsformen den öffentlich-rechtlichen Rechtsschutz letztlich leerlaufen zu lassen; vgl. etwa Bernhard Raschauer, Grenzen der Wahlfreiheit zwischen den Handlungsformen der Verwaltung im Wirtschaftsrecht, ÖZW 1977, 1 (3).

20 Theo Öblinger, Problem, 55.

21 Theo Öhlinger, Problem, 55. 
niere, lasse sich die Mitwirkung des einzelnen in Form des Vertragsabschlusses unschwer unter diesen Terminus subsumieren ${ }^{22}$.

Daß diese These letztlich nicht überzeugt, läßt sich mit denselben Argumenten belegen, die schon zuvor gegen die Ausführungen von Heinz Mayer zur Deutung des verwaltungsrechtlichen Vertrages als antragsbedürftiger Bescheid ins Treffen geführt wurden. Sie schätzt nämlich in gleicher Weise den zentralen qualitativen Unterschied zwischen Bescheid und Vertrag zu gering, der - wie erwähnt - darin besteht, daß die Mitwirkung beim Vertrag ein Essentiale für das Zustandekommen bildet, während sie beim Bescheid nur die Rechtmäßigkeit, nicht aber auch die Gültigkeit bedingt.

Wenn der verwaltungsrechtliche Vertrag aber nicht als Bescheid im Sinne des Sechsten Hauptstücks des Bundes-Verfassungsgesetzes zu werten ist, gilt nach dem bisher Gesagten für ihn folgendes: An der prinzipiellen Kompetenz des einfachen Gesetzgebers, dieses Rechtsinstitut zu verankern, kann nicht gezweifelt werden. Jedoch entspricht eine solche Regelung im Hinblick auf die gebotene Justitiabilität individuell-konkreter Normen bei den Gerichtshöfen öffentlichen Rechts nur dann der Verfassung, wenn der Gesetzgeber im Falle von Streitigkeiten eine bescheidmäßige, also justitiable, Erledigung der Angelegenheit vorsieht.

Es stellt sich in diesem Zusammenhang natürlich die Frage, in welchem Verhältnis Vertrag und Bescheid zueinander stehen, insbesondere welche Rechtswirkungen der Vertrag für das förmliche Bescheidverfahren zeitigt. Dem einfachen Gesetzgeber stehen im wesentlichen zwei Varianten offen:

- Zum einen könnte er anordnen, daß der Vertrag bei Streitanhängigkeit völlig wegfällt und die zuständige Verwaltungsbehörde bei ihrer Entscheidung ausschließlich an die einschlägigen Gesetze und Verordnungen gebunden ist.

Dies würde beispielsweise für die in der österreichischen Rechtsordnung vorgesehene verwaltungsvertragliche Pauschalierung im Steuerrecht bedeuten, daß dann, wenn der Vertrag in Zweifel gezogen wird, die Behörde ohne Rücksicht auf den Inhalt der Vereinbarung und damit ohne Berücksichtigung des diesbezüglichen Parteiwillens die gesetzmäßig vorgesehene Steuerschuld vorzuschreiben härte.

- Die Alternative wäre, daß der Vertrag auch im Rechtsmittelverfahren, das heiß\}t für den zu erlassenden Bescheid, Rechtswirkungen entfaltet.

22 Theo Öblinger, Problem, $55 \mathrm{f}$. 
Umgelegt auf das Pauschalierungsbeispiel bedeutete dies, daß die Behörde bei Bescheiderlassung zunächst darüber zu befinden hätte, ob ein Vertrag gültig zustandegekommen ist, das heißt ob er besteht oder nicht. Würde dies verneint, könnte er natürlicherweise keine Wirkungen entfalten und die Behörde wäre in ihrer Entscheidung frei, oder besser gesagt, ausschließlich an die bestehende Rechtslage gebunden. Käme die Behörde hingegen zur Auffassung, daß ein gültiger Vertrag vorliegt, so wäre sie verpflichtet, den Vertragsinhalt ibrer Entscheidung zugrundezulegen, das heißt, daß die Verwaltungsbehörde genau das bescheidmäßig vorzuschreiben hätte, was im Vertrag ausbedungen wurde, selbst wenn sie bei einseitiger Veranlagung zu einem anderen Ergebnis hätte kommen müssen.

Um es noch einmal klarzustellen: Dies bedeutet nicht, daß der Vertrag auch dann, wenn er außerhalb des Rahmens der gesetzlichen Ermächtigung abgeschlossen wurde, Bindungswirkung entfaltet. In diesem Fall ist er nichtig. Es bedeutet vielmehr, daß die Rechtslage, die den Vertragsabschluß regelt, anders gestaltet ist und der Verwaltung - etwa mit der Formel "soweit diese Vereinbarung das steuerliche Ergebnis bei den Steuerpflichtigen nicht wesentlich verändert“ mehr Spielraum einräumt als jene, die diese bei einseitiger Veranlagung determiniert.

Die österreichische Rechtsordnung geht - soweit sie verwaltungsrechtliche Verträge vorsieht - auf die Problematik, ob und welche Wirkungen ein Vertrag zeitigt, mit keinem Wort ein. Für die Praxis sinnvoller und dem Telos des verwaltungsrechtlichen Vertrages adäquater ist ohne Zweifel die zweite Lösung; daher meine ich, daß ihr bei Fehlen einer ausdrücklichen anderslautenden gesetzlichen Anordnung der Vorzug zu geben ist ${ }^{23}$. Eine Vereinbarung wäre das Papier nicht wert, auf dem sie steht, könnte sie jeder der Vertragspartner insbesondere auch die Verwaltung - bloß durch die Provozierung eines Streitfalles gänzlich beseitigen und an ihrer Stelle einen einseitigen obrigkeitlichen Bescheid erzwingen. Ein Vertrag, der die Partner nur bindet, solange es diesen beliebt, macht wenig Sinn.

Im Lichte dieser Überlegungen erweist sich letztlich auch die Judikatur des österreichischen Verfassungsgerichtshofes zum Problemkreis „verwaltungsrechtlicher Vertrag" als wohlbegründet. Richtungweisendes Erkenntnis zu dieser Thematik ist die Entscheidung vom

${ }^{23}$ So im Ergebnis auch Gerold Stoll, Das Steuerschuldverhältnis in seiner grundlegenden Bedeutung für die steuerliche Rechtsfindung, Wien 1972, 65 ff. 
6. Oktober $1981^{24}$ über die Verfassungsmäßigkeit des $\$ 6$ Abs. 7 des Wiener Vergnügungssteuergesetzes ${ }^{25}$, der der Verwaltung die Möglichkeit eröffnete, Vereinbarungen mit dem Steuerschuldner über vereinfachte Verrechnungsmodalitäten betreffend die Ermittlung des Abgabenbetrages bis hin zu einer Pauschalierung zu treffen.

In diesem Judikat hat der Verfassungsgerichtshof vorerst in Übereinstimmung mit dem Verwaltungsgerichtshof zwar dargetan, daß das österreichische Verwaltungsverfahren ebenso wie die Kontrolle der Verwaltung durch den Verwaltungsgerichtshof auf den behördlichen Verwaltungsakt - den Bescheid - abstellt. Daraus zog er aber zutreffenderweise nicht den Schluß, daß ein Kontrahieren der Behörde mit der Partei nach dem ganzen System des Rechtsschutzes ausgeschlossen sei und dem Prinzip der Rechtsstaatlichkeit widerspräche ${ }^{26}$.

Für entscheidend hielt er vielmehr, daß allenfalls vorgesehene Vereinbarungen im Rahmen öffentlich-rechtlicher Beziehungen zwischen Behörde und Rechtsunterworfenen in das bestehende System derart eingebettet werden, daß dem Verwaltungsgerichtshof die Überprü-

${ }^{24}$ VfSlg. $9226 / 1981$.

${ }^{25} \$ 6$ Abs. 7 des Vergnügungssteuergesetzes für Wien 1963, LGBl.11/1963, lautet: „Der Magistrat kann mit einzelnen Steuerpflichtigen oder Gruppen von Steuerpflichtigen Vereinbarungen über die zu entrichtende Steuer treffen, soweit diese die Besteuerung vereinfachen und das steuerliche Ergebnis bei den Steuerpflichtigen nicht wesentlich verändern."

Das mehrfach und zuletzt durch LGBl.35/1985 geänderte Vergnügungssteuergesetz 1963 trat am 1.1.1988 außer Kraft. Gleichzeitig wurde das Wiener Vergnügungssteuergesetz 1987 (VGSG), LGBl.43/1987, in Geltung gesetzt; die zitierte Bestimmung wurde wortgleich in $\$ 18$ des neuen Gesetzes übernommen. Auch das Wiener Vergnügungssteuergesetz 1987 wurde bereits mehrfach novelliert, zuletzt durch LGBI. 41/1992.

${ }^{26}$ Das Erkenntnis des VfGH erging aufgrund eines Anfechtungsantrages des $\mathrm{VwGH}$, der die Ansicht vertrat, die in $\$ 6 \mathrm{Abs} .7$ Wiener Vergnügungssteuergesetz eingeräumte Ermächtigung zu Vereinbarungen zwischen der Abgabenbehörde und den Steuerpflichtigen widerspreche verfassungsrechtlichen Bestimmungen; vgl. den auszugsweise abgedruckten Antrag des VwGH bei VfSlg. 9226/1981. In der Folge übernahm der VwGH die Argumentation des VfGH in bezug auf Begriff und Zulässigkeitsvoraussetzungen öffentlich-rechtlicher Verträge; vgl. VwSlg. 5678 (F)/ 1982.

Auch der OGH geht in seiner Entscheidung vom 10.7.1991, 1 Ob.30/91, abgedruckt in den JBl. 1992, $35 \mathrm{ff}$., wohl von der grundsätzlichen Zulässigkeit verwaltungsrechtlicher Verträge im Rahmen der österreichischen Verfassungsrechtsordnung aus, sodaß in dieser Hinsicht eine erfreuliche, sonst leider nicht immer festzustellende Einhelligkeit in den Auffassungen der Höchstgerichte besteht. 
fung des Inhalts solcher Vereinbarungen nicht verwehrt ist. Nachdem die angeführte Bestimmung des Wiener Vergnügungssteuergesetzes bei Meinungsverschiedenheiten eine Entscheidung durch förmlichen, justitiablen Bescheid vorsah, hat sie der Verfassungsgerichtshof nicht verworfen ${ }^{27}$.

Daraus ist zweierlei ableitbar:

- Erstens geht der Verfassungsgerichtshof - was die Formen individuell-konkreten Verwaltungshandelns anbelangt - vom Grundsatz der Offenbeit des Rechtsquellensystems aus ${ }^{28}$.

- Zweitens verlangt er im Hinblick auf das Prinzip des Rechtsstaates, der notwendigerweise auch Rechtsschutzstaat ist, unabdingbar, daß alles individuelle Verwaltungshandeln letztlich einer Prïfung durch die Gerichtshöfe öffentlichen Rechts unterliegen und aus diesem Grund der verwaltungsrechtliche Vertrag bei Streitigkeiten in einen Bescheid münden muß. Er geht also offenkundig davon aus, daß dieser per se nicht Bescheidqualität im Sinne des Sechsten Hauptstücks des Bundes-Verfassungsgesetzes hat, oder - anders gewendet - er versteht den verfassungsrechtlichen Terminus Bescheid nicht in einem extensiven, auch den verwaltungsrechtlichen Vertrag umfassenden Sinn.

Insgesamt ist diese Judikatur zu begrüßen. Es wäre weder einsichtig begründbar noch zielführend, auf einem Dogma von der Geschlossenheit des Katalogs individuell-konkreter Verwaltungsnormen zu beharren, wenn zweierlei berücksichtigt wird: Erstens, daß die Handlungsformen der Verwaltung dadurch eine sachgerechte Fortentwick-

27 Aus der Feststellung, „daß die Behörde im ,Streitfall“ der bescheidmäßigen Festsetzung von Abgaben die vorausgegangene Vereinbarung zugrunde zu legen hat", läßt sich wohl ableiten, daß der VfGH auch die weiter oben behandelte Frage nach den Rechtswirkungen des Vertrages im Hinblick auf das förmliche Bescheidverfahren im hier dargelegten Sinne beantwortet. So gesehen ist der Vorwurf von Gerbart Wielinger, Was bringt der verwaltungsrechtliche Vertrag?, ZfV 1983, 14 (17), der Gerichtshof habe sich diesbezüglich jeder Äußerung enthalten, nicht berechtigt.

${ }^{28}$ Entgegen der Ansicht von Walter Antoniolli/Friedrich Koja, Verwaltungsrecht, 498 kann die Frage nach der Geschlossenheit des Rechtsquellenkatalogs betreffend individuelle Rechtsnormtypen nicht offen bleiben. Selbst wenn man der oben dargelegten Auffassung, wonach die bescheidmäßigen Gestaltungskompetenzen der Behörde durch den Abschluß verwaltungsrechtlicher Verträge eingeschränkt werden, nicht folgt, darf nämlich die Rechtsquelleneigenschaft einer solchen Vereinbarung bei unstreitiger Willensübereinkunft der Vertragspartner nicht übersehen werden! 
lung erfahren, und zweitens, daß die von der Verfassung für das Verwaltungshandeln postulierten Grundsätze eingehalten werden, insbesondere daß der einzelne keine Verschlechterung seiner Rechtsposition und seiner Rechtsschutzmöglichkeiten erfährt.

Ähnlich komplexe Probleme wie der verwaltungsrechtliche Vertrag bereiten schließlich auch die informellen Absprachen im Hoheitsbereich, die ich abschließend noch ganz kurz beleuchten möchte.

Als typisches Beispiel für diese Handlungsform sei erneut eine im Steuerrecht gebräuchliche Konstruktion angeführt, nämlich der Rechtsmittelverzicht vor Erlassung des Steuerbescheides ${ }^{29}$. Anläßlich von Schlußbesprechungen in Betriebsprüfungsverfahren einigen sich die Finanzbehörde auf der einen und der Steuerschuldner auf der anderen Seite bezüglich strittiger Sach- und Rechtsprobleme - ähnlich wie bei einem zivilrechtlichen Vergleich. Die Vertreter der Finanzverwaltung sagen zu, die ausverhandelte Lösung dem Steuerbescheid zugrundezulegen ${ }^{30}$, und der Pflichtige erklärt seinerseits den Rechtsmittelverzicht ${ }^{31}$.

$\mathrm{Da}$ Vereinbarungen dieser Art - anders als die zuvor behandelten verwaltungsrechtlichen Verträge - einer gesetzlichen Grundlage entbehren, läuft die Diskussion zur Frage nach der Bindung der Verwal-

29 Vgl. dazu etwa Heinz Mayer, Vertrag, 635 f.; Hans Georg Ruppe, Konsumentenschutz und Abgabenrecht, in: Bernd Schilcher/Rudolf Bretschneider (Hrsg.), Konsumentenschutz im öffentlichen Recht, Wien 1984, 197 (210f.); und Gerold Stoll, Steuerschuldverhältnis, $81 \mathrm{f}$.

${ }^{30}$ Rechtstechnisch gesehen handelt es sich hierbei um eine Zusage, die in Anlehnung an die in Deutschland gebräuchliche Terminologie auch in Österreich als Willenserklärung der Behörde definiert wird, mit der sie sich zu einem bestimmten künftigen Verhalten, insbesondere zu einer bestimmten rechtlichen Beurteilung eines ihr vorliegenden Sachverhaltes, verpflichtet. Das Willenselement soll solche Zusagen von bloßen Ausküntten unterscheiden, die lediglich den Charakter von Wissenserklärungen haben. Wie in der Lehre zutreffend betont wird, kommt der soeben dargelegten Unterscheidung von den dogmatischen Konsequenzen her gesehen in Österreich jedoch keine besondere Bedeutung zu, sodaß die für Auskünfte gewonnenen Ergebnisse weitgehend auch auf Zusagen angewendet werden können. Vgl. zu alldem etwa Wolfgang Nikolaus, Auskünfte von Finanzbehörden nach dem Auskunftspflichtgesetz, Wien 1987, 24; Elmar Puck, Haftung des Staates für informelle Zusagen und Auskünfte, in: Josef Aicher (Hrsg.), Die Haftung für staatliche Fehlleistungen im Wirtschaftsleben, Wien 1988, 171 (172); sowie Hans Georg Ruppe, Auskünfte und Zusagen durch Finanzbehörden, Österreichische Steuer-Zeitung 1979, 50 (50).

31 Rechtsgrundlage hierfür ist $\$ 255$ Bundesabgabenordnung (BAO), BGBl. 194/ 1961 i.d. F. BGBl. 151/1980; zuletzt wurde die BAO durch die Novelle BGBl. 457/ 1991 geändert. 
tung an von ihr gemachte Zusagen letztlich darauf hinaus, in welchem Verhältnis das Legalitätsprinzip zum allgemeinen Rechts- und Auslegungsgrundsatz von Treu und Glauben steht. Anders als in Deutschland vertritt die österreichische Lehre und Judikatur diesbezüglich nahezu einhellig einen prinzipiellen Vorrang des Gesetzmäßigkeitsgrundsatzes ${ }^{32}$.

Die Maxime, daß jeder, der am Rechtsleben teilnimmt, grundsätzlich zu seinem Wort und seinem Verhalten zu stehen hat ${ }^{33}$, wird in Österreich also nicht als verfassungsrechtliches, dem Legalitätsprinzip ebenbürtiges Postulat gewertet, die dieses (partiell) derogieren könnte. Vielmehr findet sie nur insoweit Beachtung, als der Gesetzmäßigkeitsgrundsatz schon von vornherein Spielräume offenläßt, wie etwa beim Ermessen.

Verstößt eine von der Verwaltung gemachte Zusage gegen die gesetzlichen Grundlagen, muß die Behörde folglich im anschließenden Bescheid von ibrem Versprechen abweichen und die vom Gesetz geforderte Entscheidung treffen. Lediglich bei gesetzlich eingeräum-

32 Vgl. etwa Werner Doralt / Hans Georg Ruppe, Grundriß des österreichischen Steuerrechts II ${ }^{2}$, Wien 1988, 152; Erwin Melichar, Zur Frage von Treu und Glauben im Steuerrecht, in: Wirtschaftspraxis und Rechtswissenschaft (KastnerFS), Wien 1972, 309 (312); Franz Reeger/ Gerold Stoll, Kommentar zur Bundesabgabenordnung, Wien 1966, Anm. 7 zu $\$ 115$ (410f.); Emil Weinzierl, Der Grundsatz von Treu und Glauben im Abgabenverfahren, Finanzjournal 1977, 149 (149); sowie ferner Wolfgang Nikolaus, Auskünfte, 48 ff.; Elmar Puck, Haftung, 199; und Josef Werndl, Treu und Glauben im Abgabenrecht, in: Steuern im Rechtsstaat (Stoll-FS), Wien 1990, 375.

Plakativ für die Rechtsprechung der Gerichtshöfe öffentlichen Rechts ist beispielsweise die Entscheidung des VwGH Slg. 6106 (F)/1986: „Das im Art. 18 Abs. 2 B-VG normierte Legalitätsgebot ist ... stärker als jeder andere Grundsatz, insbesondere jener von Treu und Glauben (...). Da also die ,Durchsetzung der Rechtsordnung' Vorrang hat, kommt dem Grundsatz von Treu und Glauben nur dann Bedeutung zu, wenn die betroffene Vorgangsweise der Beh. nicht gegen zwingendes Recht verstößt (...).“

Vgl. in diesem Zusammenhang auch Gerold Stoll, Steuerschuldverhältnis, $81 \mathrm{ff}$., der allerdings ausschließlich auf die Formengebundenheit des Abgabenrechts abstellt, die eine Bindung der Behörde nur dann bewirkt, wenn ein mit entsprechender Bindungswirkung ausgestatteter Formalakt, also ein Bescheid, erlassen wurde. Der Grundsatz von Treu und Glauben kann - ebenso wie im Zivilrecht nicht dazu führen, daß Formvorschriften aufgelöst werden und Behördenschritte, die nicht in Bescheidform ergehen, solchen Erledigungen, die nur unter Einhaltung der Formvorschriften Bindungen ausstrahlen, gleichgestellt werden; vgl. Gerold Stoll, a. a. O., 80.

${ }^{33}$ So etwa die Definition bei Erwin Melichar, Frage, 310; sowie bei Werner Doralt/Hans Georg Ruppe, Grundriß Steuerrecht II, 152. 
ten Freiräumen hat sie als Determinante ihres Handelns die abgegebene Zusage zu berücksichtigen, die dann auch unter Berufung auf Treu und Glauben eingeklagt werden kann ${ }^{34}$.

Aber auch jene informellen Absprachen, denen keine Verbindlichkeit im Sinne einer Einklagbarkeit zukommt, weil sie gesetzwidrig sind, bleiben nicht ohne normative Konsequenzen. Vielmehr kann jeder, der vergeblich auf die Zusagen der Verwaltung vertraut hat, im Rahmen des Amtshaftungsrechtes Schadenersatz begehren ${ }^{35}$. Die Ersatzansprüche umfassen jedoch nicht das Erfüllungsinteresse - das heißt eine Abgeltung für jene Vorteile, die durch das Nichteinhalten der Vereinbarung verlorengegangen sind -, sondern beschränken sich auf die Rückerstattung des Vertrauensschadens. Der enttäuschte Private muß also bloß so gestellt werden, wie er stünde, wenn die Absprache nicht getroffen worden wäre ${ }^{36}$.

Insgesamt und abschließend gesehen mündet das heutige Thema nach Maßgabe der österreichischen Rechtsordnung in zwei Problemkreise:

1. Die Privatwirtschaftsverwaltung, wo der Rechtsstaat in Wahrheit leerläuft, wird zu zähmen sein.

2. Neue hoheitliche Gestaltungsformen mit synallagmatischem Charakter, welche durch das strikte Rechtsstaatsgebot österreichischer Prägung stark eingeengt werden, sind systemimmanent weiterzuentwickeln, und zwar im Dienste des Bürgers als Partner der Verwaltung und nicht als ihr Untertan.

${ }^{34}$ Vgl. etwa Erwin Melichar, Frage, 319; Wolfgang Nikolaus, Auskünfte, 55; und Emil Weinzierl, Grundsatz, 149.

35 Neben dem Entstehen von Amtshaftungsansprüchen auf seiten des geschädigten Steuerpflichtigen zieht das Abweichen der Behörde von einer gemachten Zusage aber auch noch weitere normative Konsequenzen nach sich, etwa das Unwirksamwerden eines im Vertrauen auf die behördliche Erklärung gemachten Rechtsmittelverzichtes i.S. des $\$ 255 \mathrm{BAO}$ (so etwa Hans Georg Ruppe, Konsumentenschutz, 211; und Gerold Stoll, Steuerschuldverhältnis, 82; vgl. in diesem Zusammenhang auch Reinbold Beiser, Irrtum bei Abgabe eines Rechtsmittelverzichts, RdW 1989, 141).

36 Vgl. etwa Gerold Stoll, Steuerschuldverhältnis, $83 \mathrm{f}$; sowie ferner auch Heinz Krejci, Das Sozialversicherungsverhältnis, Wien 1977, 259; und Hans Georg Ruppe, Auskünfte, 55. 


\title{
Verträge und Abmachungen zwischen der Verwaltung und Privaten in der Schweiz
}

\author{
3c. Landesbericht von Prof. Dr. Rainer J. Scbweizer, St. Gallen
}

1. Im Recht der Verträge zwischen Verwaltung und Privaten bildet die Schweiz keinen Sonderfall, weil sich ähnliche Probleme stellen wie im befreundeten Ausland, aber sie ist auch kein Musterland, weil alles recht wenig grundsätzlich, sondern fallbezogen und pragmatisch angegangen wird ${ }^{1}$. Auszugehen ist für diesen Bericht davon, daß es in der Schweiz keine expliziten, generellen Verfassungs- und Gesetzesregeln über Voraussetzungen und Anforderungen an Verträge und

1 Vgl. zum Tagungsthema aus der Schweiz: Lukas S. Brühwiler-Frésey, Verfügung, Vertrag, Realakt und andere verwaltungsrechtliche Handlungssysteme, Diss. 1984; Kurt Eichenberger, Verwaltungsprivatrecht, in: Privatrecht, öffentliches Recht, Strafrecht, Festgabe zum Schweizer. Juristentag 1985, S. 75 ff.; Thomas Fleiner-Gerster, Probleme des öffentlich-rechtlichen Vertrags in der Leistungsverwaltung, in: ZBl. 1989, S. 185 ff.; Sergio Giacomini, Verwaltungsrechtlicher Vertrag und Verfügung im Subventionsverhältnis „Staat - Privater", Diss. 1992; Fritz Gygi, Verwaltungsrecht, 1986, S. 206 ff.; Ulrich Häfelin/Georg Müller, Grundriß des Allgemeinen Verwaltungsrechts, 1990, S. 182 ff.; Claire Huguenin, Die bundesgerichtliche Praxis zum öffentlich-rechtlichen Vertrag, in: ZBJV 1982, S. $489 \mathrm{ff}$;; Max Imboden, Der verwaltungsrechtliche Vertrag, in: ZSR 1958, II, S. 1 a ff.; Blaise Knapp, Grundlagen des Verwaltungsrechts, Dt.-spachige Ausgabe der 4. Aufl. des „Précis de droit administratif“, Bd.I, 1992, S.319ff.; Beat Krähenmann, Privatwirtschaftliche Tätigkeit des Gemeinwesens, Diss. 1987; Pierre Moor, Droit administratif, Vol.II: Les actes administratifs et leur contrôle, 1991 S. $237 \mathrm{ff}$.; Georg Müller, Zur Rechtsnatur der Vereinbarung über die Sorgfaltspflicht der Banken bei der Entgegennahme von Geldern und über die Handhabung des Bankgeheimnisses, in: SJZ 1984, S. $349 \mathrm{ff}$.; ders., Das Verhältnis zwischen einem privatrechtlichen Vertrag über die Abtretung von öffentlichem Grund zu einer verwaltungsrechtlichen Erschließungsvereinbarung, in: recht 1988, S. 25 ff.; Paul Richard Müller, Das öffentliche Gemeinwesen als Subjekt des Privatrechts, Diss. 1970; Etienne Poltier, Les gentlement's agreements à participation publique, in: ZSR 1987, I, S. $367 \mathrm{ff}$; René A. Rhinow, Verfügung, Verwaltungsvertrag und privatrechtlicher Vertrag, in: Privatrecht, öffentliches Recht, Strafrecht, Festgabe zum Schweizer. Juristentag 1985, S. 295 ff.; ders., Verwaltungsrechtlicher oder privatrechtlicher Vertrag, in: 
Abmachungen zwischen der Verwaltung und Privaten gibt. In den eidgenössischen und den kantonalen Verfahrens- und Rechtspflegeordnungen hat man sich weitgehend darauf konzentriert, den Verwaltungsakt - Verfügung genannt - als Verfahrensziel und zugleich als Anknüpfungspunkt (Streitgegenstand) des öffentlich-rechtlichen Rechtsschutzverfahrens zu regeln. Bestimmungen über den Abschluß verwaltungsrechtlicher Verträge gibt es kaum². Bei Bedarf greift man in der Praxis für vertragliche Vereinbarungen (immer noch) auf das allgemeine privatrechtliche Schuldrecht zurück. Wenn somit auch allgemeines Verfahrensrecht und erst recht gesetztes materielles Verwaltungsrecht für Verträge fehlen, so gibt es dennoch eine stattliche Anzahl spezialgesetzlicher Vorschriften, wo Verträge vorgesehen sind, vom Enteignungsrecht über die Agrarmarktordnung bis zur neuen Rahmengesetzgebung des Bundes über öffentliche Finanzhilfen und Abgeltungen (Subventionen) ${ }^{3}$.

2. Über diese Sondervorschriften hinaus finden dialogische, einvernehmliche Regelungen von Verwaltungsrechtsverhältnissen in der Schweiz eine kaum zugegebene, doch enorm breite Anwendung 4 . Diese reicht von den Residuen der Fiskalverwaltung über die Inanspruchnahme von Einrichtungen und Anstalten der Leistungsverwaltung, über gesetzesverstärkende und -absichernde Vereinbarungen im Bodenerschließungs- und -nutzungsrecht oder Baubewilligungsrecht, über gesetzesergänzende Vereinbarungen in der Wirtschaftsaufsicht und -lenkung, im öffentlichen Verkehr und der kommunalen Verund Entsorgung, bis schließlich gar zu den, die staatliche Normsetzung substituierenden, behördlich abgesegneten Abmachungen in der Kartell- und Bankenaufsicht, im Medizinalrecht, im Banken- und Clearingwesen oder bei der Abfallverhütung. Von den letztgenannten Abmachungen ist der Schritt dann nicht mehr weit zu Verträgen, die

recht 1985, S. 57 ff.; Paul Richli, Rechtsformen für die Gewährung von Finanzhilfen, in: ZSR 1986, I, S. 79 ff.; ders., Zu Gründen, Möglichkeiten und Grenzen für Verhandlungselemente im öffentlichen Recht, in: ZBl. 1991, S. 381 ff.; Henri Zwablen, Le contrat de droit administratif, in: ZSR 1958, II, S. $461 \mathrm{ff}$.

2 Vgl. immerhin zum öffentlich-rechtlichen Vertrag Art. 123-126 Gesetz des Kantons Glarus über die Verwaltungsrechtspflege, vom 4. Mai 1986.

3 Art. $16 \mathrm{ff}$. Bundesgesetz über Finanzhilfen und Abgeltungen (Subventionsgesetz), vom 5. Okt. 1990 (SR 616.1).

4 Vgl. z. B. Paul Richard Müller (Anm. 1), S.170ff.; Häfelin/Müller (Anm. 1), S. 185 ff.; Knapp (Anm. 1), S. 336f.; Poltier (Anm. 1); Krähenmann (Anm. 1). 
mit privaten Unternehmen im Hinblick auf die Privatisierung öffentlicher Aufgaben bzw. die Liquidation öffentlicher Aufgabenerfüllung geschlossen werden.

3. Wenn das Gesetz, nach einer ständigen, unbestrittenen Rechtsprechung des Bundesgerichts, die allgemeine Handlungsvoraussetzung nicht nur für die Eingriffs-, sondern auch für die Leistungsverwaltung ist, so muß auch bei Verträgen primär nach der gesetzlichen Zulässigkeit des Vertragsabschlusses und der Vertragsinhaltsgebung gefragt werden ${ }^{5}$. Dabei ist genau gesehen die Frage nicht, wo Verträge und Abmachungen ihre Rechtsgrundlage in den Gesetzen finden, denn Grundlage des Vertrags ist die Willensübereinstimmung der Parteien, sondern die Frage ist, wo das Gesetz Raum für Verträge läßt und diese anstelle der einseitigen Anordnung akzeptiert. Während das Bundesgericht früher verwaltungsrechtliche Verträge zuließ, wenn das Gesetz sie ausdrücklich vorsah, meint es heute, daß es genüge, wenn das Gesetz sie nicht ausdrücklich ausschließ $e^{6}$. Das ist ungenau, denn Sinn und Zweck des Gesetzes können auch einem Vertrag entgegenstehen. Oder das Gericht meint, daß es genüge, wenn das Gesetz Raum für eine vertragliche Regelung lasse ${ }^{7}$. Die Lehre verlangt zusätzlich, daß der Vertrag besonders geeignet und sinnvoll zur Konkretisierung und Ergänzung der gesetzlichen Ordnung sein muß. Damit scheiden vertragliche Lösungen überall dort aus, wo das Gesetz wie im Sozialversicherungsrecht eine allgemeine, rechtsgleiche Ordnung von Leistungen und Pflichten aufstellt und gar wegen der Rechtsgleichheit wie im Steuerrecht ausdrücklich Abmachungen verbietet ${ }^{8}$. Verträge scheiden sodann dort aus, wo das Gesetz Grenzen staatlicher Normierung festlegt. Schwerer fällt der Rechtsprechung und der Lehre die Beantwortung der nächsten Frage, wie weit denn der Vertragsinhalt, die Verpflichtungen der Vertragsparteien, gesetzmäßig sein müssen. Das Bundesgericht sagt, daß keine Leistungen von den Privaten gefordert werden dürfen, die sich nicht auf eine gesetzliche Grundlage abstützen lassen'. Genauer ist es wohl, daß der Vertrag die gesetzlichen Ziele und Vorgaben erfüllen und daß er die verfassungsrechtlichen Rahmenbedingungen (insbesondere die Verhältnismäßigkeit) für

${ }^{5}$ Gygi (Anm. 1), S. $206 \mathrm{ff} . ;$ Häfelin/Müller (Anm. 1), S. 47 ff.; 184 ff.; Knapp (Anm. 1), S. $319 \mathrm{ff} . ;$ Moor (Anm. 1), S. $260 \mathrm{ff}$.

6 BGE 103 I a 512; 105 I a 209.

7 BGE 103 I a 34.

8 BGE 104 V 162; 101 I a 92.

9 BGE 105 I a 210. 
den Schutz der Autonomie der privaten Partei respektieren muß. Unklar bleibt aber meist, warum die Rechtsprechung zwar präzise Vorgaben in der gesetzlichen Ermächtigung an den Verordnungsgeber, nicht aber an die Vertragsschöpfer verlangt. Das Umweltschutzgesetz zeigt beispielhaft die Problematik von Blankettnormen für Verträge $e^{g_{2}}$.

4. Soweit also nicht Spezialgesetze Verträge vorsehen ${ }^{10}$, sind die Möglichkeiten gesetzesverwirklichender und gesetzesergänzender Vereinbarungen zwischen der Verwaltung und den Privaten in der Schweiz relativ offen und unbestimmt. Dementsprechend ist es nicht erstaunlich, daß man häufig verknüpfte oder gemischte Rechtsakte antrifft, wie z. B. Entscheidungen über die Bodennutzung, oder die in Auflagen und Bedingungen zu Baubewilligungen verpackten Abmachungen mit Bauherrn, oder die zwitterhaften Konzessionen ${ }^{11}$. Wenn diese Mischformen auch bezüglich Bestand und Ausführung wie Verfügungen behandelt werden können, so ist doch zusätzlich dem Vertrauensschutz und dem Schutz wohlerworbener Rechte Rechnung zu tragen.

5. Ist die Hauptfrage, ob anstelle einer Verfügung eine zweiseitige Vereinbarung zulässig und zweckmäßig ist, entschieden, stellt sich im nächsten Schritt die Qualifikationsfrage ${ }^{12}$. Auch hier wieder gibt es verschiedene spezialgesetzliche Entscheidungen, die allerdings mehr historisch bedingt als dogmatisch begründbar sind. $\mathrm{Da}$ meistens aber eine gesetzliche Qualifikation der Verträge fehlt, kommt es nach Lehre und Rechtsprechung (in dieser besonders für den Rechtsschutz wichtigen Frage) auf den Gegenstand der durch den Vertrag geregelten Rechtsverhältnisse an. Öffentlich-rechtlich ist ein Vertrag seinem Gegenstand nach, wenn er der Erfüllung öffentlich-rechtlicher Aufga-

9a Nach Art. 43 Umweltschutzgesetz (USG) vom 7.Okt. 1983 (SR 814.01) können die „Vollzugsbehörden ... öffentlichrechtliche Körperschaften oder Private mit Vollzugsaufgaben betrauen, insbesondere mit der Kontrolle und Überwachung."

10 Z.B. Art. $18 \mathrm{c}$ Bundesgesetz über den Natur- und Heimatschutz, vom 1. Juli 1966 (SR 451), betr. Schutz und Unterhalt von Biotopen; Art. 6 Bundesgesetz über die wirtschaftliche Landesversorgung, vom 8. Okt. 1982 (SR 531), betr. Pflichtlagerverträge.

11 Vgl. Alexander Ruch, Das Recht in der Bauordnung, Habil. 1992, Ziff. $5.1 \mathrm{ff}$. $\mathrm{Zu}$ den Konzessionen z. B. Häfelin/Müller (Anm. 1), S. $442 \mathrm{ff}$; Knapp (Anm.1), S. $301 \mathrm{ff} ., \mathrm{m}$. w. H.

${ }_{12}$ Dazu z.B. Georg Müller, Zur Rechtsnatur (Anm. 1), S.349ff.; Rhinow, Verwaltungsrechtlicher und privatrechtlicher Vertrag (Anm.1), S.60ff.; Moor (Anm. 1), S. 245 ff., 250 ff.; BGE 103 I b 335; 103 II 319; 109 II 79. 
ben dient, oder, nach einer modifizierten Aussage, wenn er sich in die öffentlichen Aktivitäten integriert. Diese Kriterien werden m. E. aber dann problematisch, wenn wie heute der Kreis der als öffentlich zu erfüllenden Aufgaben immer umstrittener ist, etwa weil die öffentliche Aufgabenerfüllung unwirtschaftlich sei oder weil sie wettbewerbsverzerrend wirke. Ungeachtet dieser politischen Fragen bekundet die Praxis z. B. in der Leistungsverwaltung oder im öffentlichen Dienstrecht leider gewisse Unsicherheiten. Um den keineswegs unbegründeten Bedenken gegen ein Ausweichen ins Privatrecht, das heute auch wegen der als lästig empfundenen Beschränkungen des Haushaltsrechts und des Beamtenrechts lockt, zu begegnen, legt die Doktrin zunehmend Grenzen für die Verwendung privatrechtlicher Verträge fest ${ }^{13}$. Mittels privatrechtlicher Verträge dürfen keine öffentlich-rechtlichen Beschränkungen, insbesondere keine faktischen und rechtlichen Monopole etabliert oder ausgeübt werden. Mit privatrechtlichen Verträgen kann selbstverständlich auch nicht der fehlende gesetzliche Rahmen kompensiert oder eine gesetzesändernde Regelung getroffen werden. Eine eigenständige und bleibende Bedeutung behält der privatrechtliche Vertrag im schweizerischen Verwaltungsrecht $\mathrm{m}$. E. längerfristig nur in der Bedarfs- und der Finanzverwaltung sowie im Recht des Verkehrs mit öffentlichen Sachen, das im wesentlichen mit dem privatrechtlichen Sachenrecht arbeitet.

6. Wie sind ursprünglich fehlerhafte Verträge zu behandeln ${ }^{14}$ ? Ein privatrechtlicher Vertrag ist, wenn er widerrechtlich ist, nichtig. Bei verwaltungsrechtlichen Verträgen wird nur ganz ausnahmsweise auf Nichtigkeit geschlossen, namentlich wenn der Vertrag bewußt im Hinblick auf einen rechtswidrigen Erfolg vereinbart wurde. Hat eine unzuständige Behörde den Vertrag abgeschlossen, widerspricht sein Inhalt gesetzlichen Vorschriften oder liegt ein Willensmangel einer Partei vor, so geht die eine Auffassung dahin, daß ein solcher Vertrag nach den Grundsätzen über die Gültigkeit fehlerhafter Verfügungen zu behandeln sei, während die andere nach Schuldrecht vorgehen will,

13 Paul Richard Müller (Anm.1), S. $313 \mathrm{ff.}, 374 \mathrm{ff}$;; Eichenberger (Anm.1), S. 78 ff.; Yvo Hangartner, Öfentlich-rechtliche Bindungen privatrechtlicher Tätigkeit des Gemeinwesens, in: Festschrift zum 65. Geburtstag von Mario M. Pedrazzini, 1990, S. $129 \mathrm{ff}$.

${ }_{14}$ Dazu Detlev Dicke, Der Irrtum bei der Verwaltungsmaßnahme, in: ZSR 1984, I, S. 528 ff., 542 ff.; Gygi (Anm.1), S.210f.; Häfelin/Müller (Anm.1), S. 194 ff.; Knapp (Anm. 1), S. 329 f.; Moor (Anm. 1), S. 263 ff.; BGE 103 I a 514f.; $105 \mathrm{I}$ a $207 \mathrm{ff}$. 
aber mit gewichtigen Abweichungen im Hinblick auf die Verantwortung der Verwaltung. Demnach kann z. B. auch der Motivirrtum (nicht nur der Grundlagenirrtum) berücksichtigt werden, und es wird durchwegs für eine Interessenabwägung zwischen der Durchsetzung des Gesetzesrechts und dem Vertrauensschutz plädiert.

7. Ändern sich nachträglich die tatsächlichen Verhältnisse, so akzeptiert die Praxis großzügiger als im Zivilrecht die Berufung auf die clausula rebus sic stantibus. Ändern sich die rechtlichen Grundlagen, so ist die entsprechende Einrede allenfalls dann zulässig, wenn sich die Änderung aus dem Recht eines übergeordneten Verbandes ergibt. Einer Rechtsänderung durch die staatliche Vertragspartei selbst aber gegenüber erweist sich der Vertrag als rechtsbeständig. Namentlich lassen sich wohlerworbene Rechte aus dem Vertrag, die als Korrelat privater Leistungspflicht entstanden sind, nur unter Respektierung der Eigentumsgarantie, und die übrigen Vertragsrechte der privaten Partei nur nach Treu und Glauben und auch nur unter Entschädigung aufheben ${ }^{15}$.

8. Ein Wort zu den Regeln über die Erfüllung verwaltungsrechtlicher Verträge $^{16}$. Zweifelsohne obliegt es der Verwaltung, die Vertragserfüllung zu beaufsichtigen und durch In-Verzug-setzen einzufordern. Unklar ist, ob der verwaltungsrechtliche Vertrag auch - wie es für die Verfügung in den Verfahrensgesetzen vorgesehen ist - einen einem Gerichtsurteil gleichgestellten Vollstreckungstitel bildet. Man nimmt das zugunsten der Verwaltung wie der Privaten für die meisten Vertragstypen an, mit Ausnahme der Verträge, die durch Gesetz vorgeschrieben sind bzw. die gesetzlich vorgeschriebenen Pflichten auferlegen. In diesen Fällen müsse der Richter über den Bestand der Forderung entscheiden.

9. Besonders kompliziert ist leider die Rechtsschutzordnung. Grundsätzlich gilt zum einen, daß Streitigkeiten über und aus privatrechtlichen Verträgen klageweise vor das Zivilgericht zu bringen sind. Dieses muß dann auch die verwaltungsrechtlichen Pflichten der staatlichen Partei sowie - nach der neueren Bundesgerichtspraxis - auch deren Grundrechtsbindungen beurteilen.

15 Häfelin/Müller (Anm. 1), S. 197 f.; Moor (Anm. 1), S. 268 ff.; BGE 103 I a 31, 505; René A.Rhinow, Wohlerworbene und vertragliche Rechte im öffentlichen Recht, in: ZBl. 1979, S. 11 ff.; Huguenin (Anm. 1), S. 490 ff.

16 Dazu z. B. Fleiner-Gerster (Anm. 1), S. 193 ff.; Knapp (Anm. 1), S. $331 \mathrm{ff}$. 
Grundsätzlich gilt zum andern, daß Streitigkeiten aus verwaltungsrechtlichen Verträgen durch das spezielle Rechtsmittel der sog. verwaltungsrechtlichen Klage vor den einstufigen Verwaltungsgerichten geltend zu machen sind. Diese Ordnung ist nun auf Bundesebene im Rahmen der Maßnahmen zur Entlastung des Bundesgerichts von 1991 aufgehoben worden ${ }^{17}$. Neu muß die Behörde von sich aus oder auf Antrag verfügen, und die private Partei kann dann Verwaltungsbeschwerde an eine administrative oder spezialgerichtliche Vorinstanz erheben, oder aber beide Parteien können mit Klage an eine Schiedskommission gelangen. Erst die Entscheide dieser Vorinstanzen können mit Verwaltungsgerichtsbeschwerde vor das Bundesgericht gebracht werden. Da es nur in wenigen Bereichen Schiedskommissionen gibt, wird im Regelfall durch Verfügung entschieden, woran sich der Verwaltungsbeschwerdeweg an die erste Rechtspflegeinstanz fügt. In der Lehre ist diese Neuerung zum Teil kritisiert worden, weil sie die private Vertragspartei in die unvorteilhafte Stellung des Beschwerdeführers zwinge ${ }^{18}$. Ich denke aber, daß die Kritik ungerechtfertigt ist, weil im - vom Untersuchungsgrundsatz und der Offizialmaxime beherrschten - Verwaltungsbeschwerde- und Verwaltungsgerichtsverfahren die private Partei eine bescheidenere Mitwirkungspflicht hat als in dem ursprünglichen Verwaltungsprozeß. Zudem erleichtert die behördliche Pflicht zur Begründung von Entscheiden der privaten Partei das Rechtsmittelverfahren, und vor allem stehen nun auch für Streitigkeiten über und aus verwaltungsrechtlichen Verträgen mindestens zwei Instanzen zur Verfügung.

10. Gestatten Sie mir abschließend ein paar allgemeine Feststellungen:

a) Verträge und Abmachungen zwischen Verwaltung und Privaten sind in der Schweiz nicht nur zunehmend verbreitet und beliebt, sondern ihre Bedeutung wird auch verwaltungsrechtlich immer mehr anerkannt ${ }^{19}$. Wirtschaftsinteressen an der Übernahme von öffentlichen Aufgaben, aber auch etwa die Bereitschaft breiter Kreise zum

17 Vgl. Art. 116 Bst. b (alt) und Art. 130 (alt) Bundesgesetz über die Organisation der Bundesrechtspflege (OG), vom 16. Dez. 1943 (SR 173.110), aufgehoben durch die Änderung des OG vom 4. Okt. 1991, mit Schlußbestimmungen (Ziff. 1 Ausführungsbestimmungen).

${ }_{18}$ Paul Richli, Zum verfahrens- und prozeßrechtlichen Regelungsdefizit beim verfügungsfreien Staatshandeln, in: AJP 1992, S $198 \mathrm{f}$., $202 \mathrm{f}$.

19 Z. B. Fleiner-Gerster (Anm. 1), S. 403 ff.; Richli, Zu den Gründen (Anm. 1), S. $388 \mathrm{ff}$. 
sozialen Engagement drängen seit je nach Vereinbarungen mit staatlichen Stellen. Für die Verwaltung andererseits sind die Vereinbarungen mit Privaten schon wegen ihrer begrenzten personellen und finanziellen Ressourcen unersetzlich. Vor allem braucht die Verwaltung Verträge und Abmachungen, damit der Rechtsvollzug einigermaßen gelingt. Verhandlungslösungen haben unzweifelhaft psychologische Vorteile; sie lösen z. B. Kreativität bei den Vertragsparteien aus, und sie fördern die Akzeptanz der Regelungen. Verhandlungen und Vereinbarungen entsprechen schließlich auch oft dem Verwaltungsstil in unseren vielfach noch kleinräumigen und dezentralisierten Verhältnissen sowie dem Respekt vor dem selbstbewußten, mit-stimmberechtigten Bürger.

b) Dennoch: Beliebtheit und Bedeutung vertraglicher Regelungen rechtfertigen nicht, daß man deren erhebliche Risiken übersehen oder gar vernachlässigen darf. Man muß sich in der Schweiz wohl fragen, ob tatsächlich die öffentlichen Interessen in den Vertragslösungen immer angemessen berücksichtigt werden. Schafft sich die Verwaltung mit Verträgen nicht oft allzu langfristige Bindungen, die dann einer unerläßlichen Anpassung an die veränderten Verhältnisse entgegenstehen (z. B. Wassernutzungskonzessionen)? Wird in der Praxis tatsächlich dem Grundrechtsschutz, den Geboten der Verhältnismäßigkeit und vor allem der Gleichbehandlung der Interessenten, Konkurrenten oder Benützer angemessen Rechnung getragen? Oder wird nicht gegenteils oft mit dem Argument, daß die Vertragsparteien im Wettbewerb mit der Privatwirtschaft gleich lange Spieße benötigen, oder dem Argument, daß besondere finanzielle Umstände eine Sonderlösung erheischen, auf die Einhaltung der Verfassungsvorgaben weitgehend verzichtet? Unstreitig werden oft die Interessen von betroffenen Drittpersonen mißachtet. Korrekturen werden jetzt endlich im Subventionsrecht ${ }^{20}$ sowie in neuen Vorschriften über das öffentliche Beschaffungswesen vorgenommen. Einen Fortschritt bringt auch die erwähnte neue Rechtsschutzordnung des Bundes, weil sie den bisher im Klageverfahren vielfach ausgeschlossenen Dritten Legitimation und Parteistellung im Beschwerde-, bzw. Verwaltungsgerichtsverfahren verschafft.

20 Vgl. Art. 19 Abs. 3 Subventionsgesetz, vom 5. Okt.1990 (SR 616.1): „Die Behörde eröffnet den Antrag auch den beschwerdeberechtigten Dritten. Diese sowie der Gesuchsteller können innert 30 Tagen eine anfechtbare Verfügung verlangen." 
Das größte Risiko liegt in der Praxis aber unverändert latent darin, daß die Verwaltung über Verträge und Absprachen die Gesetzesbindungen abzuschütteln versucht. Nur allzuoft hört man von Vertretern der Exekutiven aller Ebenen, daß sie angesichts der Zwänge des Legalitätsprinzips jetzt endlich wieder einmal „regieren“ wollen. Da wird der Rechtsstaat mit dem Verwaltungsvertragsrecht herausgefordert.

c) Wie dargelegt, ist die verwaltungsrechtliche Bewältigung von Verträgen und Absprachen in der Schweiz noch stark kasuistisch und bereichsspezifisch. Sie hat allerdings durch die beachtliche Renaissance, die die Verwaltungsrechtslehre in den letzten Jahren erlebt hat, doch erheblich an Orientierungssicherheit gewonnen. Gewisse minimale allgemeine Gesetzesregeln, namentlich über die Voraussetzungen und das Verfahren zum Abschluß der Verträge, scheinen mir mehr als nur wünschenswert, auch wenn vielleicht heute in Deutschland die Ordnung im Verwaltungsverfahrensgesetz in Einzelpunkten kritisiert wird.

d) Wichtiger ist aber, daß der allgemeinen öffentlich-rechtlichen Rahmenordnung des Verwaltungshandelns auch im Vertrags- und Absprachebereich Nachachtung verschafft wird. Es genügt dabei nicht, daß bei Schädigungen auch aus privatrechtlich vereinbarten Tätigkeiten nach der neueren Rechtsprechung eine Staatshaftung (Amtshaftung) ausgelöst werden kann, wie das z. B. für Körperschäden von vertraglich zugelassenen Privatärzten an öffentlichen Krankenanstalten der Fall ist. Nötig ist vielmehr in der Schweiz auch, daß sich etwa das verfassungsrechtliche Fairnessgebot des Verwaltungsverfahrensrechts oder daß sich haushaltsrechtliche Kontrollen, Verwaltungsaufsicht und Effizienzprüfungen auf die vertraglich begründeten Tätigkeiten von öffentlichem Interesse erstrecken, oder nötig ist - mit anderen Worten -, daß vereinbarungsorientiertes Verwaltungshandeln grundsätzlich denselben Grundregeln gehorcht wie einseitiges."

* Meiner Assistentin, Frau lic. iur. Sibylle Vorbrodt, danke ich für die Vorarbeiten. 


\section{Aussprache und Schlußworte \\ Verträge und Absprachen zwischen der Verwaltung und Privaten}

Vorsitzender: Meine sehr verehrten Damen und Herren, liebe Kolleginnen und Kollegen, wir beginnen mit der Nachmittagssitzung und kommen zur Aussprache über den zweiten Beratungsgegenstand: Verträge und Absprachen zwischen der Verwaltung und Privaten. Die Gliederung der Aussprache habe ich Ihnen bereits heute vormittag angegeben und nunmehr noch an die Tafel geschrieben.*

Wir wenden uns zunächst unter I. den rechtsdogmatischen Grundsatzfragen zu. Der Punkt begriffliche und sachliche Klärungen gibt auch Gelegenheit, rechtstatsächliche Feststellungen und Erkenntnisse vorzutragen und zu bewerten und damit zur Realanalyse beizutragen. Bei der Zulässigkeitsfrage haben wir absichtlich nicht zwischen Verträgen und Absprachen unterschieden, da hier durchaus Überschneidungen bestehen können. Es wäre aber doch zweckmäßig, wenn in der Diskussion angegeben würde, ob es konkret um Absprachen oder Verträge oder beides geht. Unter II. soll dann die Ausgestaltung des Vertragsrechts behandelt werden. Damit eine gewisse Linie erreicht wird, werden einzelne Punkte aufgeführt: Vertragsschluß, Wirksamkeit von Verträgen, Abgrenzung von öffentlich-rechtlichem und pri-

* I. Rechtsdogmatische Grundsatzfragen

1. Begriffliche und sachliche Klärungen

2. Zulässigkeit von Verträgen und Absprachen

II. Ausgestaltung des Vertragsrechts

1. Vertragsschluß

2. Wirksamkeit von Verträgen

3. Abgrenzung zwischen öffentlich-rechtlichen und privatrechtlichen Verträgen

4. Weitere Aspekte des Vertragsrechts

5. Besonderes Vertragsrecht

III. Rechtsfragen der Absprache 
vatrechtlichem Vertrag. Das soll allerdings keine abschließende Aufzählung sein. Deshalb können unter 4. noch weitere Aspekte erörtert werden, etwa der Rechtsschutz, der von den deutschen Referenten absichtlich ausgeklammert worden ist, aber in den Länderberichten eingehender behandelt wurde. Unter 5. wäre dann im Anschluß an entsprechende Ausführungen von Herrn Krebs noch über die Möglichkeit und den Nutzen der Entwicklung eines „besonderen Vertragsrechts" zu diskutieren. Unter III. kommen wir schließlich hoffentlich nicht zu knapp und zu spät - zu den Rechtsfragen der Absprache. Dieser Gliederungspunkt wurde absichtlich nicht weiter aufgegliedert, um der Diskussion ausreichenden Spielraum zu lassen.

Der Diskussionsleiter hat sich in der Sache zurückzuhalten. Aber erlauben Sie mir doch noch ein kleines Bild: Herr Burmeister hat das Schiff des Verwaltungsvertrags in sehr stürmische See gebracht. Wie es ihm dabei ergangen ist, wird sich in der Diskussion - vor allem unter I. - zeigen. Herr Krebs hat dann das Schiff in ruhigeres Gewässer geführt und dabei einen guten Kompaß für die Weiterfahrt geliefert. Darüber wird dann vor allem unter II. zu reden sein.

Ich eröffne damit die Aussprache. Es hat sich zunächst gemeldet Herr Grimm, dann Herr Schmidt-Aßmann und Herr Pitschas.

Grimm: Meine Damen und Herren! Die Grunddifferenz zwischen den beiden Referenten dieses Vormittags scheint mir darin zu liegen, daß Herr Burmeister versucht hat, die heutige Verwaltungsrealität in das Korsett des klassischen Legalitätsprinzips zu zwängen, während Herr Krebs es unternommen hat, das Legalitätsprinzip den heutigen Verwaltungsrealitäten anzupassen. Auf eine Kurzformel gebracht und im Bewußtsein der Überspitzung gesagt, ist bei Herrn Burmeister die Dogmatik die Konstante und die Realität die anpassungsbedürftige Variable, bei Herrn Krebs verhält es sich umgekehrt. Herr Burmeister hat dann keine andere Wahl, als große Teile des heutigen Verwaltungshandelns ohne Rücksicht auf ihre Ursachen für illegal zu erklären, während Herr Krebs sich auf den Boden veränderter Verhältnisse stellen und diese mit Hilfe eines modifizierten Legalitätsbegriffs rechtlich kanalisieren kann.

Ich empfinde Herrn Burmeisters Versuch als ebenso beeindruckend wie vergeblich. Zur Vergeblichkeit scheint er mir verurteilt, weil Herr Burmeister die Wechselwirkungen zwischen Recht und Wirklichkeit und damit die Wirkungsvoraussetzungen dogmatischer Konzepte nicht ausreichend in Betracht zieht. Das klassische Legalitätsprinzip, das er zu retten versucht, war auf die Ordnungsverwaltung und ihr Instrumentarium, den hoheitlichen Eingriff, bezogen und hat funktio- 
niert, solange sich der Staat im wesentlichen auf hoheitliches Handeln beschränkte. Es war einer lückenlosen gesetzlichen Determinierung zugänglich. Die heutigen Anforderungen an den Staat sind dagegen so beschaffen, daß er diese Schranken sprengen muß. Ich betrachte es als eine der Schwachstellen des Burmeister-Referats, daß er sein Thema unter Ausblendung des Wandels der Staatsaufgaben behandelt hat. Der Staat ist vom bloßen Garanten einer vorausgesetzten Sozialordnung längst zum aktiven Gestalter dieser Ordnung geworden. Die damit verbundene Aufgabenausweitung kann im Detail verändert werden, im Kern liegt sie fest. Dem klassischen Legalitätsprinzip werden dadurch zwei wesentliche Voraussetzungen entzogen. Zum einen sind Gestaltungsaufgaben nur begrenzt mit hoheitlichen Mitteln zu lösen: teils weil das faktisch nicht möglich ist - Forschungserfolge oder Konjunkturaufschwünge lassen sich nicht anordnen; teils weil es rechtlich nicht erlaubt ist - die zu steuernden Sozialbereiche stehen weiter unter Grundrechtsschutz; teils weil es - obschon faktisch möglich und rechtlich erlaubt - zu hohen Konsensbedarf und zu hohe Durchsetzungskosten verursacht. Der Staat greift daher insoweit zu indirekter Steuerung und einvernehmlichen Lösungen. Diese lassen sich aber - zum zweiten - gesetzlich weit weniger determinieren als hoheitliches Handeln. Gleichwohl verlangen wir, und das Bundesverfassungsgericht hilft dabei kräftig nach, daß der Staat auch seine gestaltende Tätigkeit auf gesetzlicher Grundlage ausübt. Die Unterschiede im Regelungsgegenstand schlagen sich aber in der Eigenart der Gesetze nieder. Ich sehe die zweite Schwachstelle des BurmeisterReferats darin, daß er sein Thema ohne Rücksicht auf die Veränderung des Gesetzes behandelt hat. Gesetze, die die ordnungsgestaltende Staatstätigkeit regeln, müssen sich häufig darauf beschränken, Ziele vorzugeben und Gesichtspunkte zu nennen, die die Verwaltung bei der Zielverfolgung zu beachten hat. Die Bindungskraft solcher Gesetze ist entsprechend gering. Die Verwaltung formuliert und adaptiert ihr Handlungsprogramm weitgehend selbst und ist nachgerade gezwungen, konsensuale Wege einzuschlagen, wo hoheitliche Mittel nicht einsetzbar sind. Zwischen der Determinationskraft des Gesetzes und der Reichweite des Legalitätsprinzips besteht indessen ein unmittelbarer Zusammenhang. Daher wäre es des Aufwandes eher wert gewesen, das klassische Legalitätsprinzip zeitgemäß zu modifizieren, wie Herr Krebs es versucht hat, statt es aller strukturellen Veränderungen in seinem Anwendungsbereich zum Trotz konzessionslos, aber auch erfolglos zu verteidigen.

Die Fortentwicklung stellt allerdings ihre eigenen Probleme. Das Wichtigste, das mir bei Herrn Krebs etwas kurz gekommen 
zu sein scheint, sehe ich in der Wahrung des Gleichheitsgebots. Konsensuales Verwaltungshandeln, Verwaltungsverträge bieten als Ergebnis von Aushandlungsprozessen zwischen staatlichen und privaten Akteueren keine Gewähr für Gleichbehandlung, und die Frage, wie der Gleichheitssatz gegenüber dem verhandelnden und vertragschließenden Staat aufrechterhalten werden kann, wie insbesondere gleicher Zugang zu den Verhandlungssystemen zu gewährleisten ist, hätte eine nähere Überlegung verdient. Auch Herr Schweizer hat die Frage nur aufgeworfen, aber nicht beantwortet.

Schmidt-Aßmann: Alle fünf Vorträge stechen durch ihre klaren Aussagen hervor. Das ist eine gute Grundlage für die Diskussion. Zunächst zu den gleichlautenden Feststellungen in allen Berichten: Alle Berichte zeigen ein Doppeltes. Die Praxis verwendet den Verwaltungsvertrag in einer kaum vorstellbaren Breite der Anwendungsfelder; dabei spielt erkennbar die Unterscheidung zwischen einem öffentlich-rechtlichen und einem privatrechtlichen Verwaltungsvertrag für die Praxis nicht die entscheidende Rolle. Alle Referate heben aber auch die Zurückhaltung der verwaltungsrechtlichen Lehre und der Judikatur gegenüber Verträgen der Verwaltung hervor. Allerdings ist diese Zurückhaltung in den einzelnen Ländern unterschiedlich intensiv. Das Schweizer Bundesgericht kommt dem Vertrag am stärksten entgegen, während der Conseil d'Etat restriktiver ist, aber wenigstens die Nichtigkeit von Verträgen zu vermeiden versucht. Dazu bedarf es allerdings erheblichen dogmatischen Aufwandes, wie Herr Autexier dargestellt hat. Am größten ist die Skepsis in der Literatur. Um hier eine Grundlinie zu finden, deren unterschiedliche Determinanten in den beiden Hauptreferaten unterschiedlich bestimmt worden sind, sollte man sich folgendes vor Augen halten: Die Verwaltungsrechtsdogmatik hat die Aufgabe, die Kontakte der Verwaltung zum Bürger in ganzer Breite und darüber hinaus die administrative Aufgabenerfüllung auch in ihrer "Tiefendimension“, d.h. in den Verwaltungsbereich hinein, in den Blick zu nehmen. Sie dient nicht nur individuellem Rechts- und Interessenschutz; die These 18 von Herrn Burmeister begrenzt folglich das Erkenntnisinteresse des Verwaltungsrechts zu stark. Nimmt man die ganze Breite des Handlungsfeldes der Verwaltung in den Blick, so muß es rechtlich darum gehen, den Vertrag als eine dem Verwaltungsakt gleichwertige Handlungsform zu verstehen. Alle Kritik und alle Vorbehalte gegenüber vertraglichem Handeln dürfen nicht allein aus der Perspektive des Verwaltungsakts erfolgen, weil wir nun einmal an ihn gewöhnt sind. Man muß sich nicht gleich von dem Begriff des „kooperativen 
Staates" blenden lassen und sich ganz auf konsensuale Handlungsformen konzentrieren. Aber man darf sich noch weniger am Modell einseitiger Regelung ausrichten, weil sonst die Perspektive zu einer interessengerechten Erfassung des Vertrages und der vertragsähnlichen Handlungsformen verrutscht. Hier finde ich die von Herrn Krebs gewählte Sichtweise weiterführend. Sie befreit den Verwaltungsvertrag von dem ihm zuweilen beigemessenen rechtsstaatlichen Minderwert und macht ihn zu einer gleichgewichtigen Form der Aufgabenerfüllung. Kritische Punkte, die mit jeder administrativen Rechtsform - übrigens auch mit dem Verwaltungsakt - verbunden sind, können durch die uns vertrauten Gegenmittel bewältigt werden. Als solche Gegenmittel nenne ich das Gesetz, dessen Vorrang auch gegenüber vertraglichen Gestaltungsformen gilt, ferner das von Herrn Krebs herausgearbeitete Phasenmodell in der Entwicklung der Vertragsbeziehungen und die von ihm hervorgehobene Notwendigkeit einer Vertragstypologie, die eine Annäherung zwischen privatrechtlichen und öffentlich-rechtlichen Verträgen der Verwaltung mitumgreifen sollte. Hier sind Strukturen aufgezeigt, die zu einer rechtlichen Durchformung des gesamten konsensualen Verwaltungshandelns genutzt werden sollten. Herr Burmeister hat demgegenüber ein meines Erachtens zu starkes Mißtrauen gegenüber vertraglichen Gestaltungsformen formuliert. Ich verweise nur auf seine Thesen Nr. 5 a und $5 \mathrm{~b}$. Für richtig halte ich allerdings seinen Ausgangspunkt, nämlich die Trennung von Kompetenz und Recht. Diese Asymmetrie zwischen dem Handeln der Verwaltung und dem Handeln des einzelnen ist in der Verfassung angelegt und kann folglich weder vertraglich noch sonst durch die Wahl einer Rechtsform überwunden werden. Im weiteren Verlauf des Referats ist der Vertrag jedoch überfrachtet worden, indem er als ein Mittel aufscheint, das der Verwaltung praktisch eigene Freiräume zuweist. Das ist jedoch mit der Vertragsform keineswegs notwendig verbunden. Vertragsformen haben vielmehr, wie alle Rechtsformen des Verwaltungshandelns, Instrumentalfunktionen. Auch die Gefahr, die Gesetzesbindung zu unterlaufen, ist nicht im Vertrag als Rechtsform angelegt. Sie ist $\mathrm{m}$. E. auch praktisch nicht größer als bei anderen Rechtsformen. Im übrigen darf die Genauigkeit der gesetzlichen Vorzeichnung der einzelnen Verwaltungsentscheidung nicht überschätzt werden. Die Verwaltung hat das gesetzliche Programm abzuarbeiten; aber über die Modalitäten und den rechten Zeitpunkt der Entscheidung sagen die Gesetze wenig. Hier ist ein breiter Gestaltungsraum, der durch konsensuale Formen ausgefüllt werden darf. - Meine letzte Bemerkung betrifft die Entwicklungsperspektive der Vertragsrechtsdogmatik in der Zukunft. 
Nachdem uns die beiden Hauptreferate die Grundpositionen zum vertraglichen Handeln der Verwaltung noch einmal vor Augen geführt haben und dabei im Referat von Herrn Krebs auch deutlich geworden ist, daß die rechtsstaatlichen Basisprobleme des Verwaltungsvertrages im Griff zu halten sind, sollten wir nun den Blick frei haben für die vielfältigen konkreten Gestaltungsfragen, die das Vertragsrecht fortlaufend aufwirft. Ein Blick auf die zivilrechtliche Vertragsrechtsdiskussion kann hier anregend wirken und zugleich zeigen, daß das öffentliche Recht in diesen Fragen der Vertragstypologie, der Vertragsklauseln, der komplexen Verträge und der Verträge als Ausdruck von Dauerrechtsverhältnissen noch einen erheblichen Entwicklungsrückstand hat. Auf der Basis der heute gewonnenen Erkenntnisse sollten wir uns künftig verstärkt diesen wichtigen und großen Fragen einer Vertragsrechtsdogmatik zuwenden.

Burmeister: Nur einen Satz will ich dazu sagen, Herr ScbmidtAßmann: bitte beachten Sie doch die thematische Abschichtung, die Herr Krebs und ich vereinbart haben. Ich habe mich ganz bewußt mit dem Verwaltungsvertrag nicht näher befaßt, sondern seine Behandlung Herrn Krebs überlassen, und habe mich insoweit darauf beschränkt anzudeuten, wo bzw. in welcher Erscheinungsform der Verwaltungsvertrag auf dogmatische und praktische Bedenken stößt: nämlich in seiner Funktion als Ersatz einer Regelung durch Verwaltungsakt. Was Herr Krebs inhaltlich, in der Sache zum Verwaltungsvertrag gesagt hat, darin stimme ich weitgehend mit ihm überein.

Pitschas: Herr Vorsitzender, meine Damen und Herren, ich möchte drei Bemerkungen machen. Die erste Bemerkung bezieht sich auf das grundsätzliche Verhältnis von Verwaltungsrechtswissenschaft zur Verwaltungswissenschaft. Es sind keine überholten Fragen, die hier ausgefochten werden, und deshalb bin ich dankbar, daß uns das Referat von Herrn Burmeister die Gelegenheit gibt, diesen immerwährenden Streit um die Empirie des Verwaltungsrechts in der Auseinandersetzung mit dem Versuch der Re-Dogmatisierung einer speziellen Verwaltungspraxis auszuloten. Man muß, wenn man sich diesem Widerstreit zweier Denkprinzipien stellt, auch als Rechtsdogmatiker eine Sprache und einen gedanklichen Ansatz dafür entwikkeln, die Realität der Verwaltung aufzuhellen. Die Rechtswissenschaft bietet für diese Realitätsaufnahme nicht immer die richtige Begrifflichkeit und sie bietet für die Re-Dogmatisierung auch nicht den dynamischen Veränderungsrahmen, das passende dynamische Veränderungskonzept. So sind wir in der Tat darauf angewiesen, Hilfe bei 
den Sozialwissenschaften zu suchen. Dies wird uns immer wieder passieren, es ist ein notwendiger Wechselbezug und wir dürfen ihn nicht vernachlässigen.

Herr Burmeister, ich meine, Sie haben diesen Bezug zu meinem Bedauern außer acht gelassen und einer bestimmten Denkweise - der normativen oder besser präskriptiven Vorgabe - Raum eingeräumt, sehr viel Raum. Dies führt dann zu zwei Erscheinungen, die ich anhand zweier Thesen von Ihnen beispielhaft beleuchten möchte. Es handelt sich einmal um Ihre These $5 \mathrm{~b}$, im Hinblick auf die Sie den subordinationsrechtlichen Vertrag so verstehen, als versetze er die Verwaltung in die Lage, sich festgeschriebener inhaltlicher Handlungsmaßstäbe entziehen zu können. Ich denke, es ist bei verwaltungswissenschaftlicher Betrachtung eher Umgekehrtes anzumerken: Der Verwaltung wird durch die Inanspruchnahme des subordinationsrechtlichen Vertrags - das zeigt die Empirie in einer noch ausgiebigeren Weise, als sie uns Herr Kollege Krebs vorgestellt hat die Möglichkeit gegeben, mit dem Bürger gemeinsam die inhaltlichen Handlungsmaßstäbe, die als solche offen sind, zu konkretisieren. Es ist m. a. W. nicht damit getan, den Widerstreit Rechtswissenschaft Verwaltungswissenschaft $\mathrm{zu}$ benennen und sich von der letzteren begrifflich „abzusetzen“, sondern Verwaltungswissenschaft ist eingebettet in ein größeres Konzept der Staatswissenschaften, zu denen dann auch die Rechtswissenschaft zählt.

In diesen staatswissenschaftlichen Bezugsrahmen gehört auch Ihre These 11. „Die als Einheit erfaßte Staatsgewalt“, so formulieren Sie darin, „läßt Ausgliederungen nicht zu“. In einer staatswissenschaftlichen Perspektive ergibt sich demgegenüber sehr wohl die Möglichkeit einer solchen Ausgliederung. Sie ersprießt der Vielfalt der Erscheinungen, die in einer Betrachtung des Staatslebens aufzunehmen sind und dann in der Tat dogmatisiert werden müssen.

Meine zweite Bemerkung muß sich deshalb notwendigerweise mit dem befassen, was im Leitsatz 9 von Herrn Krebs als eine „dogmatische Zwischenebene" bezeichnet wird. In der Tat, ich meine, wir dürfen nicht der Gefahr erliegen, nur verwaltungswissenschaftlich zu denken, sondern wir müssen die Ergebnisse dieses Denkens auf die Ebene der Dogmatik "herunterbrechen“. Sie haben das interessanterweise, Herr Burmeister, versucht, nämlich mit dem Kompensationsaspekt. Sie haben sich dadurch einen Vermittlungsbereich erschlossen, eine dogmatische Zwischenschicht, die eine Rückbindung an die Verwaltungsrealität ermöglichen könnte. Leider aber benutzen Sie die „Kompensationsthese“ nur, um Fragen zu stellen, aber nicht, um Antworten zu geben. Schade! 
Ich habe deshalb mit sehr professionellem Interesse wahrgenommen - und das ist meine dritte Anmerkung -, wie Herr Krebs vorgegangen ist. Daran zeigt sich deutlich, wie man aus einer verwaltungswissenschaftlichen Perspektive herkommen, den prozeduralen Ansatz wählen und dann die erforderliche dogmatische Zwischenschicht sich erschließen kann. Dies geschieht etwa in der Phasenformulierung. Hierzu möchte ich, Herr Krebs, einerseits Zustimmung erklären, andererseits anregen, die Phasen noch etwas auszudifferenzieren: In der Rechtsstellung nach Vertragsschluß sollten wir die Phase der Vertragserfüllung - das diesbezügliche Modell der Schweiz war vorhin deutlich geworden - der Auferlegung gesetzlicher Pflichten und wie zu handeln ist sowie einer weiteren Phase gegenüberstellen, die Sie in Ihrer These 17 selbst andeuten. Das besondere Kündigungsrecht hätte eigenständigen Charakter, formulieren Sie dort, meinen also die Phase der Vertragsbeendigung, der Vertragsausleitung.

Leider wird es dann aber etwas "dünn" in der dogmatischen Brechung dieser Phase des realen Vertragshandelns. Auch für die Vertragsbeendigung sollten wir nämlich Konsens suchen. Ich darf anregen, hier so etwas einzuführen wie einen Mittler. Wir haben den Mittler in anderer Beziehung schon kennengelernt. Nun erscheint er in neuem Gewand, in der Figur des Vertragsmittlers, der uns dabei hilft, durch präventive Vertragsgestaltung die streitige Kündigung zu vermeiden.

Eine letzte und vergessene Phase ist durch den Vortrag von Herrn Autexier deutlich geworden: Welche Rolle spielt eigentlich der Richter? Müßten wir nicht in den Versuch der Requalifizierung vertraglichen Verwaltungshandelns die Phase der richterlichen Kontrolle nachschalten? Danke schön.

Zippelius: Herr Krebs hat mir in vielem aus der Seele gesprochen. Der konsentierte Kompromiß ist die legitime Lebensform der pluralistischen Demokratie. Das gilt unbestritten für die gesetzgeberische Vorformung des Verwaltungshandelns. Das Vordringen der Vertragspraxis versucht dieses Prinzip auch im Verwaltungshandeln selbst zur Geltung zu bringen. Zugleich erscheint die Ausweitung der Vertragspraxis als Antwort auf den Abbau der Ermessensspielräume und auf die zunehmende Durchnormierung staatlichen Handelns. Sie ist der Versuch, für die Verwaltung wieder Gestaltungsspielräume unter gleichzeitiger Sicherung von Akzeptanz zu gewinnen. Aus dem Satz in dubio pro libertate in Verbindung mit dem Übermaßverbot könnte man sogar ableiten, daß vertraglichem Handeln der Vorzug vor dem 
Verwaltungsakt zu geben ist, wenn es ebenso geeignet ist wie dieser und keine vorrangigen rechtsstaatlichen Gründe entgegenstehen. Es bleibt dann die einstweilen noch unvollständig gelöste Aufgabe, über die notwendigen rechtsstaatlichen Disziplinierungen vertraglichen Verwaltungshandelns, insbesondere über die Gewährleistung der Gleichbehandlung, weiterhin nachzudenken.

Graf Vitzthum: Herr Vorsitzender, meine Damen und Herren! Mein Kurzvotum ist ein Beitrag zur empirischen Befundnahme als der Grundlage für eine sachliche und begriffliche Klärung unseres Gesamtthemas. Ich möchte auf ein Phänomen aufmerksam machen, das nicht im Mittelpunkt der Referate stand: Gelegentlich vereinbaren Vertrags- oder Absprachepartner der öffentlichen Verwaltung nicht eine Erleichterung ihrer Pflichten, etwa eine Befreiung von Grenzwerten; sie übernehmen vielmehr der öffentlichen Hand gegenüber „freiwillig" zusätzliche Lasten. In einer Art vorauseilendem Gehorsam tun sie dies, um eine gewünschte Entscheidung anzustoßen oder zu beschleunigen. Diese Praxis anmelde- oder genehmigungserleichternder Absprachen ist weit verbreitet. Mit Koppelungsverboten, Kontrahierungszwang, $\ 58$ VwVfG usw., also mit den überkommenen harten Bandagen des Verwaltungsrechts, ist dem Phänomen schon angesichts der Dauer verwaltungsgerichtlicher Verfahren schwerlich beizukommen. Es entspricht offenbar einem Bedürfnis der Praxis, daß eine Genehmigungs- oder Planungsbehörde auf der einen Seite, eine Gemeinde etwa, und ein Antragsteller, also etwa eine Universität, die ein unpopuläres Laborgebäude errichten möchte, auf der anderen Seite, u. U. einschließlich des finanzierenden Landes, bi- oder trilaterale Vereinbarungen treffen, in denen der Antragsteller bzw. Betreiber der Genehmigungs- oder Planungsbehörde zusätzliche Informationsoder Beteiligungsrechte einräumt, Rechte, die der Gesetzgeber, insbesondere um die Forschung ihrer Eigengesetzlichkeit wegen zu privilegieren, gerade nicht vorgesehen hatte. Hintergrund dieser Abredepraxis ist natürlich die handgreifliche Notwendigkeit, z.B. einen Gemeinderat, in dem forschungsunfreundliche Mehrheiten herrschen, zur zügigen Bauleitplanung zu bringen; dafür wird dann seitens des Antragstellers ein Mehr an Information und Mitwirkung der Kommune, ja auch eine Verschärfung der Grenzwerte (bis hin zur NullEmission beim Abwasser) in detaillierten Absprachen zweifelhafter Rechtsnatur und Verpflichtungskraft konzediert.

Ich sehe hier vor allem drei Arten von Rechtsproblemen. Die Praxis der "freiwilligen" Übernahme von verschärften Informations- und Verfahrenspflichten ist problematisch - erstens - im Hinblick auf 
die Gesetzmäßigkeit der Verwaltung ganz allgemein. Ich brauche diesen bekannten Aspekt hier nicht zu vertiefen. Zweitens: Darüber hinaus treten gravierende Grundrechtsfragen auf. Der paktierende Verwaltungsträger, etwa eine Großforschungseinrichtung oder eine Hochschule, verfügt ja auch über Grundrechtschancen seiner Mitglieder, seiner Forscher; diese aber sind ihrerseits an der Absprache nicht beteiligt. Andererseits liefen die Grundrechte der Wissenschaftler faktisch weitgehend leer, wenn die Absprachen den Weg zur Grundrechtswahrnehmung nicht politisch deblockierten. Wie ist dieses regulierungs- und forschungspolitische Dreieck (Universität - Gemeinde - universitäre Forscher) rechtsstaats- und grundrechtskonform auszugestalten? Vor allem aber drängen sich - drittens - Kompetenzund Zuständigkeitsprobleme auf, die natürlich auch mit dem Gesetzmäßigkeitskomplex zusammenhängen. Häufig werden mittels dieser Vereinbarungen auf kommunaler Ebene, z. T. auch auf der Ebene des Landes, bewußt oder unbewußt bundesgesetzliche Weichenstellungen, etwa solche zugunsten der Forschung / zu Lasten der Öffentlichkeitsbeteiligung, umgebogen oder umschifft. Man "dispensiert" sich sozusagen von diesen in der Kompetenz des Gesamtstaates liegenden Entscheidungen und verlangt und verspricht auf kommunaler oder gliedstaatlicher Ebene ein "Nachlegen“, im Ergebnis eine gezielte „Korrektur“ der Lösung des (Bundes-)Gesetzgebers mittels zweifelhaft eingesetzter kommunal- oder gliedstaatlicher Hebel. Natürlich liegen die Rechtsfragen etwa der "gentechnikfreien Gemeinden“ heute teilweise auf einer anderen Ebene als die der ,atomwaffenfreien Gemeinden " in den 60er bzw. 80er Jahren; aber das Problem der Wahrung von verfassungs- und einfachgesetzlichen Zuständigkeitsgrenzen und Aufgabenzuweisungen tritt dort wie hier auf.

Hier also, bei den Rechten und Pflichten der Kommune (oder des Gliedstaates) auf der einen Seite und den Grundrechten der Forscher, der Durchsetzung oder Durchkreuzung der staatlichen Forschungsförderung und der Wahrung oder Desavouierung der umwelt- und technikrechtlichen Detailregelungen des Bundes (und der Europäischen Gemeinschaften) auf der anderen Seite liegt ein aktuelles Anwendungsfeld von Absprachen und Verträgen. Hier erstreckt sich aber vor allem offensichtlich ein Feld des potentiellen und gelegentlich vielleicht bereits realen Mißbrauchs dieser Instrumente. Werden hier also die gesetzlichen Bindungen der Verwaltung, der Grundrechtschutz und die Einhaltung der Kompetenzordnung gefährdet? Fehlen hier nicht, von der kommunalen Aufgabenstellung her gesehen, die Topoi etwa für eine dauerhafte Mitwirkung von Kommunalvertretern bei der inneruniversitären Forschungsplanung oder Forschungskon- 
trolle? Droht hier also nicht ein dauerhaftes Mitverwalten der Öffentlichkeit oder der Kommune in verfassungsrechtlich und bundesgesetzlich privilegierten, für sie gerade abgeriegelten Forschungsangelegenheiten? Darf das die Universität wirklich „freiwillig“ einräumen, darf darüber die Kommune mit der Hochschule eine Absprache treffen? Manche mögen diese Phänomene indes weit weniger problematisch finden. Sie mögen sich mit ihnen etwa unter dem Gesichtspunkt abfinden, ja anfreunden, daß nicht nur die Legalität, sondern auch die Leistungsfähigkeit der Verwaltung Verfassungsgebot ist, und daß letztere eben durch die geschilderten Verständigungen befördert wird. Derartige Absprachen wären dann zur Induzierung von Hoheitsakten aus Grundrechtssicht geradezu angezeigt. Darüber hinaus ließe sich anführen, daß die skizzierten Versuche, sich von normativen Bindungen zu emanzipieren, wohl ein allgemeines, ein also instrumentenunabhängiges Phänomen darstellen; im Rahmen des Themenausschnitts „Verträge und Absprachen “ verdienen sie dann in der Tat keine Vertiefung: Verträge und Absprachen sind nicht Ursache, sondern Ausdruck des dahinterliegenden Problems.

Ich darf die Herren Referenten um Belehrung bezüglich dieser Aspekte und Fragen bitten. Zweifelhaft erscheint mir jedenfalls, daß, soweit Verträge Rechtsgebote ignorieren, der Gedanke der Kompensation bzw. der Legitimation an der Leistung hilft. Darüber hinaus scheint mir das Problem der Drittbeteiligung, etwa der Forscher einer Universität, an Verträgen oder Absprachen, die ihre Hochschule mit einer Gemeinde schließt, bis auf weiteres nicht befriedigend geregelt.

Wahl: Das Jahr 1992 hat für den öffentlich-rechtlichen Vertrag noch eine andere Bedeutung, nämlich einen aktuellen Gegenwartsund Zukunftsbezug. Die Bedeutung von verwaltungsrechtlichen Verträgen ist in den neuen Bundesländern sehr groß geworden, vor allem im Planungsrecht und dort im Städtebaurecht. Man kann bereits von einem Siegeszug der verwaltungsrechtlichen Verträge in den neuen Ländern sprechen. Die Gründe dafür liegen auf der Hand: Es gibt Vorteile beim Zeitfaktor. Außerdem geht es um die Bewältigung von komplexen Lagen. Dabei haben verwaltungsrechtliche Verträge den Vorteil, daß durch sie in der zeitlichen und sachlichen Dimension verschiedene Einzelmaßnahmen miteinander verknüpft werden können.

Ein wichtiger Kontext unseres Themas ist schon mehrfach erwähnt worden, nämlich die staatstheoretische und sozialwissenschaftliche Steuerungsdiskussion, auf die sich die beiden Referenten unterschiedlich eingelassen haben. Herr Krebs sieht sich durch diese Diskussion 
in seiner Einschätzung der tatsächlichen Problemlage, die er dann dogmatisch aufarbeitet, bestätigt, während Herr Burmeister das Lager der Verwaltungswissenschaft nicht nur mit Vorsicht, sondern mit recht großer Distanz behandelt hat. Herr Burmeister, ich würde mich nicht so sehr an der sozialwissenschaftlichen Begrifflichkeit festhalten, obwohl man natürlich manches Überangebot an scientistischen Begriffen genüßlich konstatieren kann. Wichtiger ist die Sache und die Beschreibung, daß Absprachen und Verträge eine zunehmende Bedeutung erhalten. Etwas problematisch erscheint mir in diesem Zusammenhang der Begriff, der immer wieder gebraucht wird, nämlich der vom Kooperationsstaat. Solche und ähnliche Substantivierungen eines Aspekts in der Zusammensetzung mit dem Begriff "Staat“, wie sie etwa in der Bezeichnung Dienstleistungsstaat, Umweltstaat u. ä. vorkommen, sind regelmäßig Übertreibungen und Hypostasierungen. Dies gilt vor allem dann, wenn diese Beschreibungen noch einhergehen mit der Bemerkung eines Wandels. Dann stellt sich rasch die Vorstellung ein, es wäre der früher ausschließlich hoheitlich handelnde Staat heute abgelöst durch den Kooperationsstaat. Eine solche Vorstellung ist oder wäre offensichtlich eine verbale Übertreibung. Die notwendige Kritik daran kann aber die erwähnte sozialwissenschaftlich-staatstheoretische Diskussion gar nicht treffen, weil diese relativ präzise und differenziert nachweist, daß der Bedarf an konsensualem Verhalten sich aus ganz konkreten Feldern begründet, nämlich aus Feldern, in denen es die Schwierigkeiten der einseitig regelnden Steuerung ratsam erscheinen lassen, daß man sich der Mitwirkung der Betroffenen versichert. Im übrigen geht die festzustellende zunehmende Bedeutung von Absprachen und Verwaltungsverträgen in Wirklichkeit auch nicht zu Lasten des klassischen Bereichs. Das gesamte Staatshandeln ist kein Nullsummenspiel, bei dem der eine Bereich genau das verliert, was der andere gewinnt, sondern beides, die klassische hoheitliche Steuerung und das konsensuale Verhalten sind Wachstumsbereiche oder können es sein.

Mir geht es im weiteren darum, was dieser Befund für das Verwaltungsrecht und die Verwaltungsrechtsdogmatik bedeutet, wobei ich anknüpfe, was Herr Pitschas hier schon ausgeführt hat. Ganz generell gesehen läßt sich die Parallele ziehen: So wie das Staats- und Verfassungsrecht von der Staatslehre, der Staatstheorie und der Verfassungstheorie Problemstellungen und vor allem auch Problemsensibilisierungen gewinnt, so verhält es sich auch für die Beziehung zwischen dem Verwaltungsrecht und der Verwaltungswissenschaft.

Wenn ich dabei, Herr Burmeister, auf Ihren Leitsatz 18 Bezug nehmen darf, dann haben Sie dort von einem allein dem individuellen 
Rechts- und Interessenschutz dienenden Verwaltungsrecht gesprochen. Im Anschluß an das, was Herr Schmidt-Aßmann ausgeführt hat, möchte ich dieser Verengung widersprechen. Das Verwaltungsrecht ist nicht nur und soll nicht nur Verwaltungsgerichtsrecht sein, sondern es hat auch eine wichtige und sachlich sogar vorrangige Funktion in der Handlungsleitung für die Verwaltung. Im übrigen hat die durch die Verwaltungswissenschaft bereicherte Sichtweise gerade auch für die Probleme des Verwaltungsvertrags Bedeutung.

Darf ich dabei das Verhältnis zwischen Verwaltungsvertrag und Verwaltungsakt herausgreifen. Der üblicher Obersatz heißt dabei, daß durch den Verwaltungsvertrag der gesetzliche Zweck in einer anderen Weise erfüllt wird als beim Verwaltungsakt. Worauf bezieht sich aber nun die „andere Weise“, in der der Verwaltungsvertrag den gesetzlichen Zweck erfüllt? Dies hängt davon ab, wie man das Interesse des Verwaltungsrechts kennzeichnet. Wenn man nur auf die Frage der Rechtmäßigkeit abstellt, dann kommt man rasch zur schiefen Problemstellung, ob beim vertraglichen Handeln „anderes“ als die sonst bestehenden Rechtmäßigkeitsanforderungen gelten können. Was dabei übersehen wird, ist die Pluralität der Verwaltungszwecke, die in den Debatten der Vereinigung schon unter dem Stichwort der „Verwaltungsverantwortung" und des "Verwaltungsauftrags" behandelt worden ist. Die Pluralität der Verwaltungszwecke macht bewußt, daß die Verwaltung nicht nur rechtmäßig zu handeln hat, sondern daß sie auch wirtschaftlich und rechtzeitig handeln soll, daß sie auch sachliche Verknüpfungen zwischen verschiedenen Bereichen herstellen soll. Genau im Hinblick auf diese Pluralität der Verwaltungszwecke ist das Verhältnis zwischen Verwaltungsvertrag und Verwaltungsakt zu befragen. Die Funktion des Verwaltungsvertrags liegt gerade auch darin und kann gerade auch darin liegen, daß beim vertraglichen Handeln schneller, wirtschaftlicher oder sachangemessener gehandelt werden kann. In dieser Einsicht liegt, in einem kleinen Beispiel gezeigt, der Ertrag der Verwaltungswissenschaft für die Verwaltungsrechtsdogmatik. Das Verwaltungsrecht gibt, so betrachtet, mit dem Institut des Verwaltungsvertrags Spielraum, über die Dimension der Rechtmäßigkeit hinaus auch die der Rechtzeitigkeit und der Sachangemessenheit zu beachten.

Gallwas: Herr Burmeister, ich habe zwei Fragen zu Ihrer These Nr. 13. Die erste Frage: Warum soll der Zivilrechtsgesetzgeber nicht den juristischen Personen des öffentlichen Rechts, sprich den Anstalten, Stiftungen und Körperschaften, die Vollrechtsfähigkeit einräumen. Eine Unterfrage dazu: Ist dies nicht durch $\$ 89$ BGB geschehen? 
Meine zweite Frage: Wenn Sie das ernst nehmen, was Sie hier schreiben, nämlich, daß die juristischen Personen des öffentlichen Rechts außerhalb des übertragenen Wirkungsbereiches rechtlich nicht existent sind, wie steht es dann mit dem Rechtsschutz? Geraten Sie nicht in eine unauflösbare Kollision mit $\$ 61 \mathrm{VwGO}$ ? Sie nehmen ja der juristischen Person die Beteiligtenfähigkeit und infolgedessen dem Geschädigten, dem Beinträchtigten, den Beklagten.

Vorsitzender: Vielen Dank Herr Gallwas. Wir haben noch zwei Wortmeldungen zu I.1., dann eine Reihe von Wortmeldungen generell zu I. sowie zu I.1. und I. 2. zusammen. Ich werde die Wortmeldungen in dieser Reihenfolge aufrufen und dann zu den Wortmeldungen, die nur Punkt I. 2. betreffen, übergehen.

H. Dreier: Herr Vorsitzender, meine Damen und Herren, wenn man wollte, könnte man den heutigen Beratungsgegenstand eigentlich in einem einzigen Wort zusammenfassen: "Verwaltungspakte“. Mir schien die zentrale Aufgabe des Themas zu sein, der ausgefeilten Verwaltungsaktdogmatik eine jedenfalls ansatzweise adäquate Verwaltungspaktdogmatik an die Seite zu stellen. Herr Krebs hat das nach meinem Eindruck für den Verwaltungsvertrag in beeindruckender Weise getan. Der Terminus „Verwaltungspakte“ will nun aber gerade besagen, daß hier auch andere Formen wie Absprachen, Vorverhandlungen, agreements und sonstige kooperative Formen einzubeziehen sind. Eine solche Differenzierung zwischen Verwaltungsakten und Verwaltungspakten, denen dann noch Rechtssetzungsakte und Realakte an die Seite zu stellen wären, beruht allerdings auf bestimmten Voraussetzungen und schafft bestimmte Probleme. $\mathrm{Zu}$ beidem nur jeweils eine kurze Bemerkung.

$\mathrm{Zu}$ den Voraussetzungen einer solchen Differenzierung zählt insbesondere das Anerkenntnis, daß es bestimmte Stufungen der Rechtsverbindlichkeit gibt und wir eine Dogmatik für Verwaltungshandlungen brauchen, die auch das Vorfeld endgültiger rechtsverbindlicher Rechtsakte umfaßt - eben eine Verwaltungspaktdogmatik über eine reine Verwaltungsvertragsdogmatik hinaus. Solche Verwaltungspakte stehen natürlich vor großen Problemen, und diese hat Herr Burmeister in sehr grundsätzlicher Weise dargetan. Das Hauptproblem besteht nach wie vor in Art und Maß der rechtsstaatlichen Bindung. Während der Verwaltungsakt, das kann man vielleicht in dieser Allgemeinheit so sagen, ganz von der Legitimität des positiven Gesetzesrechts zehrt, ist das bei den Verwaltungspakten nicht in gleichem Maße der Fall. Hier wird der Bürger - jedenfalls ein Stück weit - 
vom Objekt eines hoheitlichen Befehls zum Subjekt tauschförmiger Verhandlungsprozesse. Zentralproblem bleibt also die rechtsstaatliche Einhegung des kooperativen oder konsensualen bzw. auch informell genannten Verwaltungshandelns; und da scheint mir, daß das hartnäckige Insistieren auf den außerordentlich hohen gesetzesstaatlichen Standard des Verwaltungsakts in der Gefahr steht, weite Bereiche unbestreitbarer staatlicher Handlungs- und Aktionsfelder gewissermaßen in die Rechtswidrigkeitszone zu drängen oder sie als bloße Faktizität abzuqualifizieren. Wenn der Jurist ausschließlich diese strengen Anforderungen eines rechtsstaatlichen liberalen Verwaltungsrechts klassischer Prägung zum Maßstab macht, dann läuft er angesichts einer Vielzahl nicht zu leugnender Erscheinungsformen kooperativen Verwaltungshandelns Gefahr, eigentlich gleich in doppelter Weise resignieren zu müssen: das eine Mal vor der Funktionslosigkeit des Normativen und das andere Mal vor der Normlosigkeit des Faktischen. Vielen Dank.

Schuppert: Herr Vorsitzender, meine Damen und Herren, ich möchte nicht sprechen zu dem Phänomen des Vordringens des Fundamentalismus in der Dogmatik des Verwaltungsrechts, sondern ich möchte zwei Bemerkungen machen in staatswissenschaftlicher oder verwaltungswissenschaftlicher Absicht. Die erste Bemerkung bezieht sich auf die Einbettung der Referate über Verträge und Absprachen mit der Verwaltung in die Diskussion über die Steuerung durch Recht, also in die sogenannte Steuerungsdebatte, die Herr Krebs ja auch schon angesprochen hat. Ich möchte es vermeiden, entlang vertrauter Trampelpfade zu argumentieren, die mit den Stichworten "Kooperativer Staat“, „Steuerung durch Recht im kooperativen Staat", „Versagen regulativer Politik“ und „Konsensuale Steuerungsstrategien“ gekennzeichnet werden können; sondern ich möchte eine Anleihe machen an dem reichen Werk von Herrn Schmidt-Aßmann und mich in einem Ausflug in die Verwaltungsrechtsdogmatik dilettierend versuchen. Ich möchte dazu anregen, darüber nachzudenken, ob man die Verwaltungsrechtswissenschaft als Steuerungswissenschaft betrachten kann, um sich dann die Frage zu stellen, wie Verwaltungshandeln eigentlich durch Verwaltungsrecht gesteuert wird. Wird die Frage so gestellt, so liegt es nahe, von einer mittelbaren Steuerungsleistung des Verwaltungsrechts zu sprechen, einem Phänomen, das ich die Bereitstellungsfunktion des Rechts nennen möchte. Das Recht, so z. B. das Verwaltungsrecht, muß dasjenige bereitstellen, was die Verwaltung braucht, um vernünftig arbeiten zu können. Also bestimmte Rechtsformen des Verwaltungshandelns wie Verwaltungsakt, Vertrag usw. 
und bestimmte Entscheidungstypen, die sich einfach als notwendig erweisen, wie etwa Vorbescheid, Standort- und Konzeptvorbescheid, Teilgenehmigungen, Entscheidungstypen also, die für das Abarbeiten gestufter Entscheidungsverfahren unverzichtbar sind und einen phasenspezifischen Rechtsschutz ermöglichen. Das heißt: das Verwaltungsrecht und die Verwaltungsrechtsdogmatik müssen dasjenige an dogmatischen Figuren bereitstellen, was die Verwaltung braucht. Und dazu gehört natürlich der Vertrag in mannigfachen Erscheinungsformen und dazu ist es auch hilfreich - und das hat mich an dem Referat von Herrn Krebs besonders beglückt - eine - wie er es genannt hat - dogmatische Zwischenschiene einzuziehen. Die Verwaltungsrechtsdogmatik, also nicht nur das geschriebene Verwaltungsrecht, muß so etwas wie eine Typologie von Verträgen liefern, an denen die rechtlichen Probleme aufscheinen und die die Diskussion über eine vielleicht notwendige Reform des Allgemeinen Verwaltungsrechts befruchten könnten.

Jetzt komme ich zum informalen Verwaltungshandeln, das von Herrn Burmeister so in die Dunkelzone der Rechtsstaatlichkeit verbannt worden ist. Das verkennt - glaube ich - nicht nur das Phänomen des informalen Verwaltungshandelns, sondern auch das Bedürfnis der Verwaltung nach solchen Handlungsformen. Es ist offenbar ein Kommunikationsbedürfnis vorhanden zwischen Verwaltung und ihrer Klientel, und zwar bevor das Verwaltungsverfahren "losgeht", also in den Vorabsprachen, in der Vorabzuleitung von Entscheidungsentwürfen etc. Statt dies zu beargwöhnen, muß man überlegen, ob diese tatsächlichen Handlungsformen rechtlich diszipliniert werden sollen oder nicht.

Der zweite Punkt ist ein rechtstheoretischer Punkt, der aber bitte erschrecken Sie nicht - natürlich praktisch gemeint ist: ich meine das Stichwort "tauschförmiges Recht". Wir haben es bei den Absprachen und den Verträgen mit der Verwaltung mit dem Einsatz von Recht als einem Tauschgut zu tun. Wenn tauschförmige Rechtsbeziehungen entstehen, führt dies zu der Notwendigkeit von empirischen Untersuchungen, wo getauscht wird und mit wem getauscht wird. Das heißt, wenn wir daraus Nutzen ziehen wollen für die dogmatische Bewältigung, müssen wir diejenigen Politikfelder genauer in den Blick nehmen, in denen getauscht wird und - was genauso wichtig ist - die Akteure betrachten, mit denen getauscht wird. Es wird wahrscheinlich nicht getauscht - formuliere ich mal als Hypothese - mit dem Sozialhilfeempfänger, weil der keine bargaining power hat, sondern es wird getauscht mit den Großinvestoren auf dem Felde städtebaulicher Sanierung oder es wird getauscht mit 
organisierten Interessen, die als Tauschmasse die Disziplinierung ihrer Mitglieder und damit die Weitergabe der Aushandlungsprozesse mit der Verwaltung einzubringen haben. Vielen Dank.

Vorsitzender: Vielen Dank Herr Schuppert. Wir kommen jetzt zu den Autoren, die generell zu I. der Gliederung sprechen wollen.

H.P. Ipsen: Zu einer These von Herrn Burmeister habe ich uneingeschränkt Zustimmung zu äußern. Leider ist sie die unwichtigste. Sie beschäftigt mich aber deshalb, weil unter unseren Kollegen zunehmend solche sind, die sich mit dem Europarecht beschäftigen. Dort leiden wir unter Erscheinungen, die Herr Burmeister beanstandet hat, weil die Sozialwissenschaften versuchen, unsere Terminologie zu vernachlässigen oder uns die ihre aufzudrängen auf Kosten unserer Klarheit an Definition. Das vollzieht sich in Bezug auf das Europarecht, wo die saubere Unterscheidung der Rechtsakte Entscheidung, Richtlinie, Verordnung aufgehoben wird unter Verlust aller Differenzierung mit dem Ausdruck „implementation“, meistens auch noch englisch gesprochen.

Ich kann nicht zustimmen der Gesamtsicht von Herrn Burmeister, die - Herr Grimm hat es am Anfang hervorgehoben - unter der Tatsache leidet, daß er die Realität der gegenwärtigen sich wandelnden öffentlichen Verwaltung nicht genügend respektiert, einschließlich alles dessen, was an Normierungen, Regulierungen und tatsächlicher Praxis mit den Beispielen, die schon genannt worden sind, in Erscheinung tritt, um in zunehmendem Maße dem Verwaltungsvertrag und auch den Absprachen Raum zu geben. Ich bemängle These $8 \mathrm{~b}$, wonach die Geltung des Satzes volenti non fit iniuria unbeachtlich sei. Gerade im Bereich des Vertragsschlusses halte ich die Möglichkeit, daß der einzelne auf die Geltendmachung gewisser Grundrechtspositionen nicht gerade verzichtet, aber doch ihre Behauptung zurückstellt gegenüber anderen Interessen, die er im Vertragsschluß verfolgt, für durchaus zulässig, und dies auch ohne Bedenken deshalb, weil die Verwaltung gehalten sei, den Gleichheitssatz zu respektieren. Ich kann auch nicht die These 11 teilen, wonach die Staatsgewalt als Einheit verfaßt sei. Sicherlich ist sie das, aber nicht, daß deshalb eine Ausgliederung als Privatrechtssubjekt unzulässig sei. Darum geht es im Kern doch nicht. Es geht um die Frage, welche Handlungsformen der Verwaltung zur Verfügung stehen, und dabei ist die Position von Herrn Burmeister, die ich eben bezeichnet habe, nach meiner Auffassung schwerlich relevant. Herr Burmeister kann in diesem Punkt natürlich bauen auf der großen Arbeit eines unserer Kollegen, den er 
nicht zitiert hat, der aber sicherlich laufend „Hurra“ hätte rufen müssen zu den Ausführungen von Herrn Burmeister. Ich meine den Kollegen Schachtschneider, der mir diese Gefühle, die ihn bewegt haben, vorhin auch ausdrücklich bestätigt hat. Schließlich sehe ich auch einen Widerspruch mit meiner Annahme, daß es auf die Handlungsformen ankäme, zu der These 11, wo Herr Burmeister doch den koalitionsrechtlichen Vertrag für zulässig erachtet, was er nach seinen vorherigen Präzisionen folgerichtig nicht hätte tun dürfen.

$\mathrm{Zu}$ dem Referat von Herr Krebs kann ich weitgehend Zustimmung äußern. Seine Ausführungen sind realitätsbewußt, sie stehen in Verwaltungsnähe, sie nutzen Verwaltungserfahrung und seine dogmatischen Abfolgerungen, die er in Verknüpfung mit der positiven Gesetzgebung, also dem $V_{w} V f G$ gezogen hat, halte ich für begründet. Ich betone einen Gesichtspunkt, der aber, glaube ich, auch bei Herrn Burmeister zur Geltung gekommen ist: daß das Vertragsverfahren entscheidend beitragen kann zur Akzeptanzverbesserung dessen, was die Verwaltung tut. Seine Anregung in These 6, sich vom Zivilrecht weitgehend zu emanzipieren, kann ich nur unterstreichen, und daß (These 7) rechtsstaatliche Standards für den privatrechtlichen Verwaltungsvertrag (auch in These 18 kommt das zum Ausdruck) zu gelten hätten, findet meine volle Zustimmung. Im zweiten Teil seiner Ausführungen fehlt meiner Meinung nach ein Abschnitt zum Thema "Leistungsstörungen“, die intensiver hätten behandelt werden sollen. Die clausula-Deutung, der Grundsatz, daß die clausula rebus sic stantibus rechtsdogmatisch eigenständig zu begreifen sei, möchte ich auch unterstreichen. Und wenn Herr Krebs am Schluß gesagt hat, der Verwaltungsvertrag habe bereits einen gewissen dogmatischen Reifegrad erreicht, würde ich meinen, daß er wesentlich dazu beigetragen hat, die Umrisse einer Kodifikation dieser Materie geliefert zu haben.

Erlauben Sie mir zum Schluß eine Bemerkung, die nicht zum Thema selbst gehört, die mir aber sehr am Herzen liegt. Wir haben zwei in der Anlage und auch in den Ergebnissen sehr kontroverse Berichte gehört. Das hat zu keinen Schwierigkeiten geführt und wird auch nicht zu Schwierigkeiten führen in der Diskussion, weil das Thema, mit dem wir uns beschäftigen, keine eigentliche politische Brisanz hat. Ich komme zurück auf unseren Personalbeschluß vom Mittwoch. Gleichviel wie man zu der Entscheidung, die gefallen ist, steht (das möge jeder für sich tun, er hat es getan mit seiner Abstimmung), ich sehe für unsere Vereinigung in der Substanz ihrer Aufgabe den Ertrag dieses Beschlusses darin, daß eine Sezession vermieden wird. Wir brauchen in unserer Vereinigung Polaritäten, um die wir uns auseinandersetzen müssen, sonst verfehlen wir unsere Aufgabe. 
Wenn eine Sezession stattfände, dann bliebe hier eine auf Harmonie bedachte Vereinigung nach der Art eines „Gesangvereins“, und daneben würde eine andere, alternative Vereinigung entstehen, die ihre Melodie singt. Die wissenschaftliche Auseinandersetzung um verfassungspolitisch optimale Lösungen würde entfallen.

Vorsitzender: Vielen Dank Herr Ipsen. Der Beifall, den Sie erhalten haben, zeigt, daß Ihre Schlußbemerkung auf große Zustimmung gestoßen ist.

Bullinger: Herr Burmeister, Sie haben ein edles Ziel verfolgt, dem ich mich aus meiner Jugendzeit noch sehr verbunden fühle: die Legalität der Verwaltung zu sichern. Aber es gibt -, das werden Sie mir zugeben, ein anderes Ziel: die Verwaltung leistungsfähig zu erhalten. Auch das ist nach neuerer deutscher Vorstellung ein Verfassungsgut, und ich glaube, daß dies ebenso für andere Länder gilt. Wenn mit dem herkömmlichen Instrumentarium der einseitigen Entscheidung nach dem Gesetz Verwaltung nicht mehr leistungsfähig sein kann, in bestimmten Bereichen jedenfalls, muß man überlegen, ob durch Verträge oder Absprachen Leistungsfähigkeit bewirkt werden kann und wie sich die Risiken für das Gesetzmäßigkeitsprinzip in Grenzen halten lassen. Nehmen Sie das Beispiel der Umweltverwaltung: Sie wird mit vagen gesetzlichen Maßstäben zu Entscheidungen gezwungen, die sie politisch nicht durchstehen kann, es sei denn, sie hat vorher durch eine informelle Klärung mit den beteiligten Gruppen und Kräften eine Verständigung herbeigeführt. Andernfalls zieht sich das Verfahren mit anschließendem Gerichtsverfahren über 10 bis 15 Jahre hin. Das aber wäre unzulässige Rechts- oder Verwaltungsverweigerung. Der Vertrag hat große Nachteile für die Legalität - ich glaube, das sollten wir klar sehen. Er ist zwar dem Gesetz als Schranke ausgesetzt, aber nicht wie die einseitige Entscheidung voll vom Gesetz abhängig. Das bewirkt ein Risiko der Illegalität. Die Frage ist also: Genügen nicht Absprachen, die jedenfalls keine rechtlichen Bindungswirkungen mit sich bringen, wie man sie in Frankreich offenbar zu vermeiden sucht? Das Ergebnis der Absprache wird anschließend in eine einseitige Entscheidung übergeleitet, die voll dem Gesetz entsprechen muß und angegriffen werden kann, auch von denen, die in die Absprache nicht einbezogen sind.

Der Gefahr, daß Absprachen oder Verträge den Bürgern aufgenötigt werden, kann man entgegenwirken. Nach Art. 19 des schweizerischen Subventionsgesetzes, den Herr Schweizer uns freundlicherweise zugänglich gemacht hat, muß die Verwaltung den Entwurf eines Vertrages den Beteiligten zustellen. Jeder kann dann statt dessen ein 
normales Verfahren mit einer anfechtbaren Entscheidung verlangen. Das beseitigt rechtlich, wenn auch vielleicht nicht immer tatsächlich, die Gefahr des Abhängigwerdens von Vertragslösungen. Der offizielle Entwurf eines japanischen Verwaltungsverfahrensgesetzes, den Herr Shiono von der staatlichen Universität Tokyo und ich im ersten Heft des Verwaltungsarchivs 1993 mit Begleitaufsätzen veröffentlichen werden, sieht allgemein vor, daß jeder an einem Verwaltungsvorgang Beteiligte von der Behörde verlangen kann, zum normalen Verfahren überzugehen und einseitig zu entscheiden, statt eine informelle Verständigung abzuwarten. Man will damit informelle Klärungsvorgänge nicht beseitigen, aber vermeiden, daß der Bürger ihnen ausgeliefert wird. Vielleicht können wir uns, Herr Burmeister, auf diese behutsame Lösung verständigen.

Aber nun Herr Krebs, zu Ihrem sehr schönen Referat. Es zeigt zu meiner Freude, wie relativ die Aussagekraft der Begriffe „Öffentliches Recht $^{\text {" }}$ und „Privatrecht" ist, gerade was die Verträge anlangt. Eine kleine Einwendung: Sie haben in Ihrem Leitsatz 22 eine Typologie der Verträge versucht. Die Frage ist aber, ob nicht für die verschiedenen Typen eine abgestufte verfassungsrechtliche oder verwaltungsrechtliche Bindung entwickelt werden müßte. Ich glaube nämlich, daß Ihr einheitlicher Verwaltungsvertrag zu einer Nivellierung der vertraglichen Handlungsmöglichkeiten führte, die die Verwaltung daran hinderte, ihre Aufgaben sachgerecht zu erfüllen. Ein Beispiel: Wenn die Bundesbank am Markt interveniert, haben Sie einen Typus von Verträgen vor sich, der nicht an den Verhältnismäßigkeitsgrundsatz oder den Gleichheitssatz gebunden werden sollte. Hier muß um der Sicherung der Währung willen frei und beweglich agiert werden. Diese Form vertraglich agierender Verwaltung müßte infolgedessen anderen Regelungen unterworfen werden als ein Vertrag, der eine umweltrechtliche Genehmigung ersetzt. Man sollte also m. E. nicht zu viel in dieselbe Kategorie fallen lassen und statt dessen Differenzierungen vornehmen.

Burmeister: Herr Bullinger, ich möchte Ihren Wortbeitrag nehmen und das Recht für einen Satz beanspruchen, um einem Mißverständnis zu begegnen: Ich möchte Sie doch mal bitten, sich die Leitsätze 15 und 16 anzusehen. Daraus ersehen Sie, daß ich mich gegen nichts anderes als den Verwaltungsvertrag in seiner Ersatzfunktion gegenüber dem Verwaltungsakt ausgesprochen und im übrigen alle Aspekte über Zulässigkeit, Inhalt und Anwendungsbereich des Verwaltungsvertrages thematisch ausgegrenzt und mich insoweit auf die Formulierung eines einzigen Leitsatzes beschränkt habe. Gemäß der thematischen 
Abschichtung mit Herrn Krebs habe ich mich überhaupt nur gegenüber dem subordinationsrechtlichen Vertrag in seiner Funktion als Ersatz für den Erlaß eines Verwaltungsaktes ausgesprochen. Deshalb sehe ich mich in Ihrem und einer Reihe anderer Wortbeiträge in eine Ecke gestellt, in der ich weiß Gott nicht stehe. Darauf werde ich nachher noch eingehen, möchte dies aber an dieser Stelle mit Nachdruck klarstellen. Ich bestreite doch - wie Sie aus Leitsatz 16 ersehen können - überhaupt nicht, daß es große Anwendungsbereiche gibt, in denen dem Verwaltungsvertrag als Handlungsform zentrale Bedeutung zukommt, insbesondere dort, wo ein staatliches Bewirkungsinteresse unter Zuhilfenahme von Privaten besteht. Verwaltungserfüllung durch Private erfolgt in erster Linie auf der Grundlage von Verwaltungsverträgen. Mit diesen Anwendungsbereichen des Verwaltungsvertrages habe ich mich aber bewußt nicht näher befaßt. Mir ging es allein darum, die dogmatische und praktische Inkonsistenz des Verwaltungsvertrages in seiner Ersatzfunktion für den Verwaltungsakt zu beleuchten und darzulegen, daß es sich insoweit um eine dogmatische Fehlkonstruktion handelt. Daß dem Verwaltungsvertrag im Bereich gleichordnungsrechtlicher Beziehungen zwischen Verwaltung und Bürger zentrale Bedeutung als Handlungsinstrument zukommt, darin stimme ich mit Herrn Krebs völlig überein.

Götz: Ich sehe keine grundsätzliche Verschiedenheit in der Stellungnahme, die die beiden Hauptreferenten gegenüber dem Legalitätsprinzip bezogen haben. Sie haben beide ihre Referate zur Gänze vom Legalitätsprinzip her aufgebaut. Wir sind uns doch alle einig, daß Vertrag und Absprache keine Instrumente und Handreichungen zur Flucht aus der Gesetzesbindung sein können. Ich glaube, so wichtig das auch in den Einzelheiten ist, daß das nicht eigentlich das spannende Diskussionsthema ist. Wir müssen uns - so meine ich fragen, was wir erwarten vom Vertrag und von der Absprache. Da knüpfe ich an Herrn Bullinger an und nenne die Stichworte, die natürlich auch in den Referaten gefallen sind: Effizienz, Akzeptanz der Verwaltungsentscheidungen. Dem ist im Hinblick auf die entscheidenden Faktoren nachzugehen. Ich nenne erstens die Normstruktur des Verwaltungsrechtes, zweitens die Struktur der Verwaltung und ihrer Arbeitsweisen, drittens die Stellung des einzelnen, des Bürgers, der der Verwaltung gegenübersteht.

Zur Normstruktur hat Herr Grimm schon das Wesentliche gesagt. Man kann aber auch einen so hausbackenen Begriff wie „Ermessen“ hier einführen. Es gibt große Spielräume, in die Vertrag und Absprache hinein ihren Platz finden. Das wissen wir. Übrigens auch in der 
gebundenen Verwaltung kommt das Ermessen wieder vor als Verfahrensermessen, etwa bei der Frage, in welchem Umfang zu ermitteln ist, und dann haben wir es plötzlich sogar im Steuerrecht und kommen dazu, daß wir Schätzungen und Absprachen und so weiter gar nicht von vornherein als etwas Illegales und Irreguläres ansehen müssen.

Zur Verwaltung kann man nur Stichworte nennen. Ist sie fähig zum Ermessen, ist sie abredefähig, bilden wir dazu aus, daß sie abredefähig ist, wird in der Ausbildung des gehobenen Verwaltungsdienstes dazu ausgebildet? Das läßt sich hier nur fragen. Ich habe aber, Herr Burmeister, doch Bedenken, Vertrag und Abrede so von vornherein ins Abseits zu stellen. Hier fiel bei Ihnen das Wort „faul“. Natürlich ist immer manches faul in der Verwaltung. Ich würde entgegen Ihrer Aussage doch annehmen, daß diese Fäulnisstellen ganz unabhängig davon sind, ob die Verwaltung die Mittel von Vertrag und Abrede gebraucht oder ob sie darauf verzichtet. Auch eine Verwaltung, die darauf verzichtet, kann im einzelnen faul sein und Faules tun. Das ist nicht von diesen Instrumenten abhängig.

Zum Dritten, zur Stellung des Individuums. Ich habe es bemerkenswert gefunden, daß Herr Krebs ganz unbefangen von der privatautonomen Rechtsstellung des Bürgers im Verwaltungsrecht spricht. Das würde ich unterstreichen. Aber das ist nichts ganz Selbstverständliches. Diese privatautonome Stellung erscheint uns aber als selbstverständlich - jetzt beginne ich einmal vom Ende her - wenn wir an den Verwaltungsprozeß denken. Dort legt der einzelne gleichberechtigt gegenüberstehend der Verwaltung die Rechtsmittel ein. Er betreibt seinen Prozeß, er macht Sachvortrag oder macht ihn nicht, er ist vergleichsfähig. In allem nehmen wir den einzelnen beim Wort. Er verfügt über seine Positionen, und nicht nur im technisch prozessualen Sinne. Denken Sie etwa an die Frage, ob ein überwiegendes Interesse anzuerkennen ist für einen vorläufigen Rechtsschutz. Hier beleuchten wir ganz genau, was der einzelne alles erklärt hat, hingenommen hat und so weiter; wir binden ihn an sein Tun, an seine Erklärungen wie ein wahrhaft privatautonom handelndes Rechtssubjekt. Das alles muß meines Erachtens deutliche Rückwirkungen haben auf das Verwaltungsverfahrensrecht und das Verwaltungsrecht. Über diese Rückwirkungen vom Verwaltungsprozeß her auf die Stellung des einzelnen im Verwaltungsrecht sollte man noch einmal nachdenken. In einem haben die beiden Referenten meine Neugier nicht ganz befriedigt: das sind die Absprachen. Offenbar absprachegemäß hat Herr Krebs dieses Thema nicht behandelt; er hat ausschließlich über den verwaltungsrechtlichen Vertrag gesprochen, und bei Herrn Bur- 
meister, der das Thema behandelt hat, ist diese Behandlung überlagert durch seine prinzipielle Skepsis. So kann ich nach diesen Referaten noch nicht, wie ich es gern tun würde, mitreden, wenn die japanischen Kollegen über administrative guidance sprechen und über das MITI. Hier verbleibt ein unerfülltes Bedürfnis. So kann ich nur erinnern an vielerlei kleine Münze, die wir auf diesem Gebiet anzubieten haben, etwa indem das Bundesverfassungsgericht im Brokdorf-Beschluß die Absprache zwischen der Versammlungsleitung und der Polizei als grundrechtlich geradezu erwünscht bezeichnet hat. Oder die Rechtsprechung der Verwaltungsgerichte, die darauf hinweisen, daß $\mathrm{Pla}$ nungen z. B. von Industriegebieten nicht ohne Absprachen gehen, die dann aber wiederum kritisch beleuchtet werden.

Vorsitzender: Vielen Dank Herr Götz. Es ist in der Tat bemerkenswert, daß die Absprachen in den beiden Referaten relativ kurz weggekommen sind. Das ist auch deshalb interessant, weil offenbar bezüglich der Verträge - sowohl in grundsätzlicher Hinsicht als auch im Blick auf Einzelfragen - noch ein großer Klärungsbedarf besteht.

Schachtschneider: Nach den ebenso herzlichen wie offenen Worten unseres Ehrenvorsitzenden zu meinem wissenschaftlichen Inneren ist es noch ein bißchen schwerer, hier zu sprechen. Aber nach seiner Aufforderung, die Polarität der Argumentation zu pflegen, macht es auch Freude, etwas zu sagen. In diesem Sinne möchte ich die These vertreten, daß die beiden Referenten von unterschiedlichen Paradigmen ausgegangen sind. Aufgrund seines Paradigmas ist es Herrn Burmeister gelungen, ein in sich konsistentes System vorzustellen und einzufordern, nämlich, wie ich es nennen möchte, ein verwaltungsrechtliches, insbesondere vertragsrechtliches, System, das einer republikanischen Lehre von der Freiheit entspricht. Aus dieser Lehre heraus muß die Lehre vom Recht und vom Staat entwickelt werden. Herr Autexier hat dafür mit Blick auf Frankreich sehr viel Hilfestellung gegeben. Dort gelingt das systemgerechte Denken besser. In Deutschland mag sich aufgrund eines Paradigmas der Freiheit einiges, wenn nicht viel verschieben. Ein System konnte Herr Krebs schlechterdings nicht vorstellen, weil er kein Paradigma reiner Art hat und ein solches nicht haben will. Er ist vielmehr, wenn ich das so scharf sagen darf, im liberalistischen Denken verfangen, das naturgemäß vom monarchischen Prinzip geprägt ist. Heute haben wir keine Monarchen mehr. Dafür haben wir die Parteien, die in deren Rolle getreten sind. Auf der Grundlage des Widerspruchs des Paradigmas eines herr- 
schaftlich geprägten Liberalismus und des republikanischen Grundgesetzes hat Herr Krebs das Bestmögliche geleistet. Deswegen sind auch fast alle mit seinen Ausführungen zufrieden. Aber wir sollten den Versuch machen, die Revolution von 1918 verwaltungsdogmatisch nachzuholen, nachdem uns das Grundgesetz 1949 auf den gleichen Standpunkt wie die Weimarer Verfassung von 1919 gestellt hat, nämlich eine Republik und eben nicht eine liberalistische Monarchie verfaßt hat, in welcher näheren Form auch immer. Unter diesem paradigmatischen Gesichtspunkt trägt der Vorwurf der Realitätsferne überhaupt nicht. Auch Herr Burmeister und jeder, der sich damit beschäftigt, will die schwierige und vielfältige Realität bewältigen. Nur auf der republikanischen Grundlage muß die Anfangsarbeit erst noch geleistet werden. Das bedeutet in der Praxis eine totale Veränderung. Das kostet viel Geld, würde allerdings auch sehr viel Geld sparen. Erlauben Sie mir, daß ich zu einigen Einzelfragen komme:

Herr Krebs hat mit Recht angesprochen, daß die instrumentelle Form des Privatrechts gar nicht mehr so sehr im Vordergrund steht und nicht so viele Probleme bereitet, weil sie längst von den Maßstäben des öffentlichen Rechts überlagert ist, die es ohnehin nicht mehr zu sagen erlauben, daß in der Verwaltung Privatrechtlichkeit begegne. Vielmehr handele es sich um eine modifizierte, also eigentlich eine staatlich geprägte Privatrechtlichkeit. Nein, die Organisationsprivatisierung ist das Problem unserer Tage. Stichworte sind: Bahn, Post, Flugsicherung und schon seit eh und je die Ver- und Entsorgung. Diese Organisationsprivatisierung hat auch finanzverfassungsrechtliche Konsequenzen. Sie kostet viel mehr, als eine andere Form der Verwaltung dieser Bereiche kosten würde. Eine echte Privatisierung wäre wünschenswert. Sie würde es rechtfertigen, von der Wettbewerblichkeit dieser Unternehmen zu sprechen, ein Topos, der für den Staat überhaupt nicht paßt, weil der Staat nicht in Wettbewerb zu Privaten treten darf. Die verfassungsrechtlich bedenkliche privatrechtliche Form von Arbeitsverhältnissen des öffentlichen Dienstes hat ebenfalls enorme Konsequenzen für die Verfassung des Gemeinwesens. Das Bundesverfassungsgericht hat diese durch eine unbegründete Entscheidung ermöglicht. Wenn alle Mängel, die mit dem Fiskusdogma gestützt werden, korrigiert werden sollen, ist viel Arbeit zu leisten. Die ewigen Versuche, hoheitliche Staatlichkeit von nichthoheitlicher Staatlichkeit zu unterscheiden, werden scheitern. Die sind immer gescheitert. Auch dem Europäischen Gerichtshof ist die Unterscheidung nicht gelungen. Warum? Weil es keinen materiellen Begriff der öffentlichen Aufgabe gibt, sondern die öffentliche Aufgabe genau das ist, was das Gesetz, wie Herr Burmeister es richtig gesagt 
hat, zur öffentlichen Aufgabe macht. Es gibt also nur einen formalen Begriff der öffentlichen Aufgabe. Immer steht im Hintergrund all der Überlegungen von der Privatrechtlichkeit der Verwaltung, auch denen von Herrn Krebs, die Vorstellung, es gebe einen materialen Begriff der öffentlichen Aufgabe.

Die Zeit drängt, deswegen nur noch einige Stichworte, zunächst zur Privatautonomie, die Herr Götz soeben angesprochen hat. Auch diesen Begriff müssen wir bedenken, diesen ehrwürdigen Begriff. Dem Privaten gibt kein Gesetz Autonomie. Im Begriff Autonomie steckt das Wort nomos, also das Wort Gesetz. Der Begriff Privatautonomie, der im Liberalismus richtig und gut war, ist in der Republik widersprüchlich. Privatheit und Autonomie passen nicht zusammen, nur die Bürgerschaft in ihrer Gesamtheit kann autonom sein. Ein weiterer Aspekt: $\mathrm{Da}$ man jetzt zum Vertrag zurückgreift, hat auch Legitimationswirkung. Angesichts des enormen Vollzugsproblems in der schwierigen vielfältigen Verwaltung gibt der Vertrag, wie es vielfach schon angesprochen wurde, Akzeptanzmöglichkeiten, Legitimationsmöglichkeiten. Aber er birgt auch die Gefahr der Korruption. Das gilt erst recht für die Absprache. Ich wage einen Schluß, wenn Sie mir das, weil Herr Ipsen das ermöglicht hat, erlauben: Wie schade für das Recht, wenn es nicht mit der Praxis übereinstimmt! Dankeschön.

Gröschner: Zwei relativ grundsätzliche, gleichwohl relativ kurze Bemerkungen: erstens zur Begriffsbildung, zweitens zur Dogmenphilosophie des öffentlich-rechtlichen Vertrages.

Zur Begrifflichkeit möchte ich anknüpfen an Herrn Burmeisters These 2. Es heißt dort: „Sozial- und verwaltungswissenschaftlichen Befassungen mit dem Phänomen des informellen Staatshandelns ist mit Vorsicht zu begegnen." Nun, ich würde nicht bereits der Befassung als solcher mit Vorsicht begegnen, sondern erst der unvermittelten Übertragung empirischer Befunde und Begriffe in die Rechtsdogmatik. Rechtsdogmatische Begriffe sollten am positiven Recht orientiert sein und an dessen normativer Strukturierung. Ich schlage deshalb vor, den aus der organisationswissenschaftlichen Terminologie stammenden Begriff des informalen Verwaltungshandelns nicht etwa durch den des informellen zu ersetzen - es gibt ja genug Streit darüber, wir kennen das -, sondern durch den des formlosen Verwaltungshandelns. Denn Formlosigkeit beziehungsweise Formfreiheit ist ein genuin juristischer Begriff, ebenso wie Einseitigkeit und Einvernehmlichkeit. Ich unterscheide daher einseitig formloses Verwaltungshandeln und einvernehmlich formloses Verwaltungshandeln das ist keine Deutschtümelei, sondern positivrechtliche Dogmatik. In 
die erste Gruppe gehören dann Aufklärungsakte, Empfehlungen, Warnungen, und in die zweite Gruppe Absprachen und ähnliches.

Punkt 2: Dogmenphilosophie des öffentlich-rechtlichen Vertrages. Ich habe erhebliche Zweifel, ob wir uns in diesem Bereich - trotz allen Respekts selbstverständlich vor dem Altmeister unserer Verwaltungsrechtsdogmatik - noch auf Otto Mayer berufen können. Der berühmte Beitrag im 3. Band des AöR beruht eben doch auf einer Staatsphilosophie, die nicht mehr die unsere ist, ja nicht mehr die unsere sein kann, und zwar wegen Art. 1 Abs. 3 GG. Die Grundrechtsbindung aller staatlichen Gewalt schließt es aus, das StaatBürger-Verhältnis als Gewaltverhältnis im Sinne Otto Mayers zu konzipieren; als Verhältnis also, in dem ein - Originalzitat Otto Mayer - „Urrecht des Staates auf Gehorsam“ durchschlägt, bei Otto Mayer durchschlagen muß, um die verwaltungsrechtliche Verwirklichung seines an $\mathrm{Hegel}$ orientierten Souveränitätsbegriffs sicherzustellen.

Schlußsatz: In einem Verfassungsrechtsverhältnis, das diese Bindung ernst nimmt, hätte ich keine Bedenken gegen Verwaltungsverträge, die auf einfachgesetzlicher Grundlage zustande gekommen sind. Danke.

Stettner: Herr Vorsitzender, meine Damen und Herren. Ich möchte einige Bemerkungen zum Referat von Herrn Burmeister machen. Herr Burmeister hat - und ich glaube, das muß auch festgestellt werden, es ist bisher noch nicht getan worden - in bemerkenswerter Klarheit den Antagonismus der staatlich verfaßten Seite gegenüber dem Bereich privater Selbstbestimmung, der Privatautonomie, festgestellt. Er hat allerdings auch die Konsequenzen dargetan, die resultieren, wenn beide Teile miteinander in vertragliche Verbindung treten, oder, wie Herr Dreier so schön sagte, paktieren, weil sie ja auf unterschiedliche Art für Verträge und Absprachen gerüstet sind.

Auf der einen Seite haben wir staatlicherseits dieses Konvolut von Aufgaben und Kompetenzen, eine Bindung an das Gemeinwohl, den Zwang, altruistisch zu agieren, die rechtliche Gebundenheit und vor allem den Ausschluß jeder Beliebigkeit. Auf der anderen Seite ist in der grundrechtlich bestimmten Sphäre des Privaten die Privatautonomie zu Hause. Wir haben Voluntativität, wir haben das Recht, eigennützig zu agieren. Wollen wir nun beide Teile zu Verträgen, zu Absprachen zusammenbinden, dann entspricht es einem Gesetz der Logik, auf der staatlichen Seite eine gewisse Angleichung in Richtung auf Voluntativität, auf das „Recht, sich selbst zu bestimmen“, vorzu- 
nehmen, letztlich Kompetenzen zu subjektivieren. Wir kommen dann aber zum Ergebnis, daß Kompetenzen teilweise nicht mehr das sind, was sie eigentlich sein sollten, nämlich altruistisch wahrzunehmende Bindungen, Macht, die im Interesse des Gemeinwohls anzuwenden ist, sondern daß sie in Richtung auf verfügbare Rechtspositionen angereichert und wohl auch verfälscht werden. Dies hat Konsequenzen für eine Pluralisierung der Verwaltung bis hin zu Insichprozessen und ähnlichen Erscheinungen, wo also mehr oder weniger verselbständigte Einheiten aus der unmittelbaren Staatsverwaltung miteinander in Rechtsstreitigkeiten geraten und diese prozessual ausfechten. Es birgt aber vor allem auch Gefahren für die Gesetzmäßigkeit, für das Legalitätsprinzip. Ein Sich-Abstrahieren von diesem rechtsstaatlichen Prinzip liegt nahe.

Auf der Seite des Privaten wird man eine Angleichung an die Gebundenheit der staatlichen Seite nicht erreichen, auch nicht wünschen können. Hier sind die Grundrechte als Gegenmittel von der Verfassung eingebaut. Versagt nun unser Rechtsstaat vor den Anforderungen der technisierten Gesellschaft, findet das Bedürfnis für Verträge und Absprachen zwischen Verwaltung und Bürger keine Entsprechung auf dem verfassungsrechtlichen Plateau? Ich glaube nicht, meine Damen und Herren. Ich glaube zwar nicht, daß die Anwendung des Grundsatzes ,volenti non fit iniuria“ sehr viel weiter hilft, auch wenn Herr Ipsen das angesprochen hat, denn allzu leicht könnte der Staat dadurch ihm genehme Einwilligungen seitens des Bürgers herbeiführen. Ich glaube auch weniger, daß ein Kompensationsgedanke, der mir noch nicht ausreichend konturiert erscheint, hier weiterhilft. Vielmehr stelle ich mir die Frage, ob wir nicht allmählich dem Gedanken einer begrenzten Verfügbarkeit über den Grundsatz der Gesetzmäßigkeit der Verwaltung nahetreten sollten. Häufig wurde eine begrenzte oder abgeminderte Bindung an das Gesetz in dieser Diskussion angesprochen, die mir aber so zu unbestimmt erscheint und nur nach Maßgabe entsprechender Gegenindikationen akzeptierbar ist. Ich darf darauf hinweisen, daß wir ein Vorbild in der Rechtsprechung des Bundesverwaltungsgerichts zur Rücknahme rechtswidrig-begünstigender Verwaltungsakte haben und es fragt sich, ob das ein Sonderfall sein muß oder ob wir dieses Abwägungsinstrumentarium nicht auch für Absprachen fruchtbar machen können. Vielen Dank.

Vorsitzender: Ich gebe nun den Referenten die Gelegenheit, in einem Zwischenwort zu den bisherigen Beiträgen Stellung zu nehmen. 
Krebs: Zunächst zur Zwischenbemerkung eine Vorbemerkung, die dann auch für das Schlußwort gilt. Wenn ich auf einige Stellungnahmen und Fragen nicht eingehe, bitte ich das keinesfalls als Achtlosigkeit und schon gar nicht als Bewertung aufzunehmen. Ich halte einiges für so bedenkenswert, daß ich mir die Freiheit nehmen möchte, erst darüber nachzudenken, bevor ich dazu Stellung nehme.

Auch in der heutigen Diskussion sind teilweise nachgerade klassische Vorurteile gegen das Vertragshandeln zum Ausdruck gebracht worden. Gleich zu Beginn hat Herr Grimm zu bedenken gegeben, ob nicht der Abschluß von Verträgen im Hinblick auf den Gleichheitssatz problematisch sein könne. Dazu zwei Bemerkungen: Erstens besteht die Gefahr gleichheitswidrigen Handelns ebenso bei einseitigen hoheitlichen Entscheidungen, die nur durch Ermessensnormen gesteuert werden. Zweitens kann der Gleichheitssatz nicht nur gleichmäßiges, sondern auch differenzierendes Handeln gebieten, und der Vertrag kann der Erfüllung dieses Gebots dienen. Ein zweites klassisches Vorurteil - wie ich es einmal polemisch überzogen bezeichnen will - ist, daß der Vertrag illegale Verwaltungsentscheidungen begünstigen würde. Das ist natürlich schwierig zu beurteilen, wenn man die Praxis nicht im einzelnen darauf hin erforscht. Nur stelle ich dem genauso ungeschützt die These entgegen, daß die Neigung zu illegalen Entscheidungen - soweit sie vorhanden sein sollte - instrumentunabhängig ist. Ich meine also nicht, daß das eine vertragstypische Gefahr ist und würde deshalb auch nicht gerade das Vertragshandeln zum Anlaß nehmen, die Realität in ein Spannungsverhältnis zur Dogmatik zu bringen. Zumindest ging es mir darum, die Anforderungen effektiver Aufgabenwahrnehmung mit den verfassungsrechtlichen Anforderungen an das Verwaltungshandeln zu verbinden. Darin sehe ich eben eine wichtige Aufgabe der Verwaltungsrechtswissenschaft und übernehme von Ihnen, Herr Schuppert, den Begriff der Bereitstellungsfunktion der Verwaltungsrechtswissenschaft. Deshalb habe ich auch von einem rechtlichen Entscheidungsrahmen gesprochen, dessen Einhaltung ein rechtlich einwandfreies Vertragshandeln gewährleisten soll. Im Hinblick darauf sind nach meiner Einschätzung gerade die rechtlichen Zuständigkeitsgrenzen und Aufgabenzuweisungen sehr wichtige Entscheidungsdaten.

$\mathrm{Zu}$ den dogmatischen Konsequenzen, die im Hinblick auf die Verwaltungspraxis zu ziehen sind, hat Herr Dreier den Vorschlag gemacht, eine gesamte Verwaltungspaktsdogmatik zu entwerfen. Der Vorschlag ist auch schon in der literarischen Diskussion gemacht worden. Ihm zu folgen ist sehr schwierig. Man würde der Absprache nicht gerecht werden, wenn man sie in der Rolle des kleinen rechtsun- 
verbindlichen Bruders des Vertrages sehen würde. Deshalb habe ich auch angedeutet, daß sich das Netz der nichtförmlichen Handlungen quer über das Netz der rechtsförmlichen legen kann. Wenn man eine Dogmatik des Ganzen entwickeln wollte, müßte man zuvor ausloten, in welchem Verhältnis das eine Beziehungsgefüge zum anderen steht. Erst wenn man sich darüber Klarheit verschafft hat, kann man möglicherweise dogmatisch nachziehen.

Im Hinblick auf die von mir vorgenommene phasenspezifische Ausdifferenzierung haben Sie, Herr Bullinger, völlig zu Recht darauf hingewiesen, daß auch die Leistungsstörungen berücksichtigt werden müßten. Es war für mich eine Frage der Selektion, ob ich auf die Leistungsstörungen oder auf den clausula-Grundsatz eingehe. Ich bin davon ausgegangen, daß sich zur Verdeutlichung meines Anliegens die clausula-Problematik besser eignet. Sie weist sehr deutlich darauf hin, daß möglicherweise 20 Jahre nach Vertragsschluß das durch Vertrag begründete Rechtsverhältnis erstens immer noch besteht und zweitens Probleme aufwerfen kann. Deshalb war mir auch der Hinweis wichtig, daß man sich gründliche Gedanken über die Vertragsgestaltung machen muß. Hilfreich wäre ein Vertragshandbuch mit Vertragsregelungen, die zuvor darauf hin untersucht wurden, ob sie rechtsstaatlich einwandfrei sind.

Burmeister: Ich möchte zunächst auf den grundlegenden Einwand eingehen, den vor allem Herr Grimm und Herr Schmidt-Aßmann, dann sehr pointiert auch Herr Schuppert formuliert haben, der aber auch in Ihren Worten, Herr Bullinger, angeklungen ist: den Grundeinwand, ich hätte bei meiner strengen legalitätsorientierten Betrachtung die Wechselwirkung zwischen Realität und Recht nicht hinreichend berücksichtigt. Ich meine indessen, daß dieser Einwand nicht trägt. Ich verkenne nicht, daß Recht, vor allem das Verwaltungsrecht, in starkem Maße durch Rückwirkungen der Realität geprägt wird. Man muß aber doch wohl die Frage stellen dürfen, ob es überhaupt noch eine dirigierende Kraft von Normen oder eine gesetzesdirigierende Funktion der Verfassung gibt. Wenn Sie etwa, Herr Schuppert, sagen, es sei Aufgabe - Sie sprachen von einer Bereitstellungsfunktion - des Verwaltungsrechts, der Verwaltung das Instrumentarium zur Verfügung zu stellen, das sie zu „vernünftigem Arbeiten“ braucht, also das Recht gewissermaßen so hinzubiegen, daß es den Brauchbarkeits- und Effizienzerfordernissen der Verwaltung entspricht, so sind gegen diese Sichtweise nach meinem Dafürhalten deutliche Vorbehalte anzumelden. Doch immer steht im Hintergrund das Erfordernis, bestimmte Erscheinungen der Realität auf ihre verfassungsrechtliche 
Fundierung hin zu befragen. Und hier muß ich in der Tat feststellen, daß wir es in Hinsicht auf den Staat als Privatrechtssubjekt bzw. privatvertragliches Handeln des Staates mit einem Befund zu tun haben, für den ich - und dies sage ich ganz deutlich - keine Erklärung auf der Grundlage des geltenden Verfassungsrechts finden kann. Ich kann keine Erklärung dafür finden, auf welcher rechtlichen Grundlage z. B. Sparkassen ihren Geschäftsbereich - nach geläufiger Terminologie - „arrondieren“ durch Aufkauf ganzer Versicherungszweige; auch für die Spekulation von Landesbanken an der New Yorker Börse sehe ich keine Legitimationsgrundlage. Ich kann keinen juristischen Grund finden für eine „Arrondierung des Geschäftsbereichs" der Deutschen Bundespost durch Einverleibung von Tätigkeitsbereichen, für die ein spezifisch öffentlicher Zweck nicht erkennbar ist. Auch kann ich keinen verfassungsrechtlichen Grund für das Phänomen erkennen, daß allenthalben in den Kommunen auf privatvertraglicher Grundlage Spielbanken gegründet und betrieben werden. Selbst für die öffentlich-rechtlichen Rundfunkanstalten wird zwischenzeitlich nicht mehr nach den Grundlagen, sondern nur noch nach den Grenzen erwerbswirtschaftlich-fiskalischer Betätigung gefragt. Das alles sind Erscheinungen der Realität, die wir daraufhin befragen müssen, wo sie in aller Welt eine Legitimationsgrundlage in der Verfassung haben und deshalb stoße ich mich, Herr Schuppert, schon etwas an Ihrer Formulierung, daß es primäre Aufgabe des Verwaltungsrechts sei, der Verwaltung diejenigen Instrumente zur Verfügung zu stellen, die sie für effizientes Arbeiten braucht.

Mein Anliegen war es, aus meiner Sicht das Grundproblem zu verdeutlichen, daß wir es mit einer ganzen Fülle von Erscheinungen von Staatlichkeit zu tun haben, für die ich selbst bei wohlwollender und realitätsbezogener Betrachtungsweise keinen Fundus in der Verfassung mehr finden kann. Dies markiert den Tatbestand der Diskrepanz zwischen Verfassungsrecht und Verfassungsrealität, der, wenn er in größerem Umfange diagnostiziert werden muß, in der Tat ein Krisensymptom darstellt. Deswegen war es mein bewußtes Anliegen, einmal die dogmatische Seite in den Vordergrund zu stellen und zu beleuchten, daß wir mit einer ,weithin gebräuchlichen Begrifflichkeit Tatbestände vernebeln, für die wir keine Erklärung auf der Basis der Verfassung haben". Die Symptome dieses Befundes ließen sich schier beliebig erweitern und Erscheinungen von Staatlichkeit benennen, für die ich jedenfalls keinen Fundus in der Verfassung sehen kann. Dazu gehört insbesondere der ständig gebrauchte Begriff der „erwerbswirtschaftlich-fiskalischen Betätigung" der öffentlichen Hand. Ich kann für diese Tätigkeit in der Verfassung keine Grundlage finden, obwohl 
sie zur gebräuchlichen Begrifflichkeit der Verwaltungsrechtsdogmatik bei der Umschreibung der Handlungsbereiche der Verwaltung gehört.

Sie, Herr Gallwas, haben die Frage gestellt, warum der Staat nicht Privatrechtssubjekt ist und warum ihm vom Gesetzgeber nicht Privatrechtssubjektivität verliehen werden könne. Schade, daß Herr Böckenförde nicht unter uns ist, denn er könnte diese Frage präzise beantworten. Genau besehen handelt es sich bei der Zuerkennung von Privatrechtsfähigkeit um eine ungewollte Folgewirkung der Übertragung der Rechtskonstruktion der juristischen Person auf den Staat. Indem wir den Staat und seine verselbständigten Untergliederungen als juristische Personen begreifen und keine andere Rechtskonstruktion kennen, um ihnen rechtliche Handlungsfähigkeit zu verleihen, haben wir auf staatliche Handlungsträger ungewollt ein wesentliches Attribut der Konstruktion der juristischen Person übertragen: die Vollrechtsfähigkeit im zivilrechtlichen Sinne. Die aus dem Zivilrecht stammende Konstruktion der juristischen Person dient ja nichts anderem, als einer Einrichtung, einer Organisationseinheit, die einer natürlichen Person zustehende volle Rechtsfähigkeit zu vermitteln. Eine Vollrechtsfähigkeit im Sinne einer grundsätzlich allumfassenden Inhaberschaft von rechtlichen Befugnissen trifft aber für den Staat überhaupt nicht zu. Dem Staat und seinen Untergliederungen kommt keine apriorische rechtliche Befugnis wie einer natürlichen Person zu; alle staatlichen Befugnisse sind begriffsnotwendig übertragene Befugnisse, Kompetenzen, wie dem Staat auch kein natürlicher Wille zusteht, sondern sein Wille stets ein rechtlich konstruierter ist. Nichts anderes besagt letztlich die ultra-vires-Lehre: sie besagt, daß ein staatlicher Funktionsträger nur in dem ihm übertragenen Kompetenzbereich rechtlich existent ist. Das Fehlen eines natürlichen Willens und autonomer Rechte ist eine jeder Organisationseinheit vorausliegende Wesenseigentümlichkeit, die nicht disponibel ist. Der Gesetzgeber kann den Staat nicht mit einer nur natürlichen Personen, Menschen zukommenden Vollrechtsfähigkeit ausstatten; er kann ihm nicht etwas verleihen, was begriffsnotwendig nur Ausfluß einer vorgegebenen Rechtsinhaberschaft sein kann. Dies würde unsere Vorstellung vom Wesen des Staates und seiner Konstruktion als Organisationsverband sprengen, weil diesem rechtliche Befugnisse nur zustehen können, soweit sie ihm konstitutiv verliehen sind.

Grimm: Ich fühle mich doch gedrängt, noch einen Satz zu sagen, Herr Burmeister. Die Diskrepanz zwischen Recht und Wirklichkeit kommt auf zwei Ebenen vor, und die beiden Ebenen sind verschieden zu behandeln. Es gibt strukturelle Veränderungen im Regelungsbe- 
reich von Rechtsnormen. In diesem Fall muß man das Recht adaptieren. Und es gibt die Gesetzesumgehung, die Rechtsverletzung, die rechtswidrige Praxis. In diesem Fall muß man die Normativität verteidigen.

Burmeister: Richtig. So ist es. Wir sind völlig einer Meinung. Nur möchte ich festhalten, daß die Erscheinung des Staates als Privatrechtssubjekt eben keine durch das Recht adaptionsfähige strukturelle Veränderung, sondern eine Erscheinung außerhalb des Rechtes darstellt, der gegenüber die Normativität der Verfassung aufrechtzuerhalten ist.

Herr Ipsen, Sie haben die Formulierung gebraucht, daß es bei der Ausgliederung von Staatlichkeit als Privatrechtssubjekt lediglich darum geht, welche Handlungsform der Verwaltung zur Verfügung steht. Dem möchte ich dezidiert widersprechen: nein, es geht nicht um die Handlungsform, es geht vielmehr um die Handlungsmaßstäbe. Die Formen sind ganz sekundär. Worüber wir aber Konsens haben müssen, sind die Maßstäbe, nach denen der Staat handeln darf, und diese dürfen nicht disponibel sein. Die Vorstellung, daß wir durch Disposition über die Handlungsformen einen Austausch der rechtlichen Handlungsmaßstäbe erreichen können, hebt die Begrenzung von Staatlichkeit auf. Diese Vorstellung löst die größte rechtsstaatliche Errungenschaft auf, die in der Beschränkung und Zurückdrängung des Staates auf die Wahrnehmung bestimmter Funktionen, auf Angelegenheiten des Gemeinwohls, besteht. Darum habe ich bewußt so pointiert hervorgehoben, daß wir uns die Konsequenzen des Satzes vergegenwärtigen müssen, durch den Gebrauch privatrechtlicher Rechtsformen ließen sich freiheitliche Befugnisse - so benennen wir es ja oft - von staatlichen Kompetenzträgern begründen, so etwa, wenn von Eigentumsfreiheit des Staates die Rede ist. Ich sage nochmals ganz deutlich: es gibt keine Eigentumsfreiheit des Staates. Es gibt überhaupt keine rechtliche Befugnis des Staates, die diesem um seiner selbst willen zustünde. Auch Eigentum vermittelt dem Staat keine subjektiven Rechte, die ihm Befugnisse um seiner selbst willen vermitteln könnten. Staatliches Eigentum ist nur rechtskonstruktiv Privateigentum; in der Sache ist es nichts anderes als eine pflichtgebundene Inhaberschaft, die, soweit sie nicht zur Erfüllung einer bestimmten Sachkompetenz gebraucht wird, ihre Legitimation zur Innehabung durch den Staat verliert. So bedarf es zur Anerkennung der staatlichen Rückgabepflicht an Private etwa von Liegenschaften, die nicht zur Erfüllung einer bestimmten öffentlichen Aufgabe benötigt werden, nicht des Rückgriffs auf den Subsidiaritätsgedanken, sie ergibt sich 
vielmehr aus dem Wesen von staatlichem Eigentum als sachgebundene Kompetenzinhaberschaft. Es gibt keine durch den Gebrauch privatrechtlicher Handlungsformen vermittelten Rechte oder Freiheiten des Staates, und wir müssen uns vergegenwärtigen, daß wir, wenn wir Erscheinungen der Realität als Ausfluß von staatlichen Freiheiten begreifen oder bezeichnen, staatlichen Handlungsbefugnissen das Wort reden, die sich aus der Verfassung nicht ableiten lassen. Das ist der entscheidende Punkt.

Gallwas: Ich mache es ganz kurz, Herr Burmeister. Ich habe ja nichts dagegen, daß Sie sagen, der ist nicht vollrechtsfähig. Die Frage ist nur, welche Konsequenz daraus zu ziehen ist. Wenn Sie meinen, er ist insoweit nicht existent, dann müssen Sie prozessual eine Konsequenz ziehen. Dann müssen Sie ihn für den Prozeß als existent fingieren, sonst nehmen Sie dem Kläger den Beklagten.

Burmeister: Das haben wir nicht selten, sowohl im Zivilrecht wie im öffentlichen Recht. Die Rechtsordnung erkennt vielfach rechtlich nicht existenten Handlungssubjekten die Fähigkeit zur prozessualen Geltendmachung von Rechten insoweit zu, als deren Existenz bzw. Inhaberschaft streitig ist. So ist im öffentlichen Recht anerkannt, daß Gemeinden, die aufgelöst sind, in bezug auf die Geltendmachung der Rechtswidrigkeit des Verlustes ihrer Existenz als fortbestehend fingiert werden. Also, für die prozessuale Seite sehe sich da keine Probleme.

Vorsitzender: Wir setzen nunmehr nach den „Zwischenworten“ der Referenten die allgemeine Diskussion fort.

Mußgnug: Ich möchte eine Anmerkung zu Herrn Burmeisters These 13 beisteuern, in der er die ultra-vires-Lehre anspricht. Auch ich halte die Teilrechtsfähigkeit, auf die diese Lehre die juristischen Personen des öffentlichen Rechts beschränkt, für ein Unding. Denn sie belastet die Verträge der juristischen Personen des öffentlichen Rechts mit einer inakzeptablen Unsicherheit. Wie soll zum Beispiel der Unternehmer, der seinen Betrieb verkaufen möchte und von einer Gemeinde ein passables Angebot erhält, zuverlässig ermitteln, ob die Gemeinde den Betrieb erwerben und betreiben darf? Das mag einfach sein, wenn es sich um einen Delikatessen-Laden handelt, wie ihn die Gemeinden mit Sicherheit nicht unterhalten dürfen, oder um ein Theater, wie sie es mit Sicherheit übernehmen dürfen. Aber es gibt Grenzfälle, etwa die Discothek, die zum Jugendtreff umgewandelt werden soll, das Fitneß-Center oder das Sanatorium, bei dem das die Rechtsaufsichtsbehörden und die Verwaltungsgerichte leicht ganz anders sehen als die Gemeinde und ihr Verkäufer. M.E. ist es ein 
Unding, in diesen Fällen den Kaufvertrag kurzer Hand als unwirksam zu verwerfen, wenn sich im nachhinein herausstellt, daß die Gemeinde mit seinem Abschluß über die Grenzen ihrer Zuständigkeit hinausgegangen ist. Es genügt, daß sie, den Betrieb, den sie nicht unterhalten darf, weiterverkaufen oder wenigstens verpachten muß. Packen wir die Fälle dieser Art - wie der Bundesgerichtshof in seinem „HeringsUrteil“ - mit der Teilrechtsfähigkeit an, so lösen wir sie auf Kosten des verwaltungsfremden Vertragspartners, der meist nicht weiß, was den juristischen Personen des öffentlichen Rechts gestattet ist und was nicht. Ginge das an, so würde ich juristische Personen des Privatrechts, auf deren Rechtsfähigkeit sicherer Verlaß ist, den juristischen Personen des öffentlichen Rechts als Vertragspartner bei weitem vorziehen. Auch die juristischen Personen des öffentlichen Rechts haben ihre Rechtsfähigkeit jedoch wohl kaum erhalten, um sie zu $V m b R$ 's, Verbänden mit beschränkter Rechtsfähigkeit, zu degradieren.

Ebenso wie Herr Burmeister mißtraue im übrigen auch ich der berühmten Befriedungsfunktion des öffentlich-rechtlichen Vertrags. Ein Vertrag über die Erteilung eines Baudispenses z. B. mag zwischen der Baurechtsbehörde, der Gemeinde und dem Baubewerber für Eintracht und Konsens sorgen. Ob er auch die Nachbarn "befriedet", steht auf einem anderen Blatt. Deshalb neige ich gegenüber der Befriedungsfunktion des öffentlich-rechtlichen Vertrags eher zur Zurückhaltung.

Dagtoglou: Herr Vorsitzender, meine Damen und Herren. Aus den heutigen Referaten und Länderberichten hat sich mit Eindeutigkeit die Verbreitung und Beliebtheit der Rechtsfigur des Verwaltungsvertrages ergeben. Selbst der französische Conseil d'État verurteilt zwar die Sünde, d.h. den Vertrag als solchen, hat aber Sympathie für die Sünder, d.h. hier Vertragspartner, und vermeidet die Nichtigerklärung. Gleichzeitig mit dieser Beliebtheit des Verwaltungsvertrags erfolgt eine Verschiebung der Grenzen der Staatlichkeit. Es ist nicht zufällig, daß der Staatsaufgabenbereich in unserer Zeit umstritten ist. Die Parole im letzten Viertel unseres Jahrhunderts ist: Weniger Staat! Dieser Rückzug des Staates erfolgt dadurch, $\mathrm{da} ß$ viele bisher als traditionell angenommene Staatsaufgaben in vielen Ländern privatisiert werden. Unter „Privatisierung“ verstehe ich hier nicht etwa den Verkauf von staatseigenen Unternehmen an Private wie in den neuen Bundesländern und in den osteuropäischen Staaten, auch nicht die Indienstnahme von Privaten im Sinne Ipsens, sondern die Einschränkung des Staatsaufgabenbereichs zugunsten des privaten Sektors. 
Wir sind nicht mehr sicher, was zum unverzichtbaren Terrain des Staates gehört. Wenn aber eine Staatsaufgabe privatisiert wird, können nicht mehr einseitige Verwaltungsakte erlassen werden. Es bleibt nur noch die Rechtsfigur des Vertrags, und zwar des privatrechtlichen. Wenn aber eine Staatsaufgabe privatisiert werden darf, dann fragt man sich, warum diese Staatsaufgabe nicht auf dem Wege des Vertrages wahrgenommen werden sollte. Das ist eben meine Frage an die Referenten: Welches ist das Verhältnis zwischen der Zulässigkeit der Privatisierung von Staatsaufgaben und der Zulässigkeit der Wahrnehmung von diesen Aufgaben auf dem Weg des Vertrages.

Oldiges: Heute morgen wurde versucht, Zweifel an der Berechtigung zweier verwaltungsrechtlicher Institute zu wecken, an die sich die Rechtswissenschaft nun schon seit langem gewöhnt hat, nämlich am privatrechtlichen Verwaltungsvertrag und am subordinationsrechtlichen Vertrag.

Herr Burmeister hat den privatrechtlichen Verwaltungsvertrag zwar nicht als Handlungs- oder als Rechtsform in Frage stellen wollen, hat ihn aber einem öffentlich-rechtlichen Regime unterstellt, was darauf hinausläuft, daß sein Anwendungsbereich auf das engste beschränkt ist. Zweifellos, so wird man zustimmen müssen, kann sich die öffentliche Hand, wenn sie privatrechtliche Verträge schließt, dabei nicht einfach auf den Grundsatz der Privatautonomie berufen. Die alte und nun schon seit einhundertsechzig Jahren virulente Vorstellung vom Staat als einer juristischen Person erschließt den staatlichen Verwaltungsträgern nicht das volle Feld der Privatautonomie. Vielmehr wird auch das privatrechtlich-paktierende Handeln des Staates in einem solchen Maße von den Bindungen an das Gemeinwohl überlagert, $\mathrm{da} ß$ sich von uneingeschränkter Privatautonomie nicht reden läßt. Wenn sich der Staat aber auf Privatautonomie nicht berufen kann, benötigt er für den Abschluß privatrechtlicher Verträge andere Kompetenztitel. Das ist der Ansatz von Herrn Burmeister, gegen den sich insoweit wohl nichts einwenden läßt. Herr Burmeister geht nun aber in der Suche nach möglichen Kompetenztiteln recht rigide vor. Er greift auf den Aspekt der Staatsaufgaben zurück und fragt, ob und wieweit solche Aufgaben auch den Abschluß privatrechtlicher Verwaltungsverträge rechtfertigen können. Seine Vorstellung von Staatsaufgaben beschränkt sich freilich im wesentlichen auf den Bereich der ordnenden Verwaltung; sie legt also ein eher älteres Staatsverständnis zugrunde. Außerhalb der hiermit doch recht eng gezogenen Kompetenzgrenzen existiert für Herrn Burmeister, ganz im Sinne der „ultra-vires-Lehre“, gar kein Staat. Das mag für hoheitli- 
ches Handeln zutreffen, ist aber für den Bereich rechtsgeschäftlicher Befugnisse fragwürdig. Die Zuerkennung von Rechtspersönlichkeit für einen öffentlich-rechtlichen Verband eröffnet ein rechtsgeschäftliches Betätigungsfeld, auf dem sich die Wirksamkeit von Rechtsakten nicht nach dem Ausmaß von Staatsaufgaben, sondern allein nach positiven Handlungsschranken bemißt. Im übrigen müßte man wohl auch einräumen, daß sich in heutiger Zeit das Aufgabenfeld des Staates beachtlich erweitert hat. Die Sozialstaatlichkeit des Staates stellt eine dermaßen weite Aufgabenzuweisung dar, daß sich von hierher sogar schon eine Kompetenzvermutung auch für privatrechtliches Verwaltungshandeln ergibt. Natürlich bestehen auch insoweit Kompetenzschranken; vor allem die Diskussion um die Schranken erwerbswirtschaftlicher oder wirtschaftsfördernder Betätigung der Gemeinden beweisen dies.

Der subordinationsrechtliche Vertrag wurde von beiden Referenten mit Skepsis betrachtet. Herr Burmeister sprach in These $5 \mathrm{~b}$ davon, daß dieses Institut dem Staat die Möglichkeit eröffne, sich der Geltung der Handlungsmaßstäbe Gesetzmäßigkeit und Verhältnismäßigkeit zu entziehen. Herr Krebs erkannte beim subordinationsrechtlichen Vertrag eine "relative Fehlerresistenz". In der Tat ermöglicht $\$ 59$ VwVfG den Bestand von verwaltungsrechtlichen Verträgen mit rechtswidrigem Inhalt. Eine genauere Analyse verhilft hier indes zu einem Befund, der Skepsis gegenüber dem subordniationsrechtlichen Vertrag unnötig erscheinen läßt. $\$ 59 \mathrm{VwVfG}$ enthält doch recht handfeste Unwirksamkeitsgründe: die allgemeine Nichtigkeitsregel des $\$ 134$ BGB, die hypothetische Nichtigkeit eines Verwaltungsaktes mit entsprechendem Inhalt sowie die Nichtigkeit bei kollusivem Handeln und bei unzulässiger Gegenleistung. Unerkannte oder einseitig erkannte Rechtswidrigkeit soll dagegen kein Unwirksamkeitsgrund sein; für den Vergleichsvertrag gilt das allerding nur, wenn tatsächlich eine Vergleichssituation bestand. Das alles beweist, daß die Verwaltung sich so leicht nicht aus der Legalität stehlen kann. Soweit indes ein Legalitätsmangel vom Gesetz akzeptiert wird, beruht die erweiterte Bestandskraft solcher Verträge auf der Mitwirkung des Bürgers. $\mathrm{Da}$ sie angesichts der Regelung in $\$ 58 \mathrm{VwVfG}$ nicht zu Lasten Dritter gehen kann, ist hiergegen nichts einzuwenden.

Breuer: Der Schatten Otto Mayers über dem deutschen Verwaltungsrecht ist lang. Aber er ist nicht so lang, wie Herr Burmeister ihn gezeichnet hat. Interessanterweise haben wir es mit einem übereinstimmenden Befund nicht nur in Deutschland, sondern auch in den anderen hier vorgestellten Ländern zu tun. Die Praxis der verwal- 
tungsrechtlichen Verträge und sonstiger Absprachen nimmt zu. Nun habe ich eine gewisse Sympathie für den Gedanken, daß die Gesetzesbindung und andere rechtsstaatliche Grundsätze nicht untergehen dürfen, aber mir scheint doch, daß wir zur Kenntnis nehmen müssen, wie sehr sich die gewandelten Verwaltungsaufgaben in der Vertragsund Absprachepraxis niederschlagen. Ist nicht - so möchte ich fragen - die Praxis der Verträge und der Absprachen oft besser geeignet, die Gesetze durchzusetzen und den Verwaltungsvollzug zu dem gebotenen Punkt zu bringen, als ein allzu enges Festhalten an der einseitig hoheitlichen Verwaltungsform? Ich meine in der Tat, daß man diese Frage für bestimmte Fallkonstellationen bejahen muß, und darf das zum einen für den privatrechtlichen Vertrag und zum anderen für den öffentlich-rechtlichen Vertrag kurz erläutern.

Zum privatrechtlichen Vertrag: Meines Erachtens ist die These nicht haltbar, daß der verwaltungsrechtliche Vertrag beschränkt sei auf die Fälle gesetzlicher Ermächtigung. Rechtssystematisch, aber auch rechtshistorisch und rechtsvergleichend ist das Privatrecht das Jedermannsrecht, das öfentliche Recht ist Sonderrecht, zum einen rechtsbegrenzend und zum anderen, wo gesetzliche Ermächtigungen vorliegen, auch rechtserweiternd. Hans Julius Wolff hat das ausgeführt, ich beziehe mich darauf. Nun ergibt sich aus den rechtsstaatlichen Prinzipien des Grundgesetzes meines Erachtens kein Anhaltspunkt für die These, daß wir einen Totalvorbehalt des Gesetzes in dem Sinne hätten, daß privatrechtliche Verträge nur noch dort zulässig seien, wo eine gesetzliche Ermächtigung vorläge. Wir haben auch andere Instrumente, um Gefährdungen im Hinblick auf die Gesetzesbindung in den Griff zu bekommen. Das Verwaltungsprivatrecht ist von Herrn Krebs sehr zu Recht herausgestellt worden. Es enthält die Tendenz, gemeinsame rechtsstaatliche und grundrechtliche Bindungen auch dort zu praktizieren, wo die Form des verwaltungsrechtlichen Vertrages angewandt wird.

Was nun die Aufgaben anlangt, Herr Burmeister, so habe ich meine Probleme mit ihrem offensichtlich sehr engen Aufgabenverständnis. Ich beginne bei der kommunalen Selbstverwaltung. Die Allzuständigkeit gehört zum Inhalt der Selbstverwaltungsgarantie, und zu diesem Aufgabenkreis gehört zum Beispiel auch eine Bodenvorratspolitik. Sie dient dazu, eine gemeindliche Bauleitplanung und eine gemeindliche Strukturentwicklung überhaupt erst zu ermöglichen. Soll es denn nicht mehr möglich sein, daß die Gemeinden zur Anlegung und zur Arrondierung ihres Bodenvorrats Grundstücke privatrechtlich erwerben, ohne daß die Enteignungsvoraussetzungen erfüllt sind? Hier ist meines Erachtens die Aufgabe der Gemeinden viel zu stark 
eingeengt. Ähnliches gilt für den Staat, der als Sozialstaat Aufgaben der Regional- und der Strukturentwicklung hat. Das belegt, daß der privatrechtliche Vertrag nach wie vor seinen Anwendungsbereich hat. Die von Ihnen erwähnten Gegenbeispiele, Herr Burmeister, überzeugen mich deshalb nicht, weil Sie zum Beispiel bei wirtschaftlichen Betrieben der Gemeinden auf gesetzliche Grenzen verweisen können. Wenn diese überschritten sind, ist der privatrechtliche Vertrag nicht zulässig. Das widerlegt aber nicht die von mir erwähnten Beispiele im Wirkungsbereich der Gemeinden.

Beim offentlich-rechtlichen Vertrag haben Sie, Herr Burmeister, eine grobe Vereinfachung gezeichnet, indem Sie Verträge erwähnt haben, in denen Gesetzesverletzungen vereinbart sind. Die Praxis der wirklich problematischen Fälle besteht darin, daß schon die Komplexität des Sachverhalts, unaufgeklärte Sachverhaltselemente und überkomplizierte Gesetzesinhalte nachgerade dazu zwingen, mit Vertragsund Abspracheinstrumenten zu operieren, damit die Verwaltung und der Gesetzesvollzug funktionsfähig bleiben. Herr Wabl hat meines Erachtens zu Recht an Beispiele aus den neuen Ländern erinnert. Wenn wir zum Beispiel in den Altlastenfällen, die in den neuen Bundesländern anstehen, nur mit einseitig hoheitlichem Verwaltungshandeln operieren wollten, wäre in der Tat der Punkt der Nichtvollziehbarkeit des geltenden Rechts erreicht.

Püttner: Ich meine, Aufgabe der Referate war es doch, auf die Probleme hinzuweisen; insofern bin ich Herrn Burmeister dankbar, daß er mutig gegen den Strom geschwommen ist. Das macht ihn nicht unbedingt bei allen populär, aber ich meine, es ist doch die Aufgabe, die sich hier stellt, den Finger auf die Wunde zu legen. Und ich möchte mit Herrn Schuppert fordern, und möchte Sie, Herr Burmeister, doch bitten, ob Sie nicht ein bißchen entgegenkommen könnten, nämlich zu differenzieren. Man sollte differenzieren zwischen den Bereichen, seien es Sachbereiche, seien es Entscheidungsbereiche, in denen öffentlich-rechtliche Verträge und Absprachen sinnvoll und notwendig sind, und andererseits den Bereichen, das hatten Sie auch angetippt, in denen an der strikten Gesetzesanwendung das größte Interesse besteht. Ich meine, es gibt auch heute noch Bereiche, in denen vertragliches Handeln fast unsinnig erscheint. Gehen Sie doch einmal zum Kraftfahrzeugzulassungsamt und fangen Sie da an zu verhandeln; gehen Sie in die Erste juristische Staatsprüfung, wollen Sie Examen durch Vertrag? Oder wollen Sie einen Führerschein durch Vertrag? Wenn Sie in die Verkehrskontrolle kommen, zeigen Sie so einen Vertrag vor, „ich hab hier einen öffentlich-rechtlichen Vertrag, 
da steht unter anderem Kraftfahrzeugzulassung drin“, das kann doch nicht gehen! Und der Mann, der zum Sozialamt geht, der nicht verhandlungsgewandt ist, der nichts anbieten kann, der muß doch gerecht nach dem Gesetz behandelt werden, und um Gottes willen nicht erst gefragt werden: „Was können Sie denn anbieten?" Oder vielleicht Asylbewerbung durch Vertrag? Ich kann mich damit nicht anfreunden und meine deshalb, daß insgesamt gesehen die Sicht von Herrn Burmeister wesentlich realitätsnäher ist als andere Sichten; Herr Ipsen, ich widerspreche Ihnen da ausnahmsweise mit aller Deutlichkeit.

Wir sollten darauf achten, daß es um die Gesetzesbefolgung geht, wie das unser Kollege Imboden so deutlich zum Ausdruck gebracht hat: Das Gesetz garantiert die rechtsstaatliche Verwaltung und nicht das Paktieren. Im übrigen meine ich, daß bei den Rechtsinstituten verwandte Dinge einbezogen werden sollten; der mitwirkungsbedürftige Verwaltungsakt könnte in meinen Augen einen Teil der Verträge durchaus ersetzen. Wir sollten darauf achten, daß es manchmal eine Hoheitsentscheidung gibt, die umkleidet ist von einer begleitenden Vereinbarung (Beispiel Professorenernennung und Berufungsvereinbarung); beides geht ineinander. Wir haben also ein viel differenzierteres Feld vor uns als nur dieses Ja oder Nein, gegen das ich mich nachdrücklich ausspreche.

Dittmann: Herr Krebs hat den Siegeszug des Verwaltungsvertrages eindringlich vor Augen geführt. Dabei fällt aber auf, daß dieser Siegeszug bemerkenswerterweise vor den Toren des Steuerrechts bisher haltgemacht hat - jedenfalls in Deutschland. Es gibt zwar gewisse Ansätze für die Zulassung von Verwaltungsverträgen auch im Steuerrecht, aber das deutsche Steuerrecht ist bisher doch noch von einer auffälligen Scheu, ja geradezu von einer Vertragsfeindlichkeit gekennzeichnet. Ähnlich offenbar in der Schweiz, während die anderen beiden Referenten in dieser Frage viel offener waren. Ich denke, es ist zumindest des Nachdenkens wert, worin die Gründe dafür liegen, daß speziell das Steuerrecht bisher von diesem Siegeszug noch nicht erreicht worden ist. Ist es nur die geradezu typische Verspätung des deutschen Steuerrechts bei der Anpassung an neuere Entwicklungen, besteht kein praktischer Bedarf, oder aber spielt hier doch das eine Rolle, was Herr Püttner soeben allgemein angedeutet hat, nämlich daß die im Steuerrecht besonders rigide ausgestalteten Prinzipien der Gesetzmäßigkeit sowie Überlegungen der Gleichmäßigkeit der Besteuerung den Verwaltungsvertrag nach wie vor als dubios erscheinen lassen? Ich würde um eine Antwort von Herrn Krebs und vielleicht auch von Herrn Schreeizer bitten. 
Bayer: Ich darf an das anknüpfen, was Herr Dittmann jetzt schon angerührt hat. Bei einem Vergleich der beiden Referate mit den drei Landesberichten fällt mir auf: Wenn ich richtig hingehört habe, kommt in den beiden Referaten der Begriff des Steuervertrages mit keinem Wort vor. Für die drei Auslandsberichte steht er, umgekehrt, geradezu im Mittelpunkt aller Überlegungen, vielleicht ein Indiz dafür, daß die Bundesrepublik Deutschland im Gegensatz zu dem, was wir gestern gehört haben, kein Steuerstaat ist! Aber - und jetzt bin ich bei einem Stichwort, das mir Herr Hengstschläger geliefert hat, und ich bitte Herrn Krebs um eine Antwort: Das Stichwort ist "Schlußbesprechung“. $\$ 201$ Abgabenordnung ermächtigt die Finanzverwaltung dazu, am Ende einer Betriebsprüfung, einer Außenprüfung, eine Schlußbesprechung anzuberaumen. Im Rahmen der Schlußbesprechung sind die tatsächlichen und rechtlichen Verhältnisse noch einmal zu erörtern. Jeder, der je an einer Schlußbesprechung teilgenommen hat, weiß, daß es in einer solchen nicht um Vereinbarungen über Rechtsfolgen geht. Es werden keine Körperschaftsteuerschulden, um das Beispiel von Herrn Autexier zu nehmen, vereinbart. Es werden Tatsachen vereinbart. Es wird eine Verständigung darüber herbeigeführt, welcher Aufwand eine Betriebsausgabe sein soll und welcher nicht. Nimmt man dazu nun noch hinzu, $\mathrm{da} ß$ sich von dem Moment an, in dem die Verständigung vorhanden ist, die ihr entsprechenden Rechtsfolgen unmittelbar aus dem Gesetz, aus dem Einkommensteuergesetz, aus dem Körperschaftssteuergesetz usw. ergeben, dann muß man wohl zu dem Schluß kommen: Das, was passiert, ist, sei es mittelbar, sei es unmittelbar, ein Vertrag. Die Rechtsprechung des Bundesfinanzhofs zu diesem Thema, zuletzt die Entscheidung vom 6. Februar 1991, ist mir bis zum heutigen Tage nicht klar geworden. Ich würde deshalb gern von Ihnen, Herr Krebs, hören: Ist denn nun das, wozu die Vorschrift des $\$ 201$ Abgabenordnung ermächtigt, die Ermächtigung zum Abschluß eines öffentlich-rechtlichen Vertrages oder nicht. Danke.

Huber: Herr Vorsitzender, meine Damen und Herren: Ich bin durch meine Vorredner darin bestärkt worden, daß die Gesetzmäßigkeit der Verwaltung nicht gegen andere Zwecke der Verwaltung ausgespielt werden kann. Wenn dies der Fall ist, so stellt die RechtmäBigkeit des Verwaltungshandelns auch eine Grenze für den Verwaltungsvertrag dar. Das wirft, und darin möchte ich an das anknüpfen, was Herr Bullinger und auch Herr Mußgnug etwas angedeutet haben, und was bei Herrn Krebs zumindest auch vorkam, Probleme im Hinblick auf die „Dritten“ auf, die gerade nicht an den Vertragsver- 
handlungen partizipieren. Der $\$ 58 \mathrm{VwVfG}$ enthält für diese Fälle eine entsprechende Beteiligungsbestimmung. Sie, Herr Krebs, haben meines Erachtens ganz zu Recht gefordert, daß auch im zivilrechtlichen Vertrag, im Bereich des Verwaltungsprivatrechts, eine analoge Anwendung oder eine Heranführung an diese Bestimmung anzustreben sei, wenn denn der zivilrechtliche Vertrag mit dem öffentlichrechtlichen funktionell weitgehend austauschbar ist. Das Problem, was ich hier nur sehe, ist, daß die Betroffenheit von grundrechtlich geschützten Interessen und Rechtssphären Dritter bei Aufnahme der Vertragsverhandlungen häufig nicht klar bestimmbar ist, sondern sich vielfach erst im Laufe des Verfahrens herausstellt. Deshalb finde ich Ihren Vorschlag auch ganz plausibel, wonach ein mehr oder weniger formalisiertes Verwaltungsverfahren dem Abschluß des Verwaltungsvertrags vorzuschalten sei. Soweit wir es allerdings mit Antragstellern oder Vertragspartnern zu tun haben, die sich an dem - wohl meist finanziellen - Ausgleich, nicht beteiligen können oder wollen, werden wir wieder dabei enden, daß die kollidierenden Interessen in diesen Vertragsverhandlungen beziehungsweise in diesem Verwaltungsverfahren, durch eine Entscheidung abgegrenzt werden müssen. Insofern finde ich den Vorschlag von Herrn Bullinger erwägenswert, daß man der Verwaltungsabsprache die Rolle zuweist, hier sozusagen als informelle Vorform, vor der eigentlichen Verwaltungsentscheidung, sei sie nun Verwaltungsakt oder öffentlich-rechtlicher Vertrag, zu dienen. Dankeschön.

Öhlinger: Eine kurze Bemerkung zu Herrn Hengstschläger. Die Grundthese Ihres Referates besteht, pointiert gesagt, darin, daß es den verwaltungsrechtlichen Vertrag als Handlungsform im österreichischen Recht nicht gibt, soweit er gesetzlich nicht vorgesehen ist. Daran ist richtig, daß die Zulässigkeit solcher Verträge eine Frage der Gesetzgebung ist. Es liegt in Österreich, schlicht gesagt, ein de lege ferenda-Problem vor. Aber, wie Sie richtig ausgeführt haben, sind verwaltungsrechtliche Verträge verfassungsrechtlich zulässig, weil die Verfassung gegenüber Rechtsformen des Verwaltungshandelns unterhalb der Ebene der generellen Normerzeugung offen ist. Es verdient dies hervorgehoben zu werden, weil es von einem Teil der Lehre bestritten wird. Sie haben auch richtig auf die Grenzen der Gestaltbarkeit durch den Gesetzgeber hingewiesen, die der Rechtsschutz setzt. Der Rechtsschutz knüpft an den Bescheid an. Nur: der verfassungsgesetzliche Bescheidbegriff - das ist meine These - ist offen gegenüber allen Mitwirkungsformen des Bescheidadressaten, und es ist daher eine Frage der einfachen Gesetzgebung, ob diese an eine mangelnde 
Willensübereinstimmung statt absoluter Nichtigkeit eine andere Form der Rechtswidrigkeit knüpft, womit das begriffliche Unterscheidungskriterium zwischen Vertrag und antragsbedürftigem Verwaltungsakt relativiert wird. Ob man das noch „Vertrag“ nennt, wie Herr Burmeister wahrscheinlich bestreiten würde, oder nicht, ist ein nominalistisches Problem. Faktum ist, daß es auch in Österreich eine Fülle von Absprachen, eine Fülle kooperativen Verwaltungshandelns gibt. Ich würde sogar meinen, daß dies der österreichischen Mentalität ganz besonders entspricht. Aber all das bleibt derzeit weitgehend rechtlich irrelevant, und es gibt genug Beispiele dafür, daß Menschen im Vertrauen auf solche Zusagen enttäuscht wurden, ohne sich rechtlich dagegen wehren zu können. Daß in Österreich die Flucht der Verwaltung in das Privatrecht ganz besonders einfach ist, haben Sie ebenfalls gezeigt, aber auch, daß das - zumindestens rechtspolitisch - keine befriedigende Lösung ist. Danke.

Meyer: Ich hätte nicht gedacht, daß das zweite Thema noch einmal in die Einigungsproblematik zurückführen würde. Wenn Herr Burmeister hinsichtlich der Bodenvorratspolitik der Gemeinden recht hätte, dann müßten wir alle die Beamten, die wir in die Grundbuchämter im Osten geschickt haben, wieder zurückrufen, um hier die Grundbücher wegen all dieser nichtigen Rechtsgeschäfte zu bereinigen.

Herr Krebs, ich bin zu These 13 nicht mit Ihnen einer Meinung, daß es bereichsspezifischer Ermächtigungen für den öffentlich-rechtlichen Vertrag bedarf. Es reicht $\$ 54 \mathrm{VwVfG}$. Ich sehe auch keine Notwendigkeit. Anders als der Verwaltungsakt gibt der Vertrag keine Möglichkeit, einseitig verbindlich tätig zu werden. Deshalb bedarf es auch des Schutzes nicht. Wenn wir wirklich bereichsspezifische Ermächtigungen benötigten, würden eine Fülle von öffentlich-rechtlichen subordinationsrechtlichen Verträgen nichtig, zum Beispiel etwa Verträge, durch die in komplizierten Baugenehmigungsverfahren Baugenehmigungen erteilt werden. Sie werden schwerlich in den Bauordnungen oder dem Bundesbaugesetz eine spezifische Ermächtigung zu solchen Verträgen finden.

Herr Burmeister, Wenn Sie recht hätten mit Ihrer These 15 von der Fehlkonstruktion des subordinationsrechtlichen Vertrages, müßten Sie auch sagen, der $\$ 36 \mathrm{VwVfG}$ sei fehlkonstruiert, denn Sie können den subordinationsrechtlichen Vertrag, jedenfalls den Austauschvertrag, ohne weiteres substituieren durch einen begünstigenden Verwaltungsakt mit Auflagen, die Sie regelmäßig ja auch vorher absprechen. Das eigentliche Problem des offentlich-rechtlichen Vertrages ist der 
$\$ 59 \mathrm{VwVfG}$. Wenn man den $₫ 59 \mathrm{VwVfG}$ etwas schärfer faßt, sind alle Bedenken erledigt, die darauf hinauslaufen, der öffentlich-rechtliche Vertrag sei eigentlich das Instrument, sich vom Gesetz zu lösen. Das Gesetz ist schlecht, wenn es erlaubt, daß die Verwaltung ohne Sanktionen bewußt rechtswidrige Verträge macht, und den Vertrag nur für nichtig erklärt, wenn kolludiert wird, wenn also auch der Vertragspartner die Rechtswidrigkeit kennt, was man immer schlecht nachweisen kann. Deshalb müßte es unser Bestreben sein, dem Vertrag, von dem die Verwaltung wissen mußte, daß er rechtswidrig ist, die Wirksamkeit zu versagen. Dann wären alle Bedenken beseitigt. Im übrigen muß ich Herrn Krebs gegen Herrn Grimm ausdrücklich zustimmen: Sie glauben gar nicht, wieviel rechtswidrige Verwaltungsakte es im völligen Einverständnis der Beteiligten gibt. Das ist also kein spezielles Problem des Vertrages.

Mit Herrn Bullinger habe ich Bedenken, Herr Krebs, und Sie sind von Herrn Scbmidt-Aßmann unterstützt worden, ob man wirklich ohne weiteres den privatrechtlichen Vertrag der öffentlichen Hand und den öffentlich-rechtlichen Vertrag der öffentlichen Hand so annähern kann. Wenn das richtig ist, dann müßte man sich ernsthaft fragen, warum wir überhaupt zwei Instrumente haben. Es muß einen Sinn haben, warum wir erlauben, daß die öffentliche Hand privatrechtlich agiert. Die Parallelproblematik haben Sie bei der Frage, ob offentliche Verwaltungsträger privatrechtlich organisiert werden können. Auch hier würden Sie bald das Argument gewinnen, eigentlich könnte die gesamte Verwaltung grundsätzlich privatrechtlich organisiert werden, da sie denselben Bedingungen unterliegen würde wie die öffentlich-rechtlichen Verwaltungsträger. Wir müssen sicherlich anerkennen, daß die privatrechtlich organisierte Verwaltung den Grundrechten unterliegt. Aber das wichtigste Grundrecht ist natürlich Art. 3 und, wenn Sie so wollen, das Verhältnismäßigkeitsprinzip. Und hier denke ich, daß die privatrechtliche Organisation und auch die privatrechtliche Handlungsform größere Freiheiten erlauben sollen als beim öffentlich-rechtlichen Vertrag und für die öffentlich-rechtlich agierende Verwaltung. Und dieser Unterschied muß bleiben, wenn wir nicht gezwungen sein wollen zu sagen, daß die ganze Unterscheidung keinen Sinn hat.

Schließlich: Ich möchte etwas davor warnen, zu versuchen, eine Verwaltungspaktdogmatik, wie Herr Dreier sie verlangt hat, aufzubauen. Wir haben ja schon Schwierigkeiten, eine ordentliche Dogmatik für die Standardinstrumente zu entwickeln. Wenn Sie anfangen, so etwas zu machen, kommen Sie in morastiges Gelände, und ich denke, es hat auch wenig Sinn. Wir müssen auch der Verwaltung einen Raum belassen, wo sie nicht durch irgendwelche dogmatischen $Z$ wänge 
gebunden ist, wenn nur die Produkte ihres Handelns der Kontrolle unterliegen und wenn - das ist der entscheidene Punkt - potentielle Drittbetroffene rechtzeitig in dieses Verfahren einbezogen werden. An diesem Punkt würde ich ansetzen.

Vorsitzender: Damit haben wir den ersten Gliederungspunkt abgearbeitet. Wir kommen zum zweiten Teil der Gliederung.

Vogel: Vier Punkte als Nachlese. Erstens: Gefehlt hat mir eine Abgrenzung zum mitwirkungsbedürftigen Verwaltungsakt. Ich habe das immer so gesehen, daß ein mitwirkungsbedürftiger Verwaltungsakt vorliegt, wo nur Abschlußfreiheit besteht, dagegen ein Vertrag, wo über die Abschlußfreiheit hinaus auch Gestaltungsfreiheit gegeben ist. Könnten Sie dem zustimmen? Zweitens: Auch wenn sich öffentlich-rechtliche und privatrechtliche Verträge eng aneinander annähern, bleibt doch die Bedeutung der Unterscheidung für den Rechtsweg. Ist da etwa der Verwaltung ein verwaltungsrechtliches forum shopping möglich? Drittens: Wie sehen Sie unter diesem Aspekt die Möglichkeit gemischt öffentlich-rechtlich/privatrechtlicher Verträge? Ein Beispiel, das ich schon in meiner Dissertation behandelt habe (on revient toujours und so weiter): gesellschaftsrechtlich vereinbarte Entsendungsrechte von Gebietskörperschaften in die Organe privatrechtlicher Gesellschaften, die, wenn sie überhaupt zu rechtfertigen sind, nur als öffentlich-rechtliche Ingerenzen gerechtfertigt werden können. Wie paßt das in Ihre Dogmatik? Und viertens und letztens eine Bemerkung zum Vergleichsvertrag: Der Bundesfinanzhof sagt, ein Vergleich über zwingendes Recht verstoße gegen das Gesetzmäßigkeitsprinzip. Er läßt allerdings tatsächliche Verständigungen als bindend zu, was hierzu im Widerspruch steht. Hätte der Bundesfinanzhof im übrigen recht, wäre also der Vergleich eine Abweichung vom Gesetzmäßigkeitsprinzip, dann wäre $\$ 55 \mathrm{VwVfG}$ keine ausreichende Ermächtigung zum Abschluß solcher Verträge, weil er nicht bereichsspezifisch ist. Nach meiner Auffassung verstößt aber der Vergleichsvertrag dann nicht gegen das Gesetzmäßigkeitsprinzip, wenn die Behörde etwas konzediert, tatsächlich oder rechtlich, was sie auch einseitig so entscheiden dürfte. Herzlichen Dank.

Vorsitzender: Abschließend noch zum dritten Gliederungspunkt, Herr Raschauer.

Raschauer: Ich melde mich nur zum Thema "Absprachen“. Ich möchte nämlich einer Entwicklung entgegentreten, daß diese Abspra- 
chen aufgrund der heutigen Veranstaltung in den Rang einer neuen Kategorie von Verwaltungshandeln erhoben werden könnten. In zweifacher Hinsicht ist mir heute der Faktor Zeit abgegangen. Einerseits in der historischen Dimension: Die Beispiele, die unter dem Titel "Absprachen" behandelt werden, sind der Verwaltung doch seit jeher geläufig. Vielleicht hat sich der Grad der Intensität gewandelt, aber im Prinzip gibt es dort, wo es Verwaltung gibt, Kommunikation. Den Lehrbüchern sind die verfahrensrechtlichen Formen der Kommunikation unter vielen Stichwörtern längst bekannt. Aber auch in einer zweiten Dimension fehlt mir der Faktor Zeit: Es wurde heute der Gedanke eines Auswahlermessens zwischen formellem und informellem Handeln in den Raum gestellt und sogleich auch wieder kritisiert. So stellt sich doch die Frage nicht. Man muß vielmehr beachten, daß man einen Verwaltungsakt kaum je „sogleich" erlassen muß. Üblicherweise muß man doch erst einmal den Sachverhalt ermitteln, den Betrieb beobachten, Messungen durchführen, möglicherweise eine mündliche Verhandlung abhalten. Bis irgendwann der formelle Verwaltungsakt erlassen worden ist, ist viel gesprochen worden. Und dann muß man sich erst überlegen, was schreibt man in den Verwaltungsakt hinein. $\mathrm{Da}$ gibt es doch z. B. Leistungsfristen, es muß eine Anlage nicht sofort mit allen ihren Einrichtungen und Schutzvorkehrungen vorhanden sein. Die Gesetze sehen auch zeitlich abgestufte Verwirklichungen vor usw. Vorhin war von der Schlußbesprechung im Abgabenverfahren die Rede, aber es hat doch jeder, der bei der Verhandlung über eine Anlagenbewilligung größeren Ausmaßes dabei war, verschiedene Varianten von "Kommunikation“ erlebt. Das ist vielfach gesetzlich geregelt: Fragen der Manuduktionspflicht, Parteiengehör, Stellungnahmen, Projektmodifikationen, nach der Judikatur sind Vorschläge des Betreibers bei der Gestaltung von Auflagen zu berücksichtigen, bei uns sind auch „Übereinkommen" in der mündlichen Verhandlung vorgesehen ( $\$ 43$ Abs. 6 AVG, $\$ 111$ Abs. 3 WRG). Wer will, kann die Fallkonstellationen in der Dogmatik des Verwaltungsverfahrensrechts zusammentragen. Es gibt auch jeweils Judikatur zu "Gut und Böse“. Und wer alles das unter pathologischen Gesichtspunkten studieren will, findet zahlreiche Fallvarianten in der Judikatur zum Amtshaftungsrecht, die sich unter Kommunikationsgesichtspunkten ordnen lassen. Was wir aber auf jeden Fall vermeiden sollten, nur weil es im Moment modern klingt, ist, die Absprache, die ja definitionsgemäß keine rechtliche Bindungswirkung entfaltet, zu einer selbständigen Form von Verwaltungshandeln hochzustilisieren. Sie ist es in der gleichen Weise, wie man sagen kann, Telefonieren ist eine Form von Verwaltungshandeln. 
Vorsitzender: Damit sind wir am Ende der Rednerliste. Wir kommen nun zu den Schlußworten.

Schweizer: Herr Vorsitzender, sehr geehrte Damen und Herren, darf ich kurz auf ein paar Punkte, die aufgegriffen wurden, eingehen. Herr Grimm, Sie sprachen die Gleichbehandlung an. Aus zeitlichen Gründen habe ich das nicht behandelt. Ich glaube tatsächlich, daß etwas getan werden kann für Gleichbehandlungsbedürfnisse bei bestehenden Verträgen. Es wird auch getan, zum Beispiel in der Typisierung von Verträgen. AGB gleichsam für Anstaltsbenutzungen. Es gibt vor allem den Weg, den auch Herr Bullinger erwähnt hat, der Öffnung für Drittinteressen bei der Offerte, aber auch bei der Bekanntgabe des Vertragsschlusses. Ich könnte mir vorstellen, gleichsam $\mathbb{4} 1$ VwVfG für Verträge einzusetzen.

Dann darf ich einen Punkt erwähnen, er mag ein Nebenpunkt sein, aber aus meiner Praxiserfahrung. Warum werden verwaltungsrechtliche Verträge, die im breiteren Maße Dritte berühren, nicht publiziert in den Gesetzessammlungen? Es werden Kooperationsverträge von Körperschaften publiziert, aber es gibt auch soundsoviele subordinationsrechtliche Verträge, die absolut publikationswürdig wären. Und da würden wir einiges an Korrekturmöglichkeiten finden. Darf ich neben diesem Hinweis noch kurz zum Steuerrecht bemerken: Selbstverständlich, Verfahrensabsprachen gibt es im Schweizer Steuerrecht genauso wie bei Ihnen. Unzulässig sind nur Absprachen über die Steuerpflicht und über den Steuerumfang. Aus einem sehr einfachen Grund haben das die Kantone untereinander abkommensmäßig untersagt, weil sie sich nicht Konkurrenz machen wollten durch solche Methoden. Die Steuerharmonisierungsgesetzgebung läßt nur eine sogenannte befristete Steuererleichterung für die Neuansiedlung von Unternehmen $\mathrm{zu}$ - als einzigen gesetzlichen Tatbestand.

Abschließend nochmals: Ich glaube, wir dürfen den verwaltungsrechtlichen Vertrag und seine vielfältigen Ausformungen getrost aufnehmen und akzeptieren und mit ihm weiterarbeiten, nicht zuletzt deshalb, weil - wie ich meine - wir heute genügend rechtsstaatliche Sicherungen rundherum haben, Haushaltsrecht, Staatshaftungsrecht, Verwaltungskontrolle, verwaltungsrechtliches Verwaltungsverfahren, Vereinheitlichung des Rechtsschutzes und so weiter. Ich hab' da keine Angst mehr. Vielen Dank!

Hengstschläger: Herr Vorsitzender, meine Damen und Herren. Aus Zeitgründen nur zwei Punkte. Erstens, Herr Öblinger hat ein 
Zentralproblem des österreichischen verwaltungsrechtlichen Vertrages angesprochen, nämlich den Rechtsschutz. In Österreich geht derzeit die Lehre und Judikatur einen sehr engen Weg, nämlich, daß nur der Bescheid justitiabel ist und daher der Vertrag bei Streitfällen in einen Bescheid münden muß, und der Bescheid dann unter die Prüfungskompetenz der Gerichtshöfe des öffentlichen Rechts fällt. Ich habe sehr viel Verständnis für die Argumente des Herrn Öblinger, die er auch in seinem Buch dargelegt hat, daß man diesen Umweg über den Bescheid weglassen sollte, und den Vertrag als Verwaltungsakt im Sinne des sechsten Hauptstückes des BVG verstehen könnte und ihn damit justitiabel machen kann. Der zweite und abschließende Punkt: Die Probleme über diese verwaltungsrechtlichen Verträge und Absprachen sind im Prinzip - so unterschiedlich auch die österreichische und deutsche Rechtsordnung ist - weitgehend parallel, und ich kann aus dieser heutigen Tagung sehr viel mit nach Hause nehmen.

Vorsitzender: Herr Autexier hat aus zeitlichen Gründen verzichtet, vielen Dank dafür und vor allem auch für Ihr Referat.

Krebs: Nur wenige Bemerkungen noch. Eine erste Bemerkung: Die auch von mir hier vorgetragene Annäherungsthese zwischen privatrechtlichem und öffentlich-rechtlichem Vertrag wäre fehlverstanden, wenn sie in dem Sinne verstanden würde, daß sie sozusagen einen Einstieg in eine möglichst totale Publifizierung des verwaltungsrechtlichen Vertrages vorbereiten sollte. Ganz im Gegenteil! Richtig ist, daß in den rechtsstaatlichen Standards der Verwaltungsverträge Übereinstimmung bestehen muß. In der rechtstechnischen Ausgestaltung meine ich demgegenüber, daß man sich erinnern muß, welch reichhaltiges Schutzinstrumentarium das Zivilrecht zum Teil entwikkelt hat, und daß man dieses auf keinen Fall dadurch verschütten sollte, daß man jetzt alles "veröffentlich-rechtlicht".

Die andere Bemerkung: Ich bin ganz dankbar, daß ganz zu Beginn des zweiten Abschnittes der Diskussion Herr Dagtoglou, aber später auch noch Herr Breuer den Zusammenhang zwischen Verwaltungsaufgabe und Verwaltungshandeln thematisiert haben. Tatsächlich glaube ich, daß der Aufgabenzuschnitt auf den Modus des Verwaltungshandelns entscheidenden Einfluß hat, und ich glaube auch, daß ein Teil der prinzipiellen Kontroversen im Vertrag den falschen Adressaten hat. Das Vertragshandeln ist die Konsequenz einer bestimmten Aufgabenstellung, nicht die Ursache. Da wir einen bestimmten Aufgabenzuschnitt haben, kommt es auf den Verwal- 
tungsvertrag an. Und deshalb bin ich auch sehr dankbar, wenn ich wenigstens für mich aus dieser Diskussion die Erkenntnis mit nach Hause nehme, daß sich in der Verwaltungsrechtswissenschaft der Vertrag inzwischen weit stärker etabliert hat, als etwa noch vor zehn Jahren, als Herr Püttner auch damals vor der Vertragseuphorie meinte warnen zu sollen. Und insofern bleibt mir als letzte Bemerkung im Hinblick auf dieses Ergebnis nur der Dank an den Vorstand für die Auswahl des Themas und dafür, daß ich dazu zu Ihnen sprechen durfte, und für Ihre freundliche Aufmerksamkeit.

Burmeister: Es sind noch eine ganze Reihe Fragen aufgeworfen, auf die ich nicht alle eingehen kann; ich möchte nur zwei wesentliche Gesichtspunkte herausgreifen: Herr Breuer, das von Ihnen angesprochene Problem ist sehr weit dimensioniert. Daß die Problematik des verwaltungsvertraglichen Handelns sich in erster Linie auf der Ebene der Gemeinden abspielt und für die Aufgabenerfüllung der Gemeinden der Verwaltungsvertrag eine so besondere Rolle spielt, wir insoweit aber auch besondere Schwierigkeiten haben, den Verwaltungsvertrag systemkonform einzuordnen, hängt vor allem damit zusammen, daß die Gemeinden historisch als antistaatliche Einrichtungen konzipiert, ihre Betätigungsbefugnisse als grundrechtlich gegen den Staat abgeschirmte Freiheiten verfaßt waren. Da die Gemeinden historisch dem gesellschaftlich-privaten Bereich angehörten, war vertragliches Handeln für sie folgerichtig ganz legitim. Auch im heutigen Verständnis der kommunalen Selbstverwaltung als grundrechtsähnlicher Verbürgung spielt der alte Artikel 127 der Weimarer Reichsverfassung noch eine wesentliche Rolle. Da die Gemeinden als antistaatliche Einrichtungen gedacht und verfaßt waren, wurde die Wahrnehmung ihrer Befugnisse konsequenterweise als Ausübung von Freiheiten, als Gebrauch subjektiv-rechtlicher Befugnisse verstanden.

\section{Zwischenruf: Nur im Rheinland, Herr Kollege!}

Burmeister: Nein! Auch im Reich. Das in Artikel 127 der Weimarer Verfassung gewährleistete Recht der Selbstverwaltung war als Grundrecht konzipiert, das - wie die Individualfreiheitsrechte des Bürgers - gegen den Staat gerichtet war. Aus diesem Verständnis der Selbstverwaltungsgarantie resultiert eine Vielzahl von Befugnissen, die den Gemeinden im Grunde im gesellschaftlich-privaten Bereich zuerkannt werden, so insbesondere im wirtschaftlichen Betätigungsbereich. Deshalb meine ich, daß man genau unterscheiden muß zwischen den Kompetenzen der Gemeinden und den Kompetenzen von 
Bund und Ländern. Die Gemeinden sind diejenigen staatlichen Einrichtungen, die an der Nahtstelle zum Bürger kraft ihrer historischen Stellung als aus dem Staat ausgegrenzte Handlungsträger weitestgehend mit gesellschaftlich-privaten Aufgaben betraut waren. Die Einbindung der Gemeinden als Einrichtungen der mittelbaren Staatsverwaltung ist ja erst vom Grundgesetz vollzogen worden. Aus der historischen Stellung der Gemeinden resultiert dennoch eine ganze Reihe von nach wie vor bestehenden Reibungen und Systembrüchen, für die insbesondere die generelle Anerkennung der Befugnis der Gemeinden symptomatisch ist, als Privatrechtssubjekt am allgemeinen Rechts- und Wirtschaftsverkehr teilzunehmen.

In diesem Zusammenhang möchte ich auf ein Mißverständnis hinweisen, das immer wieder anklingt. Ich lese noch einmal vor, was ich gesagt habe: „Die Befugnis der Gemeinde, sich des Mittels des privatrechtlichen Kaufvertrags zur Erfüllung einer ihr übertragenen Selbstverwaltungsaufgabe oder einer Auftragsangelegenheit zu bedienen, erschließt der Gemeinde nicht etwa Handlungsbefugnisse als Privatrechtssubjekt." Selbstverständlich sind alle Kompetenzen, die im Recht der kommunalen Selbstverwaltung als Befugnisse der Gemeinde, als Kompetenzen der Gemeinde aufgefangen sind, solche, zu deren Erfüllung sie sich auch des Verwaltungsvertrages bedienen kann. Hier fehlt es ja regelmäßig an der subordinationsrechtlichen Stellung des Bürgers in dem Sinne, daß die Gemeinde ihm gegenüber eine Aufgabe durch Erlaß eines Verwaltungsaktes durchsetzen könnte. So ist der gesamte Bereich der daseinsvorsorgerischen Wirtschaftsbetätigung und - wie ich gesagt habe - vor allen Dingen auch der Bedarfsdeckung genuiner Anwendungsbereich für den koordinationsrechtlichen Verwaltungsvertrag zwischen Gemeinde und Bürger. Der einzige, allerdings wesentliche Unterschied besteht darin, daß ich den unter Gebrauch von privatrechtlichen Handlungsformen zustande kommenden Vertrag nicht als privatrechtlichen Vertrag, sondern als öffentlich-rechtlichen, materiell dem staatlichen Sonderrecht unterstehenden Verwaltungsvertrag begreife.

HerrVogel, zu meiner Konzeption gehört in der Tat die Ablehnung des gemischt öffentlich-rechtlichen Vertrages. Nach meinem Dafürhalten ist es dogmatisch nicht machbar, einen Vertrag aufzuspalten in Bestandteile, die dem privaten Recht und dem öffentlichen Recht zuordnungsfähig wären. Dies erscheint mir aus dogmatischer Sicht deshalb nicht möglich, weil eine solche Konstruktion verschiedene Zurechnungsendpunkte in ein- und denselben Vertrag hineinkonstruieren müßte. Dogmatisch bereitet dies jedenfalls große Schwierigkeiten. Daß es praktisch natürlich anders gesehen werden kann, ist klar. 
Als Jurist vermag ich mir jedenfalls schwerlich eine Konstruktionsfigur vorzustellen, die davon ausgeht, daß Rechte und Pflichten aus einem Vertrag einmal dem Staat als Hoheitsträger, zum anderen dem Staat als Privatrechtssubjekt zuzurechnen sind. Deswegen bleibe ich prinzipiell ablehnend gegenüber der Anerkennung gemischt privatöffentlich-rechtlicher Verträge.

HerrMeyer, die Vorschrift des $\$ 46$ des Verwaltungsverfahrensgesetzes halte ich in der Tat...

\section{Zwischenruf: $\$ 36$ Verwaltungsverfahrensgesetz}

Burmeister: Nein, $\$ 46$ haben Sie gesagt!

\section{Mehrere Zwischenrufe: Nein, $₫ 36$ !}

Burmeister: Ich habe Sie so verstanden, daß sich Ihr Einwand auf \$46 Verwaltungsverfahrensgesetz, um keinen Zweifel aufkommen zu lassen, bezieht. Die Regelung des $\$ 46$ Verwaltungsverfahrensgesetz halte ich in der Tat für höchst problematisch, und zwar deshalb, weil diese Regelung nicht berücksichtigt, daß es Verfahrensbeteiligungsrechte gibt, die Ausfluß von Grundrechten sind. Die Aussage ist nicht haltbar, daß ein Verwaltungsakt nicht deswegen aufgehoben werden könnte, weil er nur an Form- und Verfahrensfehlern leidet. Selbstverständlich muß ein Verwaltungsakt aufgehoben werden, wenn der Verfahrensfehler in der Verletzung eines Grundrechts besteht. Infolgedessen steht die Bestimmung des $\$ 46$ Verwaltungsverfahrensgesetz auch in Diskrepanz mit der Annahme, ein den Erlaß eines Verwaltungsaktes substituierender Verwaltungsvertrag sei bei Vorliegen bloBer Form- und Verfahrensfehler wirksam.

Im übrigen will ich sagen, daß die Problematik der Drittbeteiligung am Verwaltungsvertrag dogmatisch nach meinem Dafürhalten nicht zufriedenstellend gelöst ist. Die Vorschrift, die besagt, daß ein Vertrag so lange nicht wirksam ist, bis der Dritte über den Vertragsinhalt informiert oder entsprechend an seinem Zustandekommen beteiligt worden ist, erkennt nicht, daß es eine Vielzahl von Verwaltungsverträgen gibt, die komplexe Verwaltungsverfahren betreffen, in denen schon die Vielzahl der Beteiligten, und zwar der grundrechtlich am Verfahren Beteiligten, es gar nicht zuläßt, den Weg des Vertrages zu gehen. Die Vielzahl von Verfahrensbeteiligten, die notwendigerweise in die Verhandlungen über den Abschluß eines Verwaltungsvertrages einbezogen werden müßten, verschließt - und da stimme ich wohl mit Herrn Krebs nicht ganz überein - dem Verwaltungsvertrag in 
vielen Bereichen die Anwendungsmöglichkeit. Ich kann mir beim besten Willen nicht vorstellen, wie es möglich sein soll, daß ein Verwaltungsverfahren, in das am Maßstab der Judikatur des Bundesverfassungsgerichts 500 Personen als Ausfluß ihrer grundrechtlich geschützten Beteiligungsrechte einzubeziehen sind, in den Abschluß eines Verwaltungsvertrages einmündet.

Eine letzte Bemerkung möchte ich nochmals zur Verdeutlichung meiner Position gegenüber dem mehrfach, besonders deutlich von Herrn Pitschas, Herrn Wabl und auch Herrn Götz geäußerten Einwand machen, daß ich bei meinem Verdikt gegenüber der Absprachepraxis der Verwaltung den Bedarf an konsensualen konsensstiftenden Handlungsformen zu gering veranschlagt hätte. Dazu will ich sagen: wenn wir soweit sind, daß wir als Juristen nicht die Frage stellen, wie wir eigentlich die Legitimation eines Verwaltungsträgers erklären, sich über die Bindung an eine vorhandene, ihn zu einem Tun verpflichtende Norm hinwegzusetzen, sondern uns damit begnügen, diese Befugnis ganz einfach mit Konsens- und Praktikabilitätserfordernissen zu erklären, so hat nach meinem Dafürhalten die Verwaltungslegalität als rechtliche Kategorie ausgespielt. Ich betone: Absprachen, so wie sie als informelle Handlungsformen von der herrschenden Lehre definiert werden, sind dadurch gekennzeichnet, daß sich ein Verwaltungsträger über die Bindung an ein konkretes Rechtsgebot hinwegsetzt. Für dieses Phänomen vermag ich - wenn überhaupt - eine Legitimationsbasis allein im Gedanken der Rechts- und Kompetenzkompensation zu erblicken, und ich vermag, um es ganz offen zu sagen, der ganzen Diskussion keinen Gesichtspunkt zu entnehmen, der die Befugnis der Verwaltung, über ihre Rechtsbindung zu verfügen, plausibler zu erklären vermöchte. Ich meine daher, daß das, was ich angeboten habe, nämlich den Rückgriff auf den Gedanken der Kompetenzkompensation, rechtlich zumindest ergiebiger ist als der bloße Hinweis, daß Absprachen "so praktisch“ und so "realitätsgerecht" seien.

Auch ich muß allerdings betonen, $\mathrm{da} ß$ ich aus dieser Diskussion viel Bedenkenswertes mitgenommen habe. Es ist eine Vielzahl von Aspekten angesprochen worden, die mir vergegenwärtigt haben, daß mit meinen Ausführungen das Thema nicht zu Ende geführt ist. Ich kann Ihnen versichern, daß ich nicht des Glaubens bin, dazu das letzte Wort gesagt zu haben. Vielen Dank!

Vorsitzender: Liebe Kolleginnen und Kollegen, ich fasse mich kurz, zumal ich auch die Diskussionsredner - aus zeitlichen Gründen - zur Kürze gemahnt habe, möchte es aber doch nicht versäu- 
men, für die Referate und für die Länderberichte sowie für die Teilnahme an der Diskussion, sei es als Redner, sei es als Zuhörer, herzlich zu danken! Damit ist die Aussprache und zugleich der wissenschaftliche Teil der Tagung geschlossen. 